UNIVERSIDADE DE SÃO PAULO

FACULDADE DE ECONOMIA, ADMINISTRAÇÃO E CONTABILIDADE DEPARTAMENTO DE ADMINISTRAÇÃO PROGRAMA DE PÓS-GRADUAÇÃO EM ADMINISTRAÇÃO

THINKING STYLES' INFLUENCE ON THE INDIVIDUAL'S READINESS FOR ADOPTING DESIGN THINKING IN ORGANIZATIONS

A INFLUÊNCIA DE ESTILOS DE PENSAMENTO SOBRE A PRONTIDÃO INDIVIDUAL PARA ADOÇÃO DE DESIGN THINKING NAS ORGANIZAÇÕES 
Prof. Dr. Vahan Agopyan

Reitor da Universidade de São Paulo

Prof. Dr. Fábio Frezatti

Diretor da Faculdade de Economia, Administração e Contabilidade

Prof. Dr. Moacir de Miranda Oliveira Junior

Chefe do Departamento de Administração

Prof. Dr. Eduardo Kazuo Kayo

Coordenador do Programa de Pós-Graduação em Administração 
WILLIAN SEII

\section{THINKING STYLES' INFLUENCE ON THE INDIVIDUAL'S READINESS FOR ADOPTING DESIGN THINKING IN ORGANIZATIONS}

\section{A INFLUÊNCIA DE ESTILOS DE PENSAMENTO SOBRE A PRONTIDÃO INDIVIDUAL PARA ADOÇÃO DE DESIGN THINKING NAS ORGANIZAÇÕES}

Dissertação apresentada ao Programa de PósGraduação em Administração do Departamento de Administração da Faculdade de Economia, Administração e Contabilidade da Universidade de São Paulo, como requisito parcial para a obtenção do título de Mestre em Ciências.

Orientadora: Professora Dra. Liliana Vasconcellos-Guedes

Versão corrigida

SÃo PAULO 
FICHA CATALOGRÁFICA

Elaborada por Rafael Mielli Rodrigues - CRB-8/7286

Seção de Processamento Técnico do SBD/FEA/USP

Seii, Willian

Thinking styles' influence on the individual's readiness for adopting Design Thinking in organizations / Willian Seii. - São Paulo, 2018.

$157 \mathrm{p}$.

Dissertação (Mestrado) - Universidade de São Paulo, 2018.

Orientador: Liliana Vasconcellos Guedes.

1. Design 2. Pensamento 3. Mudança organizacional I. Universidade de São Paulo. Faculdade de Economia, Administração e Contabilidade. II. Título.

CDD -658.5752 
'Now for the evidence,' said the King, 'and then the sentence.' 'No!' said the Queen, 'first the sentence, and then the evidence!' 'Nonsense!' cried Alice, so loudly that everybody jumped, 'the idea of having the sentence first!'

Lewis Carroll, Alice through the Looking Glass 

For my dearest wife Bruna, whose patience and support allowed me this life achievement.

For my beloved son Victor, fortunately born in the middle of this academic journey. 

My deepest and sincere acknowledgements to my advisor PhD professor Liliana, for wisely making me lead my own academic development. 



\section{RESUMO}

O valor da abordagem de design para problemas de negócio vêm ganhando reconhecimento pelo setor privado, governamental e acadêmico, em um contexto onde a tradicional abordagem de racionalidade técnica tem sido insuficiente para endereçar os desafios de volatilidade, incerteza, complexidade e ambiguidade do atual ambiente de negócios. Design Thinking vem crescendo desde que Tim Brown, CEO de uma prestigiada agência global de design, começou a promover e disseminar esta abordagem no ambiente corporativo há alguns anos atrás. Em vista do aumento de organizações adotando o Design Thinking (DT), esta pesquisa objetiva analizar a relação entre a Prontidão individual para adotar DT nas organizações e os estilos de pensamentos, denominados Racionalidade e Experiencialidade. Na literatura acadêmica, alguns autores caracterizam Design Thinking pelo seu foco nas necessidades humanas, objetivos abertos que estimulam a criatividade, iteratividade, confiança em métodos qualitativos, na intuição e na experiência, - para nomear algumas das características. Nesta linha, a hipótese inicial desta pesquisa propõe que indivíduos com elevada pontuação em Experiencialidade apresentam maior Prontidão para adotar Design Thinking. A pesquisa quantitativa foi baseada em instrumentos existentes na literatura acadêmica. Para a mensuração dos estilos de pensamento, o Inventário de Racionalidade-Experiencialidade (REI) desenvolvido por Pacini \& Epstein (1999) foi integralmente aplicado; para mensuração da Prontidão individual para adotar Design Thinking, a Medição de Mudança Organizacional para Prontidão (ROCM) elaborada por Holt, Armenakis, Feild, \& Harris (2007b) foi parcialmente adotada; e para coletar o entendimento dos respondentes sobre Design Thinking, questões foram elaboradas com base na publicação acadêmica de Glen, Suciu \& Baughn (2014). A amostra final obteve 251 respondentes do Estado de São Paulo (Brasil), com conhecimento ou experiência com Design Thinking. O procedimento estatístico One-way ANOVA foi executado para identificar diferenças significativas entre os tercis de Racionalidade, Experiencialidade e Prontidão para a mudança e entre os tercis de estilos de pensamento e a pontuação de Prontidão para adotar Design Thinking; análise de regressão foi realizada para determinar, entre todas as variáveis da pesquisa, quais são aquelas com poder explicativo para Prontidão para adotar Design Thinking. Os resultados apontaram que o grupo de indivíduos com alta pontuação em Racionalidade (terceiro tercil) apresentou maior Prontidão para adoção de Design Thinking, assim como o terceiro e o primeiro tercil de Experiencialidade. Adicionalmente, quando Racionalidade e Experiencialidade foram analizados em conjunto, ambos os estilos de pensamento apresentaram influência na Prontidão individual para adotar Design Thinking. O conhecimento do nível dos estilos de pensamento de cada indivíduo permite antecipar futuros desafios na aceitação de DT. Efetivos programas de mudança organizacional envolvendo Design Thinking podem ser desenhados para implementações em departamentos ou programas de treinamento. Os resultados desta pesquisa podem ajudar no desenvolvimento de outros estudos na área cognitiva de Design Thinking, considerando que o sucesso na adoção de DT em organizações pode ser influenciado pelos estilos de pensamento dominantes no departamento ou área funcional onde a mudança será implementada.

Palavras-chaves: Design Thinking, estilos de pensamento, Prontidão individual para mudanças 



\begin{abstract}
Private sector, government and the academia have been recognizing the value of a 'designerly' approach to business problems, in the context that the traditional technical-rationality has been insufficient to address issues in the contemporary volatile, uncertain, complex and ambiguous environment. Design Thinking has been growing since Tim Brown, CEO of a prestigious global design agency, started advocating and disseminating this approach in the business environment ten years ago. As more organizations are implementing Design Thinking (DT), this research aims to analyze the relation between individuals' Readiness for adopting DT in organizations and their thinking styles, namely Rationality and Experientiality. From the literature review, some authors characterize Design Thinking by its focus on human needs, open objectives so creativity can arise, iteratively, reliance on qualitative methods, intuition and experience, - to name some of the characteristics. Accordingly, the initial hypothesis of this research stated that individuals with high Experientiality score would be the ones with higher Readiness to adopt Design Thinking. A quantitative survey was designed based on existing instruments in the academic literature. For assessing the thinking styles, the Rationality-Experientiality Inventory (REI) developed by Pacini \& Epstein (1999) was integrally applied; for measuring the individual's Readiness for adoption of Design Thinking, the Readiness for Organizational Change Measure (ROCM) developed by Holt, Armenakis, Feild, \& Harris (2007b) was partially applied; and to collect the respondents' understanding on Design Thinking, questions were designed based on the paper published by Glen, Suciu \& Baughn (2014). The sample size had 251 valid respondents from the state of Sao Paulo (Brazil), with declared knowledge or experience with Design Thinking. One-way ANOVA was conducted to determine significant differences within the terciles of Rationality, Experientiality and Readiness-for-change and between the thinking styles terciles and the score of Readiness for adopting Design Thinking; Regression Analysis was conducted to determine, among all variables in the research, which are the ones explaining Readiness for adopting Design Thinking. The results pointed out that the group of individuals with high score of Rationality (third tercile) presented higher Readiness for adopting Design Thinking, as well as the third and first terciles of Experientiality. Furthermore, when Rationality and Experientiality scores were analyzed together, both thinking styles did have influence on the individuals' Readiness for adopting Design Thinking. The understanding of the level of individual's thinking styles provides some light on the challenges ahead regarding the acceptance of Design Thinking. Smoother and more efficient change management programs can be designed for educational programs relying on Design Thinking or for departments in organizations implementing Design Thinking. These findings may implicate in further researches in the cognitive field of Design Thinking, as the success of DT adoption in organizations can be influenced by the thinking style profile which is dominant in the selected department or functional area to be implemented.
\end{abstract}

Key words: Design Thinking, thinking styles, individual's Readiness for change 



\section{SUMMARY}

PRESENTATION

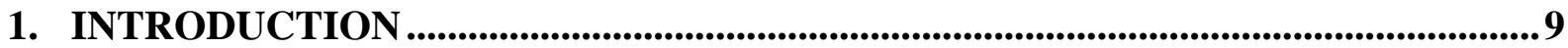

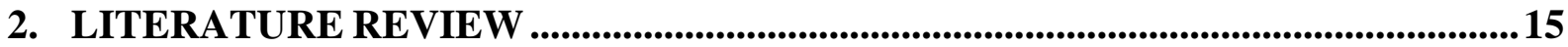

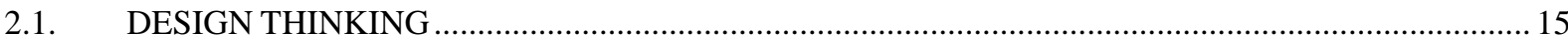

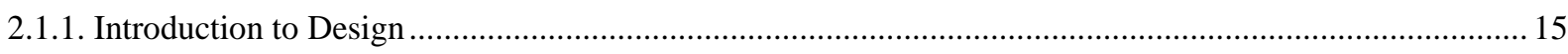

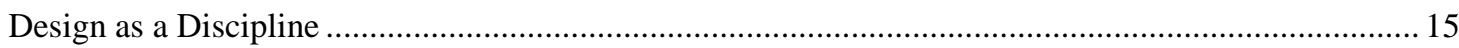

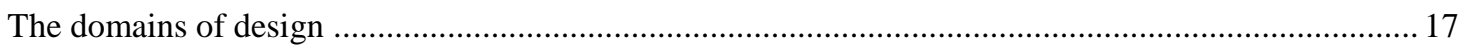

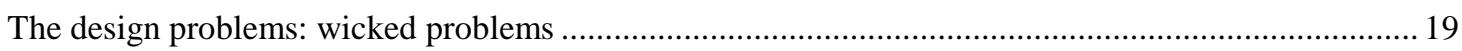

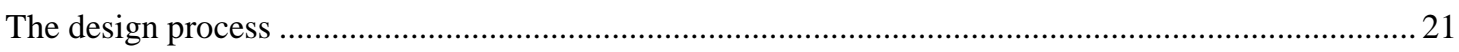

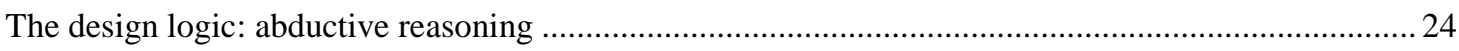

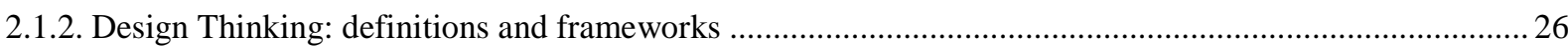

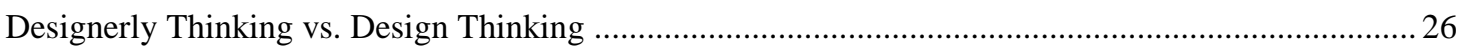

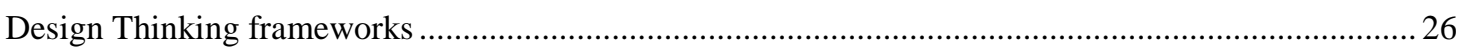

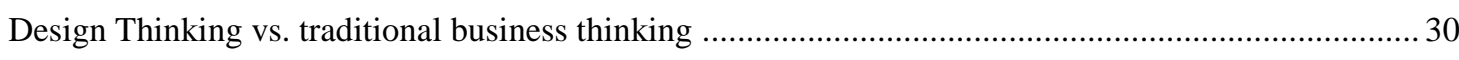

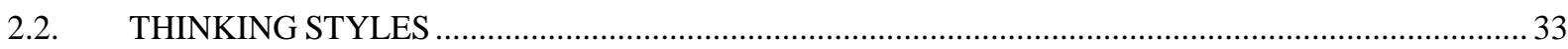

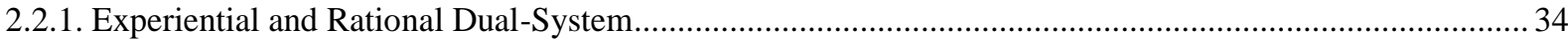

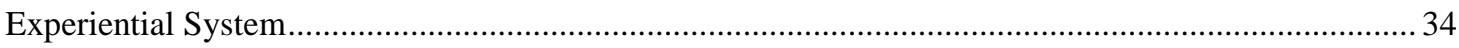

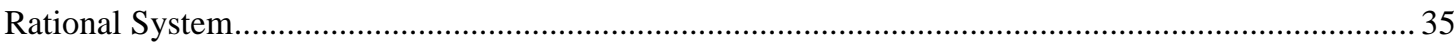

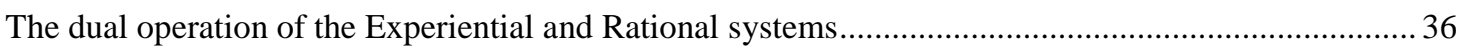

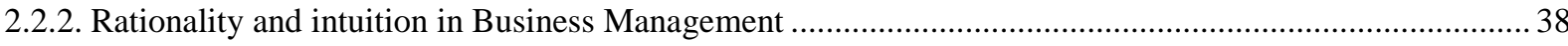

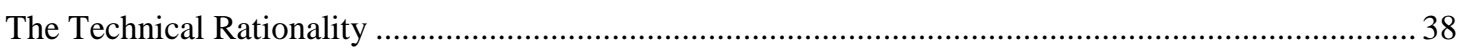

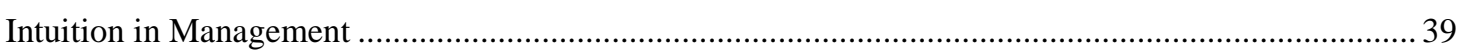

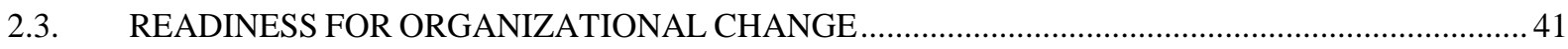

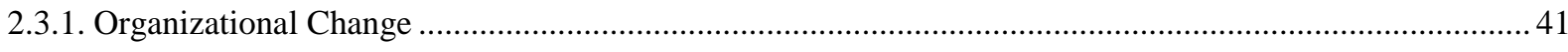

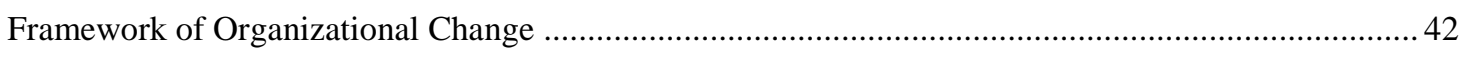

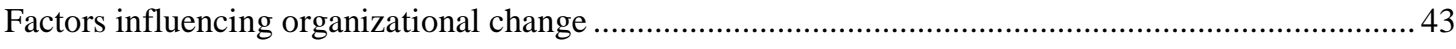

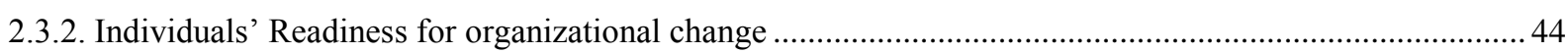

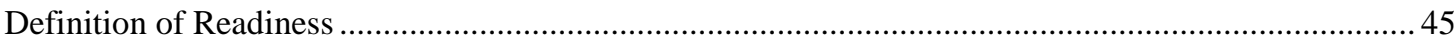

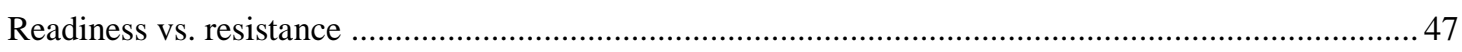

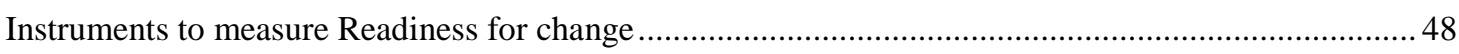

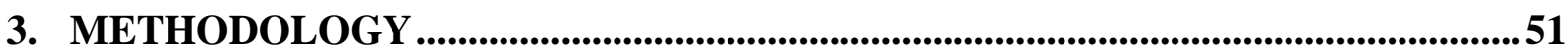

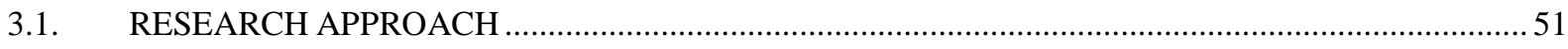

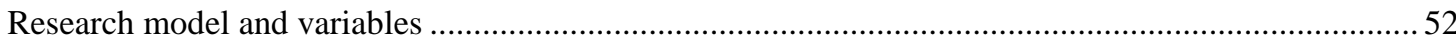

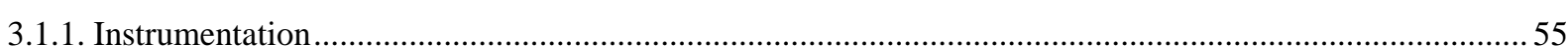

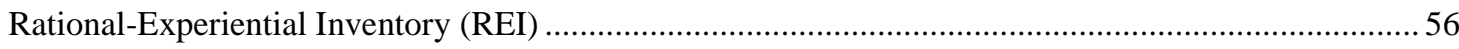

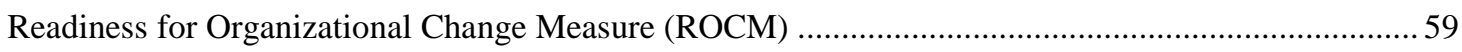

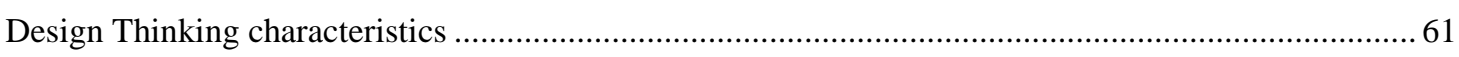

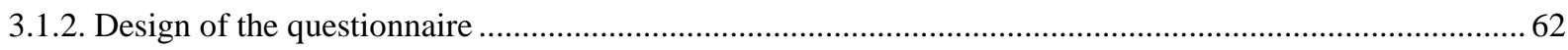

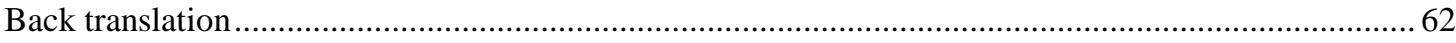

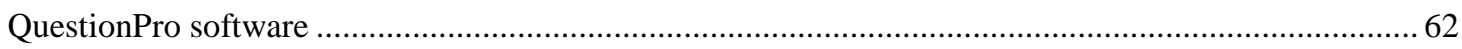




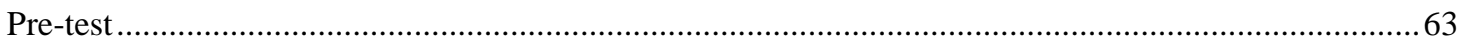

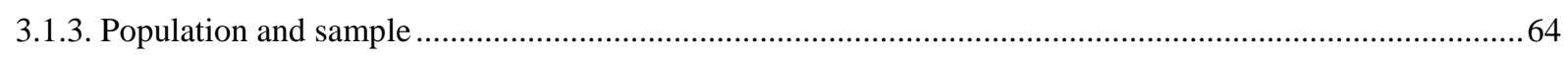

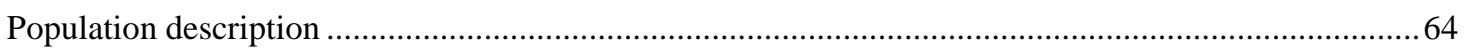

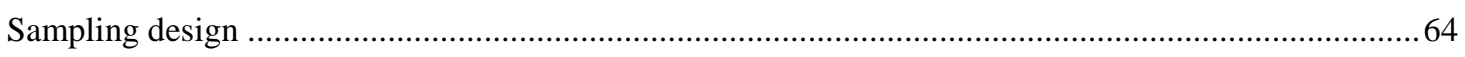

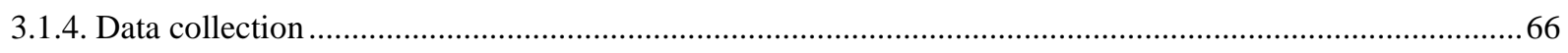

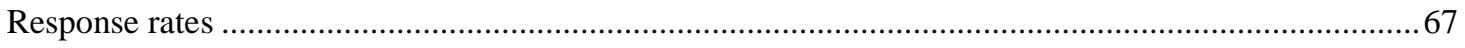

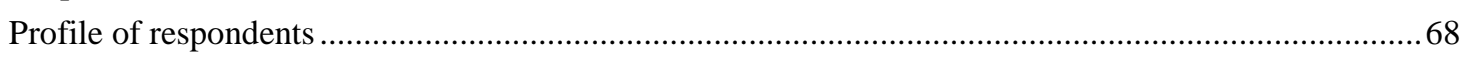

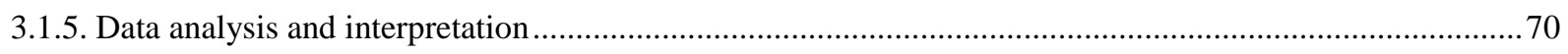

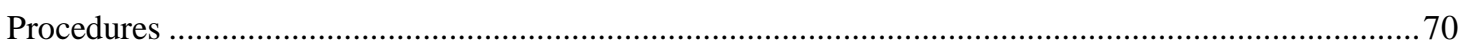

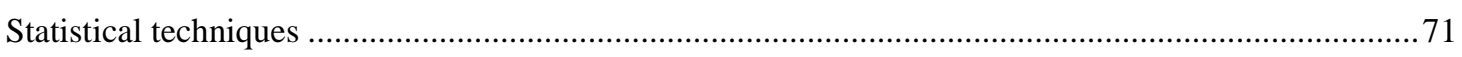

4. DATA ANALYSIS AND DISCUSSION OF RESULTS ................................................. 75

4.1. UNDERSTANDING, KNOWLEDGE \& EXPERIENCE WITH DESIGN THINKING ......................75

Understanding of Design Thinking as perceived by the respondents .............................................. 75

Respondents' understanding and knowledge/experience with Design Thinking (A) ...........................77

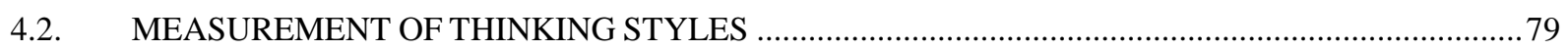

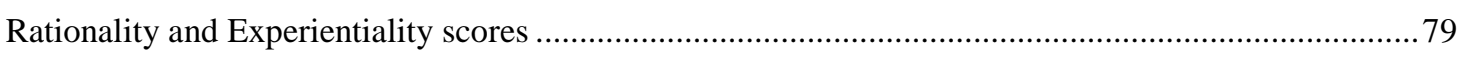

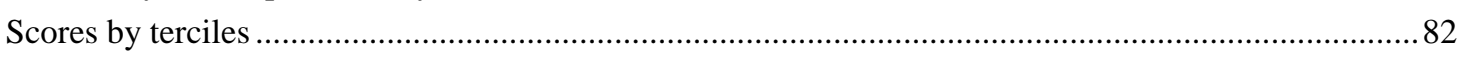

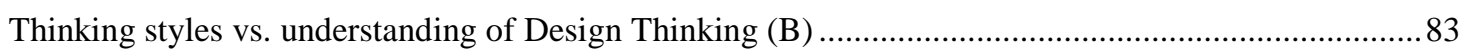

4.3. MEASUREMENT OF INDIVIDUAL'S READINESS FOR ADOPTION OF DESIGN THINKING ... 85

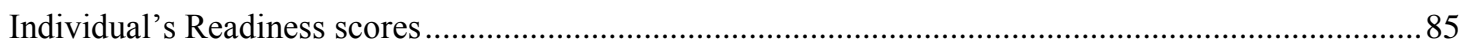

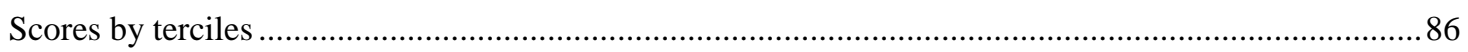

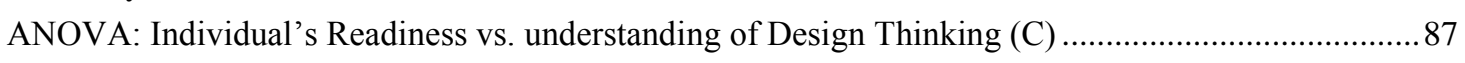

4.4. ASSOCIATION BETWEEN THINKING STYLES AND INDIVIDUAL'S READINESS (D) ............91

Rationality and Experientiality terciles vs. Readiness scores ......................................................91

ANOVA: Rationality terciles vs. Readiness scores ....................................................................... 93

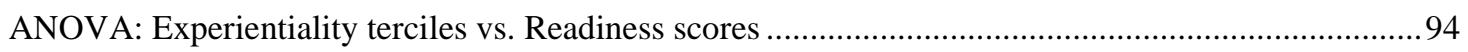

Regression analysis: Thinking Styles + other variables vs. Readiness .................................................99

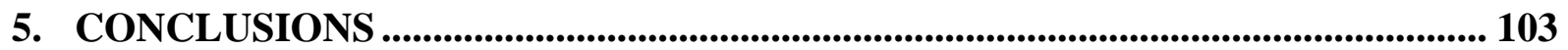

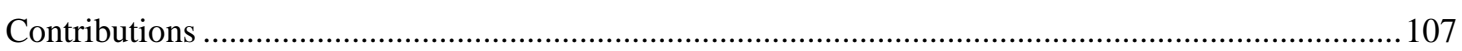

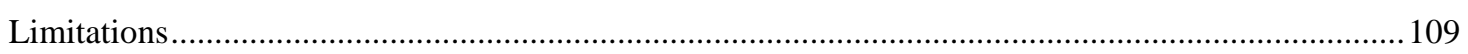

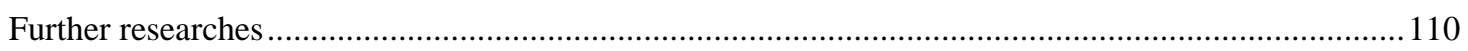

REFERENCES ..................................................................................................................................111

APPENDIX I - QUESTIONNAIRE IN PORTUGUESE LANGUAGE......................................... 119

APPENDIX II - BACK TRANSLATION ....................................................................... 127

APPENDIX III - LINKEDIN CAMPAIGN AD ............................................................. 133

APPENDIX IV - LINKEDIN CAMPAIGN METRICS.......................................................... 135

APPENDIX V - ANOVA RESIDUAL ANALYSIS ............................................................... 143

APPENDIX VI - ANOVA STATISTICAL DATA: UNDERSTANDING OF DESIGN THINKING. 149

APPENDIX VII - ANOVA STATISTICAL DATA: THINKING STYLES SUB-COMPONENTS .. 153

APPENDIX VIII - ANOVA STATISTICAL DATA: READINESS SUB-COMPONENTS.............. 155 


\section{LIST OF FIGURES}

Figure 1 - Relation between Thinking Styles and schools of thinking ............................... 12

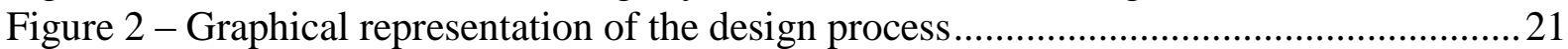

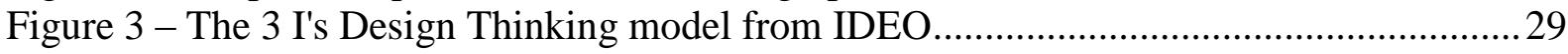

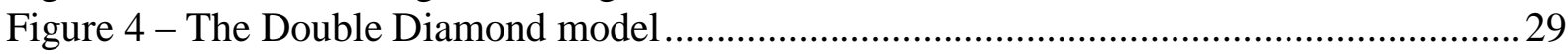

Figure 5 - Relation between Thinking Styles and Design Thinking ..................................... 40

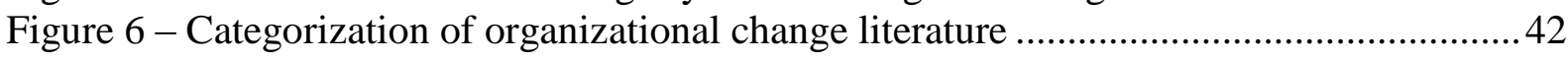

Figure 7 - Integrated model of Readiness: context, content, process, individual attributes .... 46

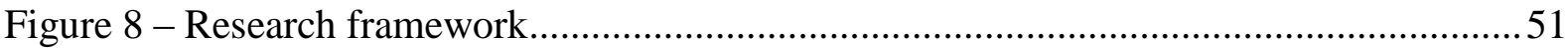

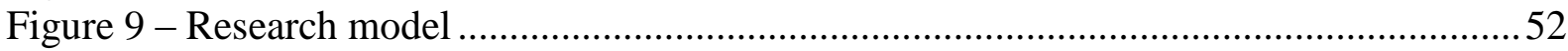

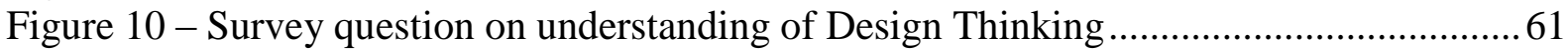

Figure 11 - LinkedIn respondents vs. ESPM/ Sioux respondents .........................................67

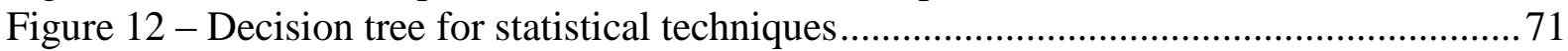

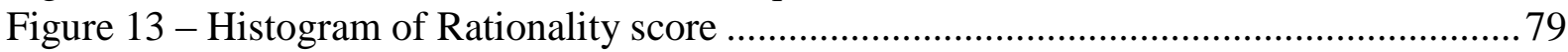

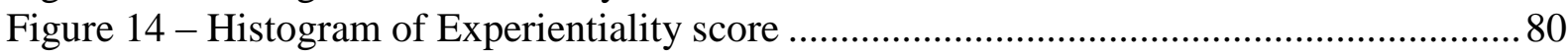

Figure 15 - Scatter plot for Rationality and Experientiality ........................................... 81

Figure 16 - One-way ANOVA: Rationality scores vs. Rationality terciles ............................ 83

Figure 17 - One-way ANOVA: Experientiality scores vs. Experientiality terciles ................. 83

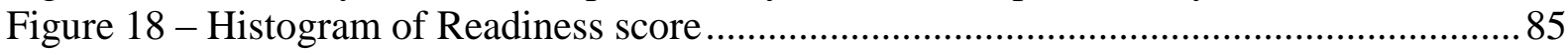

Figure 19 - One-way ANOVA: Readiness scores vs. Readiness terciles .............................. 86

Figure 20 - One-way ANOVA: Design Thinking outcome vs. Readiness scores .................. 88

Figure 21 - Rationality and Experientiality terciles vs. Readiness scores .............................92

Figure 22 - Experientiality and Rationality terciles vs. Readiness scores ............................93

Figure 23 - One-way ANOVA: Rationality terciles vs. Readiness scores ............................ 93

Figure 24 - One-way ANOVA: Experientiality terciles vs. Readiness scores .......................94

Figure 25 - 3D Scatterplot of Rationality vs. Experientiality vs. Readiness ..........................98

Figure 26 - Regression analysis: variables influencing Readiness .................................... 99 



\section{LIST OF TABLES}

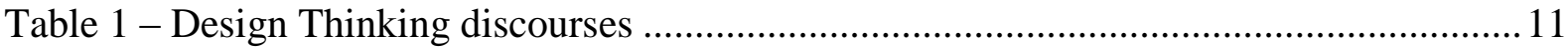

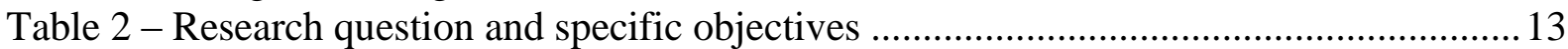

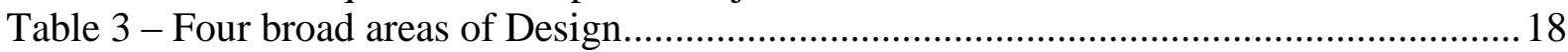

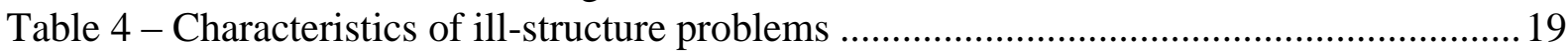

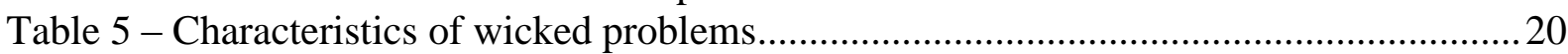

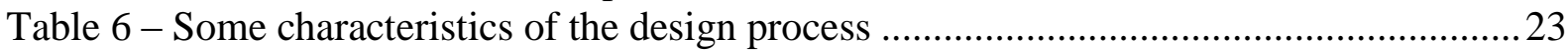

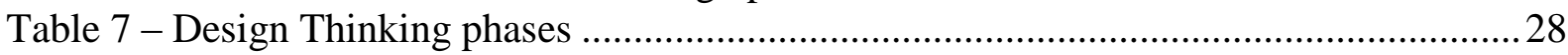

Table 8 - Comparison of Rational-Analytic and Design-Thinking approaches ...................... 31

Table 9 - Review of terminologies for modes of processing information ...............................33

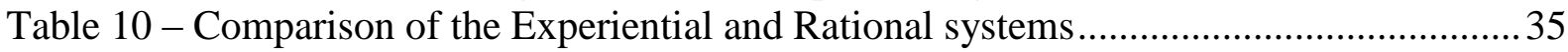

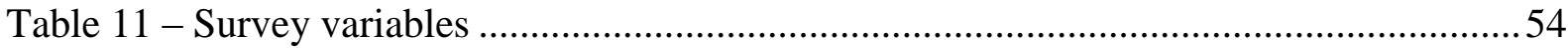

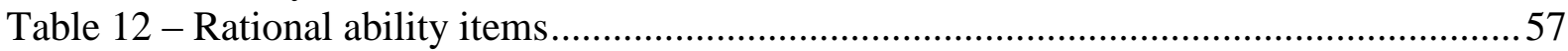

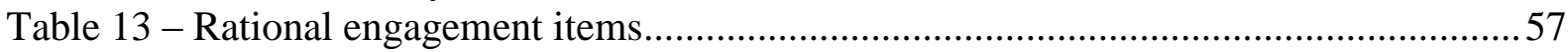

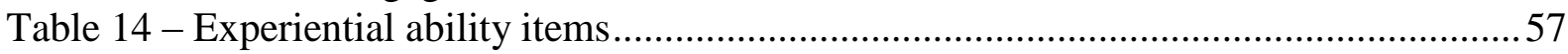

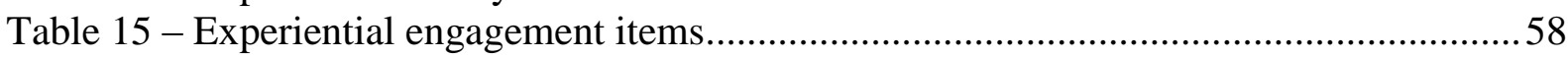

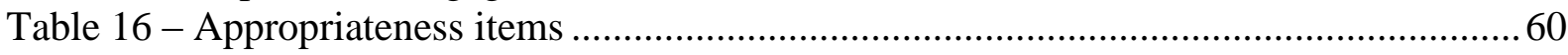

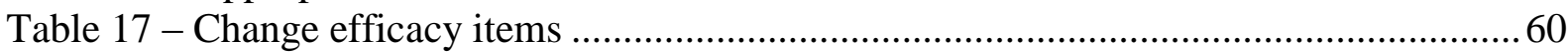

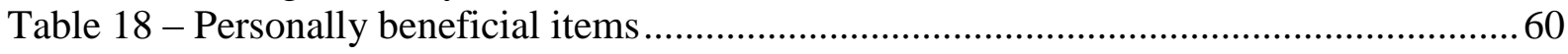

Table 19 - Back translations: list of divergences from original version ...............................62

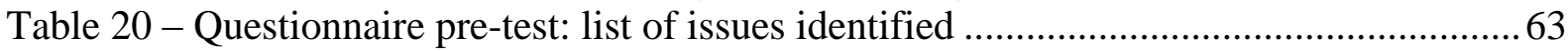

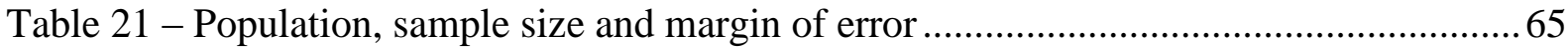

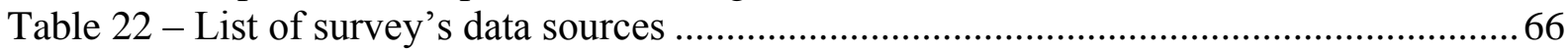

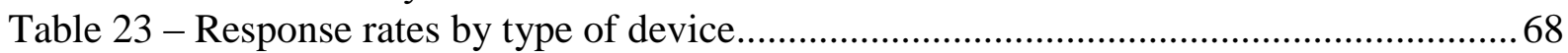

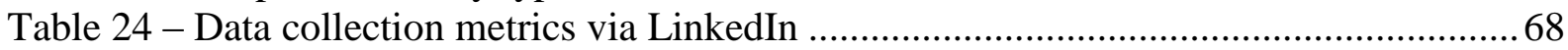

Table 25 - Respondents' knowledge and experience with Design Thinking..........................68

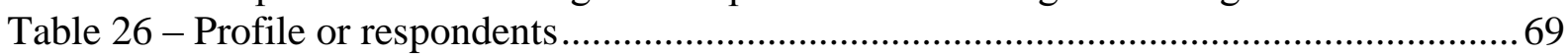

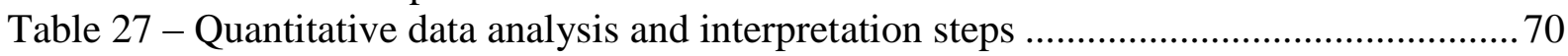

Table 28 - Respondents' understanding of Design Thinking .............................................. 76

Table 29 - Respondents' understanding of DT solution process by job role ............................76

Table 30 - Respondents' knowledge and experience with DT by job role ............................. 77

Table 31 - Respondents' understanding and knowledge/experience with DT .......................78

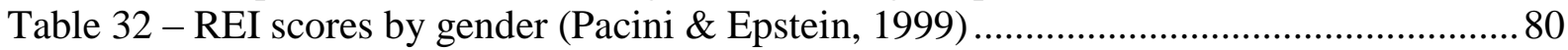

Table 33 - REI scores by gender (this survey's respondents) ............................................... 81

Table 34 - Description of terciles: Rationality and Experientiality ...................................... 82

Table 35 - Respondents' understanding of DT solution process by Thinking Style .............. 84

Table 36 - Description of terciles: Readiness for adopting Design Thinking.......................... 86

Table 37 - Summary of ANOVA: understanding of DT vs. Readiness scores........................87

Table 38 - Design Thinking approach and outcome, vs. Readiness scores ............................. 88

Table 39 - Rationality and Experientiality terciles vs. Readiness scores ..............................91

Table 40 - Combination of Rationality and Experientiality terciles vs. Readiness scores ...... 92

Table 41 - Rationality and Experientiality sub-components vs. Readiness scores.................95

Table 42 - Thinking styles sub-components terciles vs. Readiness sub-components scores... 96

Table 43 - Regression analysis: summary of regression equations ..................................... 100

Table 44 - Regression analysis: Change Efficacy vs. Rationality; Experientiality; sex ........ 101

Table 45 - Research question, specific objectives and findings ........................................ 103 



\section{PRESENTATION}

This session presents the author's motivation for this research theme and introduces a brief point-of-view on why Design Thinking may find a relevant territory in the business field, following the example of so-considered non-management disciplines as sociology and psychology that are now integrated by the academia and practitioners.

The author started co-working with designers more than three years ago, having the chance to experience the development of innovation projects with top global design agencies as Continuum and Smart Design. While developing these projects, many situations emerged demonstrating how business managers and designers could approach problems and solutions in different ways. As a business formally-educated person, fundamentally relying on deductive and inductive reasoning, this author has realized that designers are trained differently, they additionally apply abductive reasoning, they develop different cognitive skills, and they are likely to approach and eventually solve complex problems (not only for 'innovation'-related projects) that business managers are currently struggling with.

Top consultancy companies as McKinsey and Accenture have acquired global design agencies in latest years, as Lunar Design, Veryday and Fjord. Large companies, like Procter \& Gamble and IBM, have adopted Design Thinking practices in their organizations. In the same time period, academic journals have also highlighted the emergence of design in management, as presented by Gruber, Leon, George, \& Thompson (2015) in the editorial of the Academy of Management Journal. This phenomenon, introduction of Design Thinking in organizations, occurs within the context of VUCA, a more volatile, uncertain, complex and ambiguous world (Horney, Pasmore, \& O'Shea, 2010; Johansen \& Euchner, 2013; Lawrence, 2013) which increasingly demands not only innovative products and services, but also creative and out-of-the-box solutions for a variety of complex business problems.

Indeed, current capabilities and way of thinking of professionals are being recognized as limited or insufficient to deal with these contemporary challenges (Schön, 1983; Martin, 2009; Dorst, 2010; Glen, Suciu, \& Baughn, 2014), and organizations have started adopting Design Thinking as an alternative approach not only to foster innovation but also to help solving complex problems. Design Thinking has been progressively introduced by companies, mainly focusing on innovation, but it is now expanding within and across the organizations.

The adoption of Design Thinking, beyond $\mathrm{R} \& \mathrm{D}$ and product-related innovation departments, is of interest for this author and for this dissertation. If designers think and solve problems differently from businessmen, it may be relevant to understand cognitive aspects of the thinking styles and its association with Readiness to adopt Design Thinking. 


\section{INTRODUCTION}

The editorial of the Academy of Management Journal (Gruber, Leon, George, \& Thompson, 2015) raised attention to the development of design in the management field. For years, Design Thinking as a tool for innovation of products and services has been studied by management scholars, focusing in the impact on business performance (Kotler \& Rath, 1984). Recently, the importance of design for business has grown and it has been recognized by the private sector, government and academia (Gruber et al., 2015; Erichsen \& Christensen, 2013; Tschimmel, 2012; Kimbell, 2011; Liedtka, 2010; Martin, 2009, 2004; Brown, 2009; Ungaretti et al., 2009; Boland \& Collopy, 2004).

Organizations as Apple and IDEO, and institutions as the UK Government and Stanford University - just to name a few examples - have recognized the value of a more 'designerly' approach for business problems, beyond products and services, in line with today's ever challenging context. Companies are struggling to develop models for the complex scenarios they are now operating. Current practices are not helping enterprises to cope with their big problems. CEOs have admitted that they are facing issues that cannot be solved by gathering additional data (even with the rise of big data), defining problems more clearly, or breaking them down into smaller pieces (Camillus, 2008; Kurman \& Beckman, 2011). PWC $20^{\text {th }}$ CEO Survey (PricewaterhouseCoopers, 2017) reported top 10 concerns in the CEO agenda, including complex problems as over-regulation, geopolitical uncertainty, increasing tax burden and social instability. Most of existing planning tools do not generate fresh ideas on how to solve these problems. Governments are facing issues like environmental degradation, poverty, terrorism - which have multiple causes, are hard to define, and do not have a right answer (Camillus, 2008). Better solutions might not arise from new comers from business schools, which are under intense criticism from management practitioners as MBA programs are not matching contemporary challenges (Dunne \& Martin, 2006).

The new paradigm is moving from a world of optimization, Six Sigma, Total Quality Management, which demanded speed, analysis, bottom-line focus and uncertainty-free; to a world of dilemmas, that requires patience to foster breakthroughs, sense-making, creation of new top-line revenues and an engagement of uncertainty (Ungaretti, et al., 2009). Authors have adopted the acronym VUCA to address this volatile, uncertain, complex, and ambiguous context that organizations are facing today (Bennett \& Lemoine, 2014; Johansen \& Euchner, 2013; Lawrence, 2013). The most unpredictable and ill-structured problem type is the dilemma, as often there is always a compromise and no solution satisfies most of the people. 
Even when solutions are proposed or implemented, one may never know if that is the best one, given the complex and unpredictable situation (Jonassen, 2000).

For such ill-structured issues, or wicked issues as defined in the design literature, only traditional business problem-solving processes may not resolve them, as these problems are in the opposite spectrum of well-known problems. Wicked problems may not be solved in a specific timeframe, and standard techniques or declarative logic may be applied but not be successful. Analytical processes may fail to approach wicked problems, and they may even generate unexpected consequences (Camillus, 2008); the sole reliance on analytical capabilities has been proved insufficient (Glen, Suciu, \& Baughn, 2014).

Schön (1983) articulated the limitations of the Technical Rationality ${ }^{1}$, which has been institutionalized in the education system of the $20^{\text {th }}$ century. When outputs are clear and welldefined, the decision making consists in instrumental problem solving supported by scientific theory and methods. But when outputs are fuzzed, Technical Rationality does not properly frame the problem and it becomes insufficient to achieve solutions.

For these ill-defined outputs, and ill-defined problems, the approach of Design Thinking (DT) has called attention of organizations and management scholars, as designers' approach to problems is different from that applied by business practitioners (Cross, 1982; Schön, 1983; Boland \& Collopy, 2004; Lawson, 2005; Martin, 2009; Tschimmel, 2012). Cross (1982) pointed out that design has a particular type of thinking. The 'constructive' or 'creative' thinking is indeed different from the well-established inductive and deductive reasoning embedded in the Technical Rationality.

Instead of being positioned as opposite or better approach to business problem solving, some authors argued that Design Thinking takes place as an important and needed complement for the analytical capabilities and methods that managers are used to (Glen et al., 2014). Martin (2010) reconciled the designers' way of thinking with the analytical way of thinking. "Neither analysis nor intuition alone is enough. In the future, the most successful businesses will balance analytical mastery and intuitive originality in a dynamic interplay that I call Design Thinking" (Martin, 2010, p. 37). This balance is also supported by other authors (e.g. Adler, 2006) and articulated by Glen et al. (2014, p. 660): “Although Design Thinking does entail analysis, analysis is in greater balance with intuitive and insight-producing processes than one finds in business schools."

\footnotetext{
${ }^{1}$ Technical Rationality: "Technical Rationality is the heritage of Positivism, the powerful philosophical doctrine that grew up in the nineteenth century as an account of the rise of science and technology and as a social movement aimed at applying the achievements of science and technology to the well-being of mankind. Technical Rationality is the Positivist epistemology of practice." (Schön, 1983, p. 21)
} 
Other authors reinforce Design Thinking as a thought process based on experience and intuition, and its difference from the technical-rationality embedded in the business thinking. This understanding has origins from the Design field, as exemplified by Gregory (1966) in the book The Design Method: "the key to brilliant design remains the designer himself with all his intangible design capabilities such as intuition, judgement, determination, courage, spatial vision, and imagination" (p. 18). This understanding also found resonance in the Design Thinking literature, as exemplified by Dorst (2010) in his paper The Nature of Design Thinking. Brown \& Wyatt (2010, p. 33) also supported this argument: "Design thinking relies on our ability to be intuitive, to recognize patterns, to construct ideas that have emotional meaning as well as being functional, and to express ourselves in media other than words or symbols". Tschimmel (2012, p. 14) reminded that the ideation phase aims to generate large amount of ideas, "where emotions and intuition are more important than rational thinking".

These two views from authors of Design Thinking are summarized in Table 1.

Table 1 - Design Thinking discourses

\begin{tabular}{cl}
\hline Academic view & \multicolumn{1}{c}{ Examples of authors } \\
\hline $\begin{array}{c}\text { Design Thinking as } \\
\text { a combination of } \\
\text { analysis and } \\
\text { intuition }\end{array}$ & $\begin{array}{c}\text { Adler (The arts and leadership: Now that we can do anything, what will we do?, 2006) } \\
\text { Martin (Design thinking: achieving insights via the "knowledge funnel", 2010) } \\
\text { Glen et al. (The need for design thinking in business schools, 2014) }\end{array}$ \\
$\begin{array}{c}\text { Design Thinking } \\
\text { based on intuition }\end{array}$ & $\begin{array}{l}\text { Dorst (The Nature of Design thinking, 2010) } \\
\text { Brown \& Wyatt (Design Thinking for Social Innovation, 2010) } \\
\text { Tschimmel (Design Thinking as an effective Toolkit for Innovation, 2012) }\end{array}$ \\
\hline
\end{tabular}

Source: prepared by the author

Indeed, intuition and analysis are related to the two independent but connected modes of processing information that have been studied by various psychologists. One is referred as intuitive, natural, automatic, implicit, imagistic-nonverbal, experiential, first-signal system, System 1; the other is referred as conceptual-logical, analytical-rational, explicit, verbal, second-signal system, System 2 (Epstein, Pacini, Denes-Raj, \& Heier, 1996). The Cognitiveexperiential self-theory (CEST) developed by Epstein (1994) stated that each individual has two process information systems running in parallel and interacting with each other; one is the rational system, the other is the experiential system:

The rational system operates primarily at the conscious level and is intentional, analytic, primarily verbal, and relatively affect free. The experiential system is assumed to be automatic, preconscious, holistic, associationistic, primarily nonverbal, and intimately associated with affect (Epstein, Pacini, Denes-Raj, \& Heier, 1996, p. 391) 
Consequently, the theory of dual process modes of information processing can be connected to schools of thinking. The analytical-rational thinking is a foundation of the Technical Rationality (Schön, 1983; Dorst, 1997) while the intuitive-experiential thinking is considered the foundation to the way designers think - the designerly way of thinking (Gregory, 1996; Dorst, 2010). Figure 1 illustrates these relations.

\section{Figure 1 - Relation between Thinking Styles and schools of thinking}

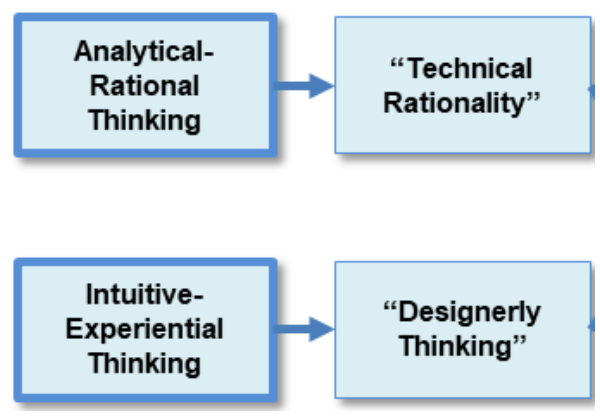

Source: prepared by the author, based on Epstein et al. (1996), Schön (1983), Dorst (2010), Martin (2007) and Johansson-sköldberg \& Woodilla (2013).

If Design Thinking is a combination of analysis and intuition, and cognitive theories points out dual process information systems referring to one side of the brain being analytical and other intuitive, this research raises the question on to what extent thinking styles can influence the individual's Readiness for a change such adopting Design Thinking in their organizations or departments.

This author is aligned with the academic view that Design Thinking is a combination of analysis and intuition. However, this may not be the understanding of Design Thinking practitioners. The hypothesis for this research considers that, due to the association with the Design field, respondents would understand Design Thinking as based on experience and intuition. Within this context, individuals highly intuitive and experiential would present higher score of Readiness for adopting Design Thinking, given that the individuals' confidence on their own intuitive and experiential's abilities would influence towards higher Readiness for adopting DT.

Readiness for Change is defined by Holt, Armenakis, Harris, \& Field (2007a, p. 326) as "the extent to which an individual or a collection of individuals is cognitively and emotionally inclined to accept, embrace, and adopt a particular plan to purposefully alter the status quo", influenced by the content, context and process of the change.

Therefore, within this research context, the Research Question of this dissertation aims to examine, analyze and discuss: to what extent individual attributes (Thinking Styles, 
Knowledge, Experience and Understanding of Design Thinking) influence the individual's Readiness for adopting Design Thinking in the organization? To address this question, four specific objectives, in a logical order, were established to support the operationalization of this research. Firstly, the research had to capture the understanding of Design Thinking by the respondents, as it could differ from the characteristics described in the academic literature. Secondly, the thinking styles of each individual had to be measured and somehow discriminated, to allow identification of differences between groups. Same procedure had to be applied for the Readiness-for-change. Finally, the relation between thinking styles and individual's Readiness could be tested (see Table 2).

Table 2 - Research question and specific objectives

\begin{tabular}{ll}
\hline RESEARCH QUESTION & $\begin{array}{l}\text { To what extent individual attributes (Thinking Styles, Knowledge, Experience } \\
\text { and Understanding of Design Thinking) influence the individual's Readiness } \\
\text { for adopting Design Thinking in the organization? }\end{array}$ \\
Specific Objective 1 & $\begin{array}{l}\text { Analyze respondents' perceived understanding of Design Thinking } \\
\text { characteristics }\end{array}$ \\
Specific Objective 2 & $\begin{array}{l}\text { Measure and discriminate the Rationality and Experientiality's individual } \\
\text { scores of the selected sample }\end{array}$ \\
Specific Objective 3 & $\begin{array}{l}\text { Measure and discriminate the individuals' Readiness for adoption of Design } \\
\text { Thinking in their organizations }\end{array}$ \\
Specific Objective 4 & $\begin{array}{l}\text { Test the relation of thinking styles (while considering the understanding of } \\
\text { Design Thinking and knowledge and experience with Design Thinking) with } \\
\text { the individuals' Readiness for adopting Design Thinking }\end{array}$ \\
\hline
\end{tabular}

Source: prepared by the author

This relation between Design Thinking and thinking styles may be of interest of companies, researchers and educators, as it allows anticipating issues and avoiding further resistance when implementing this rising and recently new approach of Design Thinking.

Following this introduction, this dissertation is organized in other four major chapters. The Literature Review chapter is organized in three sessions: Design Thinking, Thinking Styles and Readiness for Organizational Change. The Methodology chapter provides details for the fieldwork operationalization and describes the instruments utilized in this research. The Data Analysis and Discussion of Results chapter is organized by the specific objectives and by the research model, and it combines the descriptive analysis, the inferential statistics and discussion of the findings. Last chapter is named Conclusions, where contributions, limitations and opportunities for further researches are presented. 


\section{LITERATURE REVIEW}

\subsection{DESIGN THINKING}

This session provides an introduction to the discipline of Design, presenting its domains, nature of problems and process and well as the design logic. This introduction is required before entering the literature review of Design Thinking, as it presents core elements from the Design discipline.

\subsubsection{Introduction to Design}

Design is a fragmented discipline and even the word 'design' addresses different meanings for researchers, practitioners or general population (Kimbell, 2011; Lawson, 2005). General population usually relates design to aesthetics, form and function; but design academics actually share different school of thoughts when defining design.

For an overall perspective of these differences, Kimbell's (2011) explanation of the tension between two notable authors, Christopher Alexander (1971) and Herbert Simon (1996), is remarkable to evidence the divergence on the school of thoughts.

Alexander (1971) stated that design is about giving form and its central concern is about materiality. $\mathrm{He}$ is aligned with the craft and design fields, which traditionally focus on creating objects, as furniture, buildings and clothing. Design is about doing things with and to objects, including the design of experiences and intangible services.

For Simon (1996), abstraction is the central work for designers, referring to a specific knowledge as a main domain for professions such as engineering; designers work with envisioning. For him, it is this design way of thinking that is common for the design professions, not just the creation of artifacts.

This dissertation falls into the latter stream, where the way of thinking is of interest.

\section{Design as a Discipline}

In his book The Sciences of the Artificial (1996), Simon stated that design field is concerned with "what ought to be", while sciences are concerned with "what is". The belief that design has a "designerly way of thinking and communicating that is both different from scientific and scholarly ways of thinking and communicating" was presented by Bruce Archer (1979, p. 17). For Archer (1979), the phenomenon of study is different for each discipline. Science traditionally focuses in the natural world; Humanities in the human experience; while Design is concerned with the artificial world. 
Archer (1979, p. 20) articulated the differences among Science, Humanities and Design:

The repository of knowledge in Science is not only the literature of science but also the analytical skills and the intellectual integrity of which the scientist is the guardian. The repository of knowledge in the Humanities is not simply the literature of the humanities but also the discursive skills and the spiritual values of which the scholar is the guardian. In Design, the repository of knowledge is not only the material culture and the contents of the museums but also the executive skills to designerly think, make and do things.

This idea was further developed by Cross (1982, p. 3), whom pointed out distinctions in the methods and values of Sciences, Humanities and Design. "Science applies controlled experiments, classifications, analyses; Humanities work with analogies, metaphors, criticisms, evaluations; and Design methods include modelling and synthesis". The values for each discipline also differ. "The value of Science is on objectivity, rationality, neutrality, and there is a concern for truth; for Humanities, it is subjectivity, imagination, commitment, and the concern for justice; while Design highlights the practicality, ingenuity, empathy, and the concern for appropriateness".

In fact, in the academic design literature, different authors debate about the need to differentiate Design from Science, in the interest of leveling up the recognition and prestige of the design field among scholars (Archer, 1979; Simon, 1996; Schön, 1983; Buchanan, 1992; Cross, 2001). Buchanan (1992) observed that some non-design academics position design as an 'applied' science or 'applied' fine arts, given the fact that they see design as an extension of other subject matters.

For Archer (1979), the concept of Design as a discipline is not well accepted given the prevalence of Science and Humanities in the modern education, which has focused on the transmission of skills of reading, writing and arithmetic, summarized in the terms of literacy and numeracy. Furthermore, some trials to communicate design theories have been made either with the use of Science language or Humanities'. But mathematics and scientific notation were actually not appropriate to articulate the discipline of Design, which addresses the medium of making, doing or creating a desired state of affairs. Regarding Humanities, Archer (1979) articulated that the concern of Humanities focuses on the human values but excludes fine arts and performing arts.

Science is about generalizable theory and method. The remarkable characteristic of science is the intellectual rigor and procedures that support the discoveries based on measurements, formulation and testing of theories and experiments. It is reasonable to point out that science does not cover all the subject matters of mankind, and some phenomena are 
seen as inappropriate and not accessed by the scientific community. The scientist is, after all, concerned with generalizable knowledge and theorization (Archer, 1979).

Design, on the other hand, focuses on the particular (Buchanan, 1992). Methodology is the core of science, so results can be validated and replicated; in case of design practice, the major concern may be the novelty and originality, and replication is not really a priority (Cross, 2001). For Buchanan (1992), design is not science. Eventually, an artifact created by designers can be an object of study of the sciences, as claimed by Simon (1996) in his book "The Science of the Artificial", but design is different from science. Science focuses on understanding and explaining existing structures and its components, while designers are interested in creating and shaping new structures (Alexander, 1971).

Gregory (1966, p. 6) also established a comparison between science and design:

The scientific method is a pattern of problem-solving behavior employed in finding out the nature of what exists, whereas the design method is a pattern of behavior employed in inventing things, which do not yet exist. Science is analytic; design is constructive.

Cross (2001) defended design as a discipline, which should differentiate itself from science. He claimed for design having its own terms and culture, as a discipline that develops its own approaches and researches. Schön (1983) also stated that design should develop its own intellectual culture, apart from science and arts, but not disregarding these other cultures.

\section{The domains of design}

In general, design is perceived as a generic activity, but the end products of the design domains are significant different (Lawson, 2005). A useful comparison between the design practice in engineering and in fashion design is illustrated by Lawson (2005, p. 5):

A structural engineer may describe the process of calculating the dimensions of a beam in a building as design. In truth such a process is almost entirely mechanical. Several mathematical formulae are applied and the appropriate values are inserted for various loads known to act on the beam and the required size results. It is quite understandable that an engineer might use the word 'design' here since this process is quite different from the task of 'analysis', by which the loads are properly determined.

However, a fashion designer creating a new collection might be slightly puzzled by the engineer's use of the word 'design'. The engineer's process seems to be relatively precise, systematic and even mechanical, whereas fashion design seems more imaginative, unpredictable and spontaneous. The engineer knows more or less what is required from the outset. In this case a beam that has the properties of being able to span the required distance and hold up the known loads. The fashion designer's knowledge of what is required is likely to be vaguer. The collection attracts attention and sells well and probably enhances the reputation of the design company. 
Design domains should be visualized in a spectrum. Design can have clear-cut or fuzzy ideas, systematic or back-forward thinking, and creative thoughts or very mechanical calculations. Some design fields may be placed in the middle of this spectrum, as architecture and industrial design (Lawson, 2005).

Four broad areas of design were organized by Buchanan (1992). The first of these areas is the design of symbolic and visual communications, followed by the design of material objects, and then by the design of activities and organized services. Finally, the fourth area is the design of complex systems or environments for living, working, playing, and learning. A detailed description of each area can be found in Table 3.

Table 3 - Four broad areas of Design

\begin{tabular}{ll}
\hline \multicolumn{1}{c}{ Broad area of Design } & \multicolumn{1}{c}{ Description } \\
\hline & $\begin{array}{l}\text { The traditional work of graphic design includes typography and advertising, book } \\
\text { and magazine production, and scientific illustration, and has expanded into } \\
\text { communication through photography, film, television, and computer display. The } \\
\text { area of communications design is rapidly evolving into a broad exploration of the } \\
\text { problems of communicating information, ideas, and arguments through a new } \\
\text { visual communications } \\
\text { synthesis of words and images that is transforming the 'bookish culture' of the } \\
\text { past }\end{array}$
\end{tabular}

Material objects is the traditional concern for the form and visual appearance of everyday products, clothing, domestic objects, tools, instruments, machinery, and vehicles, but has expanded into a more thorough and diverse interpretation of the

Design of material objects physical, psychological, social, and cultural relationships between products and human beings. This area is rapidly evolving into an exploration of the problems of construction in which form and visual appearance must carry a deeper, more integrative argument that unites aspects of art, engineering and natural science, and the human sciences

Includes the traditional management concern for logistics, combining physical resources, instrumentalities, and human beings in efficient sequences and schedules to reach specified objectives. However, this area has expanded into a concern for logical decision making and strategic planning and is rapidly evolving into an exploration of how better Design Thinking can contribute to achieving an organic flow of experience in concrete situations, making such experiences more intelligent, meaningful, and satisfying. The central theme of this area is connections and consequences. Designers are exploring a progressively wider range of connections in everyday experience and how different types of connections affect the structure of action

Design of activities and organized services

Design of complex systems or environments for living, working, playing, and learning
The design of complex systems or environments for living, working, playing, and learning includes the traditional concerns of systems engineering, architecture, and urban planning or the functional analysis of the parts of complex wholes and their subsequent integration in hierarchies. But this area has also expanded and reflects more consciousness of the central idea, thought, or value that expresses the unity of any balanced and functioning whole. This area is more and more concerned with exploring the role of design in sustaining, developing, and integrating human beings into broader ecological and cultural environments, shaping these environments when desirable and possible or adapting to them when necessary 
All these areas happen to have specific job titles, as graphic designer, industrial designer, architects, urban planners, but they are interconnected and it is the connection and overlap among them that help bringing unexpected outcomes for innovation (Buchanan, 1992).

\section{The design problems: wicked problems}

Before investigating how designers think, the understanding of the nature and the characteristics of design problems is of great importance to move further (Lawson, 2005).

Design problems are usually unstable, changeable, sometimes vague, embedded in contradictions and most of the times opened to multiple interpretations (Dorst, 2006, 2010).

Archer (1979) stated that design problems are characterized by being ill-defined. An illdefined problem is "one in which the requirements, as given, do not contain sufficient information to enable the designer to arrive at a means of meeting those requirements simply by transforming, reducing, optimizing or superimposing the given information alone" (p. 17).

Simon (1973) presented interesting comments on ill-structure problems. At the same time he categorized problems either as being ill-structured or well-structured, whenever an illstructure problem becomes a well-structure problem, it is actually no longer a problem, given the fact that the problem is already addressed for a solution. For him, the challenge of illstructure problems lay on giving these problems some structure.

On the ill-structured problems, dilemmas are in the extreme of the spectrum. Often the solution will not satisfy all the stakeholders, with every solution having a compromise and some unpredictability, and often different parts do not accept the proposed solution. Dilemmas usually include social aspects in a situation of conflict (Jonassen, 2000).

Jonassen (2000) summarized the characteristics of ill-structured problems, based on different authors, as summarized in Table 4.

Table 4 - Characteristics of ill-structure problems

\begin{tabular}{ll}
\hline \multicolumn{1}{c}{ Characteristics } & \multicolumn{1}{c}{ Author } \\
\hline Possess problem elements that are unknown or not known with any degree of confidence & Wood (1983) \\
\hline Possess multiple solutions, solution paths, or no solutions at all & Kitchner (1983) \\
$\begin{array}{ll}\text { Possess multiple criteria for evaluating solutions, so there is uncertainty about which } \\
\text { concepts, rules, and principles are necessary for the solution and how they are organized }\end{array}$ & Jonassen (2000) \\
$\begin{array}{ll}\text { Require judgments and express personal opinions or beliefs about the problem, so ill- } \\
\text { structured problems are uniquely human interpersonal activities }\end{array}$ & $\begin{array}{l}\text { Meacham \& } \\
\text { Emont (1989) }\end{array}$ \\
\hline
\end{tabular}

Source: Jonassen (2000, p. 67) 
Rittel \& Webber (1973) published a seminal paper that established the foundation for the concept of wicked problems. The ten distinguishing properties are presented in Table 5, which descriptions were organized by Camillus (2008). Curiously, the term 'wicked problem' was actually borrowed from the philosopher Karl Popper, but the original use of the term is not related to what Rittel \& Webber later defined (Buchanan, 1992).

Table 5 - Characteristics of wicked problems

\begin{tabular}{|c|c|}
\hline Characteristics & Description \\
\hline $\begin{array}{l}\text { 1. There is no definitive formulation of a } \\
\text { wicked problem. }\end{array}$ & $\begin{array}{l}\text { It's not possible to write a well-defined statement of the } \\
\text { problem, as can be done with an ordinary problem. }\end{array}$ \\
\hline 2. Wicked problems have no stopping rule. & $\begin{array}{l}\text { You can tell when you've reached a solution with an ordinary } \\
\text { problem. With a wicked problem, the search for solutions never } \\
\text { stops. }\end{array}$ \\
\hline $\begin{array}{l}\text { 3. Solutions to wicked problems are not true or } \\
\text { false, but good or bad. }\end{array}$ & $\begin{array}{l}\text { Ordinary problems have solutions that can be objectively } \\
\text { evaluated as right or wrong. Choosing a solution to a wicked } \\
\text { problem is largely a matter of judgment. }\end{array}$ \\
\hline
\end{tabular}

4. There is no immediate and no ultimate test of a solution to a wicked problem.

\section{Every solution to a wicked problem is a "one-shot" operation; because there is no opportunity to learn by trial and error, every attempt counts significantly.}

It's possible to determine right away if a solution to an ordinary problem is working. But solutions to wicked problems generate unexpected consequences over time, making it difficult to measure their effectiveness.

Solutions to ordinary problems can be easily tried and abandoned. With wicked problems, every implemented solution has consequences that cannot be undone.

Ordinary problems come with a limited set of potential solutions, by contrast.

An ordinary problem belongs to a class of similar problems that are all solved in the same way. A wicked problem is substantially without precedent; experience does not help you address it.

8. Every wicked problem can be considered to While an ordinary problem is self-contained, a wicked problem is entwined with other problems. However, those problems don't have one root cause.

9. The existence of a discrepancy representing A wicked problem involves many stakeholders, who all will a wicked problem can be explained in numerous ways. have different ideas about what the problem really is and what its causes are.

Problem solvers dealing with a wicked issue are held liable for

10. The planner has no right to be wrong. the consequences of any actions they take, because those actions will have such a large impact and are hard to justify.

Source: Camillus (2008, p. 3) based on Rittel \& Webber (1973)

Based on his experience in consultancy with corporate executives, Camillus (2008) has stated that the presence of five characteristics can already define a problem as wicked. 


\section{The design process}

Researchers have studied the design process and yet debates exist on the commonalities among the different design domains and the existing variations. Lawson (2005) pointed out that authors have proposed charts, or maps, describing design process as a sequence of linear activities; but this formulation is at least simplistic and incautious.

Buchanan (1992) also articulated that authors have proposed a linear process composed of main two phases, which are problem definition and problem solution. Problem definition would include analytical activities to define the problem and set the requirements for designing the solution. Problem solution would include synthetical activities where the requirements are taken and balanced, moving to the implementation and delivery of the solution. Analysis should explore relationships, formation of patterns based on the data available, and structure of the problematic situation. Synthesis should design the solution (Lawson, 2005).

From the above, it seems compelling to accept such description of the design process, which presents a logical and methodological approach. However, the design process is not linear and hardly can be separated in two main phases and into two processes of analysis and synthesis (Buchanan, 1992). In fact, designers get frustrated when processes are drawn trying to establish causality and a pathway to the solution; along with separating analysis and synthesis, this type of description seems odd to experienced designers (Archer, 1979).

Lawson (2005) presented a map (see Figure 2) that avoids linearity, by positioning analysis, synthesis and evaluation as an iterative process, where designers constantly move from one corner to the other.

Figure 2 - Graphical representation of the design process

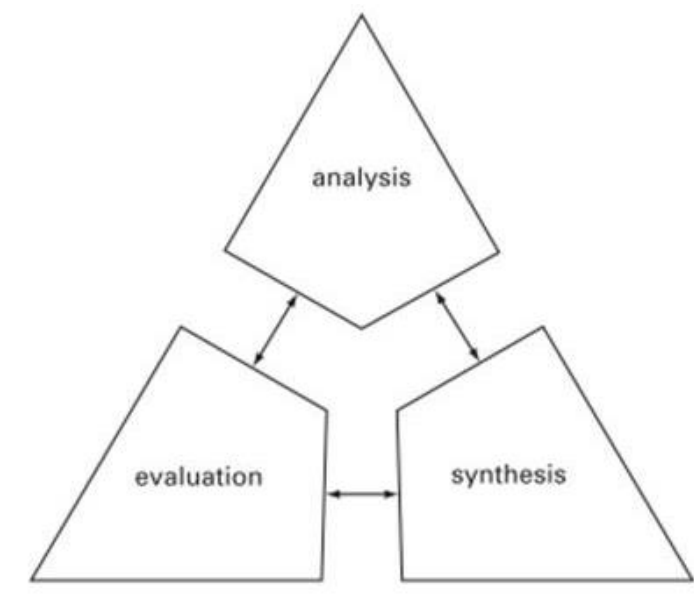

Source: Lawson (2005, p. 40) 
Lawson (2005, p. 40) claimed for caution as there are weak evidences that designers actually follow these maps, as they may be too theoretical:

They seem to have been derived more by thinking about design than by experimentally observing it, and characteristically they are logical and systematic. There is a danger with this approach, since writers on design methodology do not necessarily always make the best designers. It seems reasonable to suppose that best designers are more likely to spend their time designing than writing about methodology. If this is true then it would be much more interesting to know how very good designers actually work than to know what a design methodologist thinks they should do. One compensating factor here is that most academic writers are also involved in teaching design, and thus have many years of experience of observing their students. However, that also begs the question as to whether students might design differently to the way experienced practitioners work.

Different studies have compared how designers work when compared to other fields. Lawson (1979) did an experiment with 3D building blocks to compare the problem-solving strategies of designers and scientists. They indeed presented different adoption of strategies. Scientists were trying to explore the possible combinations, and they were engaged in discovering the general rule that would solve the problem. In the group of architects, they started proposing a variety of solutions and kept moving until identifying a good solution. In other words, scientists were focused in finding the rule (problem-focused approach) while architects were focused on finding the solution (solution-focused approach).

By trying a variety of solutions, the architects implicitly learned about the nature of the problem from the trial-and-error approach, while scientists decided to objectively analyze the problem and its rules. Cross (1982) concluded that such experiments demonstrate that designers solve problems by synthesis, instead of by analysis. It is worth mentioning the existing challenges to study the design process, as the problem-solving process actually happens inside the minds of each one (Lawson, 2005).

For Dorst \& Cross (2001), designers formulate the problem and think about solutions at the same time, establishing a constant interaction between the problem and the solution, reframing the problem given some possible solutions. This constant exercise of matching problem and solution is a characteristic of the design process, and this mental exercise keeps going until the designer identifies the most appropriate pair given the limitations presented.

Because of this pairing method, designers tend to quickly generate solutions that may be already satisfactory and functional, rather than seeking for the optimal solution. For Simon (1996), the process is more about 'satisficing' than optimizing (satisficing is a neologism 
created by Simon, to address the situation where good or satisfactory solutions are better to be delivered than finding the optimal solution).

Some important characteristics of the design process are summarized in Table 6.

Table 6 - Some characteristics of the design process

\begin{tabular}{|c|c|c|}
\hline Characteristics & Description & Authors \\
\hline $\begin{array}{l}\text { Focus on the } \\
\text { solution, not on } \\
\text { the problem }\end{array}$ & $\begin{array}{l}\text { Empirical studies of designers within cognitive psychology have } \\
\text { shown that designers focus their creativity and analytical skills on the } \\
\text { creation of solutions, testing and improving them, not on analyzing the } \\
\text { problem up front }\end{array}$ & $\begin{array}{l}\text { (Dorst, 2010, p. } \\
133 \text { ) }\end{array}$ \\
\hline $\begin{array}{l}\text { Reframe the } \\
\text { issue to have a } \\
\text { solution }\end{array}$ & $\begin{array}{l}\text { It is true that designers tend to reframe the issues before them in a way } \\
\text { that makes the problem amenable to solution. Designers tend to want to } \\
\text { reframe, even in situations that present themselves as a problem- } \\
\text { solving problem, where reframing would not be strictly necessary }\end{array}$ & $\begin{array}{l}\text { (Dorst, 2010, p. } \\
134 \text { ) }\end{array}$ \\
\hline $\begin{array}{l}\text { Run a process of } \\
\text { interpretation } \\
\text { and re- } \\
\text { interpretation }\end{array}$ & $\begin{array}{l}\text { This process of interpretation and re-interpretation through framing is a } \\
\text { crucial part of design creativity, it allows design to take flight and } \\
\text { move into truly new territory }\end{array}$ & $\begin{array}{l}\text { Dorst }(2010, \mathrm{p} . \\
135\end{array}$ \\
\hline \multirow[t]{2}{*}{$\begin{array}{l}\text { Search for the } \\
\text { paradox }\end{array}$} & $\begin{array}{l}\text { Experienced designers can be seen to do this by searching for the } \\
\text { central paradox, asking themselves what makes the problem hard to } \\
\text { solve, and only start working towards a solution once they have } \\
\text { established the nature of the core paradox to their satisfaction. }\end{array}$ & $\begin{array}{l}\text { Dorst (2011, p. } \\
527)\end{array}$ \\
\hline & $\begin{array}{l}\text { The word 'paradox' is used here in the sense of a complex statement } \\
\text { that consists of two or more conflicting statements - true or valid in } \\
\text { their own right, but they cannot be combined. The core paradox is the } \\
\text { real opposition of views, standpoints or requirements that requires } \\
\text { inventive design solutions or a reframing of the problematic situation }\end{array}$ & \\
\hline $\begin{array}{l}\text { Utilize } \\
\text { 'placement' and } \\
\text { 'categories' }\end{array}$ & $\begin{array}{l}\text { The primary concern begins in one area, but innovation comes when } \\
\text { the initial selection is repositioned at another point in the framework, } \\
\text { raising new questions and idea }\end{array}$ & $\begin{array}{l}\text { Buchanan } \\
(1992, \text { p. 11) }\end{array}$ \\
\hline
\end{tabular}

Source: organized by the author, based on Dorst (2010, 2011) and Buchanan (1992)

Regarding the concept of placements presented in Table 6, this is not a familiar concept as individuals are trained to work within categories (Buchanan, 1992). Categories establish a body of content regarding a theory or philosophy, being a platform for analyzing the existing matters. Placements are not fixed within a body of content; they actually exist to move beyond boundaries, as signs, things, actions and thoughts. A placement in a new situation can generate a new opportunity or a new solution. Buchanan (1992, p. 12) provided an example of placement:

Managers of a large retail chain were puzzled that customers had difficulty navigating through their stores to find merchandise. Traditional graphic design yielded larger signs but no apparent improvement in navigation-the larger the sign, the more likely people were to ignore it. Finally, a design consultant suggested that the problem should be studied from the perspective of the flow of customer experience. After a period of observing shoppers walking through stores, the consultant concluded that people often navigate among different sections of a store by looking for 
the most familiar and representative examples of a particular type of product. This led to a change in display strategy, placing those products that people are most likely to identify in prominent positions. Although this is a minor example, it does illustrate a double repositioning of the design problem: first, from signs to action, with an insight that people look for familiar products to guide their movements; second, from action to signs, a redesign of display strategy to employ products themselves as signs or clues to the organization of a store.

For many, placement would be call intuition or serendipity, but its nature is different. Designers have their own portfolio of placements, which they keep developing and testing during their professional experience. The creativity of the designer is much related to the ability to apply placements in different contexts, and this is an important tool in Design Thinking. Positioning and repositioning problems are made while adopting placements to test possible solutions. Because placements move from different fields and domains, one can now understand the integrative characteristic among the design domains and how knowledge from other disciplines can leverage inventions (Buchanan, 1992).

Different researchers have studied the process of how designers think and solve problems. Nigel Cross (2001) has contributed with the solution-focused orientation of designers; Donald Schön (1983) introduced the reflection-in-action for professions; Bryan Lawson (2005) contributed with the discussion of linear and non-linear process of design; Dorst \& Cross (2001) brought the discussion of pairing problems and solutions all the time. On how designers think, the next sub-session discusses the abductive reasoning.

\section{The design logic: abductive reasoning}

The comparison between the reasoning of sciences and design proves to be useful to introduce the discussion about abductive reasoning.

Simon (1996) pointed out that science is concerned with providing explanations of how things are. The declarative logic, deduction and induction, is appropriated to make solid statements about how the world actually works. Through time, deduction and induction, along with the development of statistical methods, have proven to be powerful tools for inferences. Martin (2009, p. 63) told a compelling example on how this evolution impacted the organizations:

Thirty years ago, few in a boardroom would have dared to cite the R2 of regression analysis, but now the statistical tools behind this form of induction are relatively common in business settings. So it is no wonder that deduction and induction hold privileged places in the classroom and, inevitably, the boardroom as the preeminent tools for making an argument and proving a case. 
On a different side of science, Design is concerned with envisioning. If this is the case, question exists if the declarative logic, so useful in science, is appropriate for designers creating new things (Simon, 1996). Charles Sander Peirce (1931-1958) studied the traditional forms of logic and he developed an argument that new ideas could not arise from deductive or inductive reasoning by using past data. He argued that a third reasoning exists, which he named abduction (actually, his collected papers use the term 'retroduction', but abduction is the common terminology in the literature).

Abduction is "the process of forming explanatory hypotheses" (Peirce, collected papers, cited by Frankfurt, 1958). For Peirce (1931-1958), abduction is the reasoning capable of introducing new ideas. Deduction and induction are applied in a later phase, where deduction and induction helps to test the explanatory hypothesis generated by abduction (Douven, 2011). Dunne \& Martin (2006), Martin (2009) and Dorst (2010) supported this argument of balancing the three forms of reasoning: it is not about excluding deduction or induction, nor to rely only on the looseness of abductive inferences.

Even in science, abduction occurs in the process of discoveries. Frankfurt (1958) argued that the theories developed to explain any new phenomenon were actually an output of abductive reasoning; after all, abduction is about adopting hypothesis.

Martin (2009) articulated that reasoning does not start with observation, but with wondering, and that is what abduction stands for. Abductive reasoning does not declare any conclusion true or false, but it wonders what could be true.

Given the abductive reasoning, designers have a fundamental difference when compared to professions that only rely on deductive and inductive thinking (Dorst, 2010).

As mentioned in the beginning of this session, the introduction to Design was required to precede the literature review of Design Thinking, as this approach leverages from important elements from the Design field. Next session presents Design Thinking, its frameworks, way of thinking and attitude towards problem-solving. 


\subsubsection{Design Thinking: definitions and frameworks}

\section{Designerly Thinking vs. Design Thinking}

An important distinction between designerly thinking and Design Thinking was articulated by Johansson-sköldberg \& Woodilla (2013). The discussions presented on the previous sessions are rooted in the academic field of design, linking practice and theory from a design perspective. This academic construction of the practice of design and the reflection on the theory about how to characterize the competence of designers is what the authors called 'designerly thinking'.

'Design thinking' is another approach, beyond the design context. Design thinking is the design practice for people without academic background in design, and most often with background in management (Johansson-sköldberg \& Woodilla, 2013). Within this context, Design Thinking is a simplified version of 'designerly thinking', or in other words, a way to make design accessible to non-designers, by describing design methods for an academic or practical management objectives.

Both designerly thinking and Design Thinking reflect a current design practice, far from being standardized, but already established as a basis for generalizations, descriptions and theories. Johansson-sköldberg \& Woodilla (2013) recognized that "the designerly discourse is a more scholarly discourse, where the different authors refer to and quote each other, either as followers or in opposition/as alternatives". On the other hand, part of the Design Thinking discourse is written for a business audience, where the academic rigor of referencing and discussing the text in relation to others is not mandatory. Due to this characteristic, some authors do not present theoretical or empirically-based literature. The following sessions discuss Design Thinking based on authors from both academic (e.g. Roger Martin, professor of Rotman School of Management) and non-academic (e.g. Tim Brown, CEO of IDEO) background.

\section{Design Thinking frameworks}

Design thinking, on popular definition and as clear as it could be, is the thinking of a designer (Martin, 2009).

Design thinking is about framing and solving problems, which starting point is applying empathy to the observation of users. Companies have adopted it as an approach for innovation, and to have an alternative to problem-solving approaches as Six Sigma, trying to go beyond only analytical tools. Data analysis is essential to the decision process and to 
formulate corporate strategies, but it has been not sufficient to cope with current challenges (Kurman \& Beckman, 2011).

Before getting popular, Design Thinking was already being studied by researchers, more specifically regarding the designers' cognitive process, aiming to learn about design creativity (Cross, Dorst, \& Roozenburg, 1992). Differently from the 1970's, when researchers were studying design methods, they now turned their attention in identifying the mental strategies of designers when working in projects (Tschimmel, 2012).

In 1996, Herbert Simon raised the discussion of applying design knowledge into management problems. More recently, authors as Boland \& Collopy (2004), Adler (2006), Dunne \& Martin (2006), Martin (2007) and Ungaretti (2009) have discussed the potential symbiosis of Design Thinking and business.

The popularity of Design Thinking has been growing in the business field. Companies have recognized that how designers solve problems can add value to their efforts on business transformation and innovation. Design thinking appeared at the well-known but not peerreviewed journal Harvard Business Review (Brown, 2008) and also in prestigious academic journals as the Academy of Management Journal (Gruber, Leon, George, \& Thompson, 2015) and the Academy of Management Learning and Education (Glen, Suciu, \& Baughn, 2014). Two books have much helped the popularization of Design Thinking in the business environment (Kimbell, 2011; Tschmimel, 2012): Change by Design - How Design Thinking Transforms Organizations and Inspires Innovation, by Tim Brown (2009), CEO of IDEO, a top design consultancy; and The Design of Business - Why Design Thinking is the Next Competitive Advantage, by Roger Martin (2009), Dean of the Rotman School of Management in Toronto and with experience in management consulting.

Design thinking has been framed as a human-centered approach to problem-solving, not only relying in technology or organizational resources (Kimbell, 2011). As Kimbell (2011) described, Design Thinking applies an iterative process, starting from end users' insights, ideation, testing and implementation, including visualization of proposals and solutions, prototypes, working in multidisciplinary teams and envisioning future scenarios rather than focusing in the present conditions.

Different models have been developed to represent the Design Thinking process and phases. The Design Thinking literature reviewed by Fleury, Stabile, \& Carvalho (2016) found fragmentation and low standardization on Design Thinking definition, phases and tools. Regarding phases' terminologies and number of steps, Table 7 presents the variations found in the literature: 
Table 7 - Design Thinking phases

\begin{tabular}{|c|c|c|c|c|}
\hline $\begin{array}{c}\text { Problem finding, } \\
\text { observations }\end{array}$ & $\begin{array}{l}\text { Visualization, } \\
\text { sense making }\end{array}$ & Ideation & Prototype and test & Authors \\
\hline Formulating & & Moving & $\begin{array}{l}\text { Representing } \\
\text { Evaluating }\end{array}$ & Lawson (2005) \\
\hline Inspiration & & Ideation & Implementation & $\begin{array}{l}\text { Brown (2008), } \\
\text { IDEO (2015) }\end{array}$ \\
\hline Hear & & Create & Deliver & IDEO (2011) \\
\hline What is? & & What if? & $\begin{array}{l}\text { What wows? } \\
\text { What works? }\end{array}$ & $\begin{array}{l}\text { Liedtka \& Ogilvie } \\
\text { (2011) }\end{array}$ \\
\hline Immersion & $\begin{array}{l}\text { Analysis and } \\
\text { Synthesis }\end{array}$ & Ideation & Prototyping & $\begin{array}{l}\text { Vianna, Vianna, } \\
\text { Adler, Lucena, \& } \\
\text { Russo (2011) }\end{array}$ \\
\hline Discovery & Interpretation & Ideation & $\begin{array}{l}\text { Experimentation, } \\
\text { evolution }\end{array}$ & IDEO (2012) \\
\hline Knowledge & Comprehension & $\begin{array}{l}\text { Application, } \\
\text { analysis, synthesis }\end{array}$ & Evaluation & $\begin{array}{l}\text { Carleton, } \\
\text { Cockayne, \& } \\
\text { Tahvanainem } \\
(2013)\end{array}$ \\
\hline Empathize & Define & Ideate & Prototype and test & D. School (2015) \\
\hline Discover & Define & Develop & Deliver & $\begin{array}{l}\text { UK Design Council } \\
\text { (2015) }\end{array}$ \\
\hline
\end{tabular}

Source: adapted from Fleury, Stabile, \& Carvalho (2016) and Glen et al. (2015)

Although with different terminologies, the Design Thinking phases proposed by different authors present some convergence, as they all include the first phase of problem finding and observations, followed by ideation and prototyping \& testing. It is worthy noting that older propositions did not include phases for visualization and sense making. A possible explanation may be the more recent requirement to make non-designer audiences comprehend what were the critical findings in the observation phase, before moving to ideation.

Some of these Design Thinking phases, or frameworks, achieved more prominence among practitioners, as the 3 I's model (Brown, 2008; IDEO, 2015), the HCD model (IDEO, 2011), and the Double Diamond model from the British Design Council (2015).

In a context of social innovation, IDEO (2015) spread out a framework named 3 I's, standing for Inspiration, Ideation, Implementation (see Figure 3). Inspiration includes the identification of the problem and the development of an initial design framework based on the observation of a selected group. The Ideation considers multidisciplinary teams working together diverging and converging ideas, transforming insights into opportunities, and to solutions. Implementation is about putting the solution in action, and prototyping plays important role in this phase. Prototypes can help communicating the solution to different stakeholders (Brown, 2009; Tschimmel, 2012). 
Figure 3 - The 3 I's Design Thinking model from IDEO

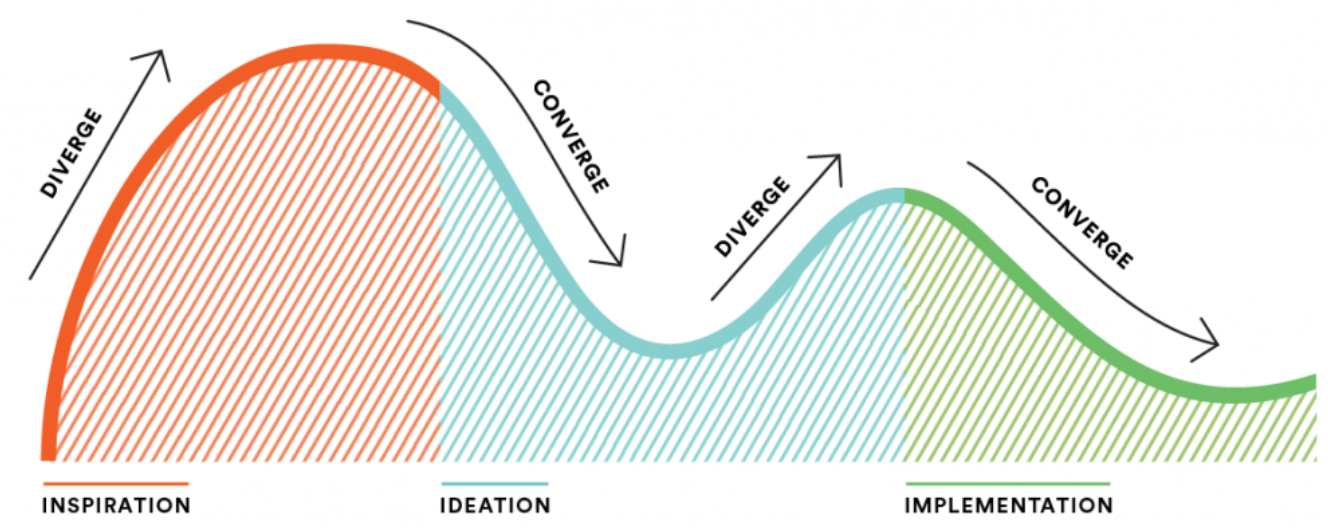

Source: IDEO (2015, p. 13)

IDEO had also developed another Design Thinking framework for NGOs and social companies focusing in helping communities from developing countries. It was named HCD model, standing for Hearing, Creating and Delivering (IDEO, 2011), but sometimes recognized as Human Centered Design. Tschimmel (2012) argued that Hear, Create and Deliver may be more suitable to describe the Design Thinking process than Inspiration, Ideation and Implementation.

The UK Design Council (2015) developed a model named Double Diamond, which is composed by two 'diamonds', each one including a divergent and a convergent stage (see Figure 4). Because the four phases' names have a 'd' - discover, define, develop and deliver -, the model is also named 4D model. Visually, this model highlights the divergent and convergent stages of the thinking as a designer.

\section{Figure 4 - The Double Diamond model}

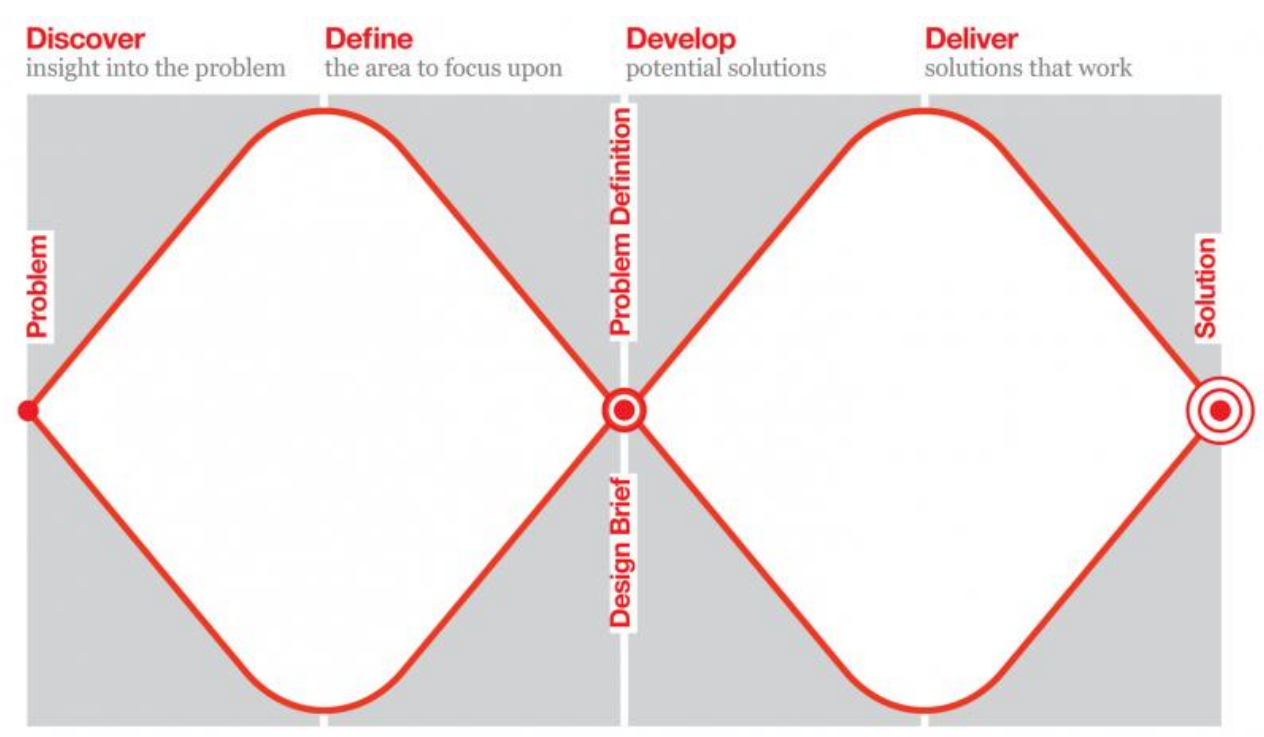

Source: The UK Design Council (2015) 
The Discovery phase includes searching for information, insights, and trends. The Definition phase is about reviewing insights and learning, selecting and discarding. The Development phase regards the creation of solutions or concepts, prototyping, testing and iterating. It is a trial and error process, when designers learn and refine their ideas. Finally, the Deliver phase is about finalizing the solution conceived, being it a product or a service, and making it available to users (The UK Design Council, 2015).

Although Design Thinking is, in a way and nowadays, walking independently from the design discipline, business managers need to be conscious that they will not become designers by simply reading books or having workshops. Training managers in Design Thinking demands developing some abilities of designers, like empathy, visualization, solving and envisioning solutions in a creative way (Tschimmel, 2012). Indeed, the design research community feels uncomfortable with the oversimplification of Design Thinking (Dorst, 2010).

For Kimbell (2011), Design Thinking is not well understood by the public or even by the practitioners. There are difficulties to articulate and to explain what Design Thinking is. She criticized the re-assembling of approaches, knowledge and practices proposed by design academics, business schools and practitioners, and stated that industry observers were questioning if Design Thinking is delivering what was expected.

Hence, the importance to move the discussion from the surface to the essence of Design Thinking, and promote a deeper investigation on what are the Design Thinking characteristics that may be of interest and of value in the business field.

\section{Design Thinking vs. traditional business thinking}

Design Thinking presents different characteristics from the linear and analytical problem-solving approach developed in business schools (Glen, Suciu, \& Baughn, 2014). The analytical approach focusses on planning, optimization, pre-established criteria, being appropriate when the problem is clearly defined, data is available before taking action, and past is a useful predictor to the future. On a different approach, Design Thinking becomes appropriate for volatile, uncertain, complex and ambiguous situations, as its process and methods leverage on quick learning and empathy, as well as proceeding with rapid iterative creation and testing of solutions (Glen, Suciu, \& Baughn, 2015).

Table 8 presents an elucidative comparison between the traditional rational-analytic and Design Thinking. Design thinking's key differentiators include an iterative method, usage of 
visual and tangible representations (prototypes), incorporation of intuition in the solution process, and acceptance of failures.

Table 8 - Comparison of Rational-Analytic and Design-Thinking approaches

\begin{tabular}{|c|c|c|}
\hline & Rational analytic & Design thinking \\
\hline Problem formulation & Well-defined goal and constraints & $\begin{array}{l}\text { Goals and constraints uncovered during } \\
\text { the design- thinking process }\end{array}$ \\
\hline Criteria & $\begin{array}{l}\text { Objective definition of criteria, } \\
\text { established before generation of } \\
\text { alternatives }\end{array}$ & $\begin{array}{l}\text { Both objective and subjective criteria } \\
\text { used to define design objectives, since } \\
\text { the end user is the ultimate judge of } \\
\text { efficacy }\end{array}$ \\
\hline Method & $\begin{array}{l}\text { Planning and analysis - thought } \\
\text { precedes action. Sequential process }\end{array}$ & $\begin{array}{l}\text { Iterative exploration of the design } \\
\text { "space," where thinking and doing are } \\
\text { intertwined }\end{array}$ \\
\hline $\begin{array}{l}\text { Information- } \\
\text { processing emphasis }\end{array}$ & $\begin{array}{l}\text { Preference for objective formulations, } \\
\text { especially verbal and quantitative }\end{array}$ & $\begin{array}{l}\text { Preference for visual and spatial } \\
\text { representations, which evoke both } \\
\text { objective and subjective insights }\end{array}$ \\
\hline Solution process & $\begin{array}{l}\text { Ideally based on conscious, rational- } \\
\text { logical reasoning process, which, over } \\
\text { time, becomes formalized into a set of } \\
\text { rules }\end{array}$ & $\begin{array}{l}\text { Solutions evolve as the result of } \\
\text { interaction with users and the ongoing } \\
\text { creation and refinement of possible } \\
\text { solutions. Incorporates experience- } \\
\text { based insights, judgment, and intuition }\end{array}$ \\
\hline Rationale & $\begin{array}{l}\text { "Get it right." Reduce chances of failure } \\
\text { though careful prior analysis }\end{array}$ & $\begin{array}{l}\text { Use rapid experimentation and } \\
\text { prototyping to learn from early, } \\
\text { inexpensive "failures" }\end{array}$ \\
\hline Outcome & $\begin{array}{l}\text { Solution optimizes predefined criteria to } \\
\text { arrive at "best" answer }\end{array}$ & $\begin{array}{l}\text { Obtain "better" answer. Process may } \\
\text { expose additional problems and } \\
\text { solutions }\end{array}$ \\
\hline
\end{tabular}

Source: Glen et al. (2014, p. 658)

Boland and Collopy (2004) also established a comparison between two problem-solving approaches, named as Design Attitude and Decision Attitude.

The decision attitude is the traditional approach learned in business schools. There are different options and the business manager needs to take a logical decision on which path to take. When options are easy to be created and problem situation is clear, the major challenge is deciding the best alternative. To support this decision, many analytic tools were developed in the last decades, supported by mathematics, statistics and scientific approaches. However, this is one of the possible scenarios in the business environment (Boland \& Collopy, 2004).

The design attitude, on the other hand, takes the assumption that creating good alternatives is actually the major challenge, and not deciding which option to go. This attitude has the premise that it can be more costly just deciding on existing options than creating new ones, given the fact that making the wrong decision will be worse than trying to find alternatives. The design attitude includes envisioning and considers the creation of future possibilities (Boland \& Collopy, 2004). Martin (2004) also articulated this design attitude of 
'nothing cannot be done', stating that constraints only increase the excitement level of designers.

If compared, taking the decision can be more passive attitude than trying to find better answers, and therefore, being more active. The design attitude assumes that invention can open up new solution paths to the problem faced, even with limitations of budget, human resources and time.

For Boland \& Collopy (2004), design attitude is also associated with expectations and an attitude that every problem is an opportunity to try something new and better. These authors stated that creating something new may not cost more than wrongly replicating action standards that will drive to common and known results.

Furthermore, the design attitude embraces the adoption of new technologies, new materials, new processes, all that can disrupt existing paradigms and lead to new approaches that are cheaper and more efficient. For this, the attitude must be open to a problem-solving process that is not fixed neither linear.

The traditional business thinking is strongly built on an analytical problem-solving approach, as discussed in this session. Next session introduces the reader to the literature review of Thinking Styles, where the debate will make room for discussion of other approaches that not necessarily solely rely on analytical and rational thinking. 


\subsection{THINKING STYLES}

Two modes of processing information have been proposed by different psychologists, although under different names. One of these modes are referred as intuitive, natural, automatic, schematic, narrative, implicit, imagistic-nonverbal, experiential, mythos or first signal system. The other mode is referred as thinking-conceptual-logic, deliberative-effortfulintentional-systematic, explicit, extensional, verbal, analytical-rational, logos and secondsignal system (Epstein, Pacini, Denes-Raj, \& Heier, 1996). Epstein et al. (1996) summarized some of these authors and their terminologies, presented in Table 9.

Table 9 - Review of terminologies for modes of processing information

\begin{tabular}{lll}
\hline \multicolumn{1}{c}{ Authors } & Processing Mode “1” & Processing Mode “2” \\
\hline Tversky \& Kahneman (1983) & Natural & Extensional \\
\hline Weinberger \& McClelland (1991) & Implicit & Explicit \\
Bucci (1985), Paivio (1986) & Imagistic-nonverbal & Verbal \\
\hline Epstein (1983) & Experiential & Analytical-rational \\
\hline Labouvie-Vief (1990) & Mythos & Logos \\
Pavlov, cited in Luria, 1961 & First-signal system & Second-signal system \\
Jung (1964), (1968) & Intuitive & Thinking-conceptual-logical \\
\hline Leventhal (1984) & Schematic & Thinking-conceptual-logical \\
Bargh (1989), Higgins (1989) & Automatic & Deliberative-effortful-intentional-systematic \\
Chaiken, 1980 & Heuristic & Deliberative-effortful-intentional-systematic \\
\hline
\end{tabular}

Source: adapted from Epstein (1996)

Dual-process theories discuss the distinction between intuition and deliberation. Intuitive processing is usually typified as preconscious, closely associated with affect, fast, and operating in an automatic, holistic manner. Rational thinking is described as slow, deliberative, driven by rules, primarily verbal and conscious. Both information processes are interactively used by any person, and individuals differ by when or if they respond primarily rationally or intuitively; in other words, the decision situations where people decide to follow their head or their heart (Witteman, Bercken, Claes, \& Godoy, 2009).

The Handbook of Psychology, edited by Millon \& Lerner (2003, p. Preface XI), recognized CEST, by Seymour Epstein, as "an innovative and dynamic framework for coordinating the cognitive, experiential, learning, and self-oriented components of personology", “(...) more consistent with contemporary evolutionary and cognitive science”. CEST proposes that individuals operate the information processing modes according to different rules and the influence of the experiential system on the rational system is similar to the role of the unconscious. 


\subsubsection{Experiential and Rational Dual-System}

The Cognitive-experiential self-theory (CEST), developed by the psychologist Seymour Epstein (1925-2016), is an integrative theory of personality compatible with cognitive scientific literature on information processing. This theory has been integrated with different areas of psychology, including cognitive style and clinical applications. CEST offered an alternative view to Freud's irrational and aggressive unconscious. While Freud emphasized the repressed unconscious, Epstein emphasized the preconscious (Epstein, 1994, 2003).

Three elements are fundamental for CEST. First, people process information by two interactive and parallel systems: a preconscious experiential system and a conscious rational system. The introduction of a new understanding of the unconscious based on an experiential system is a major contribution from Epstein, as it provided explanations in a scientifically manner. Second, the experiential system is emotionally driven. Third, the four basic needs, namely pleasure, model of world, relatedness and self-esteem, are equally important to CEST.

Epstein et al. (1996, p. 391) elaborated that "the rational system operates primarily at the conscious level and is intentional, analytic, primarily verbal, and relatively affect free. The experiential system is assumed to be automatic, preconscious, holistic, associationistic, primarily nonverbal, and intimately associated with affect."

\section{Experiential System}

A fundamental differentiation of Epstein's (2003) theory against other dual-system theories is that the humans and other higher order animals have an experiential system, and both have adapted to the environment over the years of evolution. This adaption occurs by learning from experience and not by logical inference. Indeed, logical inference is the sole domain of the rational system. The experiential system is "preconscious, automatic, rapid, effortless, holistic, concrete, associative, primarily nonverbal, and minimally demanding of cognitive resources" (p. 160). Information is encoded via memories of individual events, especially events highly emotional experienced, and also in a more abstract, general way. The experiential system is a cognitive system, but it is closely related to the experience of affect.

Epstein (2003) stated that experiential system influences and is influenced by affect. The experiential system directs behavior towards pleasurable outcomes, having the cognitions influenced by affect. The experiential conceptual system is guided by emotion. "The automatic, preconscious experiential conceptual system that regulates everyday behavior is of necessity an emotionally driven, dynamic unconscious system" (Epstein, 2003, p. 161); in other words, experiential system only exists if there is affect. 
The experiential system may solve some types of problems that the rational system cannot address. The holistic response of the experiential system better address real-life problems which are too complex to be analyzed into components. Indeed, there are lessons learned in life that do not necessarily call for logical analysis. Additionally, the experiential system is associated with the ability to develop interpersonal relationships via creativity and empathy. An important note is that the experiential system is millions of years old, while the rational system is much younger in human history.

\section{Rational System}

Epstein (2003, p. 161) defined the rational system as "an inferential system that operates according to a person's understanding of the rules of reasoning and of evidence, which are mainly culturally transmitted. (...) This system's operation is conscious, analytical, effortful, relatively slow, affect-free, and highly demanding of cognitive resources".

The rational system, and its embedded use of language, is a recent evolution of the human kind. This system deploys higher capacity of abstraction than the experiential system, allowing planning thinking, delay of gratification, theory development, and understanding of cause-and-effect events. This system allowed the human kind development of science and technology. Finally, the rational system can understand the operation of the experiential system, while the opposite is not true. Table 10 compares both systems.

Table 10 - Comparison of the Experiential and Rational systems

\begin{tabular}{|c|c|c|}
\hline & Experiential System & Rational System \\
\hline 1 & Holistic & Analytic \\
\hline 2 & Automatic, effortless & Intentional, effortful \\
\hline 3 & Affective: pleasure-pain oriented (what is good) & Logical: reason oriented (what is rational) \\
\hline 4 & Associationistic connections & Logical connections \\
\hline 5 & Behavior mediated by "vibes" from past events & $\begin{array}{l}\text { Behavioral mediated by conscious appraisal of } \\
\text { events }\end{array}$ \\
\hline 6 & $\begin{array}{l}\text { Encodes reality in concrete images, metaphors, } \\
\text { and narratives }\end{array}$ & $\begin{array}{l}\text { Encodes reality in abstract symbols, words, and } \\
\text { numbers }\end{array}$ \\
\hline 7 & $\begin{array}{l}\text { More rapid processing: oriented toward immediate } \\
\text { action }\end{array}$ & Slower processing: oriented toward delayed action \\
\hline 8 & $\begin{array}{l}\text { Slower and more resistant to change: Change with } \\
\text { repetitive or intense experience }\end{array}$ & $\begin{array}{l}\text { Changes more rapidly and easily: changes with } \\
\text { strength of argument and new evidence }\end{array}$ \\
\hline 9 & $\begin{array}{l}\text { More crudely differentiated: Broad generalization } \\
\text { gradient; stereotypical thinking }\end{array}$ & More highly differentiated \\
\hline 10 & $\begin{array}{l}\text { More crudely integrated: Dissociative, emotional } \\
\text { complexes; context-specific processing }\end{array}$ & More highly integrated: Context-general principles \\
\hline 11 & $\begin{array}{l}\text { Experienced passively and preconsciously: we are } \\
\text { seized by our emotions }\end{array}$ & $\begin{array}{l}\text { Experienced actively and consciously: We are in } \\
\text { control of our thoughts }\end{array}$ \\
\hline 12 & Self-evidently valid: "Experiencing is believing" & Requires justification via logic and evidence \\
\hline
\end{tabular}

Source: Epstein (1996, p. 391) 


\section{The dual operation of the Experiential and Rational systems}

The experiential and rational systems can operate in parallel and are interactive. The interaction may occur simultaneously or sequentially. Additionally, and importantly, a person can be high on both systems or on neither of them (Pacini \& Epstein, 1999).

Epstein (2003) explained the interactive dynamic by providing the example below:

When a person responds to an emotionally significant event, the sequence of reactions is as follows: the experiential system automatically and instantaneously searches its memory banks for related events. The recalled memories and feelings influence the course of further processing and of behavioral tendencies. If the recalled feelings are positive, the person automatically thinks and has tendencies to act in ways anticipated to reproduce the feelings. If the recalled feelings are negative, the person automatically thinks and has tendencies to act in ways anticipated to avoid experiencing the feelings. As this sequence of events occurs instantaneously and automatically, people are normally unaware of its operation. Seeking to understand their behavior, they usually succeed in finding an acceptable explanation. Insofar as they can manage it without too seriously violating reality considerations, they will also find the most emotionally satisfying explanation possible. This process of finding an explanation in the rational system for what was determined primarily by the experiential system and doing so in a manner that is emotionally acceptable corresponds to what is normally referred to as rationalization. (p. 161)

Because the experiential system is a quick reacting system, it may bias the subsequent processing of the rational system. Given this automatically and preconsciously, individuals have no awareness of the experiential system operation. Therefore, when someone believes it is thinking rationally, there was often a bias from the experiential processing.

There are positive and negative aspects about the influence of the experiential system in the rational system. Because it is an associative system and not a liner-processing rational system, the experiential system may be a source of creativity. Furthermore, being a learning system, the experiential system is also a source of useful information to be utilized by the rational system. And the experiential system is also a source of passion, meaning that intellectual objectives can be chased with heart, instead of a robotic intellectual exercise.

Being a slower system, the rational system may correct the experiential system. As an example, the spontaneity and impulsivity of thoughts and actions originated by the experiential system may be recognized as inappropriate, and the rational system can act on adjusting or changing to more constructive ones.

Within this context, the experiential system can actually be trained. If one understands the experiential system's principles of operation and its schemas, this system can be 
improved, either by disputing the maladaptive thoughts, by providing real-life corrective experiences or by utilizing projective imagery, fantasy and narratives to correct experiences.

The rational system can either influence the experiential system by unintentional (automatic) ways or by intentional purposes. The thoughts of the rational system can trigger associations and emotions in the experiential system. Epstein (2003, p. 165) provided the following example: "a student attempting to solve a mathematics word problem may react to the content with conscious thoughts that produce associations in the experiential system; the associations then elicit emotional reactions that interfere with performance". In this situation, the rational system influenced the experiential system, which in turn influenced the rational system.

The repetition of behavior, or thoughts, in the rational system can be other unintentional path to influence the experiential system. Due to repetition, behavior and thoughts controlled by the rational system may become incorporated or habitualized in the experiential system. By moving from rational to experiential, fewer cognitive resources are required and such behavior or thought can happen without conscious awareness. The drawback exists as habitual behavior or thoughts are harder to change; particularly if the behavior or thought is not desirable or appropriate.

The findings from Pacini \& Epstein (1999) pointed out a self-picture of a rational individual: emotionally well-adjusted, holder of a positive self-view and the world, capable to apply self-control and control of situations, delay gratification and take responsibility, flexible thinker, and owner of liberal values; while an experiential individual would present: good relationship with others, prompt emotional communication, tolerance, trustiness, spontaneity, and open-mindedness.

Next session discusses the rationality and intuition applied in business management, reviewing the literature on Technical Rationality and the more recent debate of intuition in management. 


\subsubsection{Rationality and intuition in Business Management}

\section{The Technical Rationality}

Technical Rationality "is the Positivist epistemology of practice” (Schön, 1983, p. 31). Positivism established its foundation from the nineteenth century, when science and technology emerged as the leading achievements of our society. Since then, positivism and its developments, like the Technical Rationality, have been solidified in the professions and in the academia. Science, and the world, has become driven by a hypothetic-deductive thinking system (Schön, 1983). Mathematics, logic, hypothesis, experiments, deduction, validation, all become important words in the vocabulary.

Many professions turned into science, focusing on theories, techniques and process, including for problem solving issues (Schön, 1983). Six Sigma and Total Quality Management (TQM) grew inside the organizations, given their scientific approach to reduce variation. Analytical skills become must-have for business managers, and business schools have been teaching how to establish consumer metrics to enhance company performance, in contrast to focusing on observation of these same consumers (Kurman \& Beckman, 2011).

Under the context of Technical Rationality, the business practice became about rationally solving problems of choice. The manager needs to take a decision based on the available means given the desired objectives. In business, when objectives are clear, the decision is made; but when objectives are yet confusing, there is yet no problem to solve (Schön, 1983). As a consequence, much of the management efforts lie on structuring problems, so decisions can be made (Simon, 1973). At business schools, students are taught to find solutions and select; they move quickly to take the decision, but do not spend much time on framing and re-framing the problem (Kurman \& Beckman, 2011). Furthermore, Jonassen (2000) pointed out that schools often design their programs based on well-structured problems.

For Schön (1983, p. 39), the "professions have suffered a crisis of legitimacy rooted both in their perceived failure to live up to their own norms and in their perceived incapacity to help society achieve its objectives and solve its problems". The complexity, uncertainty, instability, uniqueness, and value-conflict are contemporary phenomena not matching the model of Technical Rationality. By understanding the Positivist origins of Technical Rationality, Schön (1983) argued that these phenomena are big issues for practitioners that count on the Technical Rationality to find the solutions needed. Arts, which are outside the scientific approach, do not qualify in Technical Rationality, and therefore is not an alternative 
to cope with current phenomena. Abduction, a third form of reasoning, has not been relevant due to the long-time prominence of deductive and inductive reasoning (Martin, 2009).

Moreover, dealing with paradox is an evident challenge to analytical problem solving, which assumption is having the problem pre-defined (Dorst, 2010). In this context, Design Thinking may be positioned as an alternative thinking that helps redefining the problematic situation while looking for solutions from differentiated approaches.

\section{Intuition in Management}

Intuition is related to the "inborn ability to synthetize information quickly and effectively - an ability that may be hindered by more formalized procedures" (Dane \& Pratt, 2007, p. 33). Carl Jung (1946) articulated that intuition is not the opposite of reason, but something outside the territory of reason, and it is not a sixth sense neither a random process of guessing (Khatri \& Ng, 2000).

Khatri \& Ng (2000) cited Agor (1990) on the conditions when intuition is appropriate: high level of uncertainty, little precedent for actions on an emerging trend, limited or no facts, and different viable solutions to select.

Inside organizations, intuition has helped the decision making process of critical matters, particularly in terms of complexity and short-time deadlines. The alternatives and solutions that were successful in the $20^{\text {th }}$ century no longer achieve same results. The organizations are in need of new strategies that are worthy implementing, and the selection of a portfolio of hierarchical and industrial approaches no longer addresses the $21^{\text {st }}$ century chaos and complexity. More human and biological metaphors are being accepted to guide strategies (Adler, 2006).

Studies indicate that intuition is required especially in turbulent environments (Khatri \& $\mathrm{Ng}, 2000$ ). Admittedly, intuition has been seen as key differentiation between successful executive boards and dysfunctional boards.

Dane \& Pratt (2007, p. 33) cited Ralph Larsen, former CEO of Johnson \& Johnson:

Very often, people will do a brilliant job through the middle management levels, where it's very heavily quantitative in terms of the decision making. But then they reach senior management, where the problems get more complex and ambiguous, and we discover that their judgment or intuition is not what it should be. And when that happens, it's a problem; it's a big problem.

Intuition is an information processing mode that differs from the rational-analytic processes. Dane \& Pratt (2007) argued that intuition is valuable mean to achieve faster and 
more accurate decision in organizations, being intuitive judgements an effective approach for decision making.

Adler (2006) agreed that intuition-based innovation is needed to tackle such changes in the environment. But he actually articulated intuition in the form of improvisation, as in Arts. The author emphasized the importance of blending traditional planning and analytical skills with the ability to respond to problems at they arise, in the moment. Improvisation requires shifting the sequential planning-then-doing approach to the "simultaneous listening-andobserving-while-doing" (p. 431). As improvisation is important in Arts, so it is as an important managerial skill.

After this review of the academic literature on Design, Design Thinking and thinking styles and before moving forward to the discussion of Readiness-for-change, a framework could be organized to visualize these connections among the literature. Figure 5 presents the relation between the analytical-rational thinking and Technical Rationality, as well as the relation between the intuitive-experiential thinking and "Designerly Thinking". The balance of both sides is what helps defining Design Thinking: an approach based not only on intuition, experience or creativity, but also based on analytical thinking.

Figure 5 - Relation between Thinking Styles and Design Thinking

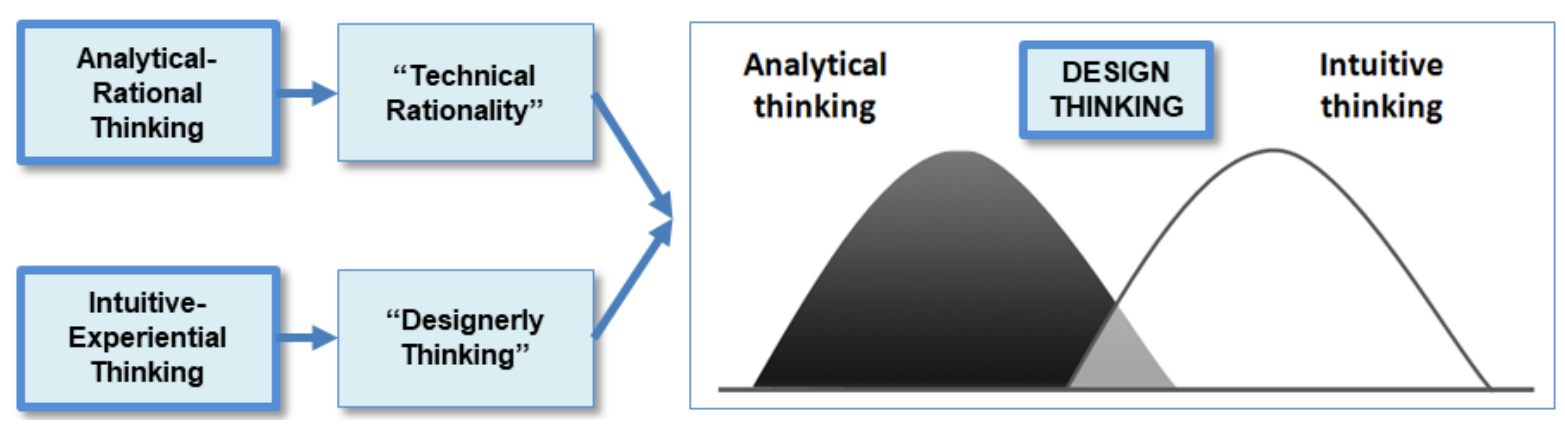

Source: prepared by the author, based on Epstein et al. (1996), Schön (1983), Dorst (2010) and Martin (2007) 


\subsection{READINESS FOR ORGANIZATIONAL CHANGE}

This session introduces a review on organizational change before focusing on the literature of individuals' Readiness for change, including discussion about instruments.

\subsubsection{Organizational Change}

Kurt Lewin (1946, 1947) provided foundation for research of organizational development (OD) in the areas of sociology and psychology. Lewin's assumption was that human conditions could be improved by solving social conflicts. He developed seminal works on the philosophy of organizational development, action research and planned change. Lewin focused on how to change human behavior, by understanding the process of change. His work stimulated further research on how individuals and groups react to changes in organizations. Lewin studied group dynamics in a period when organizations were becoming more teamoriented, and within this context, individuals were a function of the group environment, meaning that individual's behavior could only be seen and changed when in groups. Therefore, change would only happen at a team level and the change implementation should focus on the norms, values and roles of the members. Through this approach, the field of organizational development started emerging (Al-Haddad \& Kotnour, 2015).

Moving forward in time, Holt, Armenakis, Harris, \& Field (2007a) argued that successful organizational changes generally go through the phases of readiness, adoption and institutionalization. Readiness is the receptive employees' attitude toward a forthcoming change. Adoption is when organizational members change their attitudes and behaviors, at least temporarily, to align with the expected changes. Institutionalization is when the change is actually incorporated and stabilized on employees' behavior. Among these three stages, creating Readiness for change can be considered critical. If assessments can indicate existence of significant gap between the desired state and current attitude toward the change, resistance can be expected and the implementation may face tough challenges.

Researches had been covering how organizations prepared for implementation and for eventual reactions to organizational changes, but few of them focused on the change recipients' reactions to the proposed change. There is this distinctive line of research that addresses the individual's reactions to organizational changes, as this has been considered a key determinant to the success of the change (Oreg, Vakola, \& Armenakis, 2011). Recent studies have been developed with focus on change recipients' and their attitude toward proposed changes, supporting the understanding of a whole organizational change process (e.g. Vakola, 2014; Haffar, Al-Karaghouli, \& Ghoneim, 2014; Oreg et al., 2011). 


\section{Framework of Organizational Change}

Al-Haddad \& Kotnour (2015) developed a useful categorization of the organizational change literature. They identified four categories: change type, change enablers, change methods and change outcomes (see Figure 6). Change type regards the characteristic of the change, in terms of scale (small and big) and duration (short and long). Change enablers are the factors related to probability of success, including knowledge and skills, resources and commitment. Change methods are the actions taken towards the change, being divided in systematic change and change management. Finally, change outcomes are related to the results or impact of the organizational change, as achievement of project objectives or customer satisfaction about the outcomes.

In the context of this dissertation about Design Thinking, the particular interest lies on the Systematic Change. Systematic change methods are process and tools to support an organization in making decisions regarding start, stop or continuity. Examples include Six Sigma, Total Quality Management, Lean and Process Reengineering. By following this logic, Design Thinking could be included in this sub-category, as it delivers a systematic change on how an organizational addresses and solves complex problems.

Figure 6 - Categorization of organizational change literature

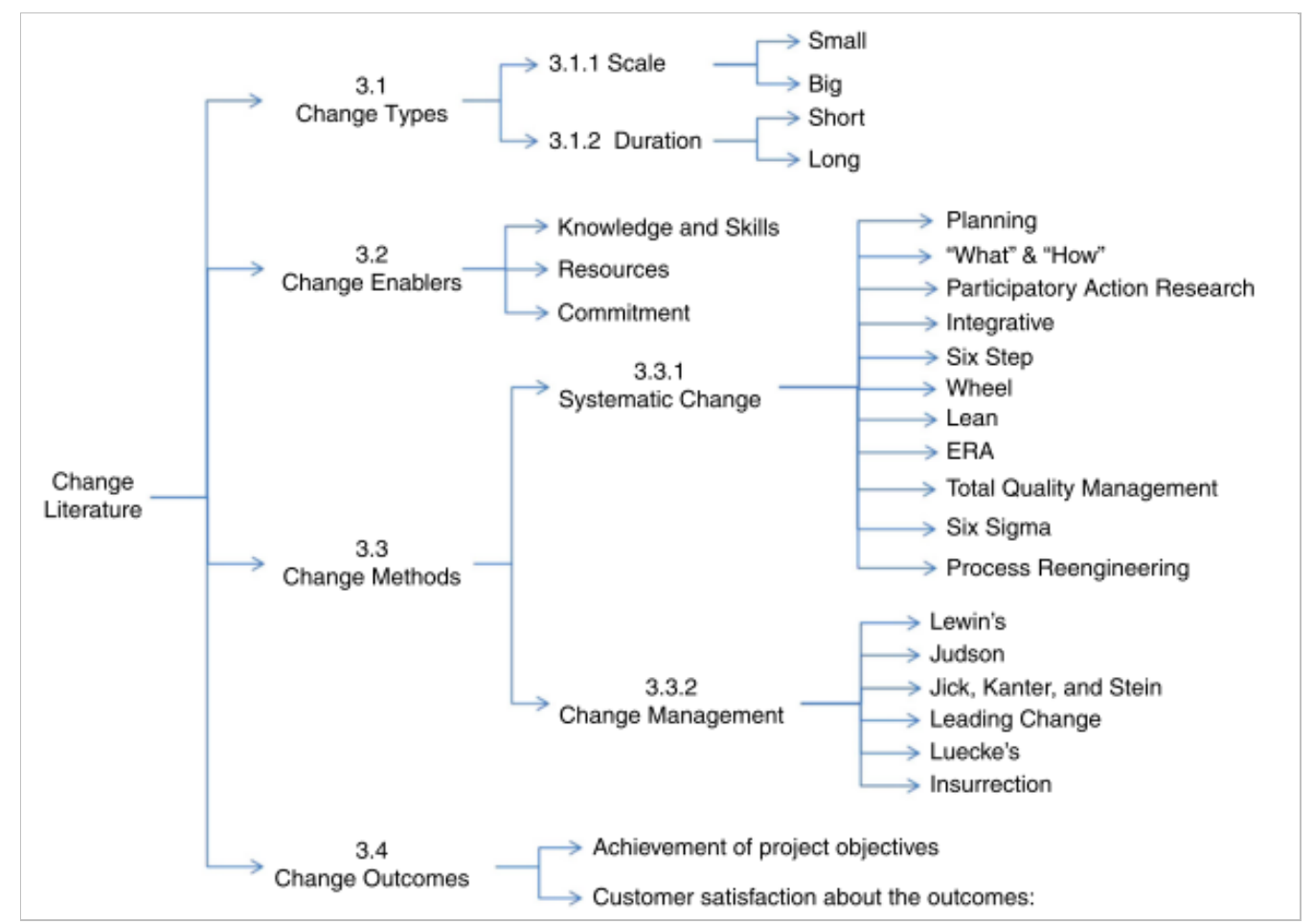

Source: Al-Haddad \& Kotnour (2015, p. 242) 


\section{Factors influencing organizational change}

Pettigrew (1985) criticized the tradition of organizational change studies due to their ahistorical, acontextual and aprocessuals approaches. He argued that treating change programs as the unit of analysis and considering change as an episode disassociated from the context in which is embedded, there would be no development of theories of change and it would continue to exist misguiding for actions. His conclusion is that robust theory and practice on strategic change should include "the continuous interplay between ideas about the context of change, the process of change, and the content of change, together with skill in regulating the relations between the three" (Pettigrew, 1985, p. 19).

The formulation of the content of a strategy inevitably includes its context and process. Content regards areas of transformation under study, as technology, manpower, products, geographical positioning or corporate culture change. The external context includes social, economic, political, and competitive environment in which the organization operates, while internal context includes structure, corporate culture, and political context within the company. The process refers to the actions, reactions, and interactions from the parties participating in the transition from the current to the desired state (Pettigrew, 1985). "Thus broadly speaking, the 'what' of change is encapsulated under the label content, much of the 'why' of change is derived from an analysis of inner and outer context, and the 'how' of change can be understood from an analysis of process" (Pettigrew, 1987, p. 657).

Years after Pettigrew's seminal work, Armenakis \& Bedeian (1999) revised the organizational change literature produced between 1990 and early 1998, focusing on the content, contextual and processual issues; and Walker, Armenakis, \& Bernerth (2007, p. 763) provided an updated but similar explanation on the content, process and context issues: content issues "refer to the change being implemented and are specific to each organization. Typically, these changes are described as either fundamental or incremental change"; process issues "involve the specifics of the change itself, process issues refer to the actions taken by change agents during the introduction and implementation of the proposed change"; and contextual issues "refer to the pre-existing forces in an organization's external (competitive pressure, governmental deregulation, legislative and technological changes) and internal environment (levels of professionalism, managerial attitudes toward change, managerial tension, technical knowledge resources)".

However, there is another factor that should be considered in an organizational change: the individual differences of the change's recipients. This factor received small attention until 
recently, as presented in the beginning of this session, but there has been an increase in this line of research, including the psychological aspects of change's recipients (Walker, Armenakis, \& Bernerth, 2007). In a recent article from the Academy of Management Review by Oreg, Bartunek, Lee, \& Do (2018), the authors noted that, for a long time, scholars were focusing on the role of change agents in organizational change, and only recently attention has been given to the change recipients.

The individual differences (micro-level of each organization) are in addition to the macro-level factors of content, process and context. Each individual in the organization has personality characteristics with the potential to influence the organization. Individual differences will present reactions to change, positively or negatively, and will present certain level of commitment to the proposed change. Walker et al. (2007) consolidated some examples: individuals highly tolerant of ambiguity may better handle the uncertainty associated with organizational change; individuals that are high in openness to experience and high self-monitors may react more positively to organizational change efforts.

Theories on individual differences state that individual's responses may diverge from each other due to different cognitive structures. Armenakis et al. (1993) cited Kirton (1980) on the example of different individual's reactions of innovators or adaptors. In the research, innovators were likely to respond positively to readiness programs preparing job incumbents to apply different mental models and develop new skills, while adaptors were more likely to respond positively to readiness programs aiming to support implementation of incremental changes that required minor changes in thought process and only fine tune some existing skills. Thus, individual difference theory highlights that different individuals may present different reactions to the same change message.

Therefore, organizational changes should address not only content, process and context, but the individual differences as well.

\subsubsection{Individuals' Readiness for organizational change}

The individual Readiness for change (IRFC) has raised significant attention from researchers. Many authors (Armenakis et al., 1993; Jones, Jimmieson, \& Griffith, 2005; Holt, Armenakis, Feild, \& Harris, 2007b; Oreg, Vakola, \& Armenakis, 2011) have published on this theme and highlighted the importance of individual human factors in organizational change efforts. 
For Holt (2007a), the own definition of Readiness implies a construct that needs to be assessed at individual level. In general, organizational changes can only be implemented by people, which means changes implies altering the way people work. Given this logic, Readiness requires assessment of these same people who should change behavior or attitudes towards the desired change.

According to the researchers, ignoring the vital role of individuals in the change process causes a failure or difficulties in implementing many change initiatives (Armenakis et al., 1993; Jones et al., 2005; Holt et al., 2007b). Researchers also argued that IRFC (i.e. attitude towards change) has a significant and positive impact on the successful implementation of organizational change (Haffar, Al-Karaghouli, \& Ghoneim, 2014).

The individuals in organizations can be either key for succeeding in change implementation success or be the biggest reason for failure. The negative attitude about a change initiative by organizational members can be of one of the key barrier which leads to the failure of intended organizational change (Jones et al., 2005). Armenakis et al. (1993) considered that low level of change Readiness is the major reason for organizations failing in their trials to implement change successfully. Therefore, change management specialists have stressed the significance of creating IRFC in order to increase the probability of change implementation success (Armenakis et al., 1993; Jones et al., 2005; Haffar et al., 2014).

The Readiness effort demands convincing a group of socially-interacting individuals to change beliefs, attitudes and intentions accordingly to the objectives of the change message, and change agents must distinguish between individual and collective Readiness, including understanding of the collective interpretation of the Readiness message. The collective Readiness is influenced by individuals' Readiness, and system members rely on one another for better understand events and circumstances happening in the organization (Armenakis, Harris, \& Mossholder, Creating Readiness for Organizational Change, 1993).

\section{Definition of Readiness}

Armenakis et al. (1993, p. 298) defined Readiness for change as "the cognitive precursor to the behaviors of either resistance to, or support of, a change effort". They suggested that Readiness is manifested in organizational members' beliefs that the proposed change is needed and that the organization is capable of changing. Jones et al. (2005, p. 362) defined Readiness for change as "the extent to which employees hold positive views about the need for organizational change (i.e. change acceptance), as well as the extent to which employees believe that such changes are likely to have positive implications for themselves 
and the wider organization". Holt (2007a) argued that Readiness is the extent to which individuals are prepared to participate in organizational development activities. He defined Readiness for Change as:

A comprehensive attitude that is influenced simultaneously by the content (i.e., what is being changed), the process (i.e., how the change is being implemented), the context (i.e., circumstances under which the change is occurring), and the individuals (i.e., characteristics of those being asked to change) involved, and collectively reflects the extent to which an individual or a collection of individuals is cognitively and emotionally inclined to accept, embrace, and adopt a particular plan to purposefully alter the status quo. (p. 326)

The internal context includes attributes of environment where initiative is implemented; the content regards attributes of the initiative being implemented; process are the steps taken to implement the initiative; and individual attributes are the attributes of employees where initiative is implemented. All these variables, or factors, influence the Readiness for change, which impacts the intentions and reactions of each individual towards the change.

Figure 7 illustrates this definition of Readiness for change by presenting an integrative model of Readiness, where each of the factors could be assessed (Holt, Armenakis, Harris, \& Feild, 2007a). The internal context could be assessed by the discrepancy and peer support; content by the appropriateness of the change; process by the leadership support; and individual attributes could be assessed by efficacy and valence.

Figure 7 - Integrated model of Readiness: context, content, process, individual attributes

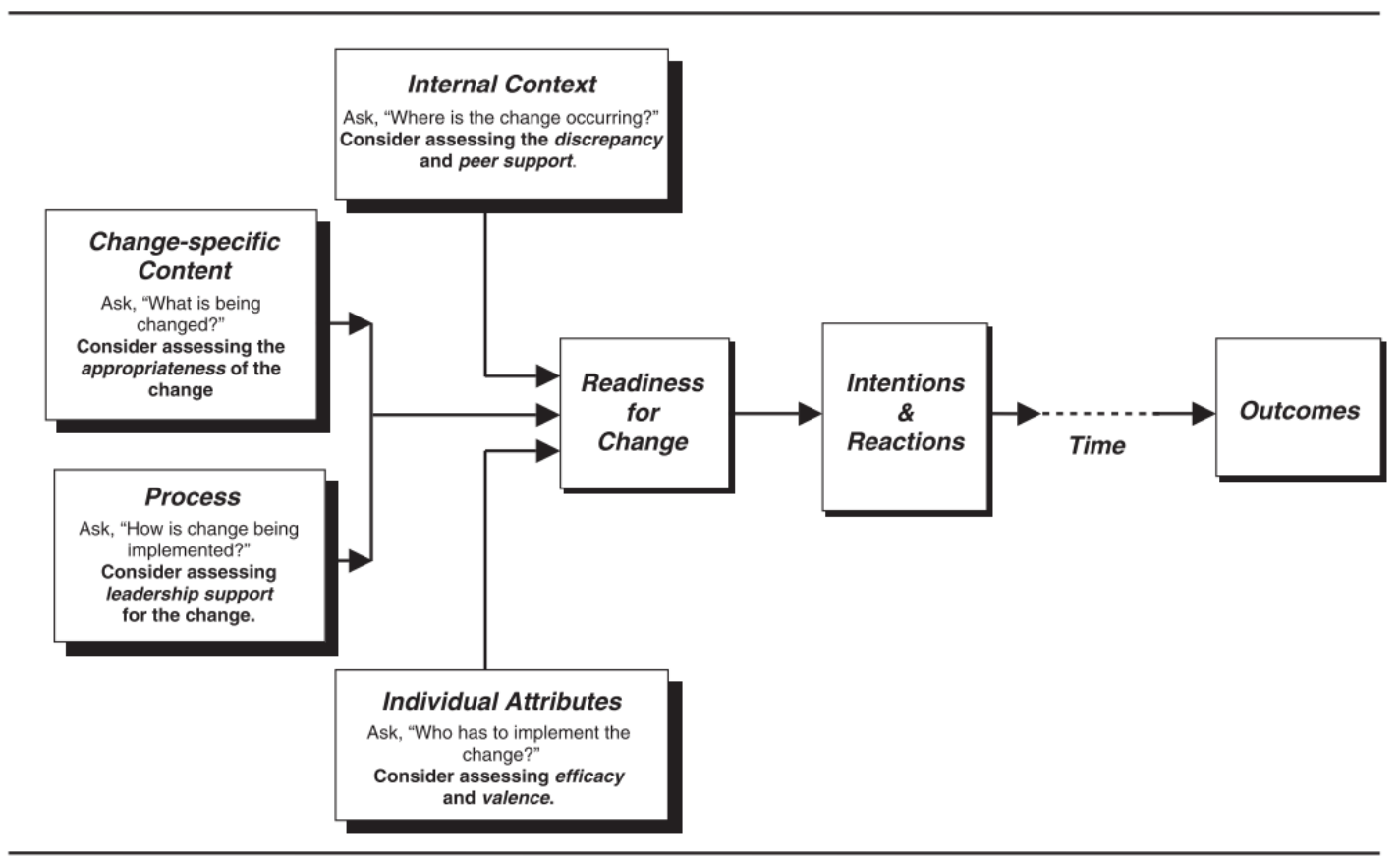

Source: Holt, Armenakis, Harris, \& Feild (2007a, p. 298) 
Armenakis et al. (1993) proposed that Readiness is influenced not only by the message transmitted, but also by change agent attributes and interpersonal and social dynamics of members of the organization. Furthermore, Readiness may be also influenced by unplanned media information (as industry layoffs, increasing foreign competition, economic conditions, etc. disseminated by the media), existing organizational conditions and significance of the change effort.

Haffar, Al-Karaghouli, \& Ghoneim (2014) supported Holt (2007b)'s proposition that IRFC is a construct constituted of four dimensions: individuals' belief in their ability to implement the proposed change (change-specific efficacy), management support for the change, appropriateness of the change, and personal benefit of the change (personal valence). This is supported by Armenakis et al. (1999, p. 763), who suggested that a successful change message must address five key areas:

- Discrepancy component: "involves an explanation of the gap between the current state of the organization and the desired state".

- Appropriateness component: "is more specific and conveys the idea that the proposed change (i.e. content) is appropriate in bridging the gap between the current state and the desired state. The change agent should focus on the factors guiding the choice of a given change effort in comparison with other possible courses of action".

- Efficacy: “expresses confidence in the organization's ability to successfully implement the change. The change target should have confidence in their ability to successfully implement the change".

- Principal support: "knowing that the leaders of the organization, both internal and external leaders, are behind the change is also important to ensuring Readiness. It is important for change agents to demonstrate that management is serious about the change".

- Personal valence: "helps clarify the benefits of the change to the employees. The change target should clearly see the personal benefits of successfully implementing the change".

\section{Readiness vs. resistance}

The concept of Readiness is historically associated within the efforts of resistance to change, either by avoiding or overcoming employee's resistance (Holt, Armenakis, Feild, \& Harris, 2007b). Coch \& French (1948), in the seminal paper Overcoming resistance to 
change, were among the first to raise the idea that managers could avoid the employees' resistance to change, which implicated in the creation of Readiness. They conducted experiments with groups of factory workers, aiming to investigate why employees presented resistance to change and what managers could do to overcome such resistance. The results demonstrated that employees had resistance to change as they did not actually participate in the planning and implementation of the changes.

Armenakis, Harris, \& Mossholder (1993) argued that Readiness is similar to the concept of unfreezing, developed by Lewin (1951), meaning that beliefs, attitudes and intentions impact the extent to which changes are needed and how successful an organizational can implement those changes. For these authors, "Readiness is the cognitive precursor to the behaviors of either resistance to, or support for, a change effort" (p. 681). However, in the literature, not much distinction is made between readiness and resistance, as the creation of readiness has been usually explained in conjunction with resistance reduction. Armenakis et al. (1993) argued that a clear distinction between readiness and resistance provides refined discussions about implementation of change and actually better captures the actions required by the change agent. Creating readiness is, therefore, associated with proactive attitude of managers willing to succeed with the organizational change, whereas managing resistance tends to be a reactive action. These authors proposed a model for creating readiness, by assessing and determining how ready the employees are before an organizational change is implemented. The identification of gaps would allow taking actions to reduce these gaps and anticipating issues with resistance.

\section{Instruments to measure Readiness for change}

Holt, Armenakis, Harris, \& Feild (2007a) published a comprehensive review of instruments to measure Readiness for change. All instruments offered some gauge of readiness, and they usually assessed readiness from one of four perspectives of change content, change process, organization's context and attributes of individuals. The paper organized a list of over 40 instruments focusing on change-specific content, change process, internal context and individual attributes.

Instruments assessing Readiness from the individual attributes perspective presented cognitive component to readiness, as employees having some ability and efficacy for change. Holt et al. (2007a) argued that the assessment of Readiness from the minimum knowledge, skills, and ability perspective suggested that Readiness in organizations may be explicitly related to an individual's actual abilities. These instruments suggested another factor that may 
be critical to an individual's Readiness in an organizational setting - a minimum level of perceived capability (i.e., self-efficacy). There was empirical evidence that demonstrated the importance of self-efficacy in an organizational setting. In sum, the employees' perceptions regarding their existing abilities and trust in the organization's systems to equip them with the necessary knowledge and skills through training programs may be keys to Readiness.

Other study developed by Oreg, Vakola, \& Armenakis (2011) focused on reviewing quantitative researches regarding change recipients' reactions to organizational change. In a similar categorization when compared to Holt el al. (2007a), these authors organized the researches by recipient characteristics (personality traits, coping styles, needs, demographics), internal context (supportive environment/trust, organizational commitment), change process, perceived benefit/harm and change content. The authors also organized instruments by their 'reaction component', namely affective, cognitive, behavioral/intentional and confounded reactions.

Further investigation of Readiness for change instruments, besides the pre-existing reviews from Holt et al. (2007a) and Oreg et al. (2011), indicated three other scales that were of interest for this dissertation. These instruments were: a) OCQ - C, P, R - Organizational Change Questionnaire - Climate of Change, Process and Readiness, developed by Bouckenooghe, Devos, \& van den Broeck (2009); b) OCRBS - Organizational Change Recipients' Beliefs Scale, developed by Armenakis, Bernerth, Pitts, \& Walker (2007); and c) ROCM - Readiness for Organizational Change Measure, developed by (Holt, Armenakis, Feild, \& Harris (2007b). ROCM was the selected instrument to support this dissertation.

The OCQ-C, P, R is a diagnostic tool incorporating three questionnaires to measure the climate of change or internal change context, the process of change, and the Readiness for change. Although OCQ - C, P, R is the most recent instrument among the three, and therefore possibly the most refined one, it proved to be not suitable for this research, as its 42 items covering 11 dimensions do not properly focus on the cognitive terms. Although Bouckenooghe, Devos, \& van den Broeck (2009) acknowledged this width of scope as an advantage over ROCM ("another advantage over the ROCM is that readiness in the OCQ-C, $\mathrm{P}, \mathrm{R}$ incorporates cognitive, affective, and intentional components instead of purely cognitive terms", p. 594), it turned out to be a drawback for this research. Other factor taken in account for not selecting this instrument refers to the authorship of Achilles Armenakis in the other two instruments. Since his seminal publication in 1993, Creating Readiness for Organizational Change, Armenakis has been a highly active and cited researcher in this field. 
Regarding OCRBS and ROCM, it is interesting to note that both instruments were published in the same year, in the same journal (OCRBS in December, and ROCM in June) and both with Achilles Armenakis as part of the author's team members (Daniel Holt is the first author of ROCM, while Achilles Armenakis is the first author of OCRBS). The OCRBS was designed to be used in any of the three phases of organization change, namely readiness, adoption and institutionalization. Furthermore, OCRBS can be used and combined with other instruments, including scales to assess attributes of change recipients or change agents. This instrument consists of 24 items assessing five critical beliefs: discrepancy, appropriateness, efficacy, principal support and valence.

In comparison with ROCM, the instruments have similar structure, as Holt et al. (2007b)'s scale is composed of 25 items covering appropriateness, management support, change efficacy and personally beneficial. The instrument was built after a thorough revision of 32 instruments focused on measuring Readiness for change quantitatively (Holt, Armenakis, Harris, \& Feild, 2007a). The decisive factor to select between these two instruments (to be utilized in this research) ended up being the volume of existing citations of Holt et al. (2007b) paper: it is 2.5 times more cited than Armenakis et al. (2007)'s publication.

These reviews on the researches and instruments were useful to help deciding the right instrument for the given research objective. In case of this dissertation, interested on the cognitive styles of the respondents as well as interested on the change-efficacy, the instrument developed by Holt, Armenakis, Feild, \& Harris (2007b) delivered proper alignment with the variables of thinking style and Design Thinking. The detailed discussion of this instrument is presented in the Methodology Chapter. 


\section{METHODOLOGY}

This chapter is organized in five sessions, providing relevant details on instrumentation, design of the questionnaire, sample design, data collection and data analyses and interpretation. This dissertation follows the survey procedures established by Creswell (2013).

\subsection{RESEARCH APPROACH}

This research framework was structured in three sequential main phases: literature review, survey design and statistical analysis (see Figure 8). The literature review, as already presented in this dissertation, was organized in dedicated sessions for Design Thinking, Thinking Styles and Readiness for Organizational Change. The selected research approach was the quantitative survey, designed to measure the relation among variables as thinking styles, understanding of Design Thinking, knowledge and experience with Design Thinking and Readiness-for-change. Recommended protocols were executed in the survey, as utilization of validated instruments, back translation, pre-test of the questionnaire and data collection and consolidation via robust and reliable research software. Finally, data collected allowed statistical inferences on the relation between individuals' thinking styles and respective Readiness to adopt Design Thinking, among other cross-analyses of the variables.

\section{Figure 8 - Research framework}
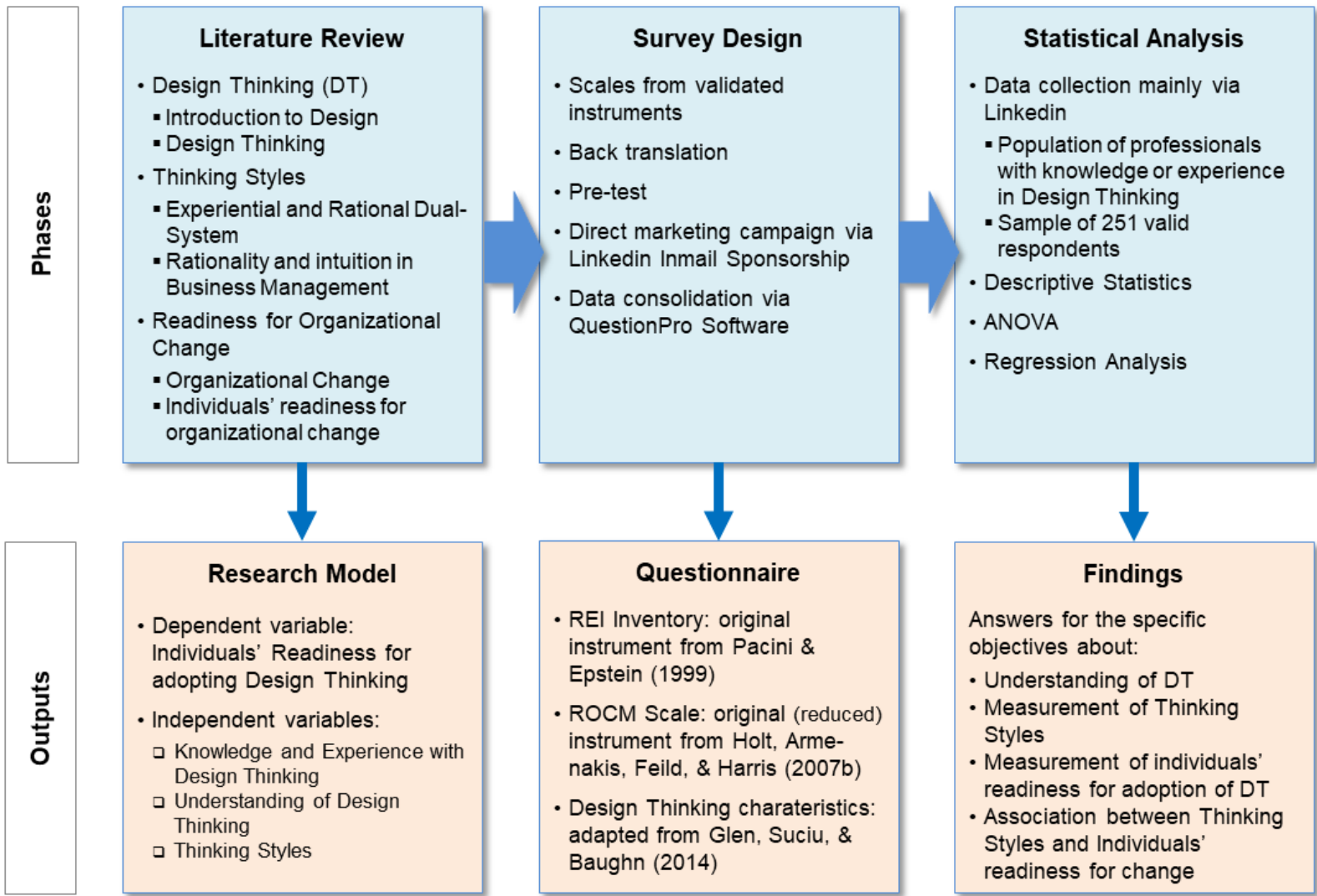

Source: prepared by the author 


\section{Research model and variables}

To what extent individual attributes (Thinking Styles, Knowledge, Experience and Understanding of DT) influence the individual's Readiness for adopting DT in the organization is the research question of this dissertation. Thinking Styles regard the Rationality and Experientiality information processing modes. Other variables may also influence the individual's Readiness for change, as the knowledge and experience with DT (from theoretical knowledge to practical experience) and the understanding of DT (captured in a spectrum between rational-analytic approach and design practice). These variables are organized in the Research Model presented in Figure 9 and discussed in this session.

Readiness for change as the dependent variable is of common usage across different conceptual and empirical studies. Jones, Jimmieson, \& Griffith (2005) presented as examples the studies performed by Armenakis et al. (1993), Eby, Adam, Russel, \& Gaby (2000), and Miller, Johnson, \& Grau (1994). Other studies of Readiness for change as a dependent variable include the ones executed by Bouckenooghe, Devos, \& van den Broeck (2009) and Cunningham, et al. (2002). This research applied three sub-components of Readiness for change: appropriateness, change efficacy and personally beneficial.

Existing researches listing the predecessor variables for Readiness for adopting Design Thinking at an individual level could not be found. This dissertation proposes three independent variables, namely knowledge and experience with Design Thinking (DT), understanding of DT and thinking styles. The supporting arguments for the relations between these variables are presented in this session; and results are presented in Chapter Four.

\section{Figure 9 - Research model}

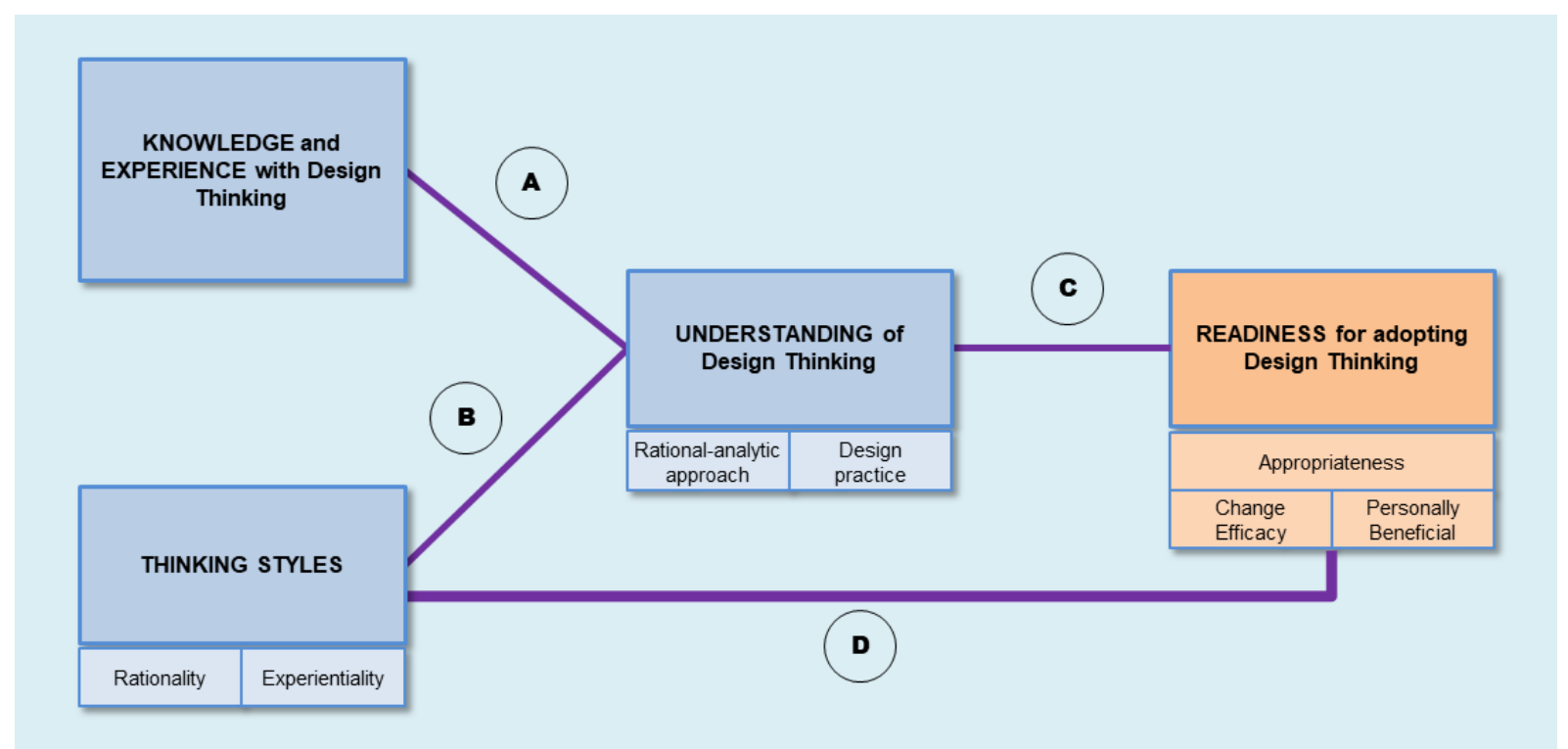

Source: organized by the author 
The first relation between variables concerns the individual's knowledge and experience with Design Thinking (DT) and their perceived understanding of what is DT (coded as ' $A$ ' in Figure 9). Design Thinking is a relatively new field in the management practice and education (Carlgren et al. 2016; Gruber et al., 2015; Rauth et al., 2015), implying that the understanding, knowledge and experience with Design Thinking has not reached maturity and its concepts and practice are yet not well-defined and established. Within this context, the understanding of Design Thinking probably differs by the different individuals' level of knowledge and experience with DT. Some academic authors understand Design Thinking as a balance between intuition/experience and logic, but practitioners may probably associate Design Thinking to an intuitive and experiential approach.

The second relation regards how individuals understand Design Thinking given their Thinking Styles (coded as 'B'). Although different authors discussed Design Thinking as a combination of analysis and intuition (e.g. Bauer \& Eagan, 2008; Martin, 2009), this explicit connection between the dual process model of cognition and Design Thinking could be only found in the paper from Glen et al. (2014, p. 659): "studies of cognition in field settings and their fit with the design-thinking process can be appreciated through the perspective of dual process models of cognition". As management education and practice have overrelied on the Technical-Rationality (Schön, 1983; Martin, 2009; Kurman \& Beckman, 2011), individuals highly trained on analysis and logical problem-solving may perceive Design Thinking as an approach which outcomes cannot be supported by data, or they can even perceive DT as too fun and not serious (Rauth, Carlgren, \& Elmquist, 2015). In other words, the individual's thinking styles may influence how one perceives and understands Design Thinking.

Thirdly, the relation between the individual's Readiness to adopt Design Thinking and one's understanding of DT is also analyzed (code ' $\mathrm{C}$ '). The Readiness-for-change literature confirms that there is a cognitive component to Readiness, as individuals need to understand what is being changed (in this case, what is DT and what it changes to someone) to assess their level of capability to adapt to this required change. Different understandings of Design Thinking may have positive or negative influence on the individual's Readiness to adopt DT.

Finally, the Readiness for adopting Design Thinking may be influenced by the individual's Thinking Styles (code 'D'). One may need to have some ability and engagement that can cope with the change; this belief in its own's ability to implement change is named self-efficacy by Armenakis et al. (1999, 2007). In this context, the rational-experiential inventory (Pacini \& Epstein, 1999) of the individual is a leading indicator of his/her abilities and may act as a predictor of someone's Readiness to adopt Design Thinking. 
Having described the research model, the details of each variables of the study are now presented. It is helpful to the reader have a summary of all the survey variables organized in the Methodology chapter (Table 11). The selected variables are related to the research model and applied in the questionnaire in the following logic: self-assessment of the knowledge and experience with Design Thinking, measurement of the individuals' thinking style, collection of understanding of Design Thinking, measurement of individuals' Readiness for adopting Design Thinking, and finally, collection of outline regarding professional experience (years in company, job title, job role), education (level, specialty area) and demographics (age and sex).

Table 11 - Survey variables

\begin{tabular}{|c|c|c|}
\hline Variable Name & Author & Description \\
\hline \multicolumn{3}{|c|}{ KNOWLEDGE AND EXPERIENCE WITH DESIGN THINKING } \\
\hline $\begin{array}{l}\text { Knowledge and experience } \\
\text { with Design Thinking }\end{array}$ & & $\begin{array}{l}\text { Six levels of knowledge and experience, from 'I don't } \\
\text { know what Design Thinking is' to 'My job regularly } \\
\text { requires Design Thinking' }\end{array}$ \\
\hline \multicolumn{3}{|c|}{ THINKING STYLES } \\
\hline Rationality Ability & $\begin{array}{l}\text { Pacini \& } \\
\text { Epstein (1999) }\end{array}$ & $\begin{array}{l}\text { "Rational Ability refers to reports of a high level of } \\
\text { ability to think logically and analytically" (p. 974) }\end{array}$ \\
\hline Rationality Engagement & $\begin{array}{l}\text { Pacini \& } \\
\text { Epstein (1999) }\end{array}$ & $\begin{array}{l}\text { "Rational Engagement refers to reliance on and } \\
\text { enjoyment of thinking in an analytical, logical manner" } \\
\text { (p. 974) }\end{array}$ \\
\hline Experientiality Ability & $\begin{array}{l}\text { Pacini \& } \\
\text { Epstein (1999) }\end{array}$ & $\begin{array}{l}\text { "Experiential Ability refers to reports of a high level of } \\
\text { ability with respect to one's intuitive impressions and } \\
\text { feelings" (p. 974) }\end{array}$ \\
\hline Experientiality Engagement & $\begin{array}{l}\text { Pacini \& } \\
\text { Epstein (1999) }\end{array}$ & $\begin{array}{l}\text { "Experiential Engagement refers to reliance on and } \\
\text { enjoyment of feelings and intuitions in making decisions" } \\
\text { (p. 974) }\end{array}$ \\
\hline \multicolumn{3}{|c|}{ UNDERSTANDING OF DESIGN THINKING } \\
\hline $\begin{array}{l}\text { Characteristics of Design } \\
\text { Thinking }\end{array}$ & $\begin{array}{l}\text { Glen et al. } \\
(2014)\end{array}$ & $\begin{array}{l}\text { Seven characteristics regarding problem formulation, } \\
\text { criteria, method, information-procession emphasis, } \\
\text { solution process, rationale and outcome }\end{array}$ \\
\hline \multicolumn{3}{|c|}{ READINESS FOR ADOPTING DESIGN THINKING } \\
\hline Appropriateness & $\begin{array}{l}\text { Holt et al. } \\
(2007 b)\end{array}$ & $\begin{array}{l}\text { "measure the extent to which members felt that a change } \\
\text { was needed (i.e., discrepancy), representing the } \\
\text { participants' perceptions regarding the legitimacy of a } \\
\text { change"; and "measure the extent to which members felt } \\
\text { the change would be beneficial to the organization (i.e., } \\
\text { organizational valence), focusing on the change's } \\
\text { benefits, gained efficiency, and goal congruence" (p. 241) }\end{array}$ \\
\hline Change Efficacy & $\begin{array}{l}\text { Holt et al. } \\
(2007 b)\end{array}$ & $\begin{array}{l}\text { "reflected the extent to which organizational members felt } \\
\text { confident that they would perform well and be } \\
\text { successful" (p. 241) }\end{array}$ \\
\hline Personally Beneficial & $\begin{array}{l}\text { Holt et al. } \\
(2007 b)\end{array}$ & $\begin{array}{l}\text { "reflected concerns about relationships, status, and } \\
\text { opportunities" (p. 244) }\end{array}$ \\
\hline
\end{tabular}




\begin{tabular}{|c|c|c|}
\hline Variable Name & Author & Description \\
\hline \multicolumn{3}{|c|}{ PROFESSIONAL OUTLINE } \\
\hline Job function & & $\begin{array}{l}\text { Eight alternatives for functional job role, including } \\
\text { Marketing, HR, Operations, Finance, IT, R\&D, Design }\end{array}$ \\
\hline Company name & & Name of the company that respondent is working for \\
\hline Year in the company & & Number of years working in the current company \\
\hline Department name & & $\begin{array}{l}\text { Name of the department (allow identification of more } \\
\text { specific role) }\end{array}$ \\
\hline $\begin{array}{l}\text { Number of departments one } \\
\text { has worked for }\end{array}$ & & $\begin{array}{l}\text { Number of different departments experienced in the } \\
\text { current company }\end{array}$ \\
\hline Education level & & $\begin{array}{l}\text { Four alternatives: high school, college, post-graduation, } \\
\text { others }\end{array}$ \\
\hline Education area & & $\begin{array}{l}\text { Eight alternatives, including Business Administration, } \\
\text { Engineering, Design and/or Architecture, Arts. }\end{array}$ \\
\hline Job position / title & & $\begin{array}{l}\text { Seven alternatives: owner, director, superintendent, } \\
\text { manager, coordinator, analyst, other }\end{array}$ \\
\hline Age & & Age of the respondent \\
\hline Sex & & Sex of the respondent (male, female) \\
\hline
\end{tabular}

Source: organized by the author

\subsubsection{Instrumentation}

This sub-session presents detailed information about the survey instruments used in this study. Each instrument is explained and provided explanation of what has been left intact or modified, and the validity of scores obtained from past use of the instrument are presented. The design of this survey lies on the validated instruments of the Rational-Experiential Inventory (Pacini \& Epstein, 1999) and Readiness for Organizational Change Measure (Holt, Armenakis, Feild, \& Harris, 2007b).

Regarding Creswell (2013, p. 206), the three traditional forms of validity are: "content validity (items measure the content they were intended to measure), predictive or concurrent validity (scores predict a criterion measure, results correlate with other results), and construct validity (items measure hypothetical constructs or concepts)". The validity of survey's scores helps identifying whether an instrument is a good one to be used in survey research. Reliability is other important discussion for the instruments, namely on internal consistency (items' responses are consistent across constructs) and test-retest correlations (scores are stable over time when the instrument is administered a second time).

Discussion of pilot testing is also presented, including report of improvements and profile and number of people that executed the pre-test of the questionnaire.

Hinkin (1998) stated that properly measuring abstract constructs is possibly the greatest challenge to understand people's behavior in organizations, and the construction of measuring 
instruments is likely to be the most important element of any study. "A construct is a representation of something that does not exist as an observable dimension of behavior, and the more abstract the construct, the more difficult it is to measure" (p. 104).

For above reasons, the survey instruments applied in this research were previously developed by academic researchers and tested in different studies, which results were published in traditional journals and which articles have been highly cited.

\section{Rational-Experiential Inventory (REI)}

The REI scale applied in this research was developed by Pacini \& Epstein (1999), as a subsequent development of the original REI scale (Epstein, Pacini, Denes-Raj, \& Heier, 1996). This original version consisted of two scales, named Need for Cognition (NFC) and Faith in Intuition (FI), respectively corresponding to the rational and experiential thinking styles. The NFC measured engagement and enjoyment with cognitive activities, and it was a modification from the scale with same name, developed by Cacioppo and Petty (1982). As a counterpart of the NFC scale, the FI scale was developed for the intuitive-processing style.

The reviewed REI have equal number of items per scale (20 items for Rationality and 20 items for Experientiality) and balanced number of positively and negatively worded items, having a more parallel content. The reliabilities of the new REI scales are higher and similar to each other. Pacini \& Epstein (1999) stated that although there were limitations in the previous REI, the new version confirmed the same findings. The new Rationality and Experientiality scales were proved independent, through the statistical procedures of factor analysis and correlation of the scales. The researchers also developed subscales to measure ability and engagement for each thinking style. The subscales were Rational Ability, Rational Engagement, Experiential Ability, and Experiential Engagement. The two ability subscales are associated with self-esteem related variables, whereas the two engagement scales are associated with value-related and attitude variables.

These REI subscales provided clarification on the main scales, by detailing the results by ability and engagement. Factor analysis proved distinction between the subscales of Rationality, but did not confirm differences for the subscales of Experientiality. However, Pacini \& Epstein (1999, p. 984) argued that "correlations with other variables provided support for the discriminant validity of the Experientiality subscales and therefore justification for retaining them".

Rational Ability regards the measurement of ability to think logically and analytically. The ten items are presented in Table 12. 
Table 12 - Rational ability items

\begin{tabular}{l}
\hline Item \\
\hline I'm not that good at figuring out complicated problems. [reverse scoring] \\
I am not very good at solving problems that require careful logical analysis. [reverse scoring] \\
I am not a very analytical thinker. [reverse scoring] \\
Reasoning things out carefully is not one of my strong points. [reverse scoring] \\
I don't reason well under pressure. [reverse scoring] \\
I am much better at figuring things out logically than most people. \\
I have a logical mind. \\
I have no problem thinking things through carefully. \\
Using logic usually works well for me in figuring out problems in my life. \\
I usually have clear, explainable reasons for my decisions. \\
\hline
\end{tabular}

Source: Pacini \& Epstein (1999, p. 976)

Rational Engagement refers to reliance on and enjoyment of thinking in an analytical, logical manner. Table 13 presents the ten items for this subscale.

\section{Table 13 - Rational engagement items}

\begin{tabular}{l} 
Item \\
\hline I try to avoid situations that require thinking in depth about something. [reverse scoring] \\
I enjoy intellectual challenges. \\
I don't like to have to do a lot of thinking. [reverse scoring] \\
I enjoy solving problems that require hard thinking. \\
Thinking is not my idea of an enjoyable activity. [reverse scoring] \\
I prefer complex problems to simple problems. \\
Thinking hard and for a long time about something gives me little satisfaction. [reverse scoring] \\
I enjoy thinking in abstract terms. \\
Knowing the answer without having to understand the reasoning behind it is good enough for me. [reverse \\
scoring] \\
Learning new ways to think would be very appealing to me. \\
\hline
\end{tabular}

Source: Pacini \& Epstein (1999, p. 976)

Experiential Ability measures the level of ability with respect to one's intuitive impressions and feelings. The ten items are shown in Table 14.

Table 14 - Experiential ability items

\begin{tabular}{l}
\hline \multicolumn{1}{c}{ Item } \\
\hline I don't have a very good sense of intuition. [reverse scoring] \\
Using my gut feelings usually work well for me in figuring out problems in my life. \\
I believe in trusting my hunches. \\
I trust my initial feelings about people. \\
When it comes to trusting people, I can usually rely on my gut feelings. \\
If I were to rely on my gut feelings, I would often make mistakes. [reverse scoring] \\
I hardly ever go wrong when I listen to my deepest gut feelings to find an answer. \\
\hline
\end{tabular}


My snap judgments are probably not as good as most people's. [reverse scoring]

I can usually feel when a person is right or wrong, even if I can't explain how I know.

I suspect my hunches are inaccurate as often as they are accurate. [reverse scoring]

Source: Pacini \& Epstein (1999, p. 976)

Experiential Engagement refers to reliance on and enjoyment of feelings and intuitions in making decisions. Table 15 details the ten items of this subscale.

Table 15 - Experiential engagement items

\begin{tabular}{l}
\hline \multicolumn{1}{c}{ Item } \\
\hline I like to rely on my intuitive impressions. \\
Intuition can be a very useful way to solve problems. \\
I often go by my instincts when deciding on a course of action. \\
I don't like situations in which I have to rely on intuition. [reverse scoring] \\
I think there are times when one should rely on one's intuition. \\
I think it is foolish to make important decisions based on feelings. [reverse scoring] \\
I don't think it is a good idea to rely on one's intuition for important decisions. [reverse scoring] \\
I generally don't depend on my feelings to help me make decisions. [reverse scoring] \\
I would not want to depend on anyone who described himself or herself as intuitive. [reverse scoring] \\
I tend to use my heart as a guide for my actions. \\
\hline
\end{tabular}

Source: Pacini \& Epstein (1999, p. 976)

To secure its validity and reliability, this dissertation's research applied exactly same questionnaire, preserving its reversed items as well as the order of the items. As the questionnaire was applied in Portuguese language, it was translated to Portuguese and then to English again to verify the accuracy of the translation (see Annex II for the reversed translation).

Björklund \& Bäckström (2008) conducted one study to investigate the structural validity of the instrument, and one other study investigated the convergent and discriminant validity, and the concurrent validity. The study 1, sample of 203 respondents, took in consideration the REI-40 for a factor analysis, and concluded that the structural validity was appropriated. In the study 2, sample of 72 respondents, the REI factors presented significant correlation to personality traits, implicating in convergent and discriminant validity. These authors also stated that scores on the Rationality scale were negatively related to risky choice framing effects in Tversky \& Kahneman's Asian disease task (1981), indicating concurrent validity. From these findings, Björklund \& Bäckström (2008) concluded that satisfactory psychometric properties were met.

Witteman, Bercken, Claes, \& Godoy (2009) discussed the relations of the two thinking styles to personality characteristics. From a sample with Dutch respondents, the authors found 
clear evidence for the independence of the two thinking styles. Additionally, based on a Spanish sample of 141 respondents, REI was analyzed against Big Five inventory. These two small studies measured the preference for rationality or intuition (by utilizing REI) and its relation to task behavior. The results demonstrated compatibility with Pacini \& Epstein (1999)'s results. The authors also concluded that the dual-information processing was valid cross-culturally.

\section{Readiness for Organizational Change Measure (ROCM)}

The assessment of Readiness can be achieved through qualitative (observation and interview techniques) and quantitative (questionnaire techniques) methods. Qualitative methods deliver rich change-specific understanding, and quantitative assessments are efficient to collect change-related data in organizations as it can be widely distributed in short periods of time, besides determining reliability and validity of the instrument (Holt, 2007b).

Over 40 quantitative instruments for measuring Readiness for change were analyzed by Holt et al. (2007a). These researchers grouped instruments in four perspectives, each one assessing change-specific content, change process, internal context or individual attributes. Despite the conclusion that these instruments typically assessed Readiness from one of the four perspectives, it was the lack of evidence of validity and reliability that stimulated Holt et al. (2007b) to develop a new instrument to measure Readiness for change.

This dissertation adopted this instrument for measuring individuals' Readiness for change developed by Holt (2007b). For Holt, Readiness for change is a multidimensional construct that includes four factors: the belief that the proposed change is appropriate for the organization (appropriateness), the capability of employees implementing a proposed change (change efficacy), the leadership commitment to the proposed change (management support) and the benefits of the proposed change to the organizational members (personal valence). All factors except management support were utilized in this research. Management support was excluded as leadership support presents no direct link with individuals' thinking styles (no association with leadership support was found in the literature review).

The appropriateness items are listed in Table 16. The appropriateness construct incorporates the ideas of discrepancy and organizational valence as a unitary construct. Discrepancy, or need for change, regards to the extent that someone feels there are legitimate needs and reasons for the proposed change. Organizational valence, organizationally beneficial, refers to the extent that someone feels that the organization will benefit from the implementation of the proposed change. 
Table 16 - Appropriateness items

\begin{tabular}{l} 
Item \\
\hline I think that the organization will benefit from this change. \\
It doesn't make much sense for us to initiate this change. [reverse scoring] \\
There are legitimate reasons for us to make this change. \\
This change will improve our organization's overall efficiency. \\
There are a number of rational reasons for this change to be made. \\
In the long run, I feel it will be worthwhile for me if the organization adopts this change. \\
This change makes my job easier. \\
When this change is implemented, I don't believe there is anything for me to gain. [reverse scoring] \\
The time we are spending on this change should be spent on something else. [reverse scoring] \\
This change matches the priorities of our organization. \\
\hline
\end{tabular}

Source: Holt et al. (2007b, p. 242)

The change efficacy items are presented in Table 17. Change efficacy reflects the extent to which organizational members feel confident that they would perform well and be successful, including the perception that they have the skills to execute tasks and activities that are related to the proposed change.

\section{Table 17 - Change efficacy items}

\begin{tabular}{l} 
Item \\
\hline I do not anticipate any problems adjusting to the work I will have when this change is adopted. \\
There are some tasks that will be required when we change that I don't think I can do well. [reverse scoring] \\
When we implement this change, I feel I can handle it with ease. \\
I have the skills that are needed to make this change work. \\
When I set my mind to it, I can learn everything that will be required when this change is adopted. \\
My past experiences make me confident that I will be able to perform successfully after this change is made.
\end{tabular}

Source: Holt et al. (2007b, p. 243)

The personally beneficial items are shown in Table 18. Personally beneficial refers to the extent that someone feels that he or she will benefit from the implementation of the proposed change.

\section{Table 18 - Personally beneficial items}

\begin{tabular}{l}
\hline Item \\
\hline I am worried I will lose some of my status in the organization when this change is implemented. [reverse \\
scoring] \\
This change will disrupt many of the personal relationships I have developed. [reverse scoring] \\
My future in this job will be limited because of this change. [reverse scoring] \\
\hline
\end{tabular}

Source: Holt et al. (2007b, p. 243) 


\section{Design Thinking characteristics}

Glen et al. (2014) compared the rational-analytic approach versus Design Thinking (revisit Table 8). He clarified that designers also apply analytical methods, but the differences become apparent when comparing the methods adopted by business schools and the design practice. In his analysis, designers diverge significantly on problem-solving from the traditional rational problem-solving paradigm embraced by the business practice.

As this comparison provides a clearer description of Design Thinking relatively to a rational-analytic approach, the characteristics provided by Glen et al. (2014) in Table 8 were adapted to this survey's questionnaire in order to capture the respondents' understanding of Design Thinking. This adaption is presented in Figure 10. As Design Thinking has no single definition by the academic literature and by practitioners, respondents may have different understanding, hence the importance of collecting their own definition of Design Thinking.

\section{Figure 10 - Survey question on understanding of Design Thinking}

Q3. In your opinion, which characteristics better describe Design Thinking: [single answer per item]

\begin{tabular}{|c|c|c|c|c|c|c|}
\hline & $<<$ & $<$ & & $>$ & $>>$ & \\
\hline Well-defined objectives & 0 & 0 & 0 & $\bigcirc$ & $\bigcirc$ & Open objectives \\
\hline Objective criteria & $\bigcirc$ & $\bigcirc$ & $\bigcirc$ & $\bigcirc$ & $\bigcirc$ & Objective and subjective criteria \\
\hline Iterative method & $\bigcirc$ & $\bigcirc$ & $\bigcirc$ & $\bigcirc$ & $\bigcirc$ & Linear method \\
\hline Qualitative & $\bigcirc$ & $\bigcirc$ & $\bigcirc$ & $\bigcirc$ & $\bigcirc$ & Quantitative \\
\hline Verbal representation & $\bigcirc$ & $\bigcirc$ & $\bigcirc$ & $\bigcirc$ & O & Visual representation \\
\hline Based in logic & $\bigcirc$ & $\bigcirc$ & $\bigcirc$ & $\bigcirc$ & $\bigcirc$ & Based in experiences and intuition \\
\hline Error reduction & 0 & $\bigcirc$ & 0 & $\bigcirc$ & $\bigcirc$ & Fail to learn \\
\hline Definitive answers & $\bigcirc$ & $\bigcirc$ & $\bigcirc$ & $\mathrm{O}$ & $\bigcirc$ & Partial answers \\
\hline
\end{tabular}

Source: adapted by the author from Glen (2014, p. 658) 


\subsubsection{Design of the questionnaire}

The research questionnaire of this dissertation dedicated special care to four elements: a) the application of sound psychometrical instruments previously tested by other researchers; b) careful translation (not adaptation) of the original instruments; c) adoption of friendly and reliable data collection software (including interface for mobile users and desktop users); and d) pre-testing of the questionnaire before starting fieldwork.

\section{Back translation}

Citing APA (2010, p. 32), “when an instrument is translated into a language other than the language in which it was developed, describe the specific method of translation (e.g., back-translation, in which a text is translated into another language and then back into the first to ensure that it is equivalent enough that results can be compared)."

For the questionnaire, the back translation procedure was executed. The original instruments, in English language, were translated to Portuguese by this author; and then an external person was requested to translate back to English Language. The results of this procedure are in the Appendix II. Three back translations presented some divergence; two of them were quite similar but were maintained as meaning was preserved, one was divergent and correction was applied. A summary of these issues are presented in Table 19.

Table 19 - Back translations: list of divergences from original version

\begin{tabular}{llll}
\hline Original version & $\begin{array}{l}\text { Translation to } \\
\text { Portuguese }\end{array}$ & Back Translation & $\begin{array}{l}\text { Translation utilized in } \\
\text { the questionnaire }\end{array}$ \\
\hline $\begin{array}{l}\text { I like to rely on my } \\
\text { intuitive impressions. }\end{array}$ & $\begin{array}{l}\text { Eu gosto de contar com } \\
\text { minhas impressões } \\
\text { baseadas em intuição. }\end{array}$ & $\begin{array}{l}\text { I like to count on my } \\
\text { impressions based on } \\
\text { intuition. }\end{array}$ & $\begin{array}{l}\text { (maintained as meaning } \\
\text { was preserved) }\end{array}$ \\
$\begin{array}{l}\text { I trust my initial } \\
\text { feelings about people. }\end{array}$ & $\begin{array}{l}\text { Eu confio em minhas } \\
\text { primeiras impressões } \\
\text { sobre pessoas. }\end{array}$ & $\begin{array}{l}\text { I trust my first } \\
\text { impressions about people. }\end{array}$ & $\begin{array}{l}\text { (maintained as meaning } \\
\text { was preserved) }\end{array}$ \\
$\begin{array}{l}\text { This change makes my } \\
\text { job easier }\end{array}$ & $\begin{array}{l}\text { Esta mudança irá tornar } \\
\text { meu trabalho mais fácil. }\end{array}$ & $\begin{array}{l}\text { This change will make } \\
\text { my work easier. }\end{array}$ & $\begin{array}{l}\text { Esta mudança torna meu } \\
\text { trabalho mais fácil. }\end{array}$ \\
\hline
\end{tabular}

Source: organized by the author

\section{QuestionPro software}

QuestionPro is an American company founded in 2005 specialized in providing survey software. The questionnaire was built on the QuestionPro's Online Survey Platform, which charges a subscription fee to utilize its services.

The tools for survey design (types of questions, logic, filter, navigation), data collection (including via desktop or mobile/tablet devices), data consolidation (export to MS-Excel) and data visualization were used for this dissertation. 
Each respondent was identified with a unique "response ID", with respective data of IP Address, time stamp, time taken to complete questionnaire, country code and region of the respondent, response status (started, terminated, completed), and device used by the respondent (mobile or computer). All questions were set as mandatory to respondents.

The URL for the questionnaire was http://designthinkingsurvey.questionpro.com.

\section{Pre-test}

The questionnaire was tested with four different individuals, two of them with experience with Design Thinking and the other two with experience with consumer research.

As the questions were integrally adopted from academic instruments, only some small adjustments were needed. Table 20 details what types of issues were identified and the actions taken to adjust the questionnaire. Major issue was related to the question about characteristics of Design Thinking. This required further review of the literature, which ended up with the adoption of the comparison between rational-analytic approach and Design Thinking developed by Glen et al. (2014).

Table 20 - Questionnaire pre-test: list of issues identified

\begin{tabular}{|c|c|c|c|}
\hline Tester & Profile & Issue identified & Action taken \\
\hline$\# 1$ & $\begin{array}{l}\text { Senior marketing } \\
\text { professional with some } \\
\text { experience with Design } \\
\text { Thinking }\end{array}$ & $\begin{array}{l}\text { - Compatibility with mobile } \\
\text { devices: she tried with an } \\
\text { Ipad but at the end preferred } \\
\text { to do the questionnaire in a } \\
\text { desktop PC } \\
\text { - Wording: 'papel funcional' } \\
\text { generated some confusion } \\
\text { about expected outcome in } \\
\text { this question }\end{array}$ & $\begin{array}{l}\text { - In the online questionnaire } \\
\text { introduction, added recommendation } \\
\text { to use desktop PC vs. mobile, } \\
\text { although questionnaire was also } \\
\text { designed for mobile interfaces } \\
\text { - Changed wording to 'função } \\
\text { principal na empresa' }\end{array}$ \\
\hline$\# 2$ & $\begin{array}{l}\text { Professor that applies } \\
\text { Design Thinking }\end{array}$ & $\begin{array}{l}\text { - The original question about } \\
\text { Design Thinking } \\
\text { characteristics made people } \\
\text { confused when terms like } \\
\text { 'abstrato' and 'analítico' } \\
\text { were used }\end{array}$ & $\begin{array}{l}\text { - This question was totally } \\
\text { reformulated based on the academic } \\
\text { paper (Glen et al., 2014) from the } \\
\text { Academy of Management Learning } \\
\text { and Education, securing a theoretical } \\
\text { background behind }\end{array}$ \\
\hline$\# 3$ & $\begin{array}{l}\text { VP of a consumer } \\
\text { researcher company }\end{array}$ & $\begin{array}{l}\text { The many reversed items } \\
\text { created some mental } \\
\text { confusion and additional } \\
\text { attention when answering } \\
\text { the questions. } \\
\text { - Concern about drop-out rate }\end{array}$ & $\begin{array}{l}\text { - Reversed items were applied as } \\
\text { formulated in the original } \\
\text { questionnaire from Pacini \& Epstein } \\
\text { (1999). } \\
\text { - Items were visually split by groups of } \\
\text { 10, making more comfortable when } \\
\text { fulfilling the questionnaire }\end{array}$ \\
\hline$\# 4$ & $\begin{array}{l}\text { Senior marketing } \\
\text { professional with } \\
\text { experience with } \\
\text { consumer insights and } \\
\text { consumer research }\end{array}$ & $\begin{array}{l}\text { - User interface: by accident, } \\
\text { she closed the questionnaire } \\
\text { in the first page, thinking it } \\
\text { was the 'next' button } \\
\text { - Wording: 'sobre como você } \\
\text { pensa' sounded incomplete } \\
\text { for proper understanding }\end{array}$ & $\begin{array}{l}\text { - Moved the 'exit' button to the bottom } \\
\text { of the page }\end{array}$ \\
\hline
\end{tabular}

Source: organized by the author 


\subsubsection{Population and sample}

This sub-session describes two essential components of the research plan: population description and sampling design. The population and its size are described, as well as how to identify it within the general population. It is also described how to access this population, including availability of samples, as via mailing lists or visiting locations to collect data. Regarding the sample, discussions include the selection of sample, categorization type (single stage or multistage/clustering), sample size and margin of error.

\section{Population description}

The rationale for applying a survey research includes the objective to generalize from a sample to a population and identify attributes of a large population from a small group of individuals.

The population of this survey was defined from the professionals with declared skill in Design Thinking based in the State of São Paulo. The calculation of the size of this population was based on available data from LinkedIn and Government sources.

There were 22.6 million people actively working or willing to work in the State of São Paulo (latest official data is from IBGE, 2012). At LinkedIn, there were 7.5 million people with profiles registered as of December, 2017 (LinkedIn Campaign Manager ${ }^{2}$ ). Therefore, the LinkedIn penetration rate in the State of São Paulo was calculated at $33.2 \%$.

From the LinkedIn Campaign Manager, it was known that 4,000 professionals from the State of São Paulo had declared skill in Design Thinking. By applying the penetration rate described in the paragraph above, the size of population with skill in Design Thinking in the State of São Paulo was reached by calculating 4,000 divided by $33.5 \%$, which result was approximately 12,000 people.

\section{Sampling design}

The sampling design for this population is single stage ("a single-stage sampling procedure is one in which the researcher has access to names in the population and can sample the people directly", Creswell, 2013, p. 204), cross-sectional (data was collected only once in time) and selection of online sample was non-stratified.

The literature recommends a random sample, in which each individual in the population has an equal probability of being selected (a systematic or probabilistic sample). By having this randomization, a representative sample from a population allows generalization to a

\footnotetext{
${ }^{2}$ The Linkedin Campaign Manager is the online tool provided by Linkedin to manage direct marketing campaigns from the 'Sponsored Inmail'. Sponsored InMail allows targeting selected audiences with content delivered through Linkedln messenger.
} 
population. The sample could also be stratified, which would require characteristics of the population members being known. Stratification means that specific characteristics of individuals (as sex and age) are represented in the sample and the sample reflects the true proportion in the population of individuals with certain characteristics. Stratification is useful to secure that characteristics of the population is proportionally represented in the sample (Creswell, 2013). The LinkedIn Campaign Manager tool secured a random raffle, where each individual had an equal probability of being selected (printed questionnaires did not have a random sample) $)^{3}$. There was no stratification of the population for defining the sample; in other words, there was no requirement to have characteristics as age and sex in the same proportion found in the population. The only selection criterion applied referred to the level of knowledge and experience with Design Thinking (if one did not know what Design Thinking is, or just heard about Design Thinking, the questionnaire was terminated).

Regarding the sample size, 567 individuals opened/received and started fulfilling the questionnaire. Out of 567, 507 individuals were from the State of São Paulo (checked by the region of the IP address or location where printed questionnaire was fulfilled). From these 507 respondents, 43 respondents were excluded by the filter question, 213 respondents started but did not complete the questionnaire, resulting in a valid sample of 251 individuals that fully completed the survey.

Consequently, the margin of error could be calculated given the population and sample size. The margin of error was at $6.12 \%$, as shown in Table 21.

Table 21 - Population, sample size and margin of error

\begin{tabular}{ll}
\hline \multicolumn{1}{c}{ Description } & Figures \\
\hline Professionals with skill in Design Thinking, residents in the State of Sao Paulo & 12,000 people \\
Valid Sample Size & 251 \\
Confidence Level & $95 \%$ \\
Margin of Error & $6,12 \%$ \\
\hline
\end{tabular}

Source: prepared by the author

\footnotetext{
${ }^{3}$ Data collected via printed questionnaire presented same responses' distribution of online sample, therefore not creating any bias in the total sample. See Figure 11.
} 


\subsubsection{Data collection}

This research performed a cross-sectional data collection to deploy a rapid turnaround in data collection and leverage online/printed questionnaires to lower costs of research by maximizing recruitment efforts.

Data collection procedure was executed via: (a) online questionnaire sent by LinkedIn Inmail box to participants and to the LinkedIn's professional network of this author, (b) printed questionnaires, personally delivered and collected from participants. The survey respondents met the following recruitment criteria: based in the State of Sao Paulo and knowledgeable of Design Thinking (for this filter question, see Appendix I, question 1).

This online direct marketing campaign started running on December $1^{\text {st }}$, 2017. Data collection terminated on January $31^{\text {st }}$, 2018. LinkedIn Inmails were sent by waves, in order to understand and assess the response rates. It was observed that better response rates were obtained on Monday and Tuesdays, with completion rates decreasing along the week. Additionally, the response rates significantly decreased from December $15^{\text {th }}$ to early January, probably due to the end of year's holiday season.

The printed questionnaires were applied on November $28^{\text {th }}, 2017$ with students of a graduate program at ESPM, and applied to employees of Sioux, a software company that utilizes Design Thinking when developing their projects. The valid respondents from each data source are presented at Table 22.

Table 22 - List of survey's data sources

\begin{tabular}{|c|c|c|c|}
\hline Source & Description & $\begin{array}{l}\text { Data collection } \\
\text { method }\end{array}$ & $\begin{array}{c}\text { Valid respondents } \\
\text { (from Sao Paulo State) }\end{array}$ \\
\hline LinkedIn & $\begin{array}{l}\text { LinkedIn Sponsorship } \\
\text { Inmail } \\
\text { Own network of this author }\end{array}$ & Online questionnaire & 229 people \\
\hline $\begin{array}{l}\text { ESPM graduate } \\
\text { program }\end{array}$ & $\begin{array}{l}\text { "Master em Marketing e } \\
\text { Comunicação Digital" }\end{array}$ & Printed questionnaire & 17 people \\
\hline Sioux Company & $\begin{array}{l}\text { Software company based in } \\
\text { São Paulo }\end{array}$ & Printed questionnaire & 5 people \\
\hline
\end{tabular}

Source: organized by the author

Regarding the data collection from the two different sources - LinkedIn and ESPM/Sioux - a statistical analysis was executed to decide if both sources could be merged and incorporated to the sample. Besides the media for data collection (online or printed questionnaire), LinkedIn respondents were exposed to an incentive - raffle with face value of $100 \mathrm{BRL}$ - while ESPM and Sioux respondents were asked to fulfill the questionnaire during 
their class or during working hours, without incentives. Figure 11 demonstrates that there is no statistical difference when histograms (for age, sex, years in company, Rationality, Experientiality and Readiness scores) are compared: all presented same patterns, meaning that data from these two sources could be merged without creating bias.

Figure 11 - LinkedIn respondents vs. ESPM/ Sioux respondents

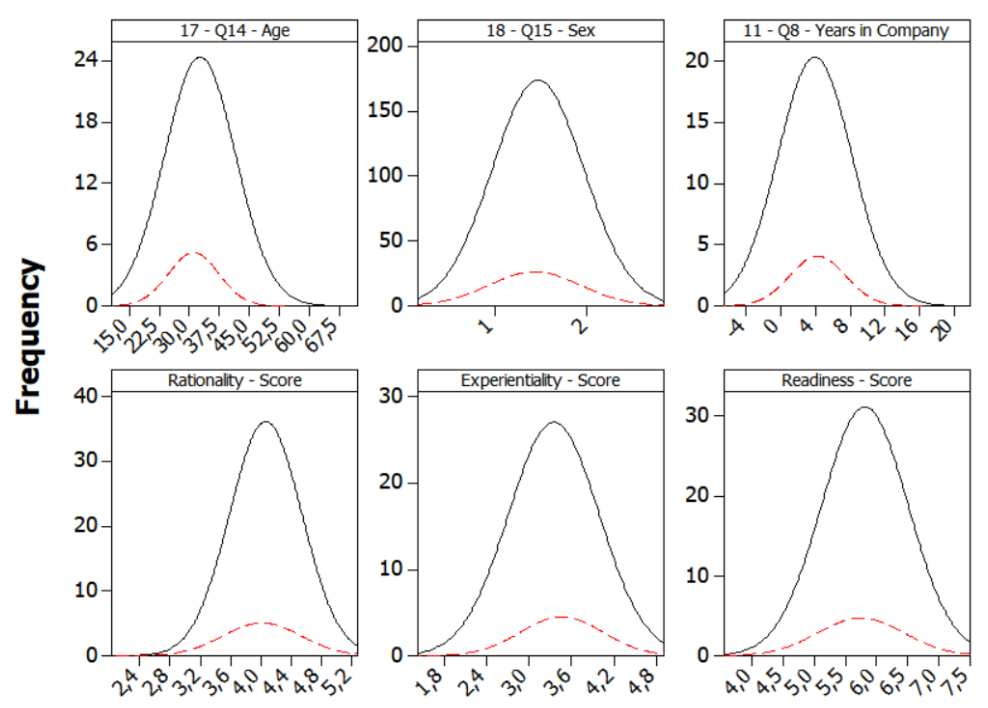

Source: prepared by the author. Note: Full line $=$ LinkedIn respondents; dotted line $=$ ESPM/Sioux respondents

\section{Response rates}

The online and printed questionnaire was accessed / received by 567 individuals and 276 respondents fully and properly completed it, reaching a response rate of $49 \%$. Out of these 276 fully completed questionnaires, 25 respondents were not from the State of São Paulo (verified by the IP address) and excluded from the valid sample. The final valid sample size obtained had 251 respondents.

The online questionnaire could be fulfilled either on desktop or mobile devices (smartphones or tablets). By analyzing response rates by type of device, it is worth noting that while $57 \%$ started fulfilling the questionnaire in a mobile phone but did not complete; the highest proportion of completed questionnaires came from personal computers. This may be of interest for other researchers, as people are dramatically adopting smartphones for everyday use, but fulfilling academic researches may yet be a challenge in mobile devices. Table 23 presents the response rates by type of device. 
Table 23 - Response rates by type of device

\begin{tabular}{l|cccc|cccc}
\hline \multicolumn{1}{c|}{$\begin{array}{c}\text { Response } \\
\text { Status }\end{array}$} & PC & $\begin{array}{c}\text { Mobile } \\
\text { Phone }\end{array}$ & Tablet & TOTAL & PC & $\begin{array}{c}\text { Mobile } \\
\text { Phone }\end{array}$ & Tablet & TOTAL \\
\hline $\begin{array}{l}\text { Terminated in } \\
\text { filter question }\end{array}$ & 21 & 29 & & $\mathbf{5 0}$ & $7 \%$ & $12 \%$ & $0 \%$ & $\mathbf{9 \%}$ \\
$\begin{array}{l}\text { Started but did } \\
\text { not concluded }\end{array}$ & 96 & 141 & 4 & $\mathbf{2 4 1}$ & $31 \%$ & $57 \%$ & $57 \%$ & $\mathbf{4 3 \%}$ \\
$\begin{array}{l}\text { Completed full } \\
\text { questionnaire }\end{array}$ & 195 & 78 & 3 & $\mathbf{2 7 6}$ & $62 \%$ & $31 \%$ & $43 \%$ & $\underline{\mathbf{4 9 \%}}$ \\
\hline Total & $\mathbf{3 1 2}$ & $\mathbf{2 4 8}$ & $\mathbf{7}$ & $\mathbf{5 6 7}$ & $\mathbf{5 5 \%}$ & $\mathbf{4 4 \%}$ & $\mathbf{1 \%}$ & $\mathbf{1 0 0 \%}$ \\
\hline
\end{tabular}

Source: QuestionPro

Total of 1,416 LinkedIn sponsored inmails were sent, 1,103 were opened, and 363 individuals clicked on the survey link. In addition to the sponsored inmails (which are charged by LinkedIn), this author also activated the own professional network (free of charge) reaching 790 people. Table 24 summarizes these metrics. For more details, - message and incentive communicated, campaign details, audience demographics -, refer to Appendix III.

Table 24 - Data collection metrics via LinkedIn

\begin{tabular}{llll}
\multicolumn{1}{c}{ Type } & \multicolumn{1}{c}{ Metric } & \multicolumn{1}{c}{ Absolute Volume } & \multicolumn{1}{c}{ \% Rate } \\
\hline LinkedIn Campaign & Sends & 1,416 Sponsored in-mails & \\
\hline LinkedIn Campaign & Opens & 1,103 opened in-mails & $77.9 \%$ open rate \\
\hline LinkedIn Campaign & Clicks & 363 clicks to survey link & 32.9 click through rate \\
\hline LinkedIn Personal Network & Impressions & 790 views & \\
\hline
\end{tabular}

Source: LinkedIn Ad Performance Report and Personal LinkedIn Account

\section{Profile of respondents}

All recipients of the questionnaire had to answer the filter question related to the level of knowledge or experience with Design Thinking. Table 25 summarizes the distribution of these answers, summing up the 251 valid respondents of this survey.

Table 25 - Respondents' knowledge and experience with Design Thinking

\begin{tabular}{lcc}
\hline \multicolumn{1}{c}{ EXCLUDED IN THE FILTER } & \# of Respondents & Distribution \% \\
\hline $\begin{array}{l}\text { I don't know what Design Thinking is } \\
\text { VALID RESPONDENTS }\end{array}$ & 16 & 34 \\
\hline I just heard about Design Thinking & 44 & $18 \%$ \\
\hline I read books/articles and/or watched videos about Design Thinking & 71 & $28 \%$ \\
\hline I took or I am taking a course about Design Thinking & 79 & $31 \%$ \\
\hline I did or I am doing a project that utilizes Design Thinking & 57 & $23 \%$ \\
\hline My job utilizes Design Thinking regularly & $\mathbf{2 5 1}$ & $\mathbf{1 0 0 \%}$ \\
\hline
\end{tabular}

Source: prepared by the author. Data collected via QuestionPro. 
Demographically, $54 \%$ of respondents were male and $46 \%$ female, and half of the sample (51\%) were aged between 25 and 34 years old. In terms of education, Design and/or architecture presented the higher penetration in the sample, followed by Human Sciences (exclusion of Business Administration) and Engineering. Regarding job roles, 29\% had declared activities in the design field, followed by Marketing/Sales/Public Relations (24\%) and Information Technology (15\%). Table 26 presents these results.

Table 26 - Profile or respondents

\begin{tabular}{|c|c|c|c|}
\hline & & \# of Respondents & Distribution \% \\
\hline \multirow[t]{2}{*}{ SEX } & Male & 136 & $54 \%$ \\
\hline & Female & 115 & $46 \%$ \\
\hline \multirow[t]{5}{*}{ AGE RANGE } & 19 - 24 years old & 41 & $16 \%$ \\
\hline & $25-29$ years old & 65 & $26 \%$ \\
\hline & 30 - 34 years old & 62 & $25 \%$ \\
\hline & 35 - 39 years old & 40 & $16 \%$ \\
\hline & Over 40 years old & 43 & $17 \%$ \\
\hline \multirow[t]{8}{*}{ EDUCATION } & Design and/or Architecture & 64 & $25 \%$ \\
\hline & Human Sciences (excluding Business Administr.) & 48 & $19 \%$ \\
\hline & Engineering & 42 & $17 \%$ \\
\hline & Business Administration & 35 & $14 \%$ \\
\hline & Exact Sciences (excluding Engineering) & 35 & $14 \%$ \\
\hline & Other not mentioned above & 19 & $8 \%$ \\
\hline & Arts & 5 & $2 \%$ \\
\hline & Biological Sciences & 3 & $1 \%$ \\
\hline \multirow[t]{8}{*}{ JOB ROLE } & $\begin{array}{l}\text { Design / Graphic Design / UI Design / UX Design / } \\
\text { Service Design }\end{array}$ & 74 & $29 \%$ \\
\hline & Marketing / Sales / Public Relations & 61 & $24 \%$ \\
\hline & Information Technology & 37 & $15 \%$ \\
\hline & Operations & 21 & $8 \%$ \\
\hline & Research and Development (R\&D) & 12 & $5 \%$ \\
\hline & Human Resources & 4 & $2 \%$ \\
\hline & Finance / Accounting / Controller & 4 & $2 \%$ \\
\hline & Other & 38 & $15 \%$ \\
\hline
\end{tabular}

Source: prepared by the author. Data collected via QuestionPro. 


\subsubsection{Data analysis and interpretation}

\section{Procedures}

The quantitative data analysis procedures adopted in this dissertation are based on the steps proposed by Creswell (2013): report sample information, deliver descriptive analysis, identity the statistical procedure, identify the statistical software, report data analysis and interpretation, and discuss the implications. A summary of steps are presented in the Table 27.

The report about sampling design, sample size, data collection, response rates and profile of respondents were previously presented and discussed in previous sub-sessions.

Table 27 - Quantitative data analysis and interpretation steps

\begin{tabular}{ll}
\hline \multicolumn{1}{c}{ Steps } & \multicolumn{1}{c}{ Description } \\
\hline $\begin{array}{l}\text { Step 1 - Report Sample } \\
\text { Information }\end{array}$ & $\begin{array}{l}\text { Report number of members of the sample who did and did not return the } \\
\text { survey. A table with numbers and percentages describing respondents and } \\
\text { non-respondents will present this information. }\end{array}$ \\
$\begin{array}{l}\text { Step 2 - Deliver descriptive } \\
\text { analysis }\end{array}$ & $\begin{array}{l}\text { Provide a descriptive data analysis for all variables in the study, indicating the } \\
\text { means, standard deviations, and range of scores for these variables. }\end{array}$ \\
$\begin{array}{l}\text { Step 3 - Identify the } \\
\text { statistical procedure }\end{array}$ & Define the statistical procedure to accomplish data analysis and interpretation. \\
$\begin{array}{l}\text { Step 4 - Identify the } \\
\text { statistical software }\end{array}$ & $\begin{array}{l}\text { Define the statistical software for testing research questions of the proposed } \\
\text { study. Explanation must be provided on the choice of statistical test and the } \\
\text { assumptions associated with the statistic. }\end{array}$ \\
$\begin{array}{l}\text { Step 5 - Report data analysis } \\
\text { and interpretation }\end{array}$ & $\begin{array}{l}\text { Report data on tables or figures, providing interpretation of the results from } \\
\text { the statistical test. }\end{array}$ \\
$\begin{array}{l}\text { Step 6 - Discuss the } \\
\text { implications }\end{array}$ & $\begin{array}{l}\text { Discuss the results and its implications for practice or for future research. } \\
\text { Inferences and conclusions to be reported. }\end{array}$ \\
\hline
\end{tabular}

Source: Adapted from Creswell (2013, p. 209)

The descriptive data analysis is presented accordingly to each specific objective, in the chapter four of this dissertation. In that chapter, detailed descriptive analysis are discussed for the understanding of Design Thinking, the measurement of thinking styles, the measurement of individual's Readiness for adoption of Design Thinking and for the association between thinking styles and individual's Readiness. The sub-sessions start with a descriptive analysis before moving to inferential statistical analysis. Descriptive statistics is the data analysis to describe, demonstrate or summarize patterns emerging from the collected data and to develop hypothesis to be later tested via statistical techniques. It yet does not allow reaching statistically reliable conclusions considering hypothesis previously established. It is simply a description of the data.

Inferential statistics are techniques conducted to achieve generalizations about a population, based on defined samples. By nature, sampling includes error and therefore no sample can perfectly represent the population (Cooper \& Schindler, 2011). 


\section{Statistical techniques}

Depending on the type of variables, different statistical techniques can be applied. A useful decision tree for the selection of the appropriate statistical technique for this research is presented in Figure 12. The decision tree starts from defining the type of response variable. The response variable can be measured or observed, and may also be called dependent variable. The response variable of this research is the Readiness-for-change. The variables that affect the dependent variable are named explanatory, predictor or independent variables.

\section{Figure 12 - Decision tree for statistical techniques}

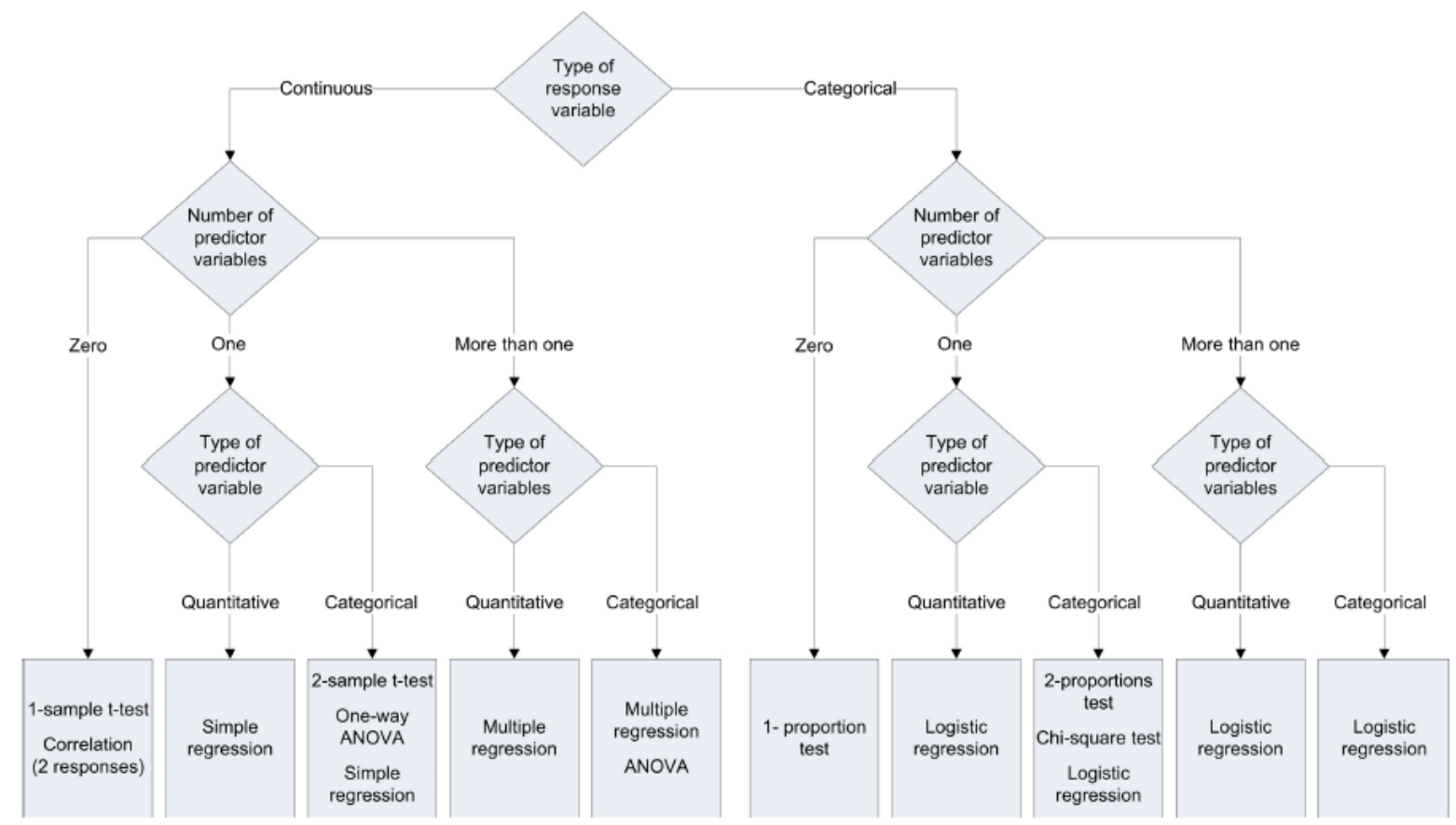

Source: Minitab (2018)

Variables can be continuous or categorical. Continuous variables are numeric variables that have an infinite number of values between any two values, being in the format of numbers, date or time. The obtained score of Readiness to adopt Design Thinking is a continuous variable. Categorical variables contain a finite number of categories or distinct groups, and might not have a logical order. For example, categorical predictors include sex, job role, and education level.

This research considers a number of predictor variables, included in the survey questionnaire, and presented in Table 11. The predictor variables can be either quantitative or categorical. In case of Rationality and Experientiality, its variables are quantitative when the scores are considered; or categorical when terciles groups are utilized.

By following the decision tree, two techniques were chosen for this study: ANOVA (analysis of variance) and Multiple Regression. 
ANOVA demands at least one categorical factor and a continuous response variable. Analysis of variance is the procedure based on variances to define if the means are different between groups. It compares the variance between group means versus the variance within groups to define if the groups have or have not different characteristics. The null hypothesis is that means of two or more groups are equal, while the alternative hypothesis is that at least one group is different (Cooper \& Schindler, 2011).

Creswell (2013) stated that solid results are obtained from extensive description, statistical significance testing and confidence intervals. The statistical significance testing assess if the observed scores reflect a pattern; it is significant if the results did not occur by chance, meaning that the null hypothesis of no differences is rejected. The p-value is an important statistical value for hypothesis tests to accept or reject the null hypothesis. The common cut-off value for the p-value is 0.05 : if $p$-value of a test statistic is lower than 0.05 , the null hypothesis is rejected and there is significant difference. The confidence interval is a range of values that describes the uncertainty level of an observed score, describing how good an estimated score might be. A confidence interval of $95 \%$ indicates that 95 out of 100 times the observed score will fall in the range of values (Minitab, 2018).

This research performed One-way ANOVA to validate the thinking styles terciles and Readiness-for-change terciles, as well for testing the association between thinking styles terciles and the Readiness-for-change score. For these analyses of variance, this dissertation relied on the Tukey's and Fischer's methods, as analyzing via both methods allowed richer conclusions specially in case of existing statistical paradoxes.

These methods provide confidence intervals to determine ranges for the differences and consequently evaluate the significance of the differences. A set of confidence intervals for the difference between pairs of means is displayed via graphs. The indication of significant difference is provided by the differences of confidence intervals that do not contain zero.

Fisher's method generates confidence intervals for all pairwise differences between factor level means while controlling the individual error rate to a significance level one specifies. It applies the individual error rate and number of comparisons to calculate the simultaneous confidence level for all confidence intervals. This simultaneous confidence level is the probability that all confidence intervals contain the true difference.

Tukey's method also generates confidence intervals for all pairwise differences between factor level means while controlling the family error rate to a level someone specifies. Therefore, one of the differences between the two methods refers to the specification of the individual confidence level (Fisher) or simultaneous confidence level (Tukey). 
Individual confidence level refers to the percentage of times that a single confidence interval would include the true difference between one pair of group means if the study were repeated multiple times. Simultaneous confidence level regards the percentage of times that a set of confidence intervals would include the true differences for all group comparisons if the study were repeated multiple times.

Regression analysis is other statistical method that allows examination of the relationship between two or more variables of interest, evaluating the influence of one or more independent variables on a dependent variable (Cooper \& Schindler, 2011). In this research, the predictor variables were included in a multiple regression model to determine which variables had some influence in the Readiness-for-change.

The statistical softwares utilized for this survey were Minitab 17 for the One-way ANOVA and SPSS 17.0 for the Regression Analysis. The report of key data outcomes from the ANOVA and Regression Analysis were included in each relevant session of the Chapter Four - Data Analysis and Discussion of Results. Annexes provide detailed statistical data of the ANOVA procedures.

Finally, presentation and discussion of results were organized in the same chapter of this dissertation, aiming to facilitate the understanding to the reader and to secure coherence between the statistical data outputs and analyses. Conclusions, limitations and recommendations for future researches are presented in the last chapter. 


\section{DATA ANALYSIS AND DISCUSSION OF RESULTS}

This chapter presents data analyses and discusses the results for each specific objective proposed in the introduction of this dissertation. The sessions of this chapter concerns the understanding and knowledge/experience of Design Thinking by the respondents, the measurement of the thinking styles of the respondents, the measurement of the respondents' Readiness for adoption of Design Thinking, and finally the association between thinking styles and individuals' Readiness. Each of these sessions addresses the research model presented in Figure 9, including the analysis of the relations between variables represented in the model by the letters A, B, C e D.

\subsection{UNDERSTANDING, KNOWLEDGE \& EXPERIENCE WITH DESIGN THINKING}

From the literature review, different definitions, characteristics or frameworks for Design Thinking may be found, as discussed in the Chapter Two. From the respondents' perspective, different understandings of Design Thinking may be also identified.

To later support the analysis of Readiness to adopt Design Thinking, this session analyses: a) the understanding of Design Thinking as perceived by the respondents, and b) the respondents' understanding of Design Thinking vs. their knowledge and experience with DT.

\section{Understanding of Design Thinking as perceived by the respondents}

Glen et al. (2014) compared Design Thinking against the rational-analytic approach, as presented in Table 8 of this dissertation. He argued that designers also apply analytic methods, but the differences were made clear when the practice of design was compared with the methods taught in business schools.

However, this survey's data analysis showed that two characteristics of Design Thinking - 'open objectives' and 'based on experience and intuition' (see Table 28) - did not have responses according to Glen et al. (2014)'s framework. Half of respondents had the understanding that DT has well-defined objectives, while Glen et al. formulated that DT is about "goals and constraints uncovered during the Design Thinking process" (p. 658).

More interesting finding regarded the significant portion of respondents (33\%) that understood that Design Thinking is between logic and experience \& intuition (when compared against other questions, no other question had such high percentage in this neutral point of the scale). This understanding finds adherence with Martin (2010), who defended that Design Thinking is a combination of analytical and intuitive skills. 
For the other characteristics of Design Thinking, respondents' understanding was close to expected definitions from Glen et al. (2014). Design Thinking is associated to objective and subjective criteria, iterative method, qualitative approach, visual representation, learn by failing and obtaining partial answers.

Table 28 - Respondents' understanding of Design Thinking

\begin{tabular}{ccccc}
\hline & $\begin{array}{c}\text { Rational- } \\
\text { Analytic } \\
\mathbf{( 1 - 2 )}\end{array}$ & $\mathbf{3}$ & $\begin{array}{c}\text { Design } \\
\text { Thinking } \\
\mathbf{( 4 - 5 )}\end{array}$ & \\
\hline Well-defined objectives & $\underline{\mathbf{5 0 \%}}$ & $7 \%$ & $43 \%$ & Open objectives \\
\hline Objective Criteria & $22 \%$ & $10 \%$ & $68 \%$ & Objective and Subjective Criteria \\
\hline Linear Method & $9 \%$ & $4 \%$ & $87 \%$ & Iterative Method \\
\hline Quantitative Approach & $9 \%$ & $24 \%$ & $67 \%$ & Qualitative Approach \\
\hline Verbal Representation & $7 \%$ & $23 \%$ & $70 \%$ & Visual representation \\
\hline Based on Logic & $17 \%$ & $\underline{\mathbf{3 3 \%}}$ & $\underline{\mathbf{5 1 \%}}$ & Based on experience and \\
intuition
\end{tabular}

Source: question 3 of the questionnaire based on Glen et al. (2014). Sample size: 251.

A closer analysis on the question about Design Thinking being more logical or intuitive (Table 29) demonstrated that the understanding of being based on experience and intuition is actually higher in respondents with job role related to marketing/sales/public relations (54\%) and information technology (51\%) than in design job roles (39\%). By analyzing responses from individuals with job role in Design, there was indication that supports argument that Design Thinking is not only based on experience and intuition, but also based on logic, as $42 \%$ placed Design Thinking as an approach equally based in logic and experience/intuition.

Table 29 - Respondents' understanding of DT solution process by job role

\begin{tabular}{lcccc}
\hline \multicolumn{1}{c}{ Job Role } & $\begin{array}{c}\text { Sample } \\
\text { Size }\end{array}$ & $\begin{array}{c}\text { Based on Logic } \\
\mathbf{( 1 - 2 )}\end{array}$ & $\begin{array}{c}\text { Neutral } \\
\mathbf{( 3 )}\end{array}$ & $\begin{array}{c}\text { Based on } \\
\text { Experience and } \\
\text { Intuition (4-5) }\end{array}$ \\
\hline Marketing / Sales / Public Relations & 61 & $16 \%$ & $\underline{\mathbf{3 0 \%}}$ & $\underline{\mathbf{5 4 \%}}$ \\
\hline $\begin{array}{l}\text { Information Technology (IT) } \\
\begin{array}{l}\text { Design / Graphic Design / UI Design / UX } \\
\text { Design / Service Design }\end{array}\end{array}$ & 74 & $11 \%$ & $38 \%$ & $\underline{\mathbf{5 1 \%}}$ \\
\hline
\end{tabular}

Source: prepared by the author.

For Marketing and Information Technology, Design Thinking is not unfamiliar territory. Indeed, the sample applied for this research collected data from 61 people with job role in Marketing, Sales or Public Relations with knowledge or experience with Design Thinking; just after the largest group of 74 people with job role in areas of Design. In other words, data 
collection demonstrated significant penetration of Design Thinking in the marketing/sales/public relations field.

Glen et al. (2014) discussed the relation between Design Thinking and Marketing. Marketing is also focused on understanding people, on a consumer-oriented bias, but yet Marketing relies on analytic and quantitative methods. He argued that "observing potential users and what they are trying to get done in their lives can provide better insights than conventional market research" (p. 662), which is deployed by Design Thinking.

Regarding Information Technology (IT) and Design Thinking, Glen et al. (2014) stated that the reliance on rational-logical planning has proved to be insufficient. IT started adopting more user-centered approaches, including the 'agile software' movement and Scrum methodology. These approaches are also iterative, user-centered, collaborative, fast in responses to new requirements and feedbacks - characteristics in resonance with Design Thinking principles.

\section{Respondents' understanding and knowledge/experience with Design Thinking (A)}

The level of knowledge and experience with Design Thinking was captured in the filter question of the survey. By aggregating two answers to be categorized as 'conceptual knowledge in Design Thinking' and other two answers as 'practical experience in Design Thinking', the Table 30 shows, as expected, that respondents with job role in Design areas presented higher practical experience than respondents in Marketing/sales/public relations and in Information Technology. However, it is worthy noting that more than half of respondents in these job roles (marketing or IT) already had practical experience with Design Thinking, considering its relatively newness in organizations.

Table 30 - Respondents' knowledge and experience with DT by job role

\begin{tabular}{|c|c|c|c|c|c|}
\hline & & $\begin{array}{l}\text { Total } \\
\text { Sample }\end{array}$ & $\begin{array}{l}\text { Marketing / } \\
\text { Sales / PR } \mathbf{1}\end{array}$ & $\begin{array}{l}\text { Information } \\
\text { Technology }\end{array}$ & $\begin{array}{l}\text { Design } \\
\text { areas }^{3}\end{array}$ \\
\hline 3 & $\begin{array}{l}\text { I read books/articles and/or watched videos } \\
\text { about Design Thinking (answer option 3) }\end{array}$ & $18 \%$ & $20 \%$ & $19 \%$ & $19 \%$ \\
\hline 4 & $\begin{array}{l}\text { I took or I am taking a course about Design } \\
\text { Thinking (answer option } 4 \text { ) }\end{array}$ & $28 \%$ & $28 \%$ & $30 \%$ & $20 \%$ \\
\hline 5 & $\begin{array}{l}\text { I did or I am doing a project that utilizes } \\
\text { Design Thinking (answer option 5) }\end{array}$ & $31 \%$ & $39 \%$ & $41 \%$ & $18 \%$ \\
\hline \multirow[t]{3}{*}{6} & $\begin{array}{l}\text { My job utilizes Design Thinking regularly } \\
\text { (answer option 6) }\end{array}$ & $23 \%$ & $13 \%$ & $11 \%$ & $43 \%$ \\
\hline & (Answers 3+4) Conceptual knowledge & $46 \%$ & $48 \%$ & $49 \%$ & $39 \%$ \\
\hline & (Answers 5+6) Practical experience & $54 \%$ & $52 \%$ & $51 \%$ & $\underline{61 \%}$ \\
\hline
\end{tabular}

Source: prepared by the author. Filter question of the survey. Sample sizes: $61^{1}, 3^{2}, 74^{3}$.

${ }^{3}$ Design areas $=$ Design / Graphic Design / UI Design / UX Design / Service Design 
When analyzing the respondents' knowledge and experience with Design Thinking versus their understanding of Design Thinking (regarding the question if based on logic vs. based on experience and intuition), Table 31 demonstrates that respondents with practical experience understood that Design Thinking is less based in logic (11\% vs. 23\%).

Table 31 - Respondents' understanding and knowledge/experience with DT

\begin{tabular}{llccc}
\hline & Based on Logic & (1-2) & $\begin{array}{c}\text { Neutral } \\
(\mathbf{3})\end{array}$ & $\begin{array}{c}\text { Based on } \\
\text { Experience and } \\
\text { Intuition (4-5) }\end{array}$ \\
\hline $\begin{array}{l}\text { I read books/articles and/or watched videos } \\
\text { about Design Thinking (answer option 3) }\end{array}$ & $27 \%$ & $30 \%$ & $43 \%$ & $100 \%$ \\
\hline $\begin{array}{l}\text { I took or I am taking a course about Design } \\
\text { Thinking (answer option 4) }\end{array}$ & $21 \%$ & $28 \%$ & $51 \%$ & $100 \%$ \\
\hline $\begin{array}{l}\text { I did or I am doing a project that utilizes Design } \\
\text { Thinking (answer option 5) }\end{array}$ & $9 \%$ & $37 \%$ & $54 \%$ & $100 \%$ \\
\hline $\begin{array}{l}\text { My job utilizes Design Thinking regularly } \\
\text { (answer option 6) }\end{array}$ & $14 \%$ & $35 \%$ & $51 \%$ & $100 \%$ \\
\hline $\begin{array}{l}\text { (Answers 3+4) Conceptual knowledge } \\
\text { (Answers 5+6) Practical experience }\end{array}$ & $\mathbf{2 3 \%}$ & $\mathbf{2 9 \%}$ & $\mathbf{4 8 \%}$ & $100 \%$ \\
\hline
\end{tabular}

Source: prepared by the author.

In summary, the analyses of respondents' understanding of Design Thinking raised important insights for the further discussion of association between thinking styles and Readiness to adopt Design Thinking. From the total sample, it called attention that $33 \%$ of respondents positioned Design Thinking as an equal balance of logic and experience/intuition (Table 28). When analyzed in more details, this balanced understanding (logic and intuition) was higher in respondents with practical experience with Design Thinking (36\%, see Table 31). Moving deeper, individuals with job role in design reported $42 \%$ for this question of balance between logic and intuition (Table 29). Not surprisingly, respondents with job role in design were the ones with higher percentage of practical experience $(61 \%$ vs. $52 \%$ in Marketing, see Table 30).

This dissertation introduced a preliminary hypothesis that high experiential individuals would have higher Readiness for adoption of Design Thinking, taken the assumption that people tend to easier embrace what they are already familiar with, in the context that Design Thinking would be understood as highly based on experience and intuition. However, this session's findings presented evidences that practitioners may also perceive Design Thinking as a combination of both analytics and intuition, aligning with some authors from the literature review. 


\subsection{MEASUREMENT OF THINKING STYLES}

The second specific objective regards the measurement of the thinking styles of the individuals from the selected sample, as necessary step to later analyze the association between Rationality and Experientiality with Readiness for adoption of Design Thinking.

\section{Rationality and Experientiality scores}

The revised version of the Rationality-Experientiality Inventory (REI) by Pacini \& Epstein (1999) deployed a balanced number of items per scale and balanced number of items worded positively and negatively, allowing the scales to achieve more parallel content. The authors conducted their study with Psychologist's undergraduate students, data was collected from 399 respondents (315 women, 75 men, 9 without sex identification) and the obtained scores for Rationality and Experientiality were 3.39 and 3.52, respectively.

Sladek, Bond \& Phillips (2010) also applied the revised REI scale (Pacini \& Epstein, $1999)$ to 520 healthcare students and professionals $(62 \%$ men). The researchers aimed to analyze age and sex differences in preferences for rational and experiential thinking. The average Rationality score obtained was 3.9 and the average Experientiality score was 3.2.

From the data collection for this dissertation $(n=251,115$ women, 136 men), it was observed the average Rationality score of 4.04 and the average Experientiality score of 3.34, as shown in Figure 13 and Figure 14.

Figure 13 - Histogram of Rationality score

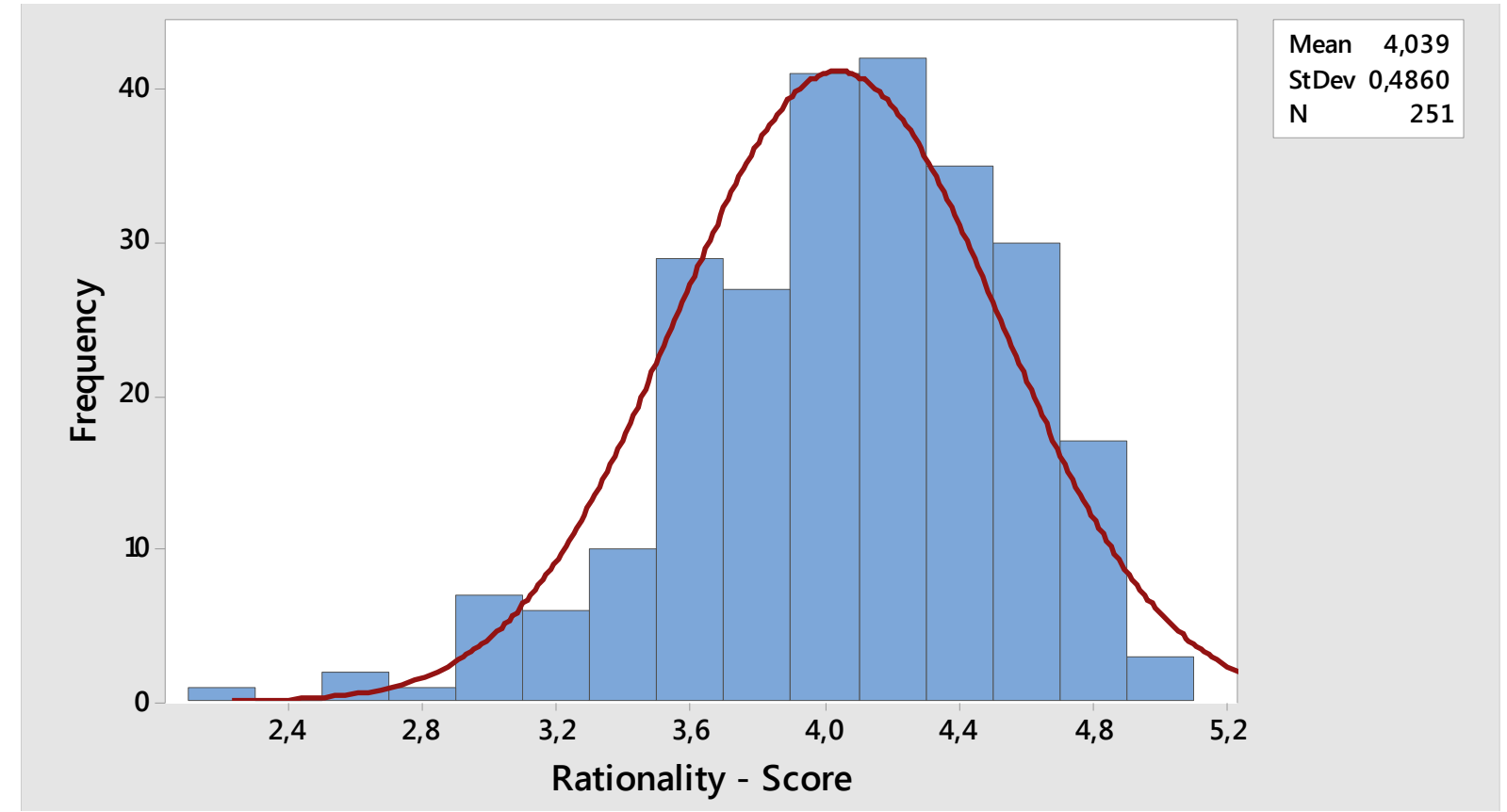

Source: Prepared by the author (Minitab 18) 
Figure 14 - Histogram of Experientiality score

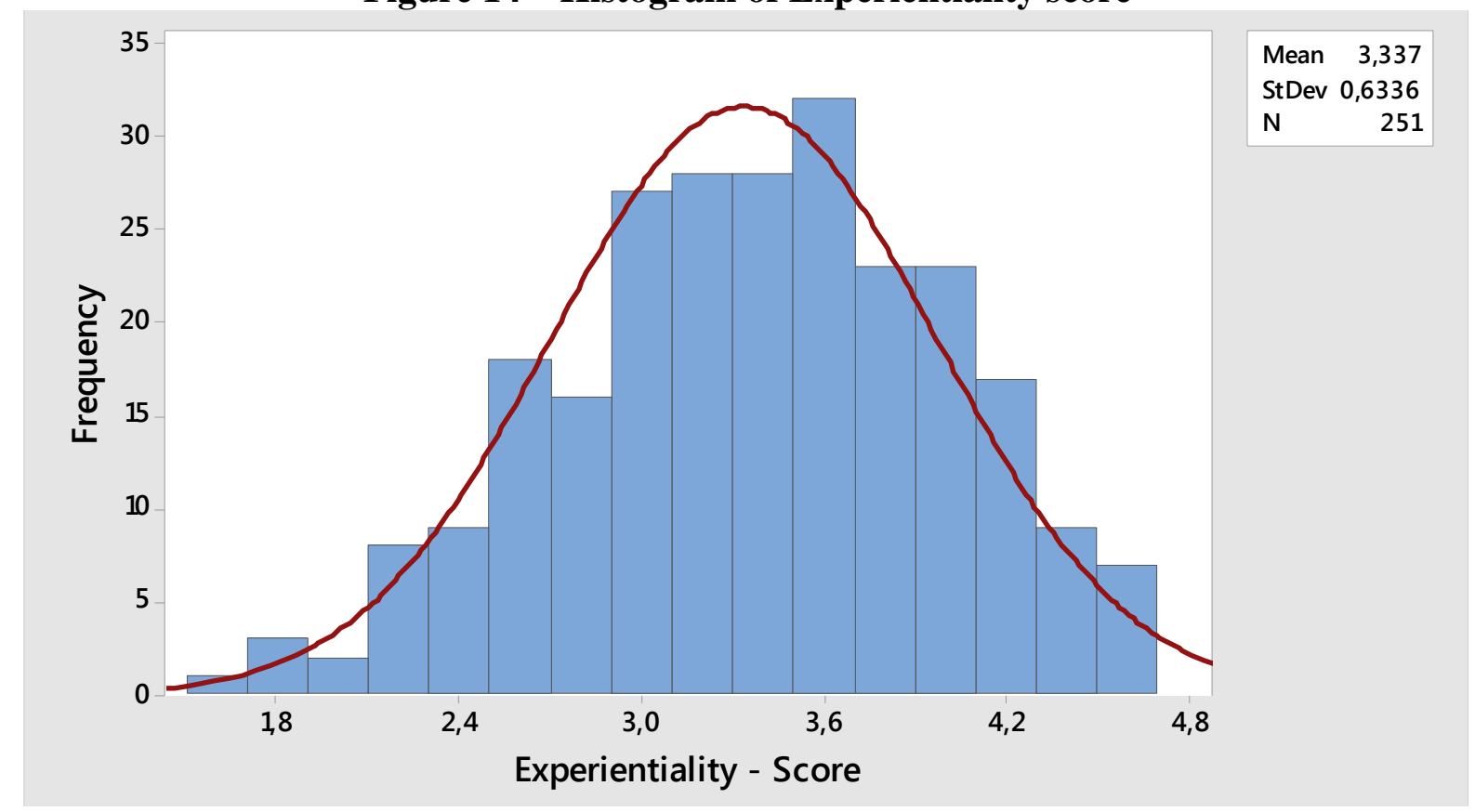

Source: Prepared by the author (Minitab 18)

The analysis by sex provided clarification on why the scores were different between Pacini \& Epstein (1999) study and this survey. First of all, Pacini \& Epstein's sample presented a large majority of women. When score was segmented by men and women, men presented higher Rationality score and women presented higher Experientiality, in both studies (see Table 32 and Table 33). Pacini \& Epstein (1999, p. 985) addressed this observation in their paper: "the findings in the present investigation revealed that men view themselves as having greater rational ability than do women, and women view themselves as valuing and engaging in experiential processing more than do men”. Sladek, Bond \& Phillips (2010) studied gender effects in REI scores and achieved same conclusion about men and women's scores. From Table 33, the percentage difference on Rationality between men and women was 4\% (4.12/3.95); from Table 32, the same calculated difference was 5\% (3.54/3.36). For Experientiality, the differences were $-6 \%$ (3.25/3.44) in Table 33 and $-7 \%$ (3.33/3.57) in Table 32. In summary, the differences were consistent between the studies.

Additionally, this significant larger gap between Rationality and Experientiality scores can be explained not only by the sex proportion but also from the profile of the respondents. While Pacini \& Epstein's survey was conducted with Psychology's undergraduate students, this survey included not only individuals from the Human Sciences, but also Engineering, Business Administration and Architecture (see Table 25) - all fields that require higher abilities in mathematics and analytical thinking. 


\begin{tabular}{lcc|cccc}
\hline & \multicolumn{2}{c}{ Total Sample } & \multicolumn{3}{c}{ Men } & \multicolumn{2}{c}{ Women } \\
\hline REI Scale & Mean & SD & Mean & SD & Mean & SD \\
\hline Rationality & 3.39 & 0.61 & $\mathbf{3 . 5 4}$ & 0.54 & 3.36 & 0.63 \\
\multicolumn{1}{c}{ Ability } & 3.34 & 0.66 & $\mathbf{3 . 5 4}$ & 0.60 & 3.29 & 0.67 \\
Engagement & 3.44 & 0.67 & $\mathbf{3 . 5 5}$ & 0.60 & 3.42 & 0.69 \\
Experientiality & 3.52 & 0.47 & 3.33 & 0.44 & $\mathbf{3 . 5 7}$ & 0.46 \\
Ability & 3.49 & 0.54 & 3.35 & 0.53 & $\mathbf{3 . 5 3}$ & 0.53 \\
Engagement & 3.55 & 0.51 & 3.31 & 0.51 & $\mathbf{3 . 6 1}$ & 0.50 \\
\hline
\end{tabular}

Source: Pacini \& Epstein (1999, p. 979). Note: $N=399$. For men, $n=75$; for women, $n=315$.

Table 33 - REI scores by gender (this survey's respondents)

\begin{tabular}{lcc|ccccc}
\hline & \multicolumn{2}{c}{ Total Sample } & \multicolumn{3}{c}{ Men } & \multicolumn{3}{c}{ Women } \\
\hline REI Scale & Mean & SD & Mean & SD & Mean & SD \\
Rationality & 4.04 & 0.49 & $\mathbf{4 . 1 2}$ & 0.45 & 3.95 & 0.51 \\
\multicolumn{1}{c}{ Ability } & 3.92 & 0.60 & $\mathbf{4 . 0 0}$ & 0.56 & 3.82 & 0.63 \\
Engagement & 4.16 & 0.51 & $\mathbf{4 . 2 4}$ & 0.47 & 4.07 & 0.54 \\
Experientiality & 3.34 & 0.63 & 3.25 & 0.61 & $\mathbf{3 . 4 4}$ & 0.64 \\
Ability & 3.38 & 0.64 & 3.26 & 0.62 & $\mathbf{3 . 5 3}$ & 0.63 \\
Engagement & 3.29 & 0.73 & 3.24 & 0.70 & $\mathbf{3 . 3 6}$ & 0.76 \\
\hline
\end{tabular}

Source: prepared by the author. Note: $N=251$. For men, $n=136$; for women, $n=115$.

From the above comparisons with other studies, the measurements of thinking styles achieved in this survey were in line with other researches applying REI.

As average scores of Rationality and Experientiality from different studies could not be a useful reference to discriminate individuals with high and low Rationality and Experientiality, terciles were applied to define groups and eliminate any issue or concern with the scale calibration among studies. See this survey's distribution of scores in Figure 15.

Figure 15 - Scatter plot for Rationality and Experientiality

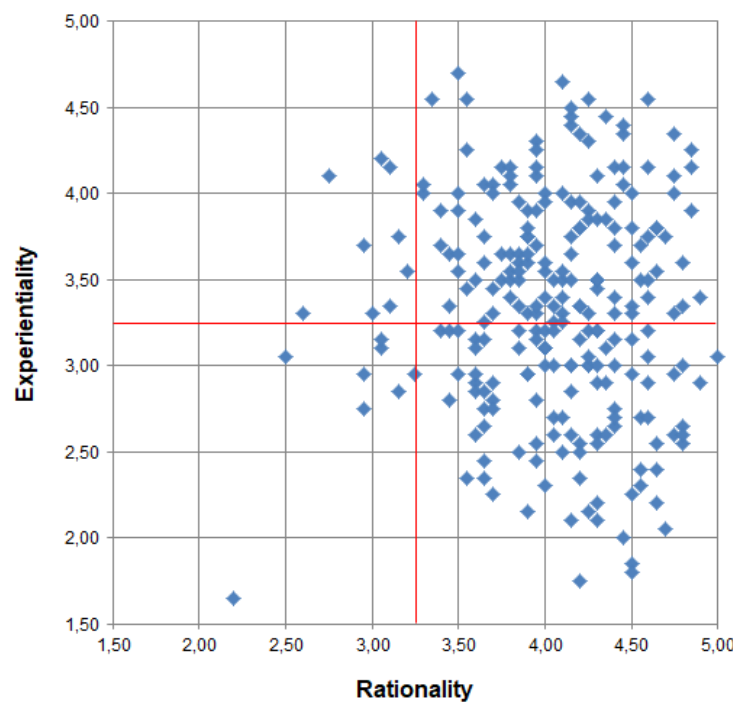




\section{Scores by terciles}

Aiming to secure fair comparison between Rationality and Experientiality, each thinking style's score was categorized in terciles. By adopting terciles, data analysis was underpinned by groups of high, mid and low scores, as presented in Table 34. For Rationality, terciles were distributed in the portions of $33 \%, 33 \%$ and $34 \%$ for R-T1, R-T2 and R-T3, respectively. For Experientiality, the distribution was established as 33\%, 32\% and 34\% for E-T1, E-T2 and E-T3, respectively. The minimum and maximum values of each terciles are also presented in the table, given the 5-point scale developed by Pacini \& Epstein (1999).

Table 34 - Description of terciles: Rationality and Experientiality

\begin{tabular}{cccccc}
\hline & $\begin{array}{c}\text { \# of } \\
\text { Respondents }\end{array}$ & Distribution & $\begin{array}{c}\text { Average } \\
\text { Score }\end{array}$ & $\begin{array}{c}\text { Minimum } \\
\text { Value }\end{array}$ & $\begin{array}{c}\text { Maximum } \\
\text { Value }\end{array}$ \\
\hline RATIONALITY & $\mathbf{2 5 1}$ & & $\mathbf{4 . 0 4}$ & $\mathbf{2 . 2 0}$ & $\mathbf{5 . 0 0}$ \\
\hline Tercile 1 (R-T1) & 83 & $33 \%$ & 3.49 & 2.20 & 3.85 \\
Tercile 2 (R-T2) & 83 & $33 \%$ & 4.07 & 3.90 & 4.25 \\
\hline Tercile 3 (R-T3) & 85 & $34 \%$ & 4.54 & 4.30 & 5.00 \\
\hline EXPERIENTIALITY & $\mathbf{2 5 1}$ & & $\mathbf{3 . 3 4}$ & $\mathbf{1 . 6 5}$ & $\mathbf{4 . 7 0}$ \\
\hline Tercile 1 (E-T1) & 84 & $33 \%$ & 2.63 & 1.65 & 3.05 \\
Tercile 2 (E-T2) & 81 & $32 \%$ & 3.35 & 3.10 & 3.60 \\
\hline Tercile 3 (E-T3) & 86 & $34 \%$ & 4.02 & 3.65 & 4.70 \\
\hline
\end{tabular}

Source: prepared by the author

Analysis of Variance (ANOVA) was executed to test that each tercile was statistically different from each other. To define if differences between the means are statistically significant, the p-value was compared to the significance level to assess the null hypothesis (null hypothesis: population means are all equal).

The adopted significance level $(\alpha)$ is 0.05 , meaning that there is a $5 \%$ risk of concluding that a difference exists when there is no actual difference. If P-value $\leq \alpha$, the differences between means are statistically significant. If P-value $>\alpha$, the differences between means are not statistically significant and there is not enough evidence to reject the null hypothesis (population means are all equal).

The statistical values for the analysis of the Rationality and Experientiality terciles are shown in Figure 16 and Figure 17. Regarding Rationality, the terciles were significantly different from each other, with P-value of 0.000 at $95 \%$ significance level and R-square (adjusted) of $77.44 \%$. 
Figure 16 - One-way ANOVA: Rationality scores vs. Rationality terciles

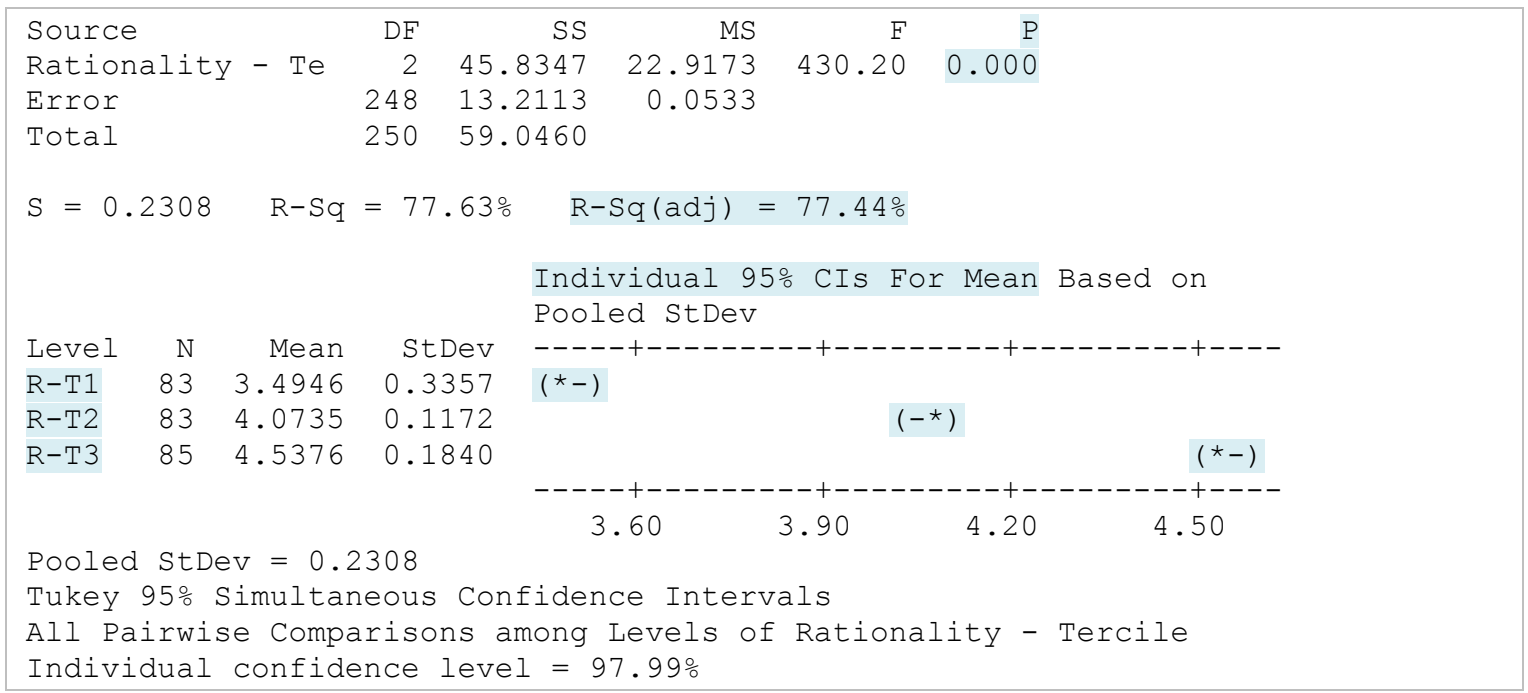

Source: Minitab.

For Experientiality, the terciles were also significantly different from each other. The Pvalue was 0.000 at $95 \%$ significance level and R-square (adjusted) of $81.95 \%$.

Figure 17 - One-way ANOVA: Experientiality scores vs. Experientiality terciles

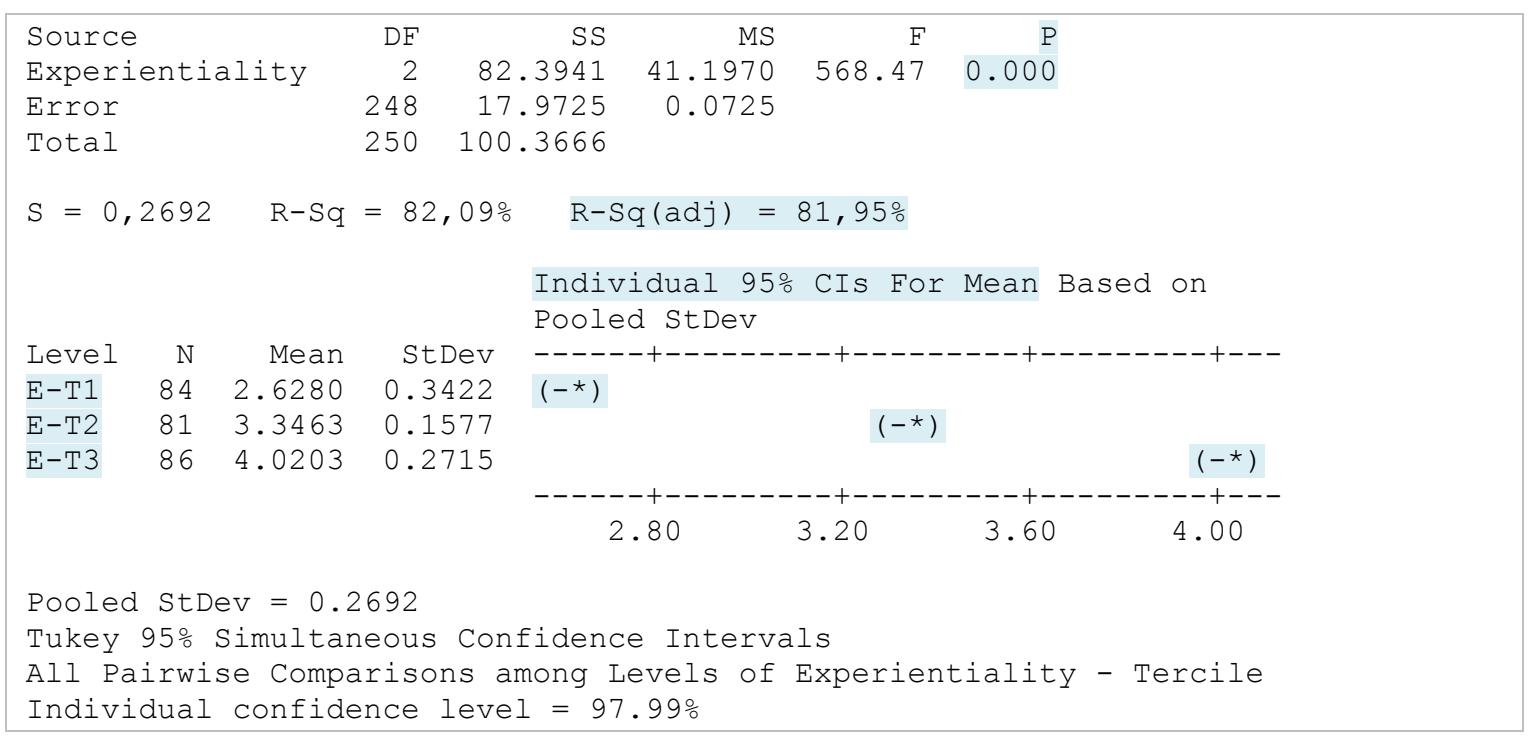

Source: Minitab.

\section{Thinking styles vs. understanding of Design Thinking (B)}

Descriptive analyses were made by crossing thinking styles' terciles with each of the eight perceived characteristics of Design Thinking assigned by the respondents. Regarding the margin of error of 6 percentage points, the first and third Experientiality terciles demonstrated difference regarding the understanding of Design Thinking being based on logic or being based on experience and intuition (see Table 35, figures in bold). 
Table 35 - Respondents' understanding of DT solution process by Thinking Style

\begin{tabular}{|c|c|c|c|c|}
\hline \multicolumn{2}{|r|}{$\begin{array}{c}\text { Based on Logic } \\
\text { (1-2) }\end{array}$} & $\begin{array}{c}\text { Neutral } \\
\text { (3) }\end{array}$ & $\begin{array}{l}\text { Based on Experience } \\
\text { and Intuition (4-5) }\end{array}$ & \multirow{2}{*}{$\sum$} \\
\hline Tercile 1 (R-T1) & $16 \%$ & $29 \%$ & $55 \%$ & \\
\hline Tercile 2 (R-T2) & $18 \%$ & $31 \%$ & $51 \%$ & $100 \%$ \\
\hline Tercile 3 (R-T3) & $16 \%$ & $38 \%$ & $46 \%$ & $100 \%$ \\
\hline Experientiality & $\begin{array}{c}\text { Based on Logic } \\
(1-2)\end{array}$ & $\begin{array}{c}\text { Neutral } \\
\text { (3) }\end{array}$ & $\begin{array}{l}\text { Based on Experience } \\
\text { and Intuition (4-5) }\end{array}$ & \\
\hline Tercile 1 (E-T1) & $\underline{26 \%}$ & $33 \%$ & $\underline{41 \%}$ & $100 \%$ \\
\hline Tercile 2 (E-T2) & $14 \%$ & $31 \%$ & $55 \%$ & $100 \%$ \\
\hline Tercile 3 (E-T3) & $10 \%$ & $34 \%$ & $\underline{56 \%}$ & $100 \%$ \\
\hline
\end{tabular}

Source: prepared by the author. Sample size: 251; Margin of Error: 6pp.

The analysis of Rationality terciles (R-T1, R-T2, R-T3) indicated that the higher the Rationality tercile (and therefore the Rationality score), the lower the percentage of respondents that understood Design Thinking as based on experience and intuition (scale 4 and 5). However, due to six-point margin of error, the percentage difference cannot be considered significant between R-T1 and R-T3.

On the other hand, regarding Experientiality, it is possible to state that the higher the Experientiality (E-T3), the lower the percentage of respondents that understood Design Thinking as being based on logic (scale 1 and 2) and the higher the percentage of respondents that understand Design Thinking as being based on experience and intuition (scale 4 and 5).

Other relevant comparison is between the less rational tercile (R-T1) and the less experiential tercile (E-T1): they presented large difference in percentage responses for 'based on experience and intuition'. 55\% of the less rational tercile understood that DT is based on experience and intuition, while $41 \%$ of the less experiential tercile had the same understanding. It is interesting to note the opposite directions: the more rational the tercile, the lower the understanding of DT being based on experience and intuition; the more experiential the tercile, the higher the understanding of DT being based on experience and intuition.

From above comparisons, there is a different understanding of DT depending on the score of the Experientiality. The higher the Experientiality, the higher the understanding of DT as based on experience and intuition, which aligns with the description of Design Thinking developed by Glen et al. (2014). These pieces of data support one of the initial hypotheses of this dissertation: the higher the intuitive-experiential thinking in a person, the higher his understanding that Design Thinking is based on experience and intuition. 


\subsection{MEASUREMENT OF INDIVIDUAL'S READINESS FOR ADOPTION OF DESIGN THINKING}

The third specific objective regards the measurement of the individuals' Readiness for adoption of Design Thinking. The calculated scores are presented, the establishment of terciles is explained and the relation with characteristics of Design Thinking is discussed.

\section{Individual's Readiness scores}

ROCM's (Readiness for Organizational Change Measure) items have a 7-point scale, scoring from 1 = strongly disagree to 7 = strongly agree, as presented in the Methodology Chapter. At the time of development of the instrument, Holt et al. (2007b) conducted two different waves of the study: the first one occurred six weeks before the implementation of a new organization structure, sample size of 264 employees; the second wave had 156 of the 264 employees responding the abbreviated version seven months later. The obtained scores for appropriateness, management support (not utilized in this dissertation's research), change efficacy and personally beneficial were, respectively, 4.5, 5.3, 5.3 and 4.9 for the first study, and 4.0, 4.9, 4.8 and 4.8 for the second study.

The results of the fieldwork of this dissertation's survey pointed out the Readiness scores for adopting Design Thinking as 5.8, 5.7 and 6.1 for appropriateness, change efficacy and personally beneficial, respectively. The overall Readiness score of 5.8 was calculated from the simple average of all the Readiness-for-change items (see Figure 18).

Figure 18 - Histogram of Readiness score

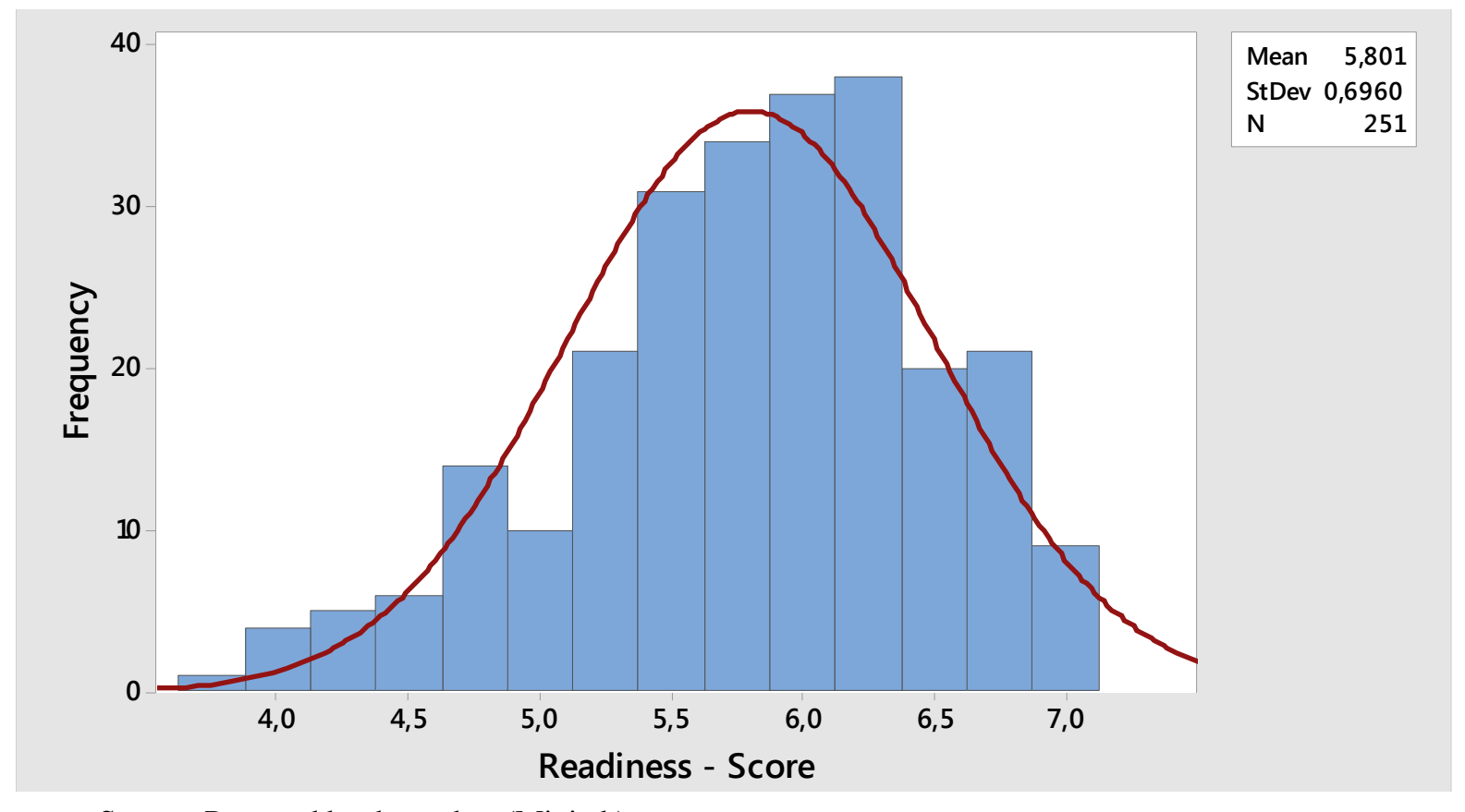

Source: Prepared by the author (Minitab) 
In a relevant note, there would be no meaning comparing Readiness scores from different studies, as the score is related to the situations of change, which differ case by case.

\section{Scores by terciles}

By applying same rationale utilized in the Rationality and Experientiality scores, terciles were calculated for Readiness for Change, aiming to secure a proper analysis of the responses on Readiness for change, by working with similar size groups of high (Rd-T3: 35\%), mid (Rd-T2: 33\%) and low scores (Rd-T1: 32\%), as presented in Table 36. The simple average score for each tercile was 5.00, 5.83 and 6.51 respectively for Rd-T1, Rd-T2 and Rd-T3. The minimum and maximum values of each tercile are described in the table, given the scale of seven points as originally defined by Holt et al. (2007b).

Table 36 - Description of terciles: Readiness for adopting Design Thinking

\begin{tabular}{crcccc}
\hline & \# of Respondents & Average Score & Minimum Value & Maximum Value \\
\hline READINESS & $\mathbf{2 5 1}$ & $\mathbf{5 . 8 0}$ & $\mathbf{3 . 7 4}$ & $\mathbf{7 . 0 0}$ \\
\hline Tercile 1 (Rd-T1) & 81 & $32 \%$ & 5.00 & 3.74 & 5.53 \\
Tercile 2 (Rd-T2) & 82 & $33 \%$ & 5.83 & 5.58 & 6.11 \\
Tercile 3 (Rd-T3) & 88 & $35 \%$ & 6.51 & 6.16 & 7.00 \\
\hline
\end{tabular}

Source: prepared by the author

The statistical differences among terciles were tested by One-way ANOVA, which confirmed that all three terciles had significant difference. The obtained P-value was 0.000 for a 95\% significance level and R-square (adjusted) of 79.84\% (see Figure 19 for the One-way ANOVA statistical values), therefore validating the use of terciles for analysis.

\section{Figure 19 - One-way ANOVA: Readiness scores vs. Readiness terciles}

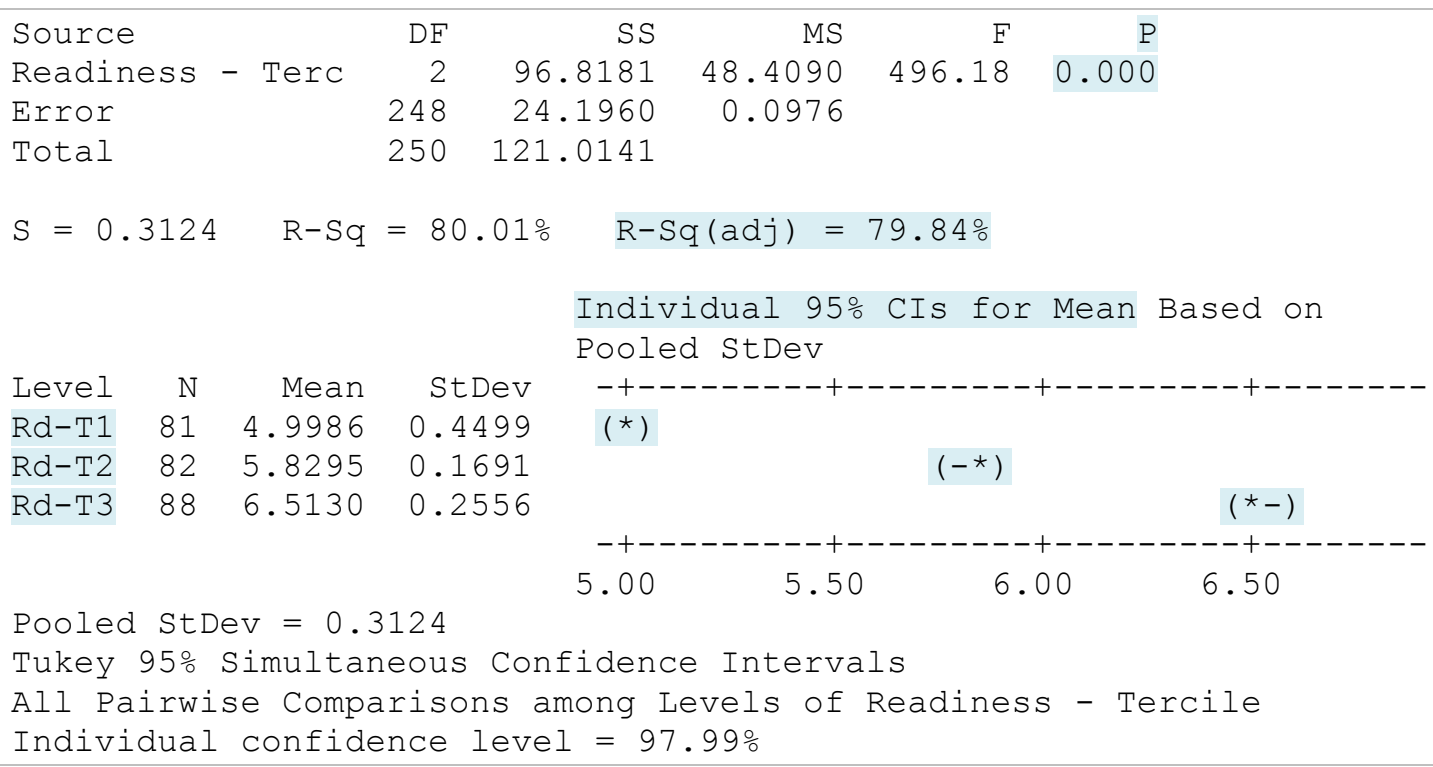

Source: Minitab. 


\section{ANOVA: Individual's Readiness vs. understanding of Design Thinking (C)}

The respondents' understanding of Design Thinking was assessed on the question three of the survey, adapted from the description provided by Glen et al. (2014) and explained in the Methodology Chapter of this dissertation. Each question had a 5-point scale, where only two questions applied a reversed scale. By comparing the responses for each question (regarding understanding of Design Thinking) against the Readiness score, two characteristics presented some distinctive difference when running One-way ANOVA: approach (quantitative vs. qualitative) and outcome (definitive answers and partial answers). The statistical results for P-value, Tukey's and Fisher's significant difference analyses for each of the Design Thinking characteristics versus the Readiness score are summarized in Table 37.

Table 37 - Summary of ANOVA: understanding of DT vs. Readiness scores

\begin{tabular}{|c|c|c|c|c|}
\hline $\begin{array}{l}\text { Readiness Scores vs. } \\
\text { responses of: }\end{array}$ & P-value & Tukey Test & Fisher Test & Conclusion \\
\hline $\begin{array}{r}\text { Well-defined objectives [1] } \\
- \\
\text { Open objectives [5] }\end{array}$ & 0.015 & $\begin{array}{l}4 \neq 5 \\
1=2=3=4 \\
1=2=3=5\end{array}$ & $\begin{array}{l}1 \neq 4,2 \neq 5,4 \neq 5 \\
1=2=3 \\
1=3=5 \\
2=3=4\end{array}$ & $\begin{array}{l}\text { Both suggest statistical } \\
\text { dilemmas } \rightarrow \text { no difference } \\
\text { among groups }\end{array}$ \\
\hline $\begin{array}{r}\text { Objective criteria [1] } \\
- \\
\text { Objective and subjective [5] }\end{array}$ & 0.054 & $\begin{array}{l}4 \neq 5 \\
1=2=3=4 \\
1=2=3=5\end{array}$ & $\begin{array}{l}4 \neq 5 \\
1=2=3=4 \\
1=2=3=5\end{array}$ & $\begin{array}{l}\text { Both suggest statistical } \\
\text { dilemmas } \rightarrow \text { no difference } \\
\text { among groups }\end{array}$ \\
\hline $\begin{array}{r}\text { Iterative method [1] } \\
-\quad \text { (reversed scale) } \\
\text { Linear method [5] }\end{array}$ & 0.000 & $\begin{array}{l}1 \neq 2,1 \neq 4 \\
1=3=4=5 \\
2=3=4=5\end{array}$ & $\begin{array}{l}1 \neq 2,1 \neq 4,4 \neq 5 \\
1=3=5 \\
2=3=4 \\
2=5\end{array}$ & $\begin{array}{l}\text { Both suggest statistical } \\
\text { dilemmas } \rightarrow \text { no difference } \\
\text { among groups }\end{array}$ \\
\hline $\begin{array}{r}\text { Qualitative [1] } \\
-\quad(\text { reversed scale) } \\
\text { Quantitative [5] }\end{array}$ & 0.000 & $\begin{array}{l}1 \neq 2,2 \neq 3,2 \neq 5 \\
1=3=4=5 \\
2=4=5\end{array}$ & $\begin{array}{l}1 \neq 2,2 \neq 3,2 \neq 4, \\
2 \neq 5 \\
1=3=4=5\end{array}$ & $\begin{array}{l}\text { Response } 2 \text { presented } \\
\text { significant difference } \\
\text { among groups }\end{array}$ \\
\hline $\begin{array}{r}\text { Verbal representation [1] } \\
\text { Visual representation [5] }\end{array}$ & 0.290 & $1=2=3=4=5$ & $1=2=3=4=5$ & No difference among groups \\
\hline $\begin{array}{r}\text { Based in logic [1] } \\
\text { Based in exper. and intuit. [5] }\end{array}$ & 0.084 & $1=2=3=4=5$ & $\begin{array}{l}1 \neq 5,4 \neq 5 \\
1=2=3=5 \\
1=2=3=4\end{array}$ & $\begin{array}{l}\text { Following Tukey, no } \\
\text { difference among groups }\end{array}$ \\
\hline $\begin{array}{r}\text { Error reduction [1] } \\
\text { Fail to learn [5] }\end{array}$ & 0.033 & $\begin{array}{l}4 \neq 5 \\
1=2=3=4 \\
1=2=3=5\end{array}$ & $\begin{array}{l}2 \neq 5,4 \neq 5 \\
1=2=3=4 \\
1=2=3=5\end{array}$ & $\begin{array}{l}\text { Both suggest statistical } \\
\text { dilemmas } \rightarrow \text { no difference } \\
\text { among groups }\end{array}$ \\
\hline $\begin{array}{r}\text { Definitive answers [1] } \\
- \\
\text { Partial answers [5] }\end{array}$ & 0.001 & $\begin{array}{l}2 \neq 5,3 \neq 5,4 \neq 5 \\
1=2=3=4 \\
1=5\end{array}$ & $\begin{array}{l}1 \neq 5,2 \neq 5,3 \neq 5, \\
4 \neq 5 \\
1=2=3=4\end{array}$ & $\begin{array}{l}\text { Response } 5 \text { presented } \\
\text { significant difference } \\
\text { among groups }\end{array}$ \\
\hline
\end{tabular}

Source: prepared by the author.

Note: see Appendix VI for detailed statistical data

The significant difference of the response 2 of the 'Qualitative - Quantitative' represented an unexpected statistical result, as response 1 did not have significant difference and the Readiness scores did not present a linear down trend. In Table 38, it is possible to observe that response 5 ('quantitative') presented Readiness score of 6.2 , response 4 and 3 
decreased to 5.9, then response 2 dropped Readiness score to 5.5, but response 1 bounced the score back to 5.9. It would be expected that response 1 presented an equal or lower Readiness score than response 2; in other words, the more someone understands Design Thinking is qualitative, the lower the Readiness score would be. Statistically, it presented significant difference, but conceptually this result was disregarded in the context of this study.

Table 38 - Design Thinking approach and outcome, vs. Readiness scores

\begin{tabular}{|c|c|c|c|c|}
\hline \multirow[b]{3}{*}{ Scale } & \multicolumn{2}{|c|}{ Approach } & \multicolumn{2}{|c|}{ Outcome } \\
\hline & \multicolumn{2}{|c|}{ Qualitative (1) - Quantitative (5) } & \multicolumn{2}{|c|}{ Definitive answers (1) - Partial answers (5) } \\
\hline & $\begin{array}{c}\text { Response } \\
\text { distribution }\end{array}$ & Readiness Score & $\begin{array}{c}\text { Response } \\
\text { distribution }\end{array}$ & Readiness Score \\
\hline 1 & $39 \%$ & 5.9 & $6 \%$ & 5.6 \\
\hline 2 & $27 \%$ & $\underline{5.5}$ & $12 \%$ & 5.7 \\
\hline 3 & $24 \%$ & 5.9 & $24 \%$ & 5.8 \\
\hline 4 & $6 \%$ & 5.9 & $31 \%$ & 5.7 \\
\hline \multirow[t]{2}{*}{5} & $4 \%$ & 6.2 & $27 \%$ & $\underline{6.1}$ \\
\hline & $100 \%$ & 5.8 & $100 \%$ & 5.8 \\
\hline
\end{tabular}

Source: prepared by the author.

Regarding the significant difference of response 5 for 'Definitive answers - Partial answers', this result indicated that individuals with clear understanding that Design Thinking delivers partial answers presented higher score for Readiness (see Table 38).

The Analysis of Variance (ANOVA) demonstrated that there is significant difference for the response 5, for Fisher 95\% significance levels and P-value of 0.001 . The statistical outputs are presented in Figure 20.

Figure 20 - One-way ANOVA: Design Thinking outcome vs. Readiness scores

\begin{tabular}{|c|c|c|c|c|}
\hline Source & & $\mathrm{DF}$ & SS & MS \\
\hline $5-Q 4$ & -8 & 4 & 8.913 & 0.001 \\
\hline Error & & 246 & 112.101 & 0.456 \\
\hline Total & & 250 & 121.014 & \\
\hline \multirow{2}{*}{\multicolumn{2}{|c|}{$S=0.6751$}} & $\mathrm{R}-\mathrm{Sq}$ & $y=7.37 \%$ & $\mathrm{R}-\mathrm{Sq}(\mathrm{adj})=5.86 \%$ \\
\hline & & & & $\begin{array}{l}\text { Individual 95\% CIs For Mean Based on } \\
\text { Pooled StDev }\end{array}$ \\
\hline Level & $\mathrm{N}$ & Mean & StDev & ---------++----------+----------+----------+ \\
\hline 1 & 15 & 5.6073 & 0.6730 & $(------------\star *-------------)$ \\
\hline 2 & 29 & 5.6862 & 0.6338 & $\left(--------{ }^{\star}----------\right)$ \\
\hline 3 & 61 & 5.7579 & 0.7961 & $(-----\star------)$ \\
\hline 4 & 78 & 5.6527 & 0.6658 & $(-----\star-----)$ \\
\hline \multirow[t]{2}{*}{5} & 68 & 6.1015 & 0.5777 & $(-----*------)$ \\
\hline & & & & 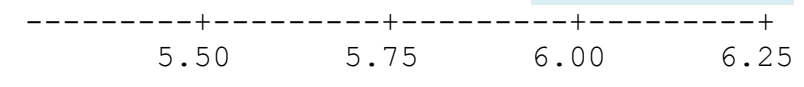 \\
\hline \multicolumn{5}{|c|}{$\begin{array}{l}\text { Fisher 95\% Simultaneous Confidence Intervals } \\
\text { All Pairwise Comparisons among Levels of } 5-24-8 \\
\text { Simultaneous confidence level }=71.91 \%\end{array}$} \\
\hline
\end{tabular}

Source: Minitab. 
The above analyses of Design Thinking characteristics' perceived by respondents and their Readiness to adopt Design Thinking address academic discussions on the challenges of implementation. Rauth, Carlgren, \& Elmquist (2015) argued that managers and co-workers that do not appreciate Design Thinking values - as unexpected directions, learn by failing and interacting with users -, are source of challenge for implementation. Design Thinking can be even perceived as ‘too fun' and hence not serious. Design Thinking may not be appreciated as it encourages failure and exploration (qualitative approach) beyond the existing organizational scope, given the fact that companies are oriented towards failure reduction and efficiency enhancement to increase profitability. Rauth, Carlgren, \& Elmquist (2015) articulated that the resistance against Design Thinking can be higher than faced by Lean method, for example, which is more aligned with a rational and quantitative logic.

Glen et al. (2014) recognized that characteristics of Design Thinking needs to be explained to the business world, moving beyond the discussion of what designers do, in order to be established as a tangible option for the complex and ill-defined problems being faced by organizations. Such explanation, or clarification, is required as Design Thinking studies have demonstrated that designers solve problems dramatically different from businessmen oriented by the traditional rational problem-solving paradigm. Designers do not completely define the problem to then work on the final solutions, as taught in business schools. While the Technical Rationality approach focuses on the problem to identify which solution rule to be applied, designers learn about the problem while developing the solution. And this solution may not even be final, but partial. For designers, there are no right or wrong answers, or true or false conclusions; for organizations, answers are needed so decisions can be made. Individuals working in organizations with strong reliance on the Technical Rationality, expecting to have a final answer, may have lower Readiness for Design Thinking, as it applies a dramatically different approach from the one they are used to.

In a different study, Carlgren, Elmquist, and Rauth (2016) identified challenges for implementing Design Thinking such as "clash of logics and difficulties to achieve mindset change", "fear of failure", "Design Thinking skills are difficult to learn" and "culture clash hard to make Design Thinking fit with a very risk-averse and evidence-based culture" (p. 350351). As noted by these authors, there is typical stress between the logics of design and the rational ways of thinking that are established in many organizations. The Readiness score may be influenced by the individuals' perceived understanding of some Design Thinking characteristics, as discussed in this session. These results provided indication to include these variables in the regression model, modeled in later phase of this data analysis. 


\subsection{ASSOCIATION BETWEEN THINKING STYLES AND INDIVIDUAL'S READINESS (D)}

By accomplishing the specific objectives of discriminating the thinking styles and Readiness-for-change in groups, as well as analyzing how respondents understand Design Thinking, the associations between thinking styles and Readiness-for-change are now analyzed in this session. The statistical analyses are firstly presented, followed by the discussions.

\section{Rationality and Experientiality terciles vs. Readiness scores}

For each tercile of Rationality and Experientiality, the Readiness-for-change average score was calculated. For Rationality, it is observed that the Readiness score increases by tercile (R-T1: 5.59, R-T2: 5.79, R-T3: 6.02). For Experientiality, same pattern was not observed, as the Readiness average decreased in the second tercile (E-T2) to then increase in the third tercile (E-T3). Table 39 organizes these results.

Table 39 - Rationality and Experientiality terciles vs. Readiness scores

\begin{tabular}{lcccc}
\hline & \# of Respondents & Lower Bound & $\begin{array}{c}\text { Average of } \\
\text { Readiness Score }\end{array}$ & Upper Bound \\
\hline RATIONALITY & 83 & & & 5.74 \\
\hline R-T1 & 83 & 5.44 & $\mathbf{5 . 5 9}$ & 5.93 \\
\hline R-T2 & 85 & 5.65 & $\mathbf{5 . 7 9}$ & 6.17 \\
\hline R-T3 & & 5.87 & $\mathbf{6 . 0 2}$ & 6.04 \\
\hline EXPERIENTIALITY & 84 & & & 5.70 \\
\hline E-T1 & 81 & 5.72 & $\mathbf{5 . 8 8}$ & 6.09 \\
\hline E-T2 & 86 & 5.40 & $\mathbf{5 . 5 5}$ & $\mathbf{5 . 9 6}$ \\
\hline E-T3 & 5.83 & & \\
\hline
\end{tabular}

Source: prepared by the author

Analysis was also made by combining Rationality and Experientiality against the average Readiness Score. Table 40 (next page) is organized by terciles of Rationality and terciles of Experientiality. The third column indicates the number of respondents by combination of terciles, having the total sum of 251 respondents. The portion column sums $100 \%$. The last column is the average score of Readiness calculated for each of the nine combined groups of terciles.

Respondents in the third tercile of Rationality (R-T3) and also of Experientiality (E-T3) had the highest averaged score for Readiness (6.14). If Design Thinking utilizes both sides of the brain - rational and intuition - as described by some authors in the academic literature, the 
presented results help supporting the proposition that respondents with high score on both REI scales are expected to have higher Readiness for adopting Design Thinking.

Table 40 - Combination of Rationality and Experientiality terciles vs. Readiness scores

\begin{tabular}{ccccc}
\hline Rationality & Experientiality & \# of Respondents & Portion \% & $\begin{array}{c}\text { Readiness Average } \\
\text { Score }\end{array}$ \\
\hline \multirow{3}{*}{ R-T1 } & E-T1 & 23 & $9 \%$ & $\mathbf{5 . 4 4}$ \\
& E-T2 & 30 & $12 \%$ & $\mathbf{5 . 4 3}$ \\
\multirow{2}{*}{ R-T2 } & E-T3 & 30 & $12 \%$ & $\mathbf{5 . 8 6}$ \\
& E-T1 & 26 & $10 \%$ & $\mathbf{5 . 9 9}$ \\
& E-T2 & 28 & $11 \%$ & $\mathbf{5 . 4 8}$ \\
\multirow{2}{*}{ R-T3 } & E-T3 & 29 & $12 \%$ & $\mathbf{5 . 9 0}$ \\
& E-T1 & 35 & $14 \%$ & $\mathbf{6 . 0 9}$ \\
& E-T2 & 23 & $9 \%$ & $\mathbf{5 . 7 8}$ \\
\hline
\end{tabular}

Source: prepared by the author

The graphical visualization of these terciles' combinations allowed some additional analysis. Figure 21 presents a boxplot on the left and a 2-D line graph with a trend line on the right. The horizontal axis is organized by Rationality terciles and then by Experientiality terciles. The vertical axis shows the Readiness score. A U-shape pattern can be seen in each Rationality tercile, as a reflection of the results presented in the Table 40: the higher the Rationality, the higher the Readiness score; for Experientiality, the first and third terciles present higher Readiness score.

Figure 21 - Rationality and Experientiality terciles vs. Readiness scores
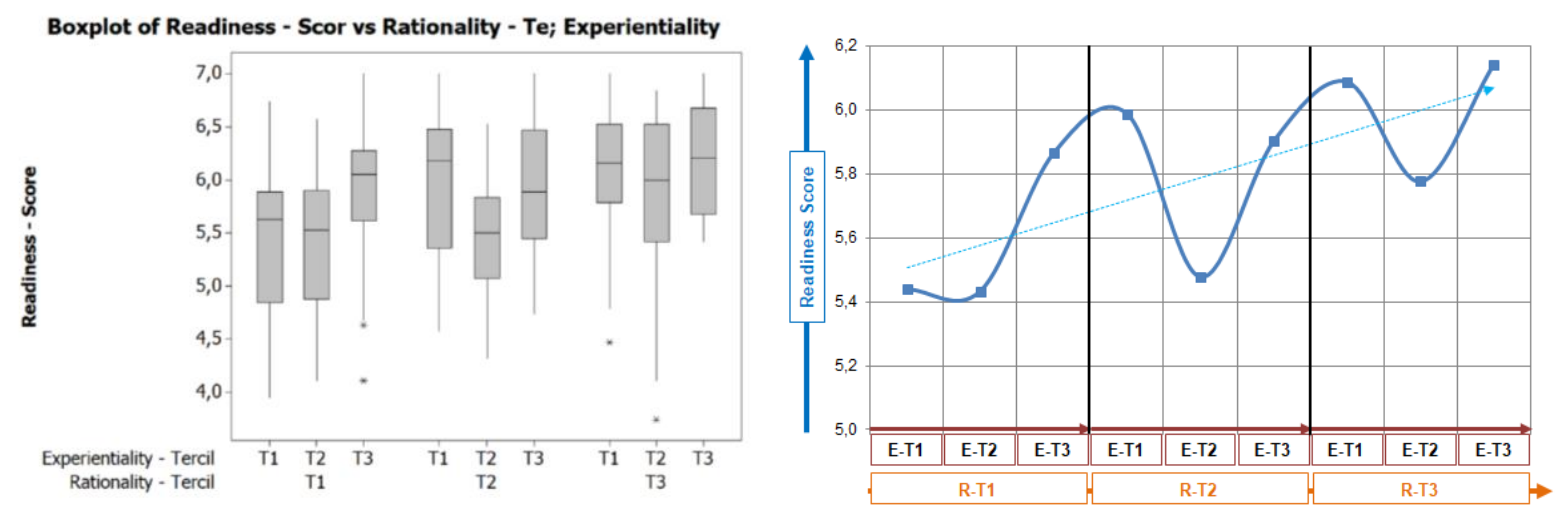

Source: prepared by the author

By swapping the variables in the horizontal axis, a new graphical visualization provided additional insights. In Figure 22, the horizontal axis is organized by Experientiality terciles and then by Rationality terciles. The boxplot is on the left, the 2-D line graph is on the right. 
The 2-D line graph is divided by a dotted line. The area 1 shows that individuals with low Experientiality score (E-T1) but high Rationality score (R-T2 and R-T3) presented high score for Readiness. The area 2 shows that the higher the Experientiality and Rationality scores, the higher the Readiness score. These graphs indicate that Rationality and Experientiality together may contribute to the explanation of the Readiness score.

Figure 22 - Experientiality and Rationality terciles vs. Readiness scores
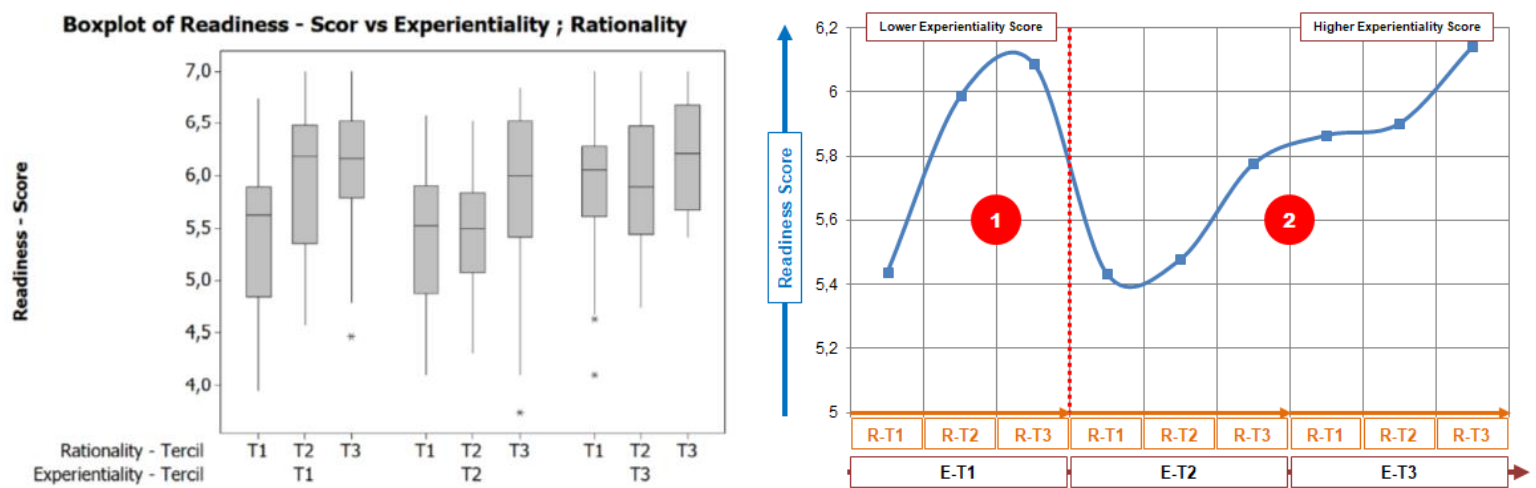

Source: prepared by the author

\section{ANOVA: Rationality terciles vs. Readiness scores}

Rationality terciles and Readiness scores were tested via one-way ANOVA. There was difference with statistical significance between the first and second terciles (R-T1 and R-T2) from the third tercile of Rationality (R-T3). R-T3 was different from R-T1 and R-T2 and RT1 was equal to R-T2. The statistical values are shown in Figure 23. P-value was 0.000 for a 95\% significance level. 'Mean' is the average Readiness score for each of the terciles.

Figure 23 - One-way ANOVA: Rationality terciles vs. Readiness scores

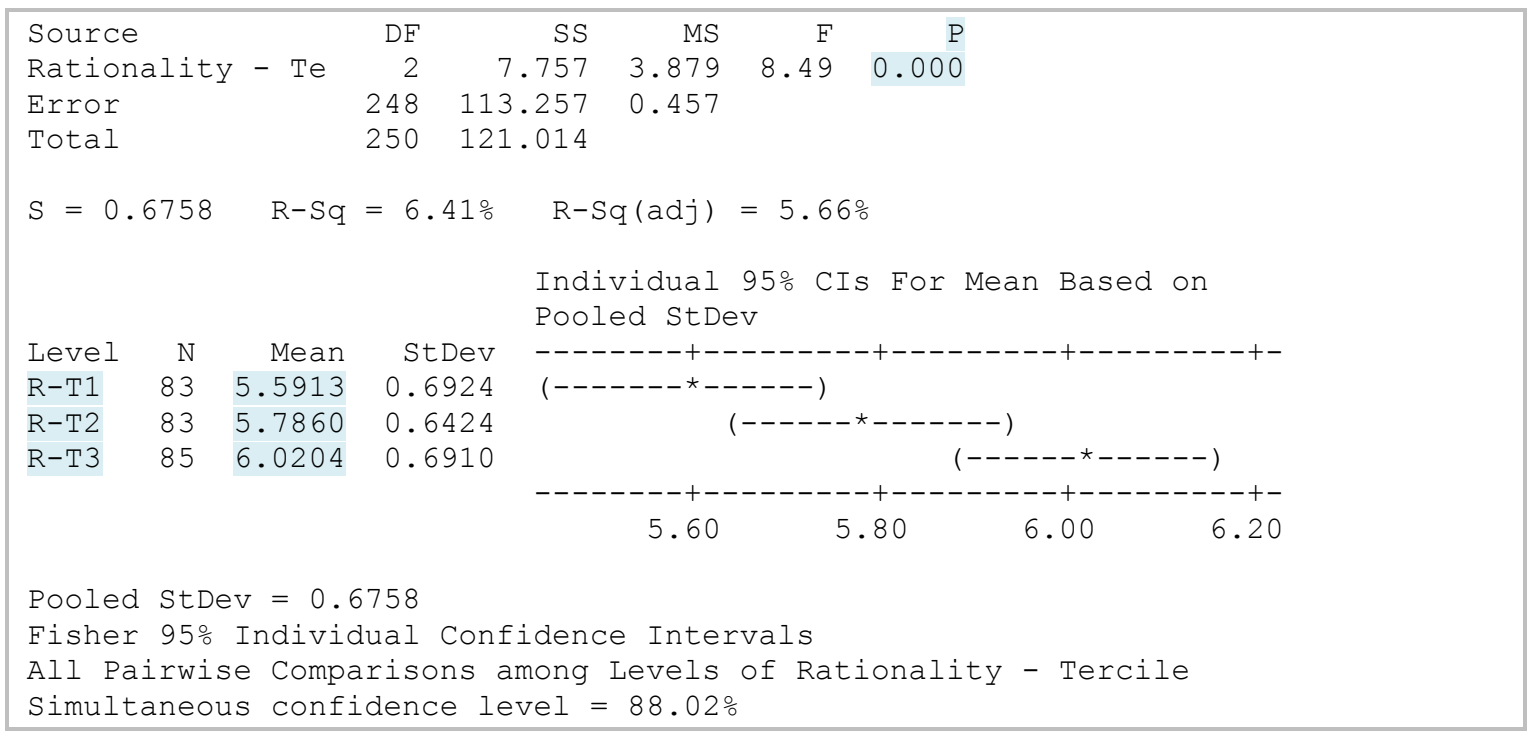




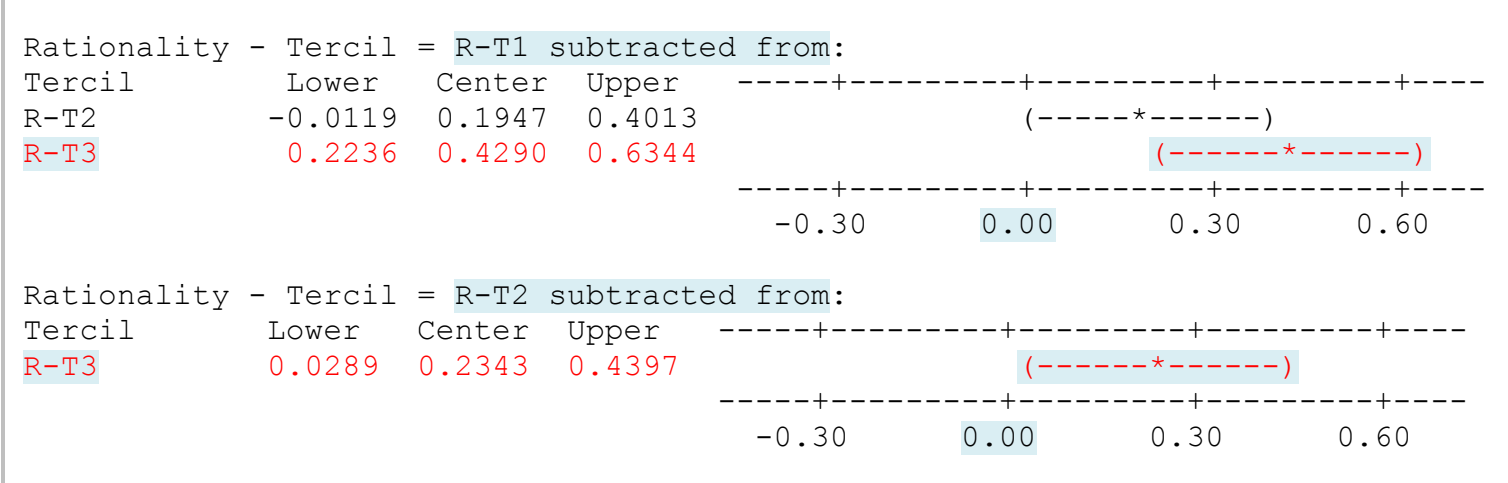

Source: Minitab

Rationality Ability and Rationality Engagement's terciles were also tested, and differences with statistical significance were found for the sub-component Engagement. These results are presented after following session.

\section{ANOVA: Experientiality terciles vs. Readiness scores}

Following the same procedure, Experientiality terciles and Readiness scores were also tested via one-way ANOVA. There was difference with statistical significance between the first and third terciles (E-T1 and E-T3) from the second tercile of Experientiality (E-T2). E-T2 was different from E-T1 and E-T3 and E-T1 was equal to E-T3. Experientiality Ability and Experientiality Engagement were also tested, and as occurred with Rationality, the subcomponent Engagement presented significant difference (results are presented in the following page). The statistical values are shown in Figure 24. P-value was 0.000 for a $95 \%$ significance level. 'Mean' is the average Readiness score for each of the terciles.

Figure 24 - One-way ANOVA: Experientiality terciles vs. Readiness scores

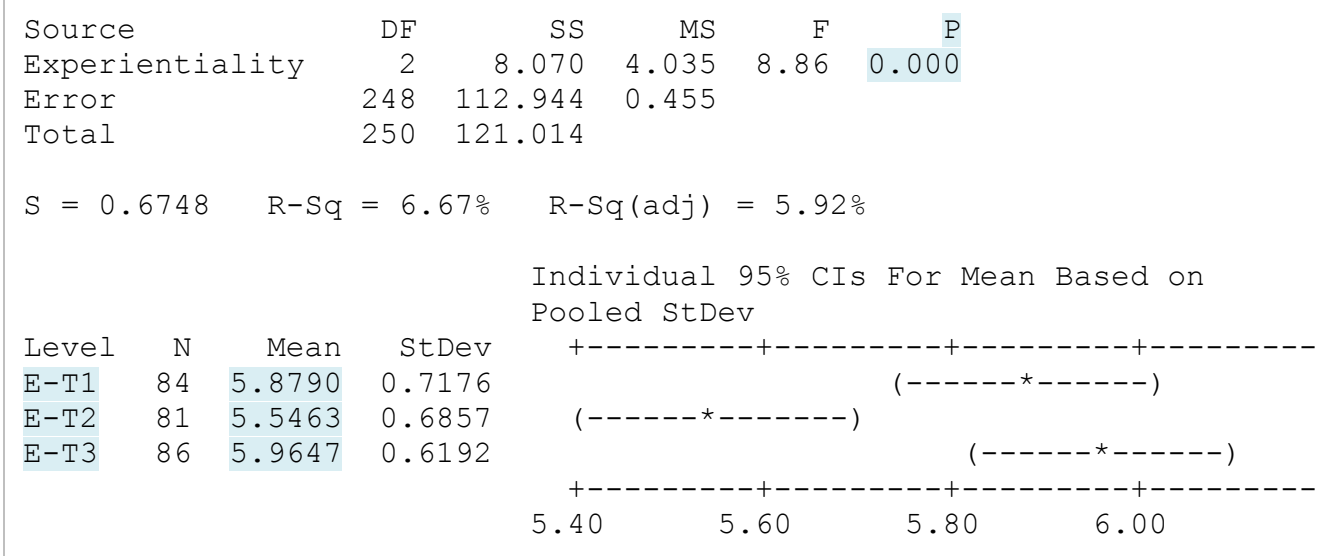

Pooled StDev $=0.6748$

Fisher 95\% Individual Confidence Intervals

All Pairwise Comparisons among Levels of Experientiality - Tercil

Simultaneous confidence level $=88.02 \%$ 


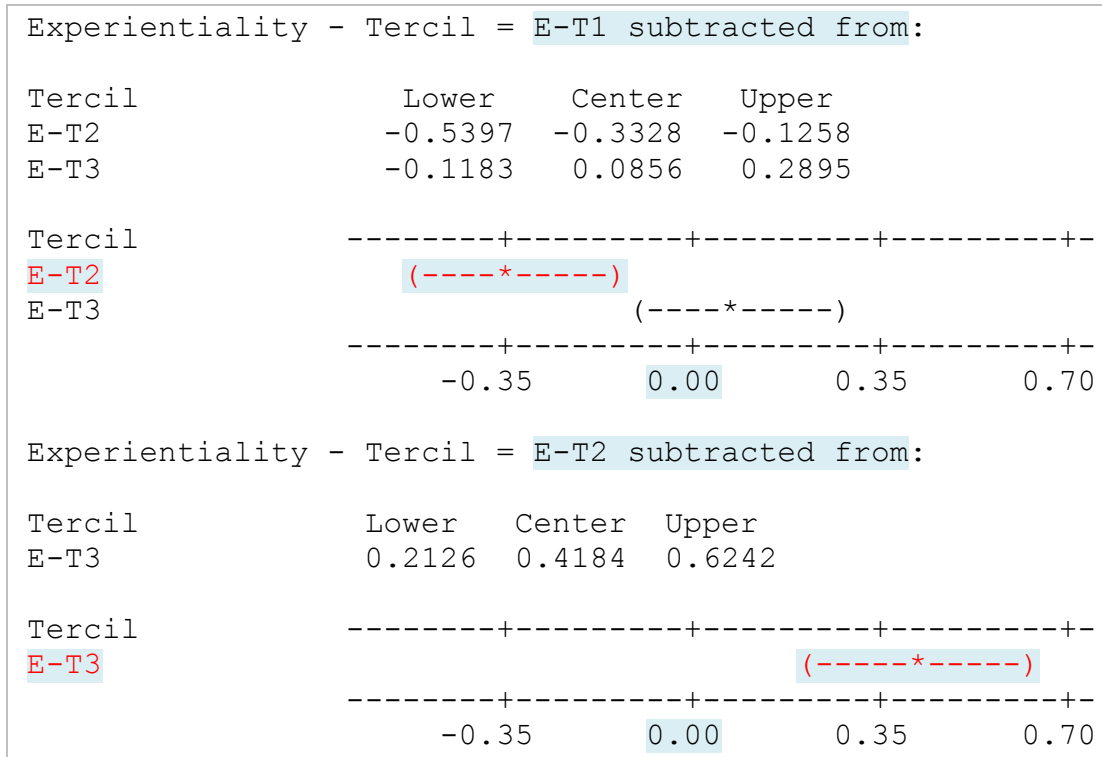

Source: Minitab

Above analyses demonstrated that the third Rationality tercile had significant difference on the Readiness score, while the first and third Experientiality terciles presented significant difference on the Readiness score. These findings connect to the academic stream that supports Design Thinking as a balance between analysis and intuition (Dorst, 2010; Brown \& Wyatt, 2010), being the related discussion presented in the following pages, after below presentation of results regarding the thinking styles sub-components and the Readiness-forchange sub-components.

Table 41 summarizes results from Figure 23 and Figure 24 and introduces the analysis regarding the thinking styles sub-components of ability and engagement. Regarding the comparison against Readiness score, the sub-component 'Rationality engagement' and 'Experientiality engagement' presented significant difference. For the former, Re-T3/Re-T2 presented higher Readiness score than Re-T1; and for the latter, Ee-T3/Ee-T1 presented higher Readiness score than Ee-T2.

Table 41 - Rationality and Experientiality sub-components vs. Readiness scores

\begin{tabular}{|c|c|c|}
\hline & \multicolumn{2}{|r|}{ Readiness score } \\
\hline & $P$-value & Differences \\
\hline Rationality tercile & 0.000 & $(\mathrm{R}-\mathrm{T} 3) \neq(\mathrm{R}-\mathrm{T} 1=\mathrm{RT} 2) . \mathrm{R}-\mathrm{T} 3$ is different vs. R-T1/ R-T2 \\
\hline Rationality Ability tercile & $0.044 *$ & $(\mathrm{Ra}-\mathrm{T} 3)=(\mathrm{Ra}-\mathrm{T} 2)=(\mathrm{Ra}-\mathrm{T} 1)$ \\
\hline Rationality Engagement tercile & 0.000 & $(\mathrm{Re}-\mathrm{T} 3=\mathrm{Re}-\mathrm{T} 2) \neq \mathrm{Re}-\mathrm{T} 1 . \mathrm{R}-\mathrm{T} 3 / \mathrm{R}-\mathrm{T} 2$ is different vs. R-T1 \\
\hline Experientiality tercile & 0.000 & $(\mathrm{E}-\mathrm{T} 3=\mathrm{E}-\mathrm{T} 1) \neq \mathrm{E}-\mathrm{T} 2 . \mathrm{E}-\mathrm{T} 3 / \mathrm{E}-\mathrm{T} 1$ is different vs. E-T2 \\
\hline Experientiality Ability tercile & $0.011 *$ & $(\mathrm{Ea}-\mathrm{T} 3)=(\mathrm{Ea}-\mathrm{T} 2)=(\mathrm{Ea}-\mathrm{T} 1)$ \\
\hline Experientiality Engagement tercile & 0.003 & $(\mathrm{Ee}-\mathrm{T} 3=\mathrm{Ee}-\mathrm{T} 1) \neq \mathrm{Ee}-\mathrm{T} 2 . \mathrm{E}-\mathrm{T} 3 / \mathrm{E}-\mathrm{T} 1$ is different vs. E-T2 \\
\hline
\end{tabular}

Source: prepared by the author. Note: see Appendix VI for detailed statistical data.

*Although P-value is lower than 0.050, statistical dilemmas ocurred with Tukey's and Fisher's method. 
The analysis of the Readiness-for-change sub-components enriched the understanding on the sources of significant difference on the Readiness score. In the case of Rationality Engagement, the differences regarded the third/second tercile of Change Efficacy and Personally Beneficial vs. the first tercile. First tercile presented significant difference by having lower score for Readiness than the other terciles. For Experientiality sub-components, differences were no confirmed. Table 42 presents these results.

Table 42 - Thinking styles sub-components terciles vs. Readiness sub-components scores

\begin{tabular}{|c|c|c|c|c|c|c|}
\hline & \multicolumn{2}{|c|}{$\begin{array}{c}\text { Appropriateness } \\
\text { Score }\end{array}$} & \multicolumn{2}{|c|}{$\begin{array}{c}\text { Change Efficacy } \\
\text { Score }\end{array}$} & \multicolumn{2}{|c|}{$\begin{array}{c}\text { Personally Beneficial } \\
\text { Score }\end{array}$} \\
\hline & $P$-value & Differences & $P$-value & Differences & $P$-value & Differences \\
\hline Rationality Tercile & $0.003 *$ & $\mathrm{~T} 3=\mathrm{T} 2=\mathrm{T} 1$ & 0.008 & $\mathrm{~T} 3 \neq(\mathrm{T} 1=\mathrm{T} 2)$ & 0.002 & $\mathrm{~T} 3 \neq(\mathrm{T} 1=\mathrm{T} 2)$ \\
\hline Rationality Ability (Ra) & 0.183 & $\mathrm{~T} 3=\mathrm{T} 2=\mathrm{T} 1$ & 0.083 & $\mathrm{~T} 3=\mathrm{T} 2=\mathrm{T} 1$ & $0.043 *$ & $\mathrm{~T} 3=\mathrm{T} 2=\mathrm{T} 1$ \\
\hline Rat. Engagement (Re) & $0.004^{*}$ & $\mathrm{~T} 3=\mathrm{T} 2=\mathrm{T} 1$ & 0.001 & $(\mathrm{~T} 3=\mathrm{T} 2) \neq \mathrm{T} 1$ & 0.000 & $(\mathrm{~T} 3=\mathrm{T} 2) \neq \mathrm{T} 1$ \\
\hline Experientiality Tercile & 0.001 & $(\mathrm{~T} 3=\mathrm{T} 1) \neq \mathrm{T} 2$ & 0.000 & $(\mathrm{~T} 3=\mathrm{T} 1) \neq \mathrm{T} 2$ & 0.117 & $\mathrm{~T} 3=\mathrm{T} 2=\mathrm{T} 1$ \\
\hline Exper. Ability (Ea) & $0.024 *$ & $\mathrm{~T} 3=\mathrm{T} 2=\mathrm{T} 1$ & $0.005^{*}$ & $\mathrm{~T} 3=\mathrm{T} 2=\mathrm{T} 1$ & 0.451 & $\mathrm{~T} 3=\mathrm{T} 2=\mathrm{T} 1$ \\
\hline Exper. Engagement (Ee) & $0.014^{*}$ & $\mathrm{~T} 3=\mathrm{T} 2=\mathrm{T} 1$ & $0.008 *$ & $\mathrm{~T} 3=\mathrm{T} 2=\mathrm{T} 1$ & 0.086 & $\mathrm{~T} 3=\mathrm{T} 2=\mathrm{T} 1$ \\
\hline
\end{tabular}

Source: prepared by the author

Note: see Appendix VII for detailed statistical data

*Although P-value is lower than 0.050, statistical dilemmas occurred with Tukey's and Fisher's method.

From the above data analyses, the discussion is now conducted referencing to the existing literature of Design Thinking, aiming to explain the reasons for the differences.

Some authors reinforce Design Thinking as a thought process based on experience and intuition, and its difference from the technical-rationality embedded in the business thinking. This understanding has origins from the Design field, as exemplified by Gregory (1966) in the book The Design Method: "the key to brilliant design remains the designer himself with all his intangible design capabilities such as intuition, judgement, determination, courage, spatial vision, and imagination" (p. 18). This understanding also found resonance in the Design Thinking literature, as exemplified by Dorst (2010, p. 133) in his paper The Nature of Design Thinking:

"Designers are often seen playing around with ideas, tossing up possibilities (proposals) in what may look like a hit-and-miss process. What they are in fact doing is trying out and thinking through many possibilities, thus building up a repertoire of experiences that help them developing an intuition of what will work in the problematic situation." 
Brown \& Wyatt (2010, p. 33) also supported this argument: "Design thinking relies on our ability to be intuitive, to recognize patterns, to construct ideas that have emotional meaning as well as being functional, and to express ourselves in media other than words or symbols". Tschimmel (2012, p. 14) reminded that the ideation phase aims to generate large amount of ideas, "where emotions and intuition are more important than rational thinking". From the understandings listed above, it was expected that high Experientiality individuals would present higher Readiness for adoption of Design Thinking, as Design Thinking sits in a familiar and comfortable territory to them. Indeed, significant difference was identified with the third tercile of Experientiality, but results also presented significant difference for the first tercile. Significant difference with the first tercile of Experientiality eventually made sense when analyzed in conjunction with the third tercile of Rationality. From the data already presented, high rational individuals presented high score of Readiness for adopting Design Thinking. If taking in consideration high rational individuals (R-T3) with low scores of Experientiality (E-T1), this is the group presenting the second highest score of Readiness (6.09) among the nine possible combinations (see Table 40). In other words, highly rational but lowly intuitive individuals presented high Readiness for adopting Design Thinking.

Moving forward on the discussion, individuals with high score of Rationality thinking style also presented higher Readiness for adopting Design Thinking (see Table 41). Theoretical explanations for this are provided by authors as Schön (1983), Martin (2009), Dorst (2010) and Glen et al. (2014), whose discussions made evident situations where the traditional rationality is not sufficient to address all problems. Schön (1983) stated that the model of Technical Rationality is built on assumption that the expected output is defined. "When ends are fixed and clear, then the decision to act can present itself as an instrumental problem. But when ends are confusing and conflicting, there is a yet no problem to solve." (Schön, 1983, p. 41). When the phenomenon is complex, uncertain, instable, unique and value-conflict, Schön (1983) recognized that the model of Technical Rationality was not fit for purpose. Martin (2009) concluded that a reasoning toolbox dependent of inductive and deductive logic is incomplete. Dorst (2010) articulated that dealing with paradox is an evident contrast to analytical problem solving. Glen et al. (2014) had a clear statement on such limitation of the analytical approach:

"Sole reliance on analytic abilities instilled in business school education is proving insufficient for such challenges. Design thinking provides a much-needed approach for dealing with complex, ill-defined problems. As such, it can complement analytic perspectives and methods in preparing graduates for their careers." 
For the above reasons, when rationality is not sufficient to help solving problems, individuals with high score of rational thinking style may perceive Design Thinking as a valuable alternative or complementary approach for problem-solving. This interpretation explains why individuals in the third tercile of Rationality presented high scores for Readiness to adopt Design Thinking.

Regarding the significant difference of higher terciles of Rationality Engagement with Change Efficacy scores (see Table 42), the literature also provided support for the interpretation. Rational Engagement refers to one's enjoyment of hard thinking and intellectual challenges, and includes the appealing of learning new things (review Table 13 Rational engagement items). The Change Efficacy includes the self-confidence of being able to learn whatever requested to the proposed change (review Table 17 - Change efficacy items). Therefore, individuals with high Rationality Engagement have the intellectual curiosity to learn new ways of thinking, and as consequence they presented higher scores for Change Efficacy. Same interpretation is applied for the Personally Beneficial score, as 'personally beneficial' refers to the extent someone feels that the proposed changes will bring benefits for one's own.

Finally, the statistical analyses called attention that both Rationality and Experientiality's thinking styles should also be examined together, and not only individually, regarding its influence on the Readiness for adopting Design Thinking. When Rationality, Experientiality and Readiness' scores were plotted together, there was an indication that both thinking styles may be together influencing the Readiness score (see Figure 25). From the 3-D graph, it is observed some convergence when the scores get higher for Rationality, Experientiality and Readiness. In other words, when Rationality and Experientiality scores increased there was an increase in the Readiness score.

Figure 25 - 3D Scatterplot of Rationality vs. Experientiality vs. Readiness

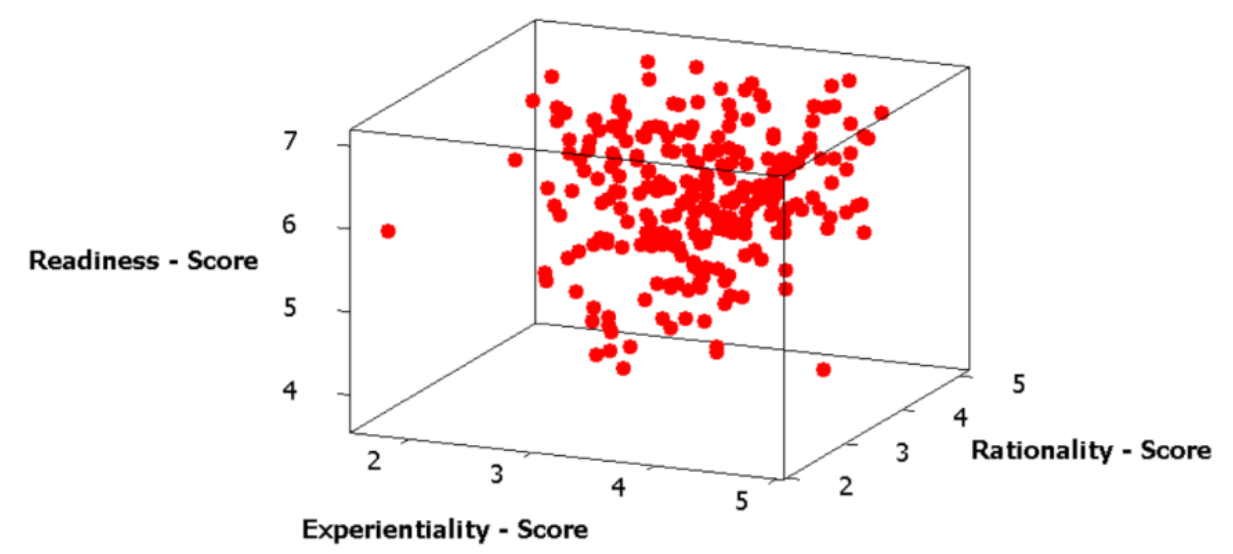

Source: Minitab 


\section{Regression analysis: Thinking Styles + other variables vs. Readiness}

From the findings of these previous analyses, a regression model was tested to assess which variables would explain the Readiness score, given that a regression analysis generates an equation to describe the statistical relationship between one or more predictors (not limited to the thinking styles) and the response variable (Readiness for adopting Design Thinking).

All variables listed in Table 11 (except job function, company name and department name) were considered for the regression analysis, including categorical and continuous variables. As defined by the statistical theory, the predictors can be either continuous or categorical, while the response variable should be continuous.

Additionally, the correlation among the predictors (multicollinearity) should not be severe. If correlation is severe, the statistical model may not determine which predictors should be considered. The collinearity concern could exist for the thinking styles if the CEST theory did not prove the independence between Rationality and Experientiality.

The results of the regression analysis are presented in Figure 26, including the regression equation and key statistic values. The relevant predictors were Rationality, Experientiality and Knowledge and Experience with Design Thinking (from the question 1 of the questionnaire).

Figure 26 - Regression analysis: variables influencing Readiness

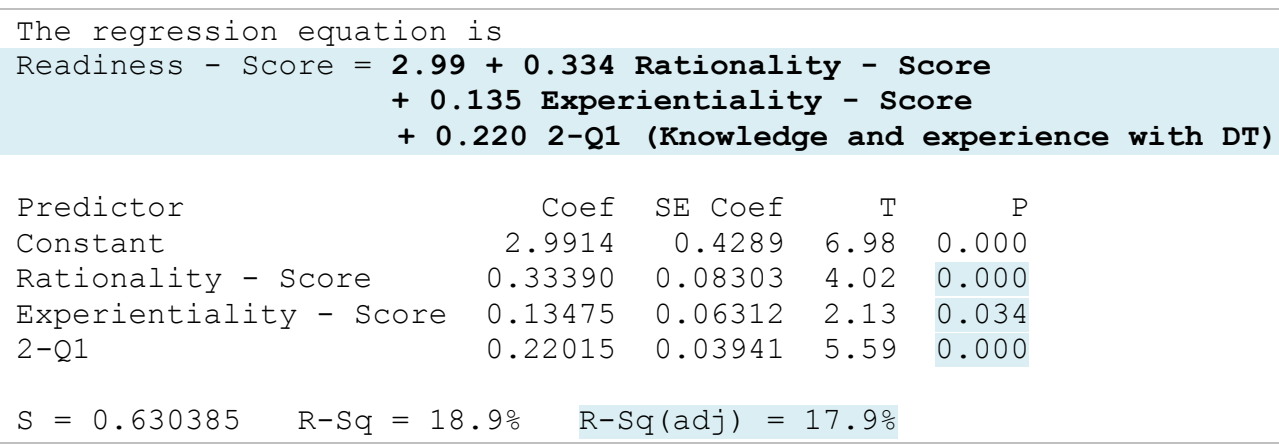

Source: Minitab

The regression equation defined the constant coefficient of 2.99 and the variables Rationality, Experientiality and Knowledge and Experience with Design Thinking as predictors for the Readiness score. The respective low P-values (0.000, 0.034 and 0.000) demonstrated that these predictors are significant for a $95 \%$ significance level.

Regarding how well the model fits the data, the Adjusted R-Square pointed out $17.9 \%$. R-Square is a value between $0 \%$ and $100 \%$, and the higher the R-Square the better the model fits the data. The Adjusted R-Square is used when there are different numbers of predictors. In this case, these three variables - Rationality, Experientiality and Knowledge and 
Experience with Design Thinking - explained 17.9\% of the response of Readiness. It does mean that these variables are relevant to explain the Readiness score, but they are not sufficient; there are other variables that need to be added to the regression model. The literature indicates that context, content and process are also important predictors of Readiness-for-change. The objective of this dissertation was not to include all variables relevant to explain Readiness, - but to focus on individual attributes as Rationality and Experientiality influencing Readiness -, hence the results of the regression models delivered on the purpose.

Regression analysis was also executed for each of the sub-components of Readiness adopted in this survey, namely Appropriateness, Change Efficacy and Personally Beneficial. While Appropriateness and Personally Beneficial had Rationality Score as the predictor, Change Efficacy's regression equation also included Experientiality Score and Sex. Table 43 details each regression equation by its coefficients and P-values.

\section{Table 43 - Regression analysis: summary of regression equations}

\begin{tabular}{|c|c|c|c|c|c|c|c|c|c|}
\hline \multirow{3}{*}{$\begin{array}{l}\text { RESPONSE } \\
\text { VARIABLE }\end{array}$} & \multicolumn{9}{|c|}{ PREDICTORS VARIABLES } \\
\hline & \multirow{2}{*}{$\begin{array}{c}\text { Constant } \\
\text { Coef. }\end{array}$} & \multicolumn{2}{|c|}{ Rationality Score } & \multicolumn{2}{|c|}{$\begin{array}{l}\text { Experientiality } \\
\text { Score }\end{array}$} & \multicolumn{2}{|c|}{$\begin{array}{l}\text { Knowledge and } \\
\text { Experience with } \\
\text { Design Thinking }\end{array}$} & \multicolumn{2}{|c|}{ Sex } \\
\hline & & Coef. & $P^{*}$ & Coef. & $P^{*}$ & Coef. & $P^{*}$ & Coef. & $P^{*}$ \\
\hline $\begin{array}{l}\text { Readiness } \\
\text { Score }\end{array}$ & +2.99 & +0.334 & 0.000 & +0.135 & 0.034 & +0.220 & 0.000 & -n- & $-\cdots$ \\
\hline $\begin{array}{l}\text { Appropriate- } \\
\text { ness }\end{array}$ & +4.40 & +0.343 & 0.001 & ------- & --- & ------- & ---- & ------ & --- \\
\hline $\begin{array}{l}\text { Change } \\
\text { Efficacy }\end{array}$ & +3.04 & +0.466 & 0.000 & +0.133 & 0.083 & ------ & ---- & +0.215 & 0.031 \\
\hline $\begin{array}{l}\text { Personally } \\
\text { Beneficial }\end{array}$ & +4.03 & +0.515 & 0.000 & ------- & ---- & ------ & ---- & ------ & ---- \\
\hline
\end{tabular}

Source: prepared by the author. Note: $\mathrm{P}^{*}=\mathrm{P}$-value

Change Efficacy's regression equation called attention as it differed from the other subcomponents (Table 44). However, its results would be expected given the literature review. As Change Efficacy refers to "the extent to which one feels that he or she has or does not have the skills and is or is not able to execute the tasks and activities that are associated with the implementation of the prospective change" (Holt et al., 2007b, p. 238), it is reasonable to have the 'rationality ability' and 'experientiality ability' sub-components in the equation, as "rational ability refers to reports of a high level of ability to think logically and analytically" (Pacini \& Epstein, 1999, p. 974) and "experiential ability refers to reports of a high level of ability with respect to one's intuitive impressions and feelings" (p. 974). The equation associated the two constructs related to skills, hence being reasonable. Regarding Sex, 
previous studies have shown that men tend to present higher Rationality scores than women, while women tend to present higher Experientiality scores than men. Therefore, as women were coded as ' 2 ', the female sex has higher contribution to the increase of Change Efficacy.

Table 44 - Regression analysis: Change Efficacy vs. Rationality; Experientiality; sex

\begin{tabular}{|c|c|c|c|c|c|c|c|}
\hline \multirow{3}{*}{$\begin{array}{l}\text { RESPONSE } \\
\text { VARIABLE }\end{array}$} & \multicolumn{7}{|c|}{ PREDICTORS VARIABLES } \\
\hline & \multirow{2}{*}{$\begin{array}{c}\text { Constant } \\
\text { Coefficient }\end{array}$} & \multicolumn{2}{|c|}{ Rationality Ability } & \multicolumn{2}{|c|}{ Experientiality Ability } & \multicolumn{2}{|c|}{ Sex } \\
\hline & & Coefficient & $P$-value & Coefficient & $P$-value & Coefficient & $P$-value \\
\hline $\begin{array}{l}\text { Change } \\
\text { Efficacy }\end{array}$ & +3.85 & +0.277 & 0.001 & +0.146 & 0.063 & +0.169 & 0.095 \\
\hline
\end{tabular}

Source: prepared by the author.

Regression results identify the relations between predictor and response variables, in regards of size, direction and statistical significance of the relationship. The direction of the relationship is indicated by the sign of each coefficient. Rationality and Experientiality had positive coefficients, as the higher their scores the higher the Readiness. Therefore, coefficients are the mean change in the response for one unit of change in the predictor while holding other predictors in the model constant. The null hypothesis that the coefficient is equal to zero (no effect) is tested by the P-value of each coefficient tests. If the p-value is less than or equal to the significance level, there is a statistically significant relation between the variables. As the p-values of the predictors are equal or lower than the significance level of $90 \%$, there is a statistically significant relation between the response variable and the predictors presented at Table 43 and Table 44.

In the academic literature, authors supported the connection between cognition (rationality and intuition) and Design Thinking. For Glen et al. (2014), Design Thinking addresses the System 1 (fast, intuitive) and initially relaxes System 2 (slow, rational), as the focus is on new observations and allowing novel connections. The System 2 role includes decontextualizing and depersonalizing problems, as well as serving as a check on bias and errors from System 1. Researchers as Bolland \& Collopy (2004), Martin (2009), Razzouk \& Shute (2012) have also recognized that DT demands rationality and intuition in balance.

Razzouk \& Shute (2012) argued that the reason for Design Thinking receiving attention by other disciplines as engineering is because it can modify how people learn and solve problems, which is implicitly related to individual's cognition. As example, Nagai \& Noguchi (2003) published an article in the Journal of Engineering Design regarding "an experimental study on the Design Thinking process started from difficult keywords: modeling the thinking process of creative design". Liedtka (2015) also stated that Design Thinking is generating 
significant attention in the business press as it is a new approach for problem-solving. She argued that design, as a thought process, can improve innovation outcomes but yet needs to receive more attention from the management academia. Few researches are linking Design Thinking to the literature of individual cognition and decision-making. Liedkta (2015) pointed out that Design Thinking can help decision-makers reduce their cognitive biases as the 'hypothesis confirmation bias' (when decision makers look for confirmation of their hypothesis, by focusing on supporting data-points; hence a rational process).

Design Thinking has been discussed by scholars from different lenses, being Design Thinking as a cognitive approach one of them. Kimbell (2011) proposed that there are three different ways of approaching Design Thinking: as a cognitive style (where thinking styles discussion makes sense), as a general theory of design and as an organizational source. As a cognitive style, she pointed out Cross (1982, 2006), Schön (1983), Rowe (1987), Lawson (2005) and Dorst (2006) as key scholars with publications on the topic. They focused on designers as individuals, especially on how the experts solve problems, and the key concepts were related to design ability as a form of intelligence. Fleury, Stabile, \& Carvalho (2016) identified six core groups of definitions for Design Thinking, being 'cognition' (understanding, assumption, reasoning) the most frequent reference field found (the others were business, creation, language, communication and education).

Martin (2010) discussed that Design Thinking should be a reconciliation of two ways of thinking, or two schools of thoughts. One of these schools states that value creation should not rely on the old practice of instincts and feelings; it should be driven by strategy based on quantitative analysis and analytical thinking. Judgement, personal bias and variations should all be eliminated, so better decisions are taken. The other school of thought, somehow a reaction to the analytical school, is built on the pillars of innovation and creativity. As example, many successful products did not come out from quantitative surveys, but from the 'heart and soul' of individuals. This line of thought is backed by originality, invention and intuitive thinking, which is the art of knowing without reasoning (Martin, 2010).

When comparing the academic line of thought that Design Thinking is a balance between analysis and intuition against this research's findings that individuals with high score of Rationality and Experientiality are those presenting higher scores of Readiness for adopting Design Thinking, there is a promising evidence from this research that the implementation of Design Thinking in organizations must consider both cognitive sides of individuals, specially experientiality (intuition), for so-long rejected and avoided at the light of Technical Rationality. 


\section{CONCLUSIONS}

There is influence of the thinking styles on the individuals' Readiness for adopting Design Thinking. Rationality and Experientiality, together, and along with Knowledge and Experience with Design Thinking, provided significant but not sufficient explanation to the individuals' Readiness for adopting Design Thinking. This insufficient explanation was expected as Readiness for change is an outcome derived not only from individual attributes, but also from the context, content and process of the change (Walker et al, 2007; Holt et al., 2007). The conclusions are summarized based on each specific objective of this research (see Table 45), which acted as a step-process to provide foundation to the general objective of testing the relation between thinking styles and Readiness to adopt Design Thinking.

Table 45 - Research question, specific objectives and findings

\begin{tabular}{|c|c|c|}
\hline & Description & Findings \\
\hline & $\begin{array}{l}\text { To what extent individual } \\
\text { attributes (Thinking Styles, } \\
\text { Knowledge, Experience and }\end{array}$ & $\begin{array}{l}\text { There is influence of thinking styles and knowledge and } \\
\text { experience with DT on the individuals' Readiness for } \\
\text { adoption Design Thinking. }\end{array}$ \\
\hline RESEARCH & Understanding of Design & Regression analysis showed that Rationality, \\
\hline QUESTION & $\begin{array}{l}\text { Thinking) influence the } \\
\text { individual's Readiness for } \\
\text { adopting Design Thinking in the } \\
\text { organization? }\end{array}$ & $\begin{array}{l}\text { Experientiality and knowledge and experience with } \\
\text { Design Thinking contributed } 17.9 \% \text { (adjusted R-Square) } \\
\text { to explain the Readiness score (P-values of } 0.000 \text {, } \\
0.034,0.000 \text { respectively, } 95 \% \text { confidence level). }\end{array}$ \\
\hline
\end{tabular}

Respondents' understanding of Design Thinking varied in the spectrum between rational-analytic and Design

\begin{tabular}{|c|c|}
\hline $\begin{array}{l}\text { Specific } \\
\text { Objective } 1\end{array}$ & $\begin{array}{l}\text { Analyze respondents' perceived } \\
\text { understanding of Design Thinking } \\
\text { characteristics }\end{array}$ \\
\hline
\end{tabular}

$\begin{array}{ll}\text { Specific } & \begin{array}{l}\text { Measure and discriminate the } \\ \text { Rationality and Experientiality's } \\ \text { Objective 2 }\end{array} \\ \begin{array}{l}\text { individual scores of the selected } \\ \text { sample }\end{array}\end{array}$
practice; not a uniform understanding of DT as expected by the academic literature.

Respondents with 'practical experience with DT': only $11 \%$ understood that Design Thinking is based on logic. Respondents with 'conceptual knowledge' of DT:

23\% understood that Design Thinking is based on logic.

The formation of terciles presented significant differences among the three groups, allowing analysis by Rationality and Experientiality terciles. One-way ANOVA presented P-values of 0.000 for a 95\% significance level for Rationality and Experientiality terciles.

The formation of terciles presented significant differences among the three groups, confirming differentiation of levels of Readiness.

One-way ANOVA presented P-value of 0.000 for a $95 \%$ significance level for Readiness terciles.

Test the relation of thinking styles (while considering the understanding of Design Thinking and knowledge and experience with Design Thinking) with the individuals' Readiness for adopting Design Thinking

There is significant difference for individuals with high scores of Rationality and Experientiality ( $3^{\text {rd }}$ tercile); significant difference for high Readiness score was also identified in $1^{\text {st }}$ tercile of Experientiality

$\mathrm{R}-\mathrm{T} 3 \neq(\mathrm{R}-\mathrm{T} 1=\mathrm{RT} 2) . \mathrm{R}-\mathrm{T} 3$ is different from R-T1/R-T2 $(\mathrm{E}-\mathrm{T} 3=\mathrm{E}-\mathrm{T} 1) \neq \mathrm{E}-\mathrm{T} 2 . \mathrm{E}-\mathrm{T} 3 / \mathrm{E}-\mathrm{T} 1$ is different from E-T2

Source: prepared by the author 
The first specific objective addressed an investigation on the understanding of Design Thinking by the respondents. This was necessary as Design Thinking is a relatively new approach yet to be consolidated, and different understandings of DT could have influence on the Readiness to adopt Design Thinking. Indeed, survey's respondents did not present a uniform understanding on the characteristics of Design Thinking, as well as there is no homogeneous definition of DT in the literature review. Some individuals with 'conceptual knowledge' but without project experience in Design Thinking believed Design Thinking is based on logic (23\%, see Table 31), while only some with practical experience with Design Thinking understood that it is based on logic (11\%, see Table 31). From these results (see Table 28 for all responses), it is possible to argue that the perceived understanding on the Design Thinking characteristics varies depending on the level of knowledge and experience someone has with Design Thinking. This conclusion reinforces the importance of assessing the respondents' understanding of DT, instead of simply relying on the academic definitions on the Design Thinking characteristics.

The next objective addressed how to measure, analyze and discriminate the individuals' thinking styles, namely Rationality and Experientiality. The solution applied was the utilization of terciles. By applying the original instrument developed by Pacini \& Epstein (1999), the Rationality and Experientiality scores were calculated. While the original study of this instrument presented averaged scores of 3.39 for Rationality and 3.52 for Experientiality (79\% of the sample were women), this survey obtained scores of 4.04 for the former and 3.34 for the latter (46\% of the sample were women). This significant larger gap between Rationality and Experientiality scores can be explained not only by the sex proportion but also from the profile of the respondents. While Pacini \& Epstein's survey was conducted with Psychology's undergraduate students, this survey included not only individuals purely from the Human Sciences, but also Engineering, Business Administration and Architecture (see Table 26) - all fields that require higher abilities in mathematics and analytical thinking. Given that average scores of Rationality and Experientiality from different studies could not be a useful reference to discriminate individuals with high and low Rationality and Experientiality, terciles were applied (tested by One-way ANOVA) to define groups with low, mid and high scores of each thinking style (eliminating any issue or concern with the scale calibration or differences among studies).

Regarding the relation between thinking styles and the respondents' understanding of Design Thinking, it was observed that the higher the Experientiality tercile, the lower the percentage of respondents that understood Design Thinking as being based on logic and the 
higher the percentage of respondents that understand Design Thinking as being based on experience and intuition (see Table 35). These pieces of data supported one of the hypotheses of this dissertation: the higher the intuitive-experiential thinking in a person, the higher his/her understanding that Design Thinking is based on experience and intuition.

The third specific objective regarded the measurement, analysis and discrimination of the level of Readiness for adopting Design Thinking. The applied solution of terciles confirmed that Readiness scores presented significant differences. The questionnaire items were extracted from the Readiness for Organizational Change Measure instrument, developed by Holt et al. (2007b). Following the same statistical solution adopted for the scores of Rationality and Experientiality, terciles were calculated in order to define groups with low, mid and high scores of Readiness. One-way ANOVA was once again executed and confirmed that all terciles were significant different from each other. There would be no meaning comparing and analyzing Readiness scores from different studies, as each score is related to different situations of change (context, content, process and individual attributes).

When comparing the Readiness scores against the respondents' understanding of Design Thinking characteristics, two characteristics presented some distinctive difference: approach (qualitative vs. quantitative) and outcome (definitive and partial). High score's respondents understanding Design Thinking as qualitative approach and as a provider of partial answers presented higher scores for Readiness to adopt DT. These results may indicate the importance of clarifying the Design Thinking approach and well as its outputs: as much as individuals recognize the differentiated approach of DT, the better impact on the Readiness.

Fourthly, after having discriminated the terciles for thinking styles and for Readiness, the test for differences between these variables could be performed. The One-way ANOVA results confirmed significant differences for terciles of Experientiality and Rationality. Individuals with high Experientiality ( $3^{\text {rd }}$ tercile) presented high score of Readiness for adopting Design Thinking, as well as individuals in the third tercile of Rationality. Hence, the initial hypothesis was confirmed: being Design Thinking not based on logic (as understood by those with practical experience with DT) but based on intuition and experience (as argued by some authors), individuals with high experiential/intuitive thinking presented high Readiness score for adopting Design Thinking (given that individuals' confidence on their own experiential and intuitive abilities would influence towards higher Readiness - self-efficacy defined by Holt et al., 2007b). The first tercile of Experientiality also presented significant difference with high Readiness score. The explanation is associated with high rational individuals that have this low score on Experientiality, as this combined group presented high 
score for Readiness to adopt DT. The following paragraph will help understanding why this first tercile of Experientiality presented high Readiness score.

The highly rational individuals presenting high score for Readiness was an unexpected outcome. A reasonable explanation can be sourced from the academic literature. Authors have stated that rationality is not enough to address contemporary problems in such volatile, uncertain, complex and ambiguous environment. Schön (1983) discussed the limitations of the Technical Rationality. When outputs are clear and well-defined, the decision making consists in instrumental problem solving supported by scientific theory and methods; but when outputs are fuzzed, Technical Rationality does not properly frame the problem and it becomes insufficient to achieve solutions. For these wicked problems, the approach of Design Thinking has called attention as designers' approach to problems is different from that applied by business practitioners (Cross, 1982; Schön, 1983; Boland, 2004; Lawson, 2005; Martin, 2009; Tschimmel, 2012). Highly rational individuals may understand Design Thinking as an important and needed complement of experiential cognition to the analytical capabilities and methods that managers are used to (Glen et al., 2014). Recapping the previous discussion in above paragraph, if these highly rational individuals ( $3^{\text {rd }}$ tercile) also presented low score in Experientiality ( $1^{\text {st }}$ tercile), the Readiness score would also go high, as these individuals probably recognize that Design Thinking could better support on the issues not currently being solved.

Finally, by delivering on the specific objectives, the answer to the research question of 'to what extent individual attributes influence the individual's Readiness for adopting Design Thinking in the organization' could be tackled. Additional findings demonstrated that highly rational individuals presented higher Readiness score, and significant difference was also found for Experientiality. Moving forward, descriptive statistical analyses suggested that Rationality and Experientiality should be also analyzed together, as joint predictors influencing the Readiness. Furthermore, knowledge and experience with Design Thinking as well as the perceived understanding of Design Thinking also presented relevant indications to the Readiness to adopt DT.

By executing the regression analysis, this study concluded that Rationality, Experientiality and Knowledge and Experience with Design Thinking contributed 17.9\% (adjusted R-Square) to explain the Readiness score for adopting Design Thinking. Therefore, the combined thinking styles (Rationality and Experientiality) did influence the Readiness score for adopting Design Thinking. If Design Thinking leverages from the combination of both thinking styles, as stated by some authors (Bauer \& Eagan, 2008; Martin, 2009; Glen et 
al., 2014), it does make sense that individuals with high scores of Rationality and Experientiality would present higher score of Readiness to adopt Design Thinking.

The academic line of thought that supports Design Thinking as a balance between analysis and intuition provides sustainability to this research's findings: individuals with high score of Rationality and Experientiality present higher scores of Readiness for adopting Design Thinking, as they probably value the combination of both thinking styles. This survey's results provides promising evidence that the implementation of Design Thinking in organizations should consider assessing the individuals' thinking styles and change management strategies should aim to address both cognitive sides, especially Experientiality (intuition), for so-long rejected and avoided at the light of Technical Rationality.

\section{Contributions}

The expected contributions of this dissertation are related to three fields of research: change management (adoption of Design Thinking), intuition in management (Design Thinking acting as balance between intuition and rationality) and design cognitive studies (relation between thinking styles and Design Thinking).

As Design Thinking gains prominence in the academia and in business organizations, this research contributes for deeper understand of some antecedents of adoption of Design Thinking (Oreg, Vakola, \& Armenakis, 2011) by focusing on the change recipient characteristics (traditionally, academic literature focus was on change agents of organizational change; Oreg, Bartunek, Lee, \& Do, 2018). The individual's Readiness for adopting Design Thinking is an outcome from the context, content, process and individual attributes of the given organizational change (Walker et al, 2007; Holt et al., 2007). This research focused on the investigation of some individual attributes, namely thinking styles, perceived understanding of Design Thinking and knowledge and experience with Design Thinking, in an effort to verify the relation with Readiness for adoption Design Thinking. As the research results confirmed the individual's thinking styles as well as their knowledge and experience with Design Thinking as variables associated with Readiness to adopt Design Thinking, this finding can be utilized, beforehand, by those willing to implement Design Thinking in their organizations. The model proposed by this dissertation provides some light on the challenges ahead regarding the acceptance of Design Thinking. Smoother and more efficient change management programs can be designed for educational programs relying on Design Thinking or for departments in organizations implementing Design Thinking. 
Additionally, this research can contribute to the discussion of intuition in management. As articulated by Glen, Suciu, \& Baughn (2014, p. 664), "Design Thinking serves to supplement the analytic component of business education with both the 'art' (imaginative insights) and 'craft' (learning through practical experience) dimensions that Mintzberg (2004) saw as essential to effective management." Design Thinking can be seen as complement to the analytic tools and methods currently adopted by organizations and taught in business schools; it should not be seen as a replacement. As too much focus on the art, craft and intuitive approach may mislead organizations and make them inefficient, the opposite is also true, when there is overreliance on rationality and analytical approaches. For Martin (2009), the balance between exploration and exploitation, and between abductive as well as inductive and deductive reasoning, is what defines Design Thinking. For Bauer \& Eagan (2008) analytical thinking is part of, and not the opposite of, Design Thinking. Within this context of balance between Rationality and Experientiality, Design Thinking's impact in organizations differs from previous approaches as Six Sigma, Lean, PDCA, etc. and should receive attention of scholars and practitioners.

Thirdly, the findings of this dissertation can also contribute to the literature related to the 'culture of design', which approaches Design Thinking as a cognitive style, and not as a general theory of design or as an organizational resource (Kimbell, 2011). Within the cognitive style approach, the point of interest lies on how Design Thinking can create new opportunities on problem-solving, given how designers think and what they know. This dissertation helped validating that both thinking styles, Rationality and Experientiality, are to be considered whenever discussing cognitive aspects for adoption of Design Thinking.

Finally, some other contributions could be identified in this dissertation. Regarding theoretical contributions, the presented research model deployed quantitative analyses of predecessor variables impacting the Readiness for adopting Design Thinking. Besides the applied instruments from Pacini \& Epstein (1999) and Holt et al. (2007b), the survey also applied scales for knowledge and experience with Design Thinking and perceived understanding of Design Thinking, based on Glen et al. (2014). Regarding methodological contributions, this survey utilized a recent digital marketing tool (LinkedIn Campaign Manager) to execute data collection in a simpler, faster and more efficient way, overcoming traditional research issues as having access to potential respondents. 


\section{Limitations}

The limitations of this research are derived from the lenses applied to the literature review and from the methodologies choices.

The Readiness for adopting Design Thinking was analyzed on the lenses of individual attributes, being more specific on the thinking styles, perceived understanding of Design Thinking and on the knowledge and experience with Design Thinking. The research was not designed to capture other individual attributes influences, neither to capture influences of the context, content and process of the change. Furthermore, researchers have started challenging the focus on the valence of responses from change recipients (Readiness or resistance to change), as existing approaches do not consider the degree of activation (activity vs. passivity) of the responses (Oreg, Bartunek, Lee, \& Do, 2018).

Regarding thinking styles, currently there are a number of authors that specialized research for specific disciplines, after the seminal work from Epstein (1994) published in the American Psychologist. Contemporary criticism can be found on the Epstein's Cognitiveexperiential self-theory (e.g.: considered outdated given that other researches moved forward by developing the theory in specific disciplines), but his Rational-Experiential Instrument (REI) remained as a useful and highly referenced scale in recent academic literature.

On the Design Thinking literature, criticism exists on some discourses as they are based on the design practice and do not apply the rigor from the academia (referencing theories and authors, positioning the research in relation to others), hence scholars considering Design Thinking as anecdotal and not theoretically and empirically based. Given that academic literature on Design Thinking is still limited, this dissertation presented the academic foundation of the design discipline to provide theoretical background to Design Thinking, given that "Design Thinking can be seen as a translation of designerly thinking into a popularized, management version" (Johansson-sköldberg \& Woodilla, 2013, p. 131).

Referring to the methodological choices, the quantitative survey approach was selected to allow application of statistical methods to assess the relation between thinking styles, other variables and Readiness to adopt Design Thinking. Within the context of this approach and given limitations of time and resources, the survey was applied in a specific point in time, meaning that there are no longitudinal inferences about how the Readiness changes throughout the time.

The sample profile focused on professionals in the State of São Paulo, and results should not be generalized to other regions or considered as a proxy of Brazil. The survey 
participation was voluntary, hence there is chance that respondents had some positive affection with Design Thinking. It is also worth considering that some professionals with skill in Design Thinking may not declare it in their LinkedIn profile. Participants were also eligible for a prize (incentive to respond the questionnaire), but the prize had not relation with how the respondent should response the survey.

\section{Further researches}

Suggestions for future researches in Design Thinking and thinking styles consider a deeper qualitative investigation and replication of research in other locations.

Given the result that individuals with high rationality scores present higher Readiness for adopting Design Thinking, it would be revealing to conduct in-depth interviews with this profile to deep dive on the value they see in Design Thinking. Researches with a longitudinal approach could help understanding how thinking styles change as individuals have more experience with Design Thinking.

The findings from this research could be confronted against the results from other individuals located in other regions than São Paulo, whose organizations are implementing Design Thinking, therefore likely to be in other context, content and process of change. These researches could consolidate or challenge the finding that thinking styles have influence on the Readiness for adopting Design Thinking.

During the development of this dissertation, additional research questions arose, and some of them could be avenues for future researches. Design Thinking is being incorporated by some business schools, and it may be of interest to investigate how Design Thinking can help the development of the students' experiential thinking style. Design Thinking is also calling attention of companies, especially on how it can enhance their creativity and innovation as well as how to improve problem-solving of complex problems, so traditionally backed by a technical-rational approach. The research could be designed for case studies of organizations that are running Design Thinking in a permanent and institutionalized basis, in order to understand how Design Thinking enhances (or not) the solution of ill-defined problems in business areas like Marketing and Finance. 


\section{REFERENCES ${ }^{4}$}

Adler, N. J. (2006). The arts and leadership: Now that we can do anything, what will we do? Academy of Management Learning \& Education, 5(4), 486-499.

Agor, W. H. (1990). Wanted: The intuitive director. In W. H. Agor, Intuition in organizations (pp. 125-130). Newbury Park, CA: Sage Publications.

Alexander, C. (1971). Notes on the Synthesis of Form. Cambridge: Harvard University Press.

Al-Haddad, S., \& Kotnour, T. (2015). Integrating the organizational change literature: a model for successful change. Journal of Organizational Change Management, 234262.

American Psychological Association. (2010). Publication Manual of the American Psychological Association. 6th. Washington, DC.

Archer, B. (1979). Design as a Discipline. Design Studies, 1(1), 17-20.

Armenakis, A. A., \& Bedeian, A. G. (1999). Organizational change: A review of theory and research in the 1990s. Journal of management, 25(3), 293-315.

Armenakis, A. A., Bernerth, J. B., Pitts, J. P., \& Walker, H. J. (2007). Organizational change recipients' beliefs scale: development of an assessment instrument. The Journal of Applied Behavioral Science, 43(4), 481-505.

Armenakis, A. A., Harris, S. G., \& Mossholder, K. W. (1993). Creating Readiness for Organizational Change. Human Relations, 46(6), 681-703.

Bauer, R., \& Eagan, W. (2008). Design Thinking: Epistemic Plurality in Management and Organization. Aesthesis, 2(3), 64-74.

Bennett, N., \& Lemoine, J. G. (2014). What VUCA Really Means for You. Harvard Business Review(Jan-Feb).

Björklund, F., \& Bäckström, M. (2008). Individual differences in processing styles: Validity of the Rational-Experiential Inventory. Scandinavian Journal of Psychology, 49(5), 439-446.

Boland, R. J., \& Collopy, F. (2004). Design Matters for Management. In R. J. Boland, \& F. Collopy, Managing as designing (pp. 3-18). Stanford: Stanford University Press.

Bouckenooghe, D., Devos, G., \& van den Broeck, H. (2009). Organizational change questionnaire - climate of change, processes, and readiness: development of a new instrument. The Journal of psychology, 6, 559-599.

\footnotetext{
${ }^{4}$ Note: references in accordance with APA $6{ }^{\text {th }}$ edition style (Funaro, et al., 2016).
} 
Brown, T. (2008). Design Thinking. Harvard Business Review(June), 84-95.

Brown, T. (2009). Change by Design - how design thinking transforms organizations and inspires innovation. New York: HarperCollins.

Brown, T., \& Wyatt, J. (2010). Design Thinking for Social Innovation. Stanford Social Innovation Review(Winter), 30-35.

Buchanan, R. (1992). Wicked Problems in Design Thinking. Design Issues, VIII(2), 521.

Cacioppo, J. T., \& Petty, R. E. (1982). The Need for Cognition. Journal of Personality and Social Psychology, 42(1), 116-131.

Camillus, J. C. (2008). Strategy as a wicked problem. Harvard Business Review, May, $1-10$.

Carleton, T., Cockayne, W., \& Tahvanainem, A. (2013). Playbook for Strategic Foresight and Innovation. Tekes.

Carlgren, L., Elmquist, M., \& Rauth, I. (2016). The challenges of using Design Thinking in industry - experiences from five large firms. Creativity and Innovation Management, 25(3), 344-362.

Coch, L., \& French, J. R. (1948). Overcoming resistance to change. Hman Relations, 1, 512-532.

Cooper, D. R., \& Schindler, P. S. (2011). Métodos de Pesquisa em Administração (10th ed.). (I. D. Abreu, Trans.) Porto Alegre: Bookman.

Creswell, J. W. (2013). Research Design: Qualitative, Quantitative, and Mixed Methods Approaches (4th ed.). London: Sage.

Cross, N. (1982). Designerly ways of knowing. Design Studies, 3(4), 221-227. doi:10.1016/0142-694X(82)90040-0

Cross, N. (2001). Designerly Ways of Knowing : Design Discipline versus Design Science. Design Issues, 17(3), 49-55.

Cross, N., Dorst, K., \& Roozenburg, N. (1992). Research in Design Thinking. Delft: Delft University Press.

Cunningham, C. E., Woodward, C. A., Shannon, H. S., MacIntosh, J., Lendrum, B., Rosenbloom, D., \& Brown, J. (2002). Readiness for organizational change: a longitudinal study of workplace, psychological and behavioural correlates. Journal of Occupational and Organizational Psychology, 75(4), 377-392.

D. School. (2015). Bootcamp bootleg. Stanford. Retrieved June 15, 2017, from http://cmsimpact.org/wp-content/uploads/2015/11/Bootcamp-Bootleg-Resources-casestudy.pdf 
Dane, E., \& Pratt, M. G. (2007). Exploring intuition and its role in managerial decision making. Academy of Management Review, 32(1), 33-54.

Dorst, K. (1997). Describing Design: A Comparison of Paradigms. Thesis: TU Delft.

Dorst, K. (2006). Design Problems and Design Paradoxes. Design Issues, 22(3), 4-17.

Dorst, K. (2010). The Nature of Design thinking. Proceedings of the 8th Design Thinking Research Symposium (DTRS8), (pp. 131-139). Sidney.

Dorst, K., \& Cross, N. (2001). Creativity in the design process: co-evolution of problem-solution. Design Studies, 22(5), 425-437.

Douven, I. (2011, March 9). Abduction. Retrieved August 26, 2016, from The Stanford Encyclopedia of Philosophy: http://plato.stanford.edu/entries/abduction/

Dunne, D., \& Martin, R. (2006). Design thinking and how it will change management education:an interview and discussion. Academy of Management Learning \& Education, 5(4), 512-523.

Eby, L., Adam, D. M., Russel, J. E., \& Gaby, S. H. (2000). Perceptions of organizational readiness for change: factors related to employees' reactions to the implementation of team-based selling. Human Relations, 53(3), 419-442.

Epstein, S. (1994). Integration of the cognitive and the psychdynamic unconscious. American Psychologist, 49(8), 709-724.

Epstein, S. (2003). Cognitive-Experiential Self-Theory of Personality. In T. Millon, \& M. J. Lerner, Handbook of Psychology (pp. 159-184). New Jersey: John Wiley \& Sons.

Epstein, S., Pacini, R., Denes-Raj, V., \& Heier, H. (1996). Individual differences in intuitive-experiential and analytical-rational thinking styles. Journal of Personality and Social Psychology, 71(2), 390-405.

Erichsen, P. G., \& Christensen, P. R. (2013). The evolution of the design management field: A journal perspective. Creativity and Innovation Management, 22(2), 107-120.

Fleury, A. L., Stabile, H., \& Carvalho, M. M. (2016). An Overview of the Literature on Design Thinking: Trends and Contributions. International Journal of Engineering Education, 32(4), 1704-1718.

Frankfurt, H. G. (1958). Peirce's Notion of Abduction. The Journal of Philosophy, 55(14), 593-597.

Funaro, V. M., Pestana, M., Dziabas, M. C., Garcia, E. M., dos Santos, M. F., Nascimento, M. M., \& Cardoso, S. C. (2016). Diretrizes para apresentação de dissertações e teses da USP - Parte II (APA) (3rd ed.). São Paulo: USP Sistema Integrado de Bibliotecas. 
Glen, R., Suciu, C., \& Baughn, C. (2014). The need for design thinking in business schools. Academy of Management Learning and Education, 653-667.

Glen, R., Suciu, C., \& Baughn, C. (2015). Teaching design thinking in business schools. The International Journal of Management Education, 13, 182-192.

Gregory, S. A. (1966). Design and the design method. In S. A. Gregory, The design method. London: Butterworths.

Gruber, M., Leon, N. d., George, G., \& Thompson, P. (2015). From the editors Managing by Design. Academy of Management Journal, 58(1), 1-7.

Haffar, M., Al-Karaghouli, W., \& Ghoneim, A. (2014). An empirical investigation of the influence of organizational culture on individual readiness for change in Syrian manufacturing organizations. Journal of Organizational Change Management, 5-22.

Hinkin, T. R. (1998). A brief tutorial on the development of measures for use in survey questionnaires. Organizational Research Methods, 2(1), 104-121.

Holt, D. T., Armenakis, A. A., Feild, H. S., \& Harris, S. G. (2007b). Readiness for Organizational Change: the Systematic Development of a Scale. Journal Of Applied Behavioral Science, 232-255.

Holt, D. T., Armenakis, A. A., Harris, S. G., \& Feild, H. S. (2007a). Toward a comprehensive definition of readiness for change: A review of research and instrumentation. Research in organizational change and development, 289-336.

Horney, N., Pasmore, B., \& O'Shea, T. (2010). Leadership agility: a business imperative for a VUCA world. People \& Strategy, 33(4), 32-38.

IDEO. (2011). Human Centered Design. Retrieved June 15, 2017, from http://d1r3w4d5z5a88i.cloudfront.net/assets/toolkit/IDEO.org_HCD_ToolKit_English -5fef26ba5fa5761a3b021057d1d4a851.pdf

IDEO. (2012). Design thinking for educators.

IDEO. (2015). The Field Guide to Human-Centered Design.

Instituto Brasileiro de Geografia e Estatística IBGE. (2012). Pesquisa Nacional por Amostra de Domicílios - Síntese de Indicadores 2011. Rio de Janeiro: Ministério do Planejamento, Orçamento e Gestão.

Johansen, B., \& Euchner, J. (2013). Navigating the VUCA world. Research-Technology Management(Jan-Feb), 10-15.

Johansson-sköldberg, U., \& Woodilla, J. (2013). Design Thinking: Past, Present and Possible Futures. Creativity and Innovation Management, 22(2), 121-146.

Jonassen, D. H. (2000). Toward a design theory of problem solving. Education Technology: Research and Development, 48(4), 63-85. 
Jones, R. A., Jimmieson, N. L., \& Griffith, A. (2005). The impact of organizational culture and reshaping capabilities on change implementation success: The mediating role of readiness for change. Journal of Management Studies, 42(2), 361-386.

Jung, C. G. (1946). Psychological types. London: Kegan Paul, Trench, Trubner \& Co, LTD.

Khatri, N., \& Ng, H. (2000). The role of intuition in strategic decision making. Human Relations, 53(1), 57-86.

Kimbell, L. (2011). Rethinking Design Thinking: Part I. Design and Culture, 3(3), 285306.

Kirton, M. (1980). Adaptors and Innovators in Organizations. Human Relations, 3, $213-$ 224.

Kitchner, K. S. (1983). Cognition, metacognition, and epistemic cognition: A threelevel model of cognitive processing. Human Development, 26, 222-232.

Kotler, P., \& Rath, R. G. (1984). Design : a Powerful But Neglected Strategic Tool. Journal of Business Strategy, 5(2), 16-21.

Kurman, M., \& Beckman, S. (2011, May 30th). Asking the Important Questions: A Guide to Design Thinking And a Better Way to Serve Customers. Retrieved from Innovation Management.se: http://www.innovationmanagement.se/2011/05/30/askingthe-important-questions-a-guide-to-design-thinking-and-a-better-way-to-servecustomers/

Lawrence, K. (2013). Developing Leaders in a VUCA Environment. North Caroline, USA: UNC Kenan-Flagler Business School.

Lawson, B. (1979). Cognitive strategies in architectural design. Ergonomics, 22(1), 5968.

Lawson, B. (2005). How designers think: the design process demystified (4th ed.). Oxford: Architectural Press.

Lewin, K. (1946). Action Research and Minority Problems. Journal of Social Issues, 2(4), 34-46.

Lewin, K. (1947). Frontiers in Group Dynamics: Concept, Method and Reality in Social Science; Social Equilibria and Social Change. Human Relations, 5-41.

Lewin, K. (1951). Field theory in social science. New York: Harper and Row.

Liedtka, J. (2010). Business Strategy and Design: Can this Marriage Be Saved? The Design Management Institute (DMI), 6-11. 
Liedtka, J. (2015). Perspective: Linking Design Thinking with Innovation Outcomes through Cognitive Bias Reduction. Journal of Product Innovation Management, 32(6), 925-938.

Liedtka, J., \& Ogilvie, T. (2011). Designing for growth: a design thinking tool kit for managers. New York: Columbia Business School.

Martin, R. (2004). The Design of Business. Rotman Management(Winter), 7-11.

Martin, R. (2007). Design and business: why can't we be friends? Journal of Business Strategy, 28(4), 6-12.

Martin, R. (2009). Design of Business: Why Design Thinking is the Next Competitive Advantage. Boston: Harvard Business Press.

Martin, R. (2010). Design thinking: achieving insights via the "knowledge funnel". Strategy \& Leadership, 38(2), 37-41.

Meacham, J. A., \& Emont, N. C. (1989). The interpersonal basis of everyday problem solving. In J. D. Sinnott, Everyday problem solving: Theory and applications (pp. 723). New York: Praeger.

Miller, V. D., Johnson, J. R., \& Grau, J. (1994). Antecedents to willingness to participate in a planned organizational change. Journal of Applied Communication Research, 22, 59-80.

Millon, T., \& Lerner, M. J. (2003). Handbook of Psychology Volume V: Personality and Social Psychology. New Jersey: John Wiley \& Sons.

Minitab. (2018, June 3rd). Statistical Inference. Retrieved from Minitab Services: www.minitab.com/uploadedFiles/Documents/samplematerials/TrainingTTest16EN.pdf

Mintzberg, H. (2004). Managers not MBAs. San Francisco, CA: Berrett-Koehler Publishers.

Nagai, Y., \& Noguchi, H. (2003). An Experimental Study on the Design Thinking Process Started from Difficult Keywords: Modeling the Thinking Process of Creative Design. Journal of Engineering Design, 14, 429-37.

Oreg, S., Bartunek, J. M., Lee, G., \& Do, B. (2018). An affect-based model of recipients' responses to organizational change events. Academy of Management Review, 43(1), 65-86.

Oreg, S., Vakola, M., \& Armenakis, A. (2011). Change Recipients' Reactions to Organizational Change: a 60-Year Review of Quantitative Studies. The Journal of Applied Behavioral Science, 1-64. 
Pacini, R., \& Epstein, S. (1999). The relation of rational and experiential information processing styles to personality, basic beliefs, and the ratio-bias phenomenon. Journal of Personality and Social Psychology, 972-987.

Peirce, C. S. (1931-1958). Collected Papers of Charles Sanders Peirce. edited by $C$. Hartshorne, P. Weiss, and A. Burks. Cambridge, MA: Harvard University Press.

Pettigrew, A. (1985). Research on organisational change and development and strategic change: some limitations. In A. Pettigrew, The awakening giant: Continuity and change in Imperial Chemical Industries (pp. 1-25). Oxford: Basil Blackwell.

Pettigrew, A. (1987). Context and action in the transformation of the firm. Journal of Management Studies, 649-670.

PricewaterhouseCoopers. (2017). 20th CEO Survey. United Kingdom: PwC.

Rauth, I., Carlgren, L., \& Elmquist, M. (2015). Making it happen: legitimizing Design Thinking in large organizations. Design Management Journal, 47-60.

Razzouk, R., \& Shute, V. (2012). What Is Design Thinking and Why Is It Important? Review of Educational Research, 82(3), 330-348.

Rittel, H., \& Webber, M. (1973). Dilemmas in a General Theory of Planning. Policy Sciences, 4, 155-169.

Rowe, P. (1987). Design Thinking. Cambridge, MA: MIT Press.

Schön, D. A. (1983). The Reflective Practitioner: How Professionals Think In Action. New York: Basic Books.

Simon, H. A. (1973). The structure of ill structured problems. Artificial Intelligence, 4, 181-201.

Simon, H. A. (1996). The sciences of the artificial (3rd ed.). Cambridge, USA: MIT Press.

Sladek, R. M., Bond, M. J., \& Phillips, P. A. (2010). Age and gender differences in preferences for rational and experiential thinking. Personality and Individual Differences, 49, 907-911.

The UK Design Council. (2015, March 17). Design Council. Retrieved from The Design Process: What is the Double Diamond?: www.designcouncil.org.uk/newsopinion/design-process-what-double-diamond

Tschimmel, K. (2012). Design Thinking as an effective Toolkit for Innovation. The XXIII ISPIM Conference - Action for Innovation: Innovating from Experience (pp. 120). Barcelona, Spain: ISPIM.

Tversky, A., \& Kahneman, D. (1981). The framing of decisions and the psychology of choice. Science, 211, 453-458. 
Ungaretti, T., Chomowicz, P., Canniffe, B. J., Johnson, B., Weiss, E., Dunn, K., \& Cropper, C. (2009). Business + design: Exploring a competitive edge for business thinking. SAM Advanced Management Journal, 74(3), 4-11.

Vakola, M. (2014). What's in there for me? Individual readiness to change and the perceived impact of organizational change. Leadership \& Organization Development Journal, 195-209.

Vianna, M., Vianna, Y., Adler, I., Lucena, B., \& Russo, B. (2011). Design Thinking. Inovação em Negócios. Rio de Janeiro: MJV Press.

Walker, J. H., Armenakis, A. A., \& Bernerth, J. B. (2007). Factors influencing organizational change efforts. Journal of Organizational Change Management, 761773.

Witteman, C., Bercken, J., Claes, L., \& Godoy, A. (2009). Assessing rational and intuitive thinking styles. European Journal of Psychological Assessment, 25(1), 39-47.

Wood, P. K. (1983). Inquiring systems and problem structures: Implications for cognitive development. Human Development, 26, 249-265. 


\section{APPENDIX I - Questionnaire in Portuguese language}

Olá,

Você está convidado(a) a participar desta pesquisa da Universidade de São Paulo (USP). Trata-se de um questionário com duração de 12 minutos, sobre como você pensa e sobre a adoção de Design Thinking em sua organização.

Sua participação é voluntária, os dados coletados são confidenciais, a análise será realizada em nível agregado e não individual, e sua identificação pessoal somente ocorrerá caso deseje receber o resultado de seu estilo de pensamento. Se tiver dúvidas sobre o questionário ou sobre a privacidade da pesquisa, entre em contato com Willian Seii através do telefone (11) 98162-0388 ou pelo e-mail willian.seii@usp.br. Muito obrigado pelo seu tempo e atenção.

Q1. Qual é o seu conhecimento e experiência com Design Thinking? [opção única]

O Eu não sei o que é Design Thinking

Eu apenas ouvi falar sobre Design Thinking

O Eu li livros/artigos e/ou assisti vídeos sobre Design Thinking

O Eu já fiz ou estou fazendo um curso sobre Design Thinking

O Eu já executei ou estou executando um projeto que utiliza Design Thinking

O Meu trabalho utiliza Design Thinking regularmente 
Q2. Os seguintes items permitem entender como você pensa. Você deve responder tendo em mente a grande maioria das situações, sem considerar situações de exceção: [opção única por item]

\begin{tabular}{|c|c|c|c|c|}
\hline $\begin{array}{c}\text { Definitivament } \\
\text { e não } \\
\text { verdadeiro } \\
\text { sobre mim }\end{array}$ & $\begin{array}{l}\text { De alguma } \\
\text { forma não } \\
\text { verdadeiro } \\
\text { sobre mim }\end{array}$ & Indeciso & $\begin{array}{l}\text { De alguma } \\
\text { forma } \\
\text { verdadeiro } \\
\text { sobre mim }\end{array}$ & $\begin{array}{l}\text { Definitivament } \\
\text { e verdadeiro } \\
\text { sobre mim }\end{array}$ \\
\hline
\end{tabular}

\begin{abstract}
Eu tento evitar situações que requerem pensamentos profundos sobre algo.

Eu não sou tão bom assim em resolver problemas complicados.
\end{abstract}

sobre mim
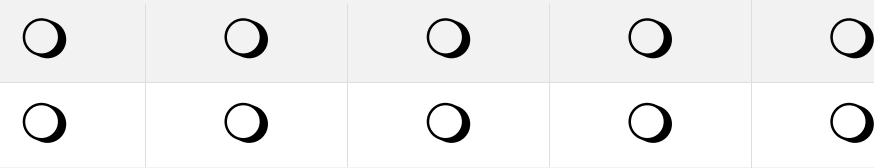

Eu aprecio desafios intelectuais.
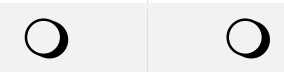

○

Eu não sou muito bom em resolver problemas que requerem cuidadosas análises lógicas.

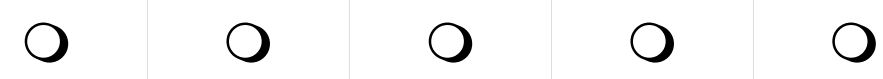

Eu não gosto de ter que pensar muito.

Eu aprecio resolver problemas que requerem muito pensamento.

Ficar pensando não é minha ideia de atividade prazerosa.

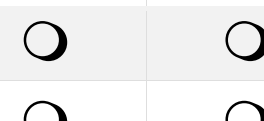

Eu não sou um pensador muito analítico.

Raciocinar cuidadosamente sobre coisas não é um de meus pontos fortes.

$\mathrm{O}$

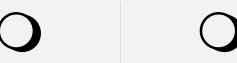

Eu prefiro problemas complexos a problemas simples.
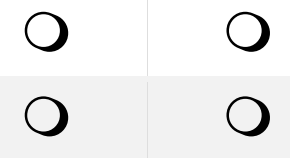

$\mathrm{O}$

O

O

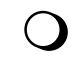

Pensar profundamente sobre algo e durante um longo tempo me dá pouca satisfação.

Eu não raciocino bem sobre pressão.

Eu sou muito melhor que a maioria das pessoas em descobrir coisas de forma lógica.

$\mathrm{O}$
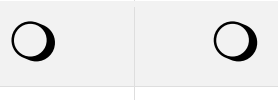

O

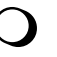

$\mathrm{O}$

$\mathrm{O}$

O

0

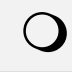

Eu tenho uma mente lógica.

Eu aprecio pensar em termos abstratos.

Eu não tenho problemas em pensar cuidadosamente sobre coisas.

$\mathrm{O}$
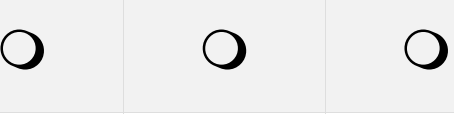

O $\quad 0$

O
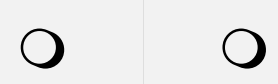

$\bigcirc$

O

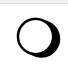

O

O

○

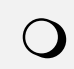

○

O

O

$\bigcirc$

O

0

0

O

$\mathrm{O}$

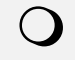

O

$\mathrm{O}$

$\bigcirc$

○

O

Utilizar lógica geralmente funciona bem para eu resolver problemas em minha vida.

O

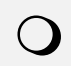

O

O

Saber a resposta sem ter que entender a razão por trás é bom o suficiente para mim.

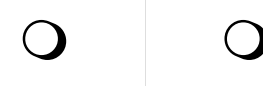

Eu geralmente tenho razões claras e explicáveis para minhas decisões.
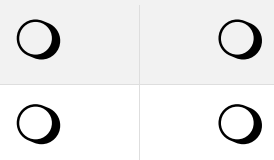

O

O

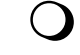

Aprender novas formas de pensar pode ser muito atrativo para mim. 


\begin{tabular}{|c|c|c|c|c|c|}
\hline & $\begin{array}{l}\text { Definitivament } \\
\text { e não } \\
\text { verdadeiro } \\
\text { sobre mim }\end{array}$ & $\begin{array}{l}\text { De alguma } \\
\text { forma não } \\
\text { verdadeiro } \\
\text { sobre mim }\end{array}$ & Indeciso & $\begin{array}{l}\text { De alguma } \\
\text { forma } \\
\text { verdadeiro } \\
\text { sobre mim }\end{array}$ & $\begin{array}{l}\text { Definitivament } \\
\text { e verdadeiro } \\
\text { sobre mim }\end{array}$ \\
\hline $\begin{array}{l}\text { Eu gosto de contar com minhas } \\
\text { impressões baseadas em intuição. }\end{array}$ & $C$ & O & $\bigcirc$ & ) & ) \\
\hline $\begin{array}{l}\text { Eu não tenho um senso de intuição } \\
\text { muito bom. }\end{array}$ & 0 & O & O & O & ) \\
\hline $\begin{array}{l}\text { Utilizar minha intuição geralmente } \\
\text { funciona bem para eu resolver } \\
\text { problemas em minha vida. }\end{array}$ & & O & & & \\
\hline Eu acredito em meus pressentimentos. & & O & & & \\
\hline $\begin{array}{l}\text { Intuição pode ser um caminho muito } \\
\text { útil para resolver problemas. }\end{array}$ & $\Omega$ & 0 & O & & \\
\hline $\begin{array}{l}\text { Eu geralmente sigo meus instintos ao } \\
\text { decidir um caminho de ação. }\end{array}$ & & & & & \\
\hline $\begin{array}{l}\text { Eu confio em minhas primeiras } \\
\text { impressões sobre pessoas. }\end{array}$ & & O & & & \\
\hline $\begin{array}{l}\text { Quando se trata de confiar em } \\
\text { pessoas, eu posso geralmente confiar } \\
\text { em meus instintos. }\end{array}$ & & & & & \\
\hline $\begin{array}{l}\text { Se eu fosse confiar em meus instintos, } \\
\text { eu geralmente cometeria enganos. }\end{array}$ & & O & & & \\
\hline $\begin{array}{l}\text { Eu não gosto de situações em que } \\
\text { tenho que confiar em minha intuição. }\end{array}$ & & 0 & $\Omega$ & & \\
\hline $\begin{array}{l}\text { Eu penso que há momentos em que } \\
\text { alguém deve confiar na intuição. }\end{array}$ & $\bigcirc$ & O & $\mathrm{O}$ & & \\
\hline $\begin{array}{l}\text { Eu penso que é tolice tomar decisões } \\
\text { importantes baseadas em intuições. }\end{array}$ & $\cap$ & O & O & & \\
\hline $\begin{array}{l}\text { Eu não penso que é um boa ideia } \\
\text { confiar na intuição de alguém para } \\
\text { decisões importantes. }\end{array}$ & 0 & $\bigcirc$ & $\mathrm{O}$ & $\bigcirc$ & $\bigcirc$ \\
\hline $\begin{array}{l}\text { Eu geralmente não dependo de minha } \\
\text { intuição para me ajudar na tomada de } \\
\text { decisões. }\end{array}$ & O & O & O & & \\
\hline
\end{tabular}

Eu dificilmente erro quando eu ouço minhas profundas intuições para encontrar uma resposta.

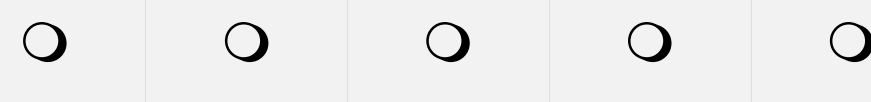

Eu não gostaria de depender de alguém que se descreve como intuitivo.

Meus julgamentos rápidos

provavelmente não são tão bons quanto os julgamentos da maioria das pessoas.

$\begin{array}{lllll}0 & 0 & 0 & 0 & 0\end{array}$

Eu tendo a utilizar meu coração como guia para minhas ações.

Eu geralmente posso sentir quando uma pessoa está certa ou errada, mesmo que eu não possa explicar como eu sei.
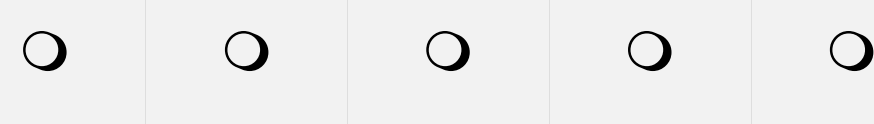

Eu suspeito que meus pressentimentos são imprecisos tanto quanto eles são precisos.

$0 \quad 0$

○
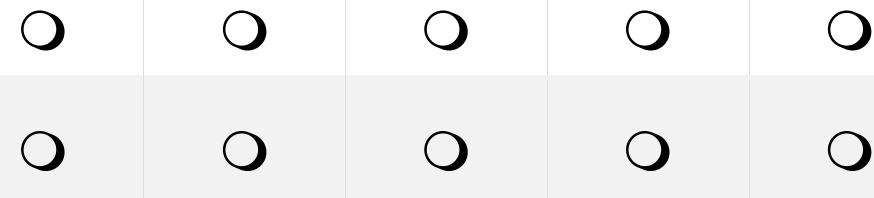
Q3. Quais características melhor descrevem o Design Thinking, em sua opinião: [opção única por item]

\begin{tabular}{|c|c|c|c|c|c|c|}
\hline & $<<$ & $<$ & & $>$ & $>>$ & \\
\hline Objetivos bem definidos & $\mathrm{O}$ & $\mathrm{O}$ & O & $\mathrm{O}$ & O & Objetivos em aberto \\
\hline Critérios objetivos & O & $\mathrm{O}$ & O & $\mathrm{O}$ & O & Critérios objetivos e subjetivos \\
\hline Método iterativo / & $\mathrm{O}$ & $\mathrm{O}$ & $\mathrm{O}$ & O & O & Método linear \\
\hline Qualitativo & $\mathrm{O}$ & $\mathrm{O}$ & $\mathrm{O}$ & $\mathrm{O}$ & O & Quantitativo \\
\hline Representação verbal & O & O & O & O & O & Representação visual \\
\hline Baseado em lógica & O & $\mathrm{O}$ & O & O & O & Baseado em experiências e intuições \\
\hline Redução de erros & $\mathrm{O}$ & $\mathrm{O}$ & O & $\mathrm{O}$ & O & Errar para aprender \\
\hline Respostas definitivas & O & 0 & 0 & 0 & 0 & Respostas parciais \\
\hline
\end{tabular}

Q4. Para os items abaixo, qual a sua opinião sobre a adoção de Design Thinking em sua empresa, como abordagem institucionalizada para resolução de problemas complexos: [opção única por item] 


\begin{tabular}{|c|c|c|c|c|c|c|c|}
\hline & $\begin{array}{l}\text { Discordo } \\
\text { fortemente }\end{array}$ & Discordo & $\begin{array}{l}\text { Discordo } \\
\text { de certa } \\
\text { forma }\end{array}$ & $\begin{array}{l}\text { Não } \\
\text { concordo } \\
\text { nem } \\
\text { discordo }\end{array}$ & $\begin{array}{l}\text { Concordo } \\
\text { de certa } \\
\text { forma }\end{array}$ & Concordo & $\begin{array}{l}\text { Concordo } \\
\text { fortemente }\end{array}$ \\
\hline $\begin{array}{l}\text { Eu penso que a organização irá se } \\
\text { beneficiar com esta mudança. }\end{array}$ & 0 & 0 & 0 & 0 & 0 & 0 & 0 \\
\hline $\begin{array}{l}\text { Não faz muito sentido para nós iniciar } \\
\text { esta mudança. }\end{array}$ & 0 & 0 & 0 & 0 & 0 & 0 & D \\
\hline $\begin{array}{l}\text { Há razões legítimas para que } \\
\text { realizemos esta mudança. }\end{array}$ & & & 0 & & 0 & & \\
\hline $\begin{array}{l}\text { Esta mudança irá melhorar a } \\
\text { eficiência geral de nossa organização. }\end{array}$ & & & $\mathrm{O}$ & & 0 & & \\
\hline $\begin{array}{l}\text { Há um conjunto de motivos racionais } \\
\text { para esta mudança ser realizada. }\end{array}$ & & 0 & 0 & 0 & 0 & & \\
\hline $\begin{array}{l}\text { No longo prazo, eu sinto que valerá a } \\
\text { pena para mim se a organização } \\
\text { adotar esta mudança. }\end{array}$ & & & 0 & & 0 & & \\
\hline $\begin{array}{l}\text { Esta mudança torna meu trabalho } \\
\text { mais fácil. }\end{array}$ & & & 0 & & 0 & & \\
\hline $\begin{array}{l}\text { Quando esta mudança for } \\
\text { implementada, eu não acredito que } \\
\text { haverá algum ganho para mim. }\end{array}$ & & & 0 & & & & \\
\hline $\begin{array}{l}\text { O tempo que estamos gastando com } \\
\text { esta mudança deveria ser gasto em } \\
\text { alguma outra mudança. }\end{array}$ & & & & & & & \\
\hline $\begin{array}{l}\text { Esta mudança se encaixa dentro das } \\
\text { prioridades de nossa organização. }\end{array}$ & & & 0 & & 0 & & \\
\hline $\begin{array}{l}\text { Eu não antevejo nenhum problema } \\
\text { para ajustar meu trabalho quando } \\
\text { esta mudança for adotada. }\end{array}$ & & & & & 0 & & ) \\
\hline $\begin{array}{l}\text { Há algumas tarefas que serão } \\
\text { solicitadas quando mudarmos que eu } \\
\text { não acho que posso fazer bem. }\end{array}$ & & & & & & & \\
\hline $\begin{array}{l}\text { Quando nós implementarmos esta } \\
\text { mudança, eu sinto que eu posso lidar } \\
\text { com facilidade. }\end{array}$ & & & & & & & \\
\hline $\begin{array}{l}\text { Eu tenho as habilidades que são } \\
\text { necessárias para fazer esta mudança } \\
\text { funcionar. }\end{array}$ & & & & & & & \\
\hline $\begin{array}{l}\text { Quando eu focar minha mente para } \\
\text { isto, eu posso aprender tudo que for } \\
\text { necessário quando esta mudança for } \\
\text { adotada. }\end{array}$ & & & & & & & \\
\hline $\begin{array}{l}\text { Minhas experiências anteriores me } \\
\text { dão confiança que eu serei capaz de } \\
\text { executar com sucesso após essa } \\
\text { mudança ser implementada. }\end{array}$ & & & & & & & \\
\hline $\begin{array}{l}\text { Eu estou preocupado que eu irei } \\
\text { perder parte de meus status na } \\
\text { organização quando esta } \\
\text { mudança for implementada. }\end{array}$ & & & & & & & \\
\hline $\begin{array}{l}\text { Esta mudança irá romper muitos } \\
\text { dos relacionamentos pessoais } \\
\text { que eu desenvolvi. }\end{array}$ & & & 0 & & 0 & $\mathrm{C}$ & C \\
\hline $\begin{array}{l}\text { Meu futuro neste trabalho estará } \\
\text { limitado por causa desta } \\
\text { mudança. }\end{array}$ & & & 0 & & 0 & 0 & \\
\hline
\end{tabular}


Q5. Qual é o sua função principal na empresa? [opção única]

O Marketing / Vendas / Relações Públicas

O Recursos Humanos

O Operações

O Finanças / Contabilidade / Controladoria

O Tecnologia da Informação (TI)

O Pesquisa e Desenvolvimento (P\&D)

O Design / Design Gráfico / Design UI / Design UX / Design de Serviço

O Outro

Q6. Qual é o nome de sua empresa?

Q7. Há quantos anos você trabalha nesta empresa?

Q8. Qual é o nome da gerência em que você trabalha?

Q9. Em quantas gerências diferentes você já trabalhou nesta empresa?

Q10. Qual é o seu grau de escolaridade? (completo ou incompleto) [opção única]

Ensino Médio (antigo colegial)

Ensino Superior (faculdade)

O Pós Graduação (cursos de especialização, mestrado, doutorado)

O Outro grau de escolaridade:

Q11. Qual é a sua formação acadêmica (graduação)? [opção única]

O Administração de Empresas

O Engenharia

O Design e/ou Arquitetura

O Formação em Ciências Humanas (excluindo Administração)

O Formação em Ciências Exatas (excluindo Engenharia)

Formação em Ciências Biológicas

O Formação em Artes

O Outra formação não mencionada acima 
Q12. Qual é a sua posição na organização? [opção única]

$\begin{array}{ll}\text { O } & \text { Proprietário / Sócio } \\ \text { O } & \text { Diretor } \\ \text { O } & \text { Superintendente } \\ \text { O } & \text { Gerente (nível júnior até sênior) } \\ \text { O } & \text { Coordenador / Supervisor } \\ \text { O } & \text { Analista (nível júnior até sênior) } \\ \text { O } & \text { Outra: }\end{array}$

Q13. Quantos anos você tem?

Q14. Qual é o seu sexo?

O Masculino

O Feminino

Caso deseje receber o resultado de seu estilo de pensamento, informe seu e-mail abaixo [opcional]:

Caso deseje registrar comentários, sugestões ou críticas, utilize o espaço abaixo [opcional]: 


\section{APPENDIX II - Back Translation}

\begin{tabular}{|c|c|c|c|}
\hline Scales & $\begin{array}{l}\text { TRANSLATION TO PORTUGUESE, by } \\
\text { Willian Seii }\end{array}$ & $\begin{array}{l}\text { BACK TRANSLATION TO ENGLISH, by } \\
\text { Bruna Terra }\end{array}$ & ORIGINAL VERSION IN ENGLISH \\
\hline \multirow{16}{*}{ Rationality } & $\begin{array}{l}\text { Eu tento evitar situações que requerem } \\
\text { pensamentos profundos sobre algo. }\end{array}$ & $\begin{array}{l}\text { I try to avoid situations that require deep } \\
\text { thinking about something. }\end{array}$ & $\begin{array}{l}\text { I try to avoid situations that require thinking in } \\
\text { depth about something. }\end{array}$ \\
\hline & $\begin{array}{l}\text { Eu não sou tão bom assim em resolver } \\
\text { problemas complicados. }\end{array}$ & $\begin{array}{l}\text { I am not that good in solving complicated } \\
\text { problems. }\end{array}$ & $\begin{array}{l}\text { I'm not that good at figuring out complicated } \\
\text { problems. }\end{array}$ \\
\hline & Eu aprecio desafios intelectuais. & I appreciate intelectual challenges. & I enjoy intellectual challenges. \\
\hline & $\begin{array}{l}\text { Eu não sou muito bom em resolver problemas } \\
\text { que requerem cuidadosas análises lógicas. }\end{array}$ & $\begin{array}{l}\text { I am not that good in solving problems that } \\
\text { require carefull logical analysis. }\end{array}$ & $\begin{array}{l}\text { I am not very good at solving problems that } \\
\text { require careful logical analysis. }\end{array}$ \\
\hline & Eu não gosto de ter que pensar muito. & I do not like to have to think a lot. & I don't like to have to do a lot of thinking. \\
\hline & $\begin{array}{l}\text { Eu aprecio resolver problemas que requerem } \\
\text { muito pensamento. }\end{array}$ & $\begin{array}{l}\text { I appreciate solving problems that require a lot } \\
\text { of thinking. }\end{array}$ & $\begin{array}{l}\text { I enjoy solving problems that require hard } \\
\text { thinking. }\end{array}$ \\
\hline & $\begin{array}{l}\text { Ficar pensando não é minha ideia de atividade } \\
\text { prazerosa. }\end{array}$ & To think is not my idea of a pleasurable activity. & Thinking is not my idea of an enjoyable activity. \\
\hline & Eu não sou um pensador muito analítico. & I am not a very analytical thinker. & I am not a very analytical thinker. \\
\hline & $\begin{array}{l}\text { Raciocinar cuidadosamente sobre coisas não é } \\
\text { um de meus pontos fortes. }\end{array}$ & $\begin{array}{l}\text { To carefully reason about things is not one of } \\
\text { my strong points. }\end{array}$ & $\begin{array}{l}\text { Reasoning things out carefully is not one of my } \\
\text { strong points. }\end{array}$ \\
\hline & $\begin{array}{l}\text { Eu prefiro problemas complexos a problemas } \\
\text { simples. }\end{array}$ & I prefer complex problems than simple ones. & I prefer complex problems to simple problems. \\
\hline & $\begin{array}{l}\text { Pensar profundamente sobre algo e durante um } \\
\text { longo tempo me dá pouca satisfação. }\end{array}$ & $\begin{array}{l}\text { To deeply think about something and during a } \\
\text { long time gives me little satisfaction. }\end{array}$ & $\begin{array}{l}\text { Thinking hard and for a long time about } \\
\text { something gives me little satisfaction. }\end{array}$ \\
\hline & Eu não raciocino bem sobre pressão. & I do not reason well under pressure. & I don't reason well under pressure. \\
\hline & $\begin{array}{l}\text { Eu sou muito melhor que a maioria das pessoas } \\
\text { em descobrir coisas de forma lógica. }\end{array}$ & $\begin{array}{l}\text { I am much better than the majority of people in } \\
\text { finding out things in a logical way. }\end{array}$ & $\begin{array}{l}\text { I am much better at figuring things out logically } \\
\text { than most people. }\end{array}$ \\
\hline & Eu tenho uma mente lógica. & I have a logical mind. & I have a logical mind. \\
\hline & Eu aprecio pensar em termos abstratos. & I appreciate thinking in abstract terms. & I enjoy thinking in abstract terms. \\
\hline & $\begin{array}{l}\text { Eu não tenho problemas em pensar } \\
\text { cuidadosamente sobre coisas. }\end{array}$ & $\begin{array}{l}\text { I do not have problems to think carefully about } \\
\text { things. }\end{array}$ & $\begin{array}{l}\text { I have no problem thinking things through } \\
\text { carefully. }\end{array}$ \\
\hline
\end{tabular}




\begin{tabular}{|c|c|c|c|}
\hline Scales & $\begin{array}{l}\text { TRANSLATION TO PORTUGUESE, by } \\
\text { Willian Seii }\end{array}$ & $\begin{array}{l}\text { BACK TRANSLATION TO ENGLISH, by } \\
\text { Bruna Terra }\end{array}$ & ORIGINAL VERSION IN ENGLISH \\
\hline & $\begin{array}{l}\text { Utilizar lógica geralmente funciona bem para eu } \\
\text { resolver problemas em minha vida. }\end{array}$ & $\begin{array}{l}\text { To utilize logic generally works well for me to } \\
\text { solve problems in my life. }\end{array}$ & $\begin{array}{l}\text { Using logic usually works well for me in } \\
\text { figuring out problems in my life. }\end{array}$ \\
\hline & $\begin{array}{l}\text { Saber a resposta sem ter que entender a razão } \\
\text { por trás é bom o suficiente para mim. }\end{array}$ & $\begin{array}{l}\text { To know the answer without having to } \\
\text { understand the reason behind it is good is } \\
\text { enough for me. }\end{array}$ & $\begin{array}{l}\text { Knowing the answer without having to } \\
\text { understand the reasoning behind it is good } \\
\text { enough for me. }\end{array}$ \\
\hline & $\begin{array}{l}\text { Eu geralmente tenho razões claras e explicáveis } \\
\text { para minhas decisões. }\end{array}$ & $\begin{array}{l}\text { I generally have clear and explainable reasons } \\
\text { for my decisions. }\end{array}$ & $\begin{array}{l}\text { I usually have clear, explainable reasons for my } \\
\text { decisions. }\end{array}$ \\
\hline & $\begin{array}{l}\text { Aprender novas formas de pensar pode ser } \\
\text { muito atrativo para mim. }\end{array}$ & $\begin{array}{l}\text { To learn new ways of thinking can be very } \\
\text { attractive for me. }\end{array}$ & $\begin{array}{l}\text { Learning new ways to think would be very } \\
\text { appealing to me. }\end{array}$ \\
\hline \multirow{12}{*}{ Experientiality } & $\begin{array}{l}\text { Eu gosto de contar com minhas impressões } \\
\text { baseadas em intuição. }\end{array}$ & $\begin{array}{l}\text { I like to count on my impressions based on } \\
\text { intuition. }\end{array}$ & I like to rely on my intuitive impressions. \\
\hline & Eu não tenho um senso de intuição muito bom. & I do not have a very good sense of intuition. & I don't have a very good sense of intuition. \\
\hline & $\begin{array}{l}\text { Utilizar minha intuição geralmente funciona } \\
\text { bem para eu resolver problemas em minha vida. }\end{array}$ & $\begin{array}{l}\text { To utilize my intuition generally works well for } \\
\text { me to solve problems in my life. }\end{array}$ & $\begin{array}{l}\text { Using my gut feelings usually works well for me } \\
\text { in figuring out problems in my life. }\end{array}$ \\
\hline & Eu acredito em meus pressentimentos. & I believe in my presentiments. & I believe in trusting my hunches. \\
\hline & $\begin{array}{l}\text { Intuição pode ser um caminho muito útil para } \\
\text { resolver problemas. }\end{array}$ & $\begin{array}{l}\text { Intuition can be a very useful way to solve } \\
\text { problems. }\end{array}$ & $\begin{array}{l}\text { Intuition can be a very useful way to solve } \\
\text { problems. }\end{array}$ \\
\hline & $\begin{array}{l}\text { Eu geralmente sigo meus instintos ao decidir um } \\
\text { caminho de ação. }\end{array}$ & $\begin{array}{l}\text { I generally follow my instincts when deciding a } \\
\text { path of action. }\end{array}$ & $\begin{array}{l}\text { I often go by my instincts when deciding on a } \\
\text { course of action. }\end{array}$ \\
\hline & $\begin{array}{l}\text { Eu confio em minhas primeiras impressões } \\
\text { sobre pessoas. }\end{array}$ & I trust my first impressions about people. & I trust my initial feelings about people. \\
\hline & $\begin{array}{l}\text { Quando se trata de confiar em pessoas, eu posso } \\
\text { geralmente confiar em meus instintos. }\end{array}$ & $\begin{array}{l}\text { When it is about trusting people, I can generally } \\
\text { trust my instincts. }\end{array}$ & $\begin{array}{l}\text { When it comes to trusting people, I can usually } \\
\text { rely on my gut feelings. }\end{array}$ \\
\hline & $\begin{array}{l}\text { Se eu fosse confiar em meus instintos, eu } \\
\text { geralmente cometeria enganos. }\end{array}$ & $\begin{array}{l}\text { If I were to trust my instincts, I would generally } \\
\text { make mistakes. }\end{array}$ & $\begin{array}{l}\text { If I were to rely on my gut feelings, I would } \\
\text { often make mistakes. }\end{array}$ \\
\hline & $\begin{array}{l}\text { Eu não gosto de situações em que tenho que } \\
\text { confiar em minha intuição. }\end{array}$ & $\begin{array}{l}\text { I do not like situations in which I have to trust } \\
\text { my intuition. }\end{array}$ & $\begin{array}{l}\text { I don't like situations in which I have to rely on } \\
\text { intuition. }\end{array}$ \\
\hline & $\begin{array}{l}\text { Eu penso que há momentos em que alguém deve } \\
\text { confiar na intuição. }\end{array}$ & $\begin{array}{l}\text { I think that there are moments in which someone } \\
\text { needs to trust the intuition. }\end{array}$ & $\begin{array}{l}\text { I think there are times when one should rely on } \\
\text { one's intuition. }\end{array}$ \\
\hline & Eu penso que é tolice tomar decisões & I think it is foolish to make important decisions & I think it is foolish to make important decisions \\
\hline
\end{tabular}




\begin{tabular}{|c|c|c|c|}
\hline Scales & $\begin{array}{l}\text { TRANSLATION TO PORTUGUESE, by } \\
\text { Willian Seii }\end{array}$ & $\begin{array}{l}\text { BACK TRANSLATION TO ENGLISH, by } \\
\text { Bruna Terra }\end{array}$ & ORIGINAL VERSION IN ENGLISH \\
\hline & importantes baseadas em intuições. & based on intuition. & based on feelings. \\
\hline & $\begin{array}{l}\text { Eu não penso que é um boa ideia confiar na } \\
\text { intuição de alguém para decisões importantes. }\end{array}$ & $\begin{array}{l}\text { I do not think that it is a good idea to trust } \\
\text { someone's intuition for important decisions. }\end{array}$ & $\begin{array}{l}\text { I don't think it is a good idea to rely on one's } \\
\text { intuition for important decisions. }\end{array}$ \\
\hline & $\begin{array}{l}\text { Eu geralmente não dependo de minha intuição } \\
\text { para me ajudar na tomada de decisões. }\end{array}$ & $\begin{array}{l}\text { I generally do not depend on my intuition to } \\
\text { help me in the decision making. }\end{array}$ & $\begin{array}{l}\text { I generally don't depend on my feelings to help } \\
\text { me make decisions. }\end{array}$ \\
\hline & $\begin{array}{l}\text { Eu dificilmente erro quando eu ouço minhas } \\
\text { profundas intuições para encontrar uma } \\
\text { resposta. }\end{array}$ & $\begin{array}{l}\text { I hardly make mistakes when I listen to my deep } \\
\text { intuitions to find an answer. }\end{array}$ & $\begin{array}{l}\text { I hardly ever go wrong when I listen to my } \\
\text { deepest gut feelings to find an answer. }\end{array}$ \\
\hline & $\begin{array}{l}\text { Eu não gostaria de depender de alguém que se } \\
\text { descreve como intuitivo. }\end{array}$ & $\begin{array}{l}\text { I would not like to depend on someone that } \\
\text { describes themselves as intuitive. }\end{array}$ & $\begin{array}{l}\text { I would not want to depend on anyone who } \\
\text { described himself or herself as intuitive. }\end{array}$ \\
\hline & $\begin{array}{l}\text { Meus julgamentos rápidos provavelmente não } \\
\text { são tão bons quanto os julgamentos da maioria } \\
\text { das pessoas. }\end{array}$ & $\begin{array}{l}\text { My fast judgements probably are not as good as } \\
\text { the judgements of the majority of people. }\end{array}$ & $\begin{array}{l}\text { My snap judgments are probably not as good as } \\
\text { most people's. }\end{array}$ \\
\hline & $\begin{array}{l}\text { Eu tendo a utilizar meu coração como guia para } \\
\text { minhas ações. }\end{array}$ & $\begin{array}{l}\text { I tend to utilize my heart as a guide for my } \\
\text { actions. }\end{array}$ & I tend to use my heart as a guide for my actions. \\
\hline & $\begin{array}{l}\text { Eu geralmente posso sentir quando uma pessoa } \\
\text { está certa ou errada, mesmo que eu não possa } \\
\text { explicar como eu sei. }\end{array}$ & $\begin{array}{l}\text { I generally can feel when someone is right or } \\
\text { wrong, even if I cannot explain how I know it. }\end{array}$ & $\begin{array}{l}\text { I can usually feel when a person is right or } \\
\text { wrong, even if I can't explain how I know. }\end{array}$ \\
\hline & $\begin{array}{l}\text { Eu suspeito que meus pressentimentos são } \\
\text { imprecisos tanto quanto eles são precisos. }\end{array}$ & $\begin{array}{l}\text { I suspect that my presentiments are imprecise as } \\
\text { much as they are precise. }\end{array}$ & $\begin{array}{l}\text { I suspect my hunches are inaccurate as often as } \\
\text { they are accurate. }\end{array}$ \\
\hline \multirow{5}{*}{ Appropriateness } & $\begin{array}{l}\text { Eu penso que a organização (Itaú) irá se } \\
\text { beneficiar com esta mudança. }\end{array}$ & $\begin{array}{l}\text { I think that the organization will benefit from } \\
\text { this change. }\end{array}$ & $\begin{array}{l}\text { I think that the organization will benefit from } \\
\text { this change. }\end{array}$ \\
\hline & $\begin{array}{l}\text { Não faz muito sentido para nós iniciar esta } \\
\text { mudança. }\end{array}$ & $\begin{array}{l}\text { It does not make sense for us to initiate this } \\
\text { change. }\end{array}$ & $\begin{array}{l}\text { It doesn't make much sense for us to initiate this } \\
\text { change. }\end{array}$ \\
\hline & $\begin{array}{l}\text { Há razões legítimas para que realizemos esta } \\
\text { mudança. }\end{array}$ & $\begin{array}{l}\text { There are legitimate reasons for us to make this } \\
\text { change. }\end{array}$ & $\begin{array}{l}\text { There are legitimate reasons for us to make this } \\
\text { change. }\end{array}$ \\
\hline & $\begin{array}{l}\text { Esta mudança irá melhorar a eficiência geral de } \\
\text { nossa organização. }\end{array}$ & $\begin{array}{l}\text { This change will improve the general efficiency } \\
\text { of our organization. }\end{array}$ & $\begin{array}{l}\text { This change will improve our organization's } \\
\text { overall efficiency. }\end{array}$ \\
\hline & $\begin{array}{l}\text { Há um conjunto de motivos racionais para esta } \\
\text { mudança ser realizada. }\end{array}$ & $\begin{array}{l}\text { There is a set of rational reasons for this change } \\
\text { to be done. }\end{array}$ & $\begin{array}{l}\text { There are a number of rational reasons for this } \\
\text { change to be made. }\end{array}$ \\
\hline
\end{tabular}




\begin{tabular}{|c|c|c|c|}
\hline Scales & $\begin{array}{l}\text { TRANSLATION TO PORTUGUESE, by } \\
\text { Willian Seii }\end{array}$ & $\begin{array}{l}\text { BACK TRANSLATION TO ENGLISH, by } \\
\text { Bruna Terra }\end{array}$ & ORIGINAL VERSION IN ENGLISH \\
\hline & $\begin{array}{l}\text { No longo prazo, eu sinto que valerá a pena para } \\
\text { mim se a organização adotar esta mudança. }\end{array}$ & $\begin{array}{l}\text { In the long term, I feel that it will be worth for } \\
\text { me if the organization adopts this change. }\end{array}$ & $\begin{array}{l}\text { In the long run, I feel it will be worthwhile for } \\
\text { me if the organization adopts this change. }\end{array}$ \\
\hline & Esta mudança irá tornar meu trabalho mais fácil. & This change will make my work easier. & This change makes my job easier. \\
\hline & $\begin{array}{l}\text { Quando esta mudança for implementada, eu não } \\
\text { acredito que haverá algum ganho para mim. }\end{array}$ & $\begin{array}{l}\text { When this change is implemented, I do not } \\
\text { believe that there will be some win for me. }\end{array}$ & $\begin{array}{l}\text { When this change is implemented, I don't } \\
\text { believe there is anything for me to gain. }\end{array}$ \\
\hline & $\begin{array}{l}\text { O tempo que estamos gastando com esta } \\
\text { mudança deveria ser gasto em alguma outra } \\
\text { coisa. }\end{array}$ & $\begin{array}{l}\text { The time that we are spending with this change } \\
\text { should be spent with something else. }\end{array}$ & $\begin{array}{l}\text { The time we are spending on this change should } \\
\text { be spent on something else. }\end{array}$ \\
\hline & $\begin{array}{l}\text { Esta mudança se encaixa dentro das prioridades } \\
\text { de nossa organização. }\end{array}$ & $\begin{array}{l}\text { This change fits with the priorities of our } \\
\text { organization. }\end{array}$ & $\begin{array}{l}\text { This change matches the priorities of our } \\
\text { organization. }\end{array}$ \\
\hline \multirow{6}{*}{ Change Efficacy } & $\begin{array}{l}\text { Eu não antevejo nenhum problema para ajustar } \\
\text { meu trabalho quando esta mudança for adotada. }\end{array}$ & $\begin{array}{l}\text { I do not foresee any problem to adjust my work } \\
\text { when this change is adopted. }\end{array}$ & $\begin{array}{l}\text { I do not anticipate any problems adjusting to the } \\
\text { work I will have when this change is adopted. }\end{array}$ \\
\hline & $\begin{array}{l}\text { Há algumas tarefas que serão solicitadas quando } \\
\text { mudarmos que eu não acho que posso fazer } \\
\text { bem. }\end{array}$ & $\begin{array}{l}\text { There are some tasks that will be requested } \\
\text { when we change that I do not think that I can do } \\
\text { well. }\end{array}$ & $\begin{array}{l}\text { There are some tasks that will be required when } \\
\text { we change that I don't think I can do well. }\end{array}$ \\
\hline & $\begin{array}{l}\text { Quando nós implementarmos esta mudança, eu } \\
\text { sinto que eu posso lidar com facilidade. }\end{array}$ & $\begin{array}{l}\text { When we implement this change, I feel that I } \\
\text { can handle easily. }\end{array}$ & $\begin{array}{l}\text { When we implement this change, I feel I can } \\
\text { handle it with ease. }\end{array}$ \\
\hline & $\begin{array}{l}\text { Eu tenho as habilidades que são necessárias para } \\
\text { fazer esta mudança funcionar. }\end{array}$ & $\begin{array}{l}\text { I have the abilities that are needed to make this } \\
\text { change work. }\end{array}$ & $\begin{array}{l}\text { I have the skills that are needed to make this } \\
\text { change work. }\end{array}$ \\
\hline & $\begin{array}{l}\text { Quando eu focar minha mente para isto, eu } \\
\text { posso aprender tudo que for necessário quando } \\
\text { esta mudança for adotada. }\end{array}$ & $\begin{array}{l}\text { When I focus my mind on this, I can learn } \\
\text { everything that will be needed when this change } \\
\text { is adopted. }\end{array}$ & $\begin{array}{l}\text { When I set my mind to it, I can learn everything } \\
\text { that will be required when this change is } \\
\text { adopted. }\end{array}$ \\
\hline & $\begin{array}{l}\text { Minhas experiências anteriores me dão } \\
\text { confiança que eu serei capaz de executar com } \\
\text { sucesso após essa mudança ser implementada. }\end{array}$ & $\begin{array}{l}\text { My previous experiences give me confidence } \\
\text { that I will be capable of executing successfully } \\
\text { after this change is implemented. }\end{array}$ & $\begin{array}{l}\text { My past experiences make me confident that I } \\
\text { will be able to perform successfully after this } \\
\text { change is made. }\end{array}$ \\
\hline \multirow{2}{*}{$\begin{array}{l}\text { Personally } \\
\text { Beneficial }\end{array}$} & $\begin{array}{l}\text { Eu estou preocupado que eu irei perder parte de } \\
\text { meus status na organização quando esta } \\
\text { mudança for implementada. }\end{array}$ & $\begin{array}{l}\text { I am worried that I will lose part of my status in } \\
\text { the organization when this change is } \\
\text { implemented. }\end{array}$ & $\begin{array}{l}\text { I am worried I will lose some of my status in the } \\
\text { organization when this change is implemented. }\end{array}$ \\
\hline & $\begin{array}{l}\text { Esta mudança irá romper muitos dos } \\
\text { relacionamentos pessoais que eu desenvolvi. }\end{array}$ & $\begin{array}{l}\text { This change will break many personal } \\
\text { relationships that I have developed. }\end{array}$ & $\begin{array}{l}\text { This change will disrupt many of the personal } \\
\text { relationships I have developed. }\end{array}$ \\
\hline
\end{tabular}




\begin{tabular}{|l|l|l|l|}
\hline Scales & $\begin{array}{l}\text { TRANSLATION TO PORTUGUESE, by } \\
\text { Willian Seii }\end{array}$ & $\begin{array}{l}\text { BACK TRANSLATION TO ENGLISH, by } \\
\text { Bruna Terra }\end{array}$ & ORIGINAL VERSION IN ENGLISH \\
\hline & $\begin{array}{l}\text { Meu futuro neste trabalho estará limitado por } \\
\text { causa desta mudança. }\end{array}$ & $\begin{array}{l}\text { My future in this job will be limited because of } \\
\text { this change. }\end{array}$ & $\begin{array}{l}\text { My future in this job will be limited because of } \\
\text { this change. }\end{array}$ \\
\hline
\end{tabular}

Source: organized by the author 


\section{APPENDIX III - LinkedIn Campaign Ad}

\section{The LinkedIn Campaign Ad sent via LinkedIn Campaign Manager}

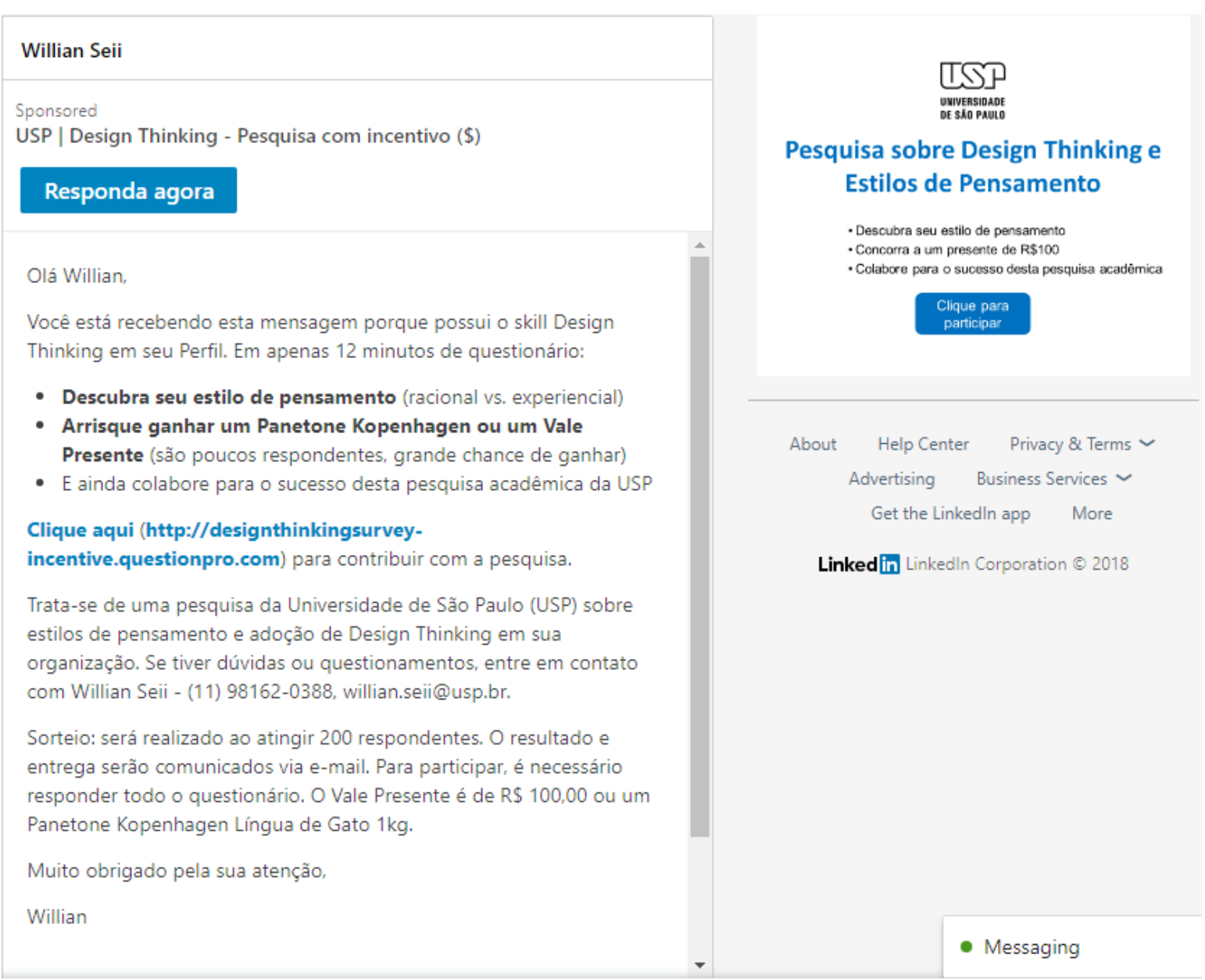

Source: LinkedIn 


\section{APPENDIX IV - LinkedIn Campaign Metrics}

LinkedIn Campaign Metrics: volume of "sends"

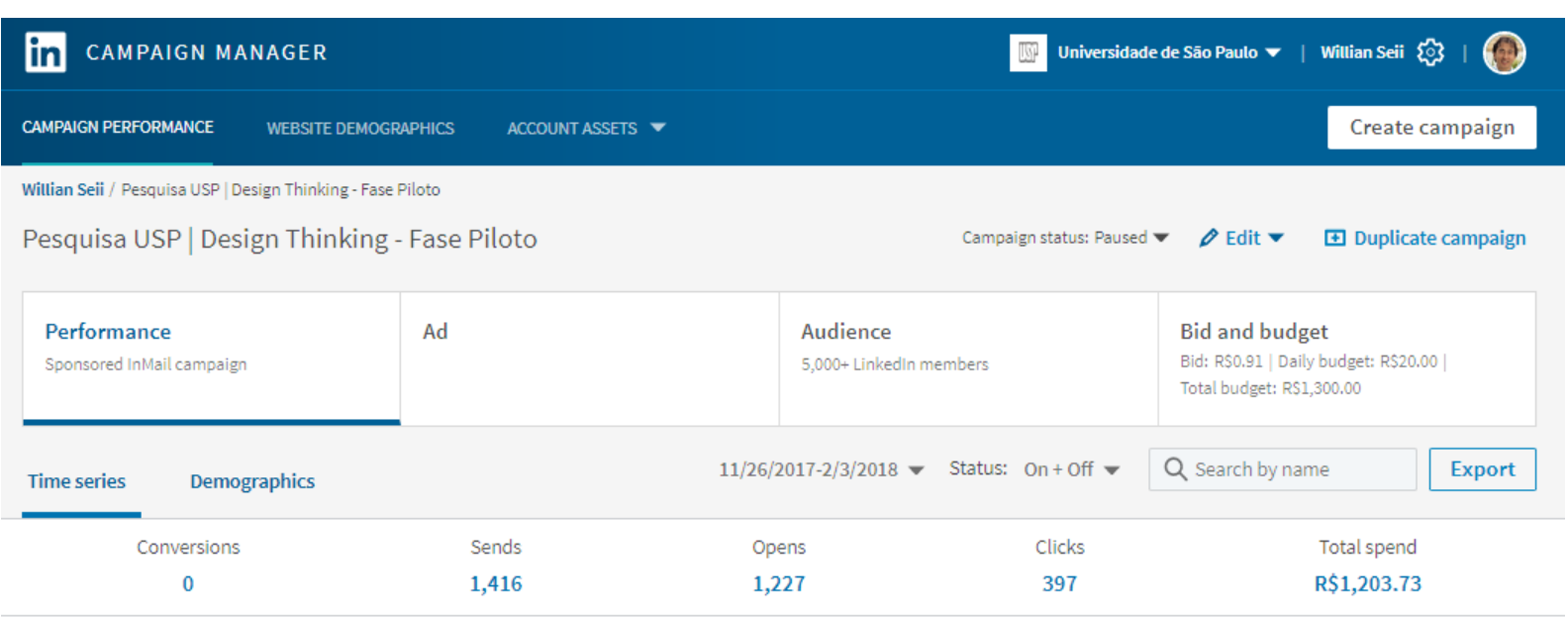

Metric: Sends .

200

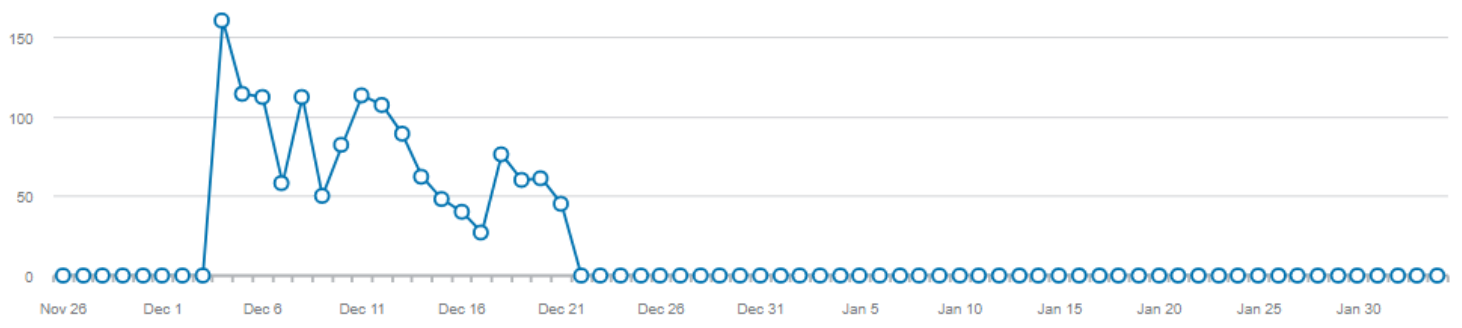

Source: LinkedIn Campaign Manager

\section{LinkedIn Campaign Metrics: volume of "Opens"}

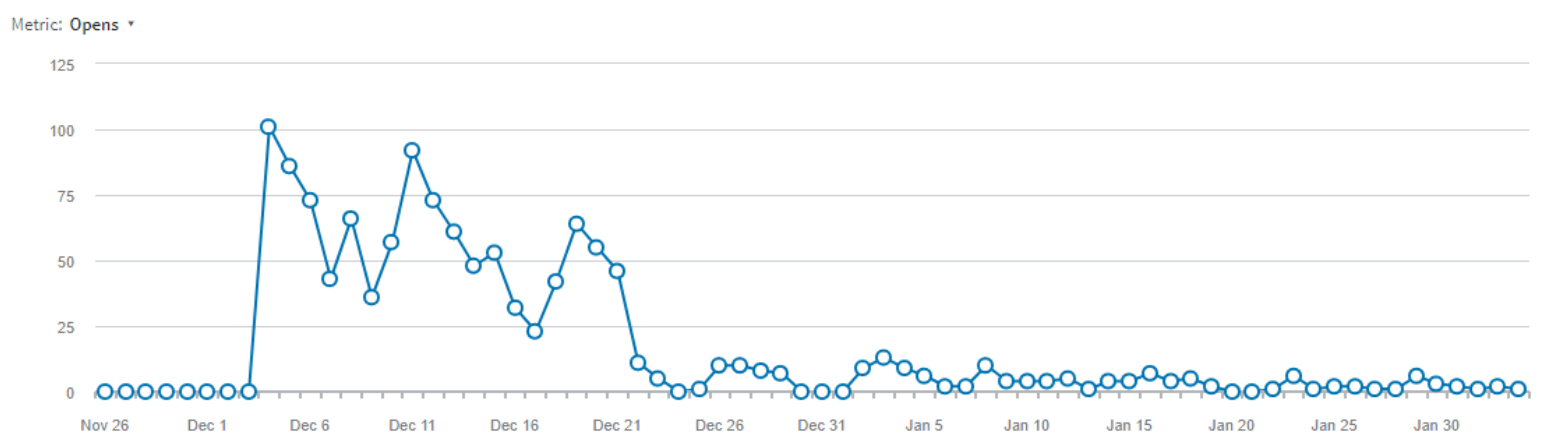

LinkedIn Campaign Metrics: volume of "Clicks"

Metric: Clicks .

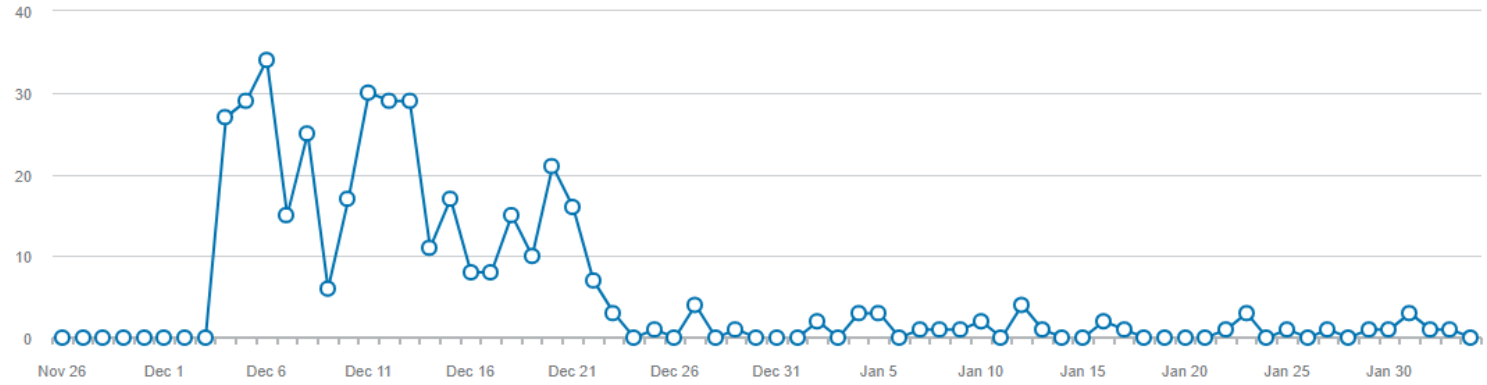


LinkedIn Campaign Metrics: demographics for location

Demographics for Location $\mathbf{v}$

Demographic metrics are approximate to protect member privacy. Learn more.

\begin{tabular}{|c|c|c|}
\hline Impressions & Clicks - & CTR \\
\hline Säo Paulo Area, Brazil 1205 (85.196) & 1.029 (89.496) & - 84.89696 \\
\hline Campinas Area, Brazil $100(7.196)$ & $D_{\mathrm{aB}(7.296)}$ & - $98.000 \%$ \\
\hline $\begin{array}{l}\text { São José dos Campos Area, } \\
\qquad \text { Brazil } \\
I_{21}(1.5 \% 6)\end{array}$ & $I_{22(1.996)}$ & - $104.762 \%$ \\
\hline Sorocaba Area, Brazil | 13 (0.996) & $\mathbf{I}_{13(1.196)}$ & - $100.000 \%$ \\
\hline Bauru Area, Brazil | 11 (0.896) & $I_{11(0.9 \%)}$ & - $100.000 \%$ \\
\hline Ribeiräo Preto Area, Brazil | $9(0.696)$ & $\lg (0.796)$ & - $100.000 \%$ \\
\hline Limeira Area, Brazil | $6(0.496)$ & $I_{6(0.596)}$ & - $100.000 \%$ \\
\hline Piracicaba Area, Brazil | $10(0.7 \%)$ & $I_{6(0.5 \%)}$ & - $60.000 \%$ \\
\hline Taubaté Area, Brazil | 7 (0.5\%) & $I_{6(0.596)}$ & 85.71496 \\
\hline Cruzeiro Area, Brazil | $\$$ (0.296) & I $5(0.496)$ & - 166.68796 \\
\hline São Carlos Area, Brazil | $1(0.1 \%)$ & $I_{4(0.3 \%)}$ & $400.000 \% 6$ \\
\hline $\begin{array}{l}\text { Sáo José do Rio Preto Area, } \\
\qquad \text { Brazil } I_{2}(0.196)\end{array}$ & Is(0.296) & - $150.000 \%$ \\
\hline
\end{tabular}

Source: LinkedIn Campaign Manager 
LinkedIn Campaign Metrics: demographics for company industry

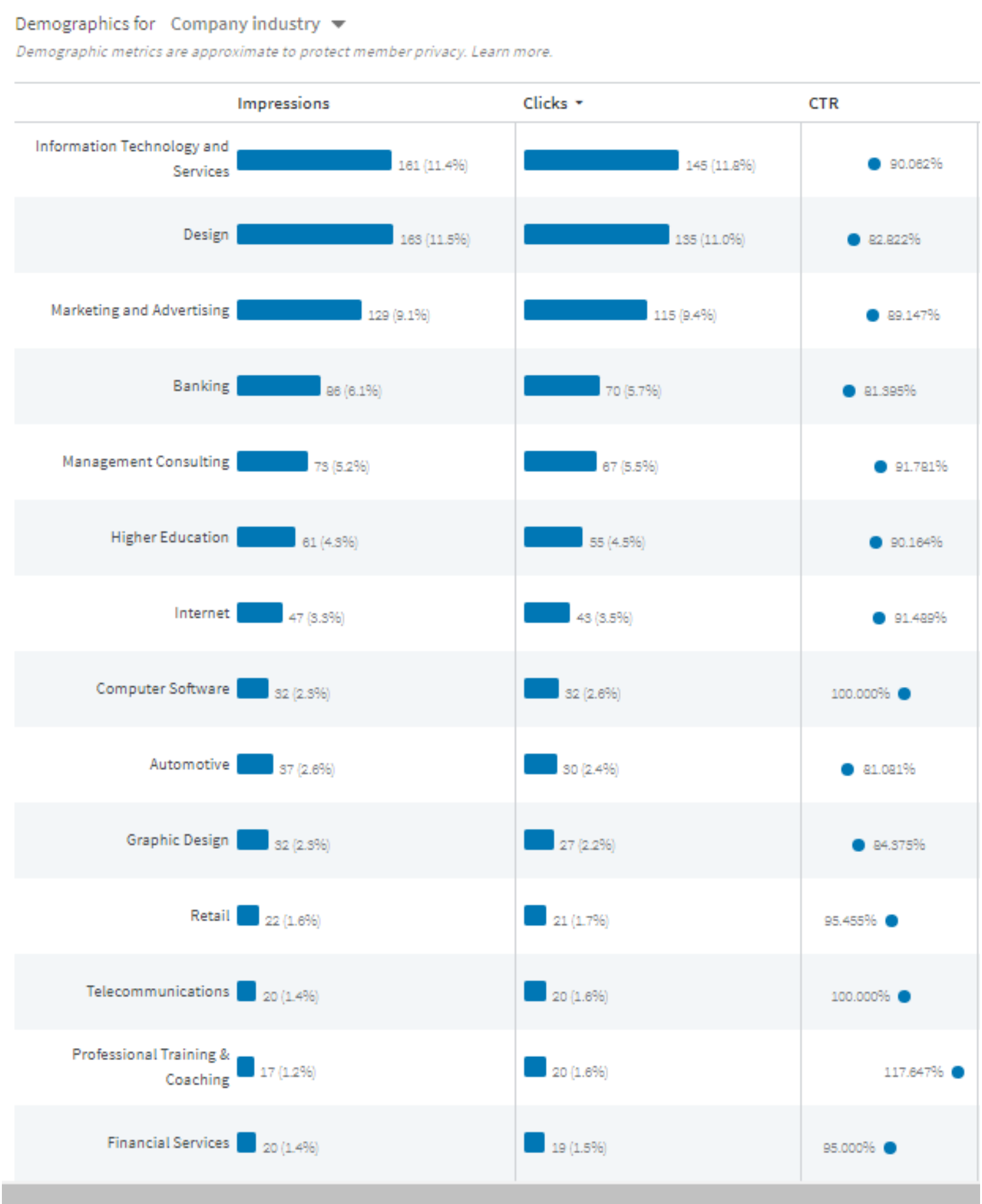

Source: LinkedIn Campaign Manager 
LinkedIn Campaign Metrics: demographics for company size

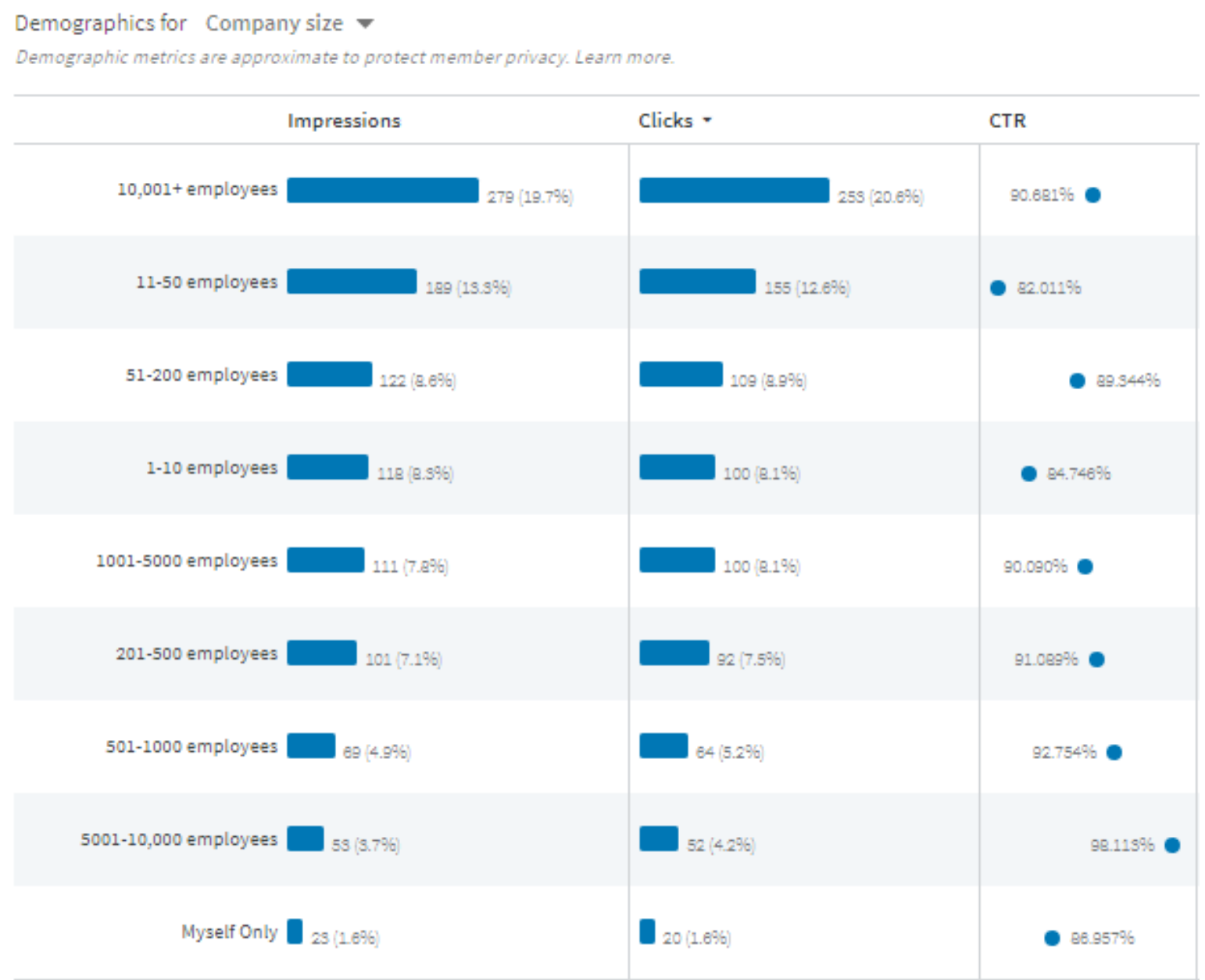

Source: LinkedIn Campaign Manager 
LinkedIn Campaign Metrics: demographics for company

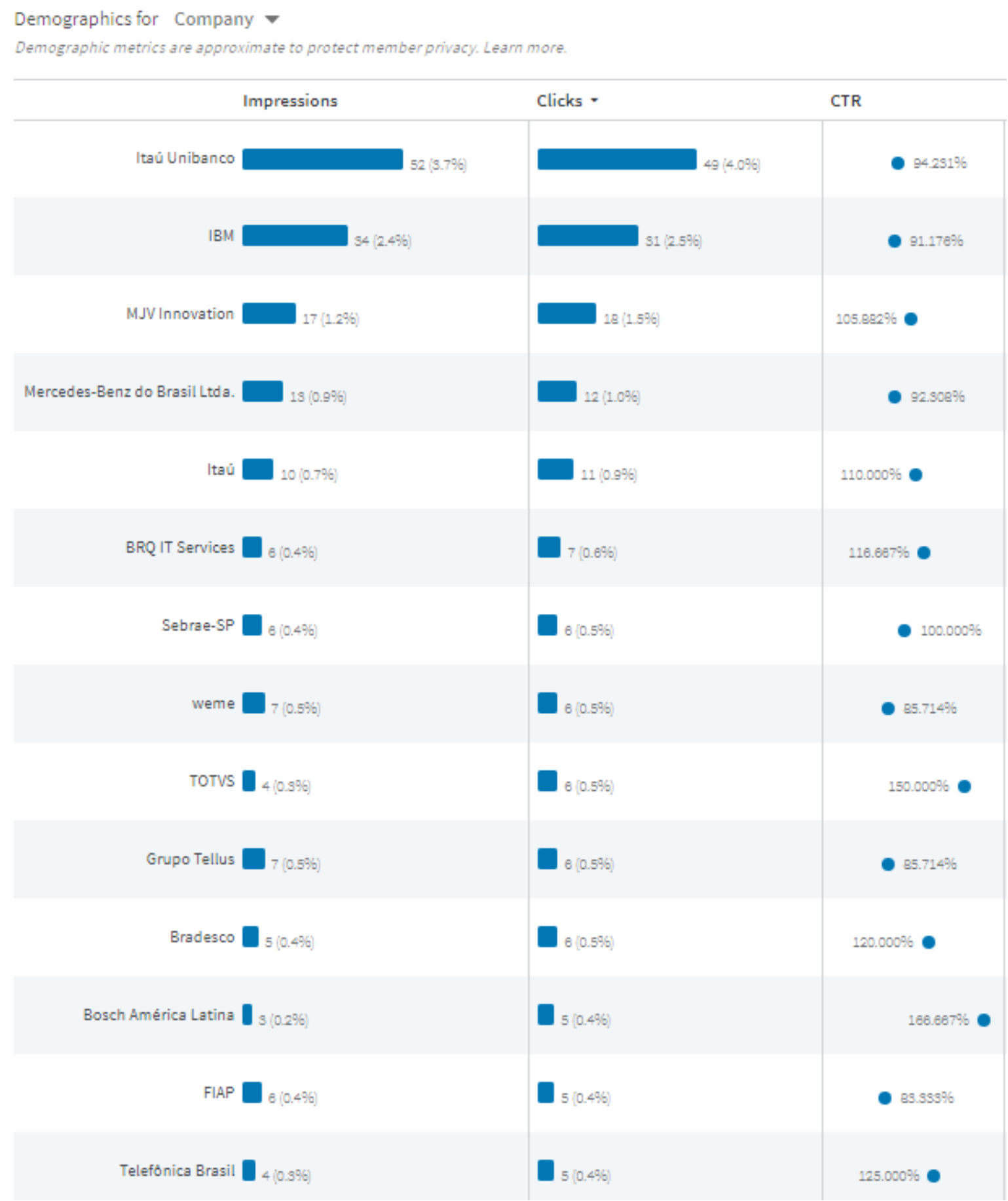

Source: LinkedIn Campaign Manager (continue on next page) 


\begin{tabular}{|c|c|c|}
\hline Itau BBA $\square(0.496)$ & $5(0.496)$ & - 89.35996 \\
\hline Universidade Federal do ABC $\mathbf{D}_{5(0.496)}$ & $5(0.496)$ & - $100.000 \%$ \\
\hline SulAmérica ${ }_{4(0.396)}$ & $D_{5}(0.496)$ & $125.000 \%$ \\
\hline Cielo $\square(0.6 \%)$ & $4(0.596)$ & - 44.44496 \\
\hline Grupo Rái L & $4(0.596)$ & $80.000 \%$ \\
\hline SAP D $5(0.496)$ & $4(0.596)$ & $80.000 \%$ \\
\hline ESAMC $4(0.396)$ & $4(0.596)$ & $100.000 \%$ \\
\hline Marisa S.A. $4(0.396)$ & $4(0.596)$ & $100.000 \%$ \\
\hline Jüssi $\$(0.296)$ & $4(0.596)$ & $153.399 \%$ \\
\hline Johnson \& Johnson $5(0.496)$ & $\mathbf{U}_{\mathrm{S}(0.296)}$ & $60.000 \%$ \\
\hline Claro Brasil $5(0.496)$ & S $(0.296)$ & $60.000 \%$ \\
\hline
\end{tabular}

Source: LinkedIn Campaign Manager 
LinkedIn Campaign Metrics: demographics for job function

Demographics for Job function -

Demographic metrics are approximate to protect member privacy. Learn more.

\begin{tabular}{|c|c|c|}
\hline Impressions & Clicks - & CTR \\
\hline $\mathrm{S2S}(22.996)$ & $279(22.296)$ & - $84.520 \%$ \\
\hline Business Development & 142 (11 696) & - $94024 \%$ \\
\hline Information Technology & $131(10.796)$ & 9424596 \\
\hline $109(7.796)$ & $101(8.2 \%)$ & - $92.661 \%$ \\
\hline Marketing & $89(7.3 \% 6)$ & - 99.68496 \\
\hline $\begin{array}{l}\text { Program and Project } \\
\text { Management }\end{array}$ & $82(0.796)$ & - 82.82996 \\
\hline Engineering & $81(6.6 \%)$ & - $94.186 \%$ \\
\hline Entrepreneurship & $62(5.196)$ & - 80.51996 \\
\hline Operations & $59(4.7 \% 6)$ & - $84.058 \%$ \\
\hline Media and Communication & $50(4.196)$ & - $80.645 \%$ \\
\hline Consulting & $48(3.996]$ & - 85.71496 \\
\hline $\begin{array}{r}\text { Community and Social } \\
\text { Services }\end{array}$ & $48(3.796)$ & - $90.196 \%$ \\
\hline $49(3.596)$ & 41 (3.596) & - 83.67396 \\
\hline Research $\square_{43}(3.096)$ & $\square_{S B(2.996)}$ & - 89.72196 \\
\hline
\end{tabular}

Source: LinkedIn Campaign Manager 
LinkedIn Campaign Metrics: demographics for job seniority

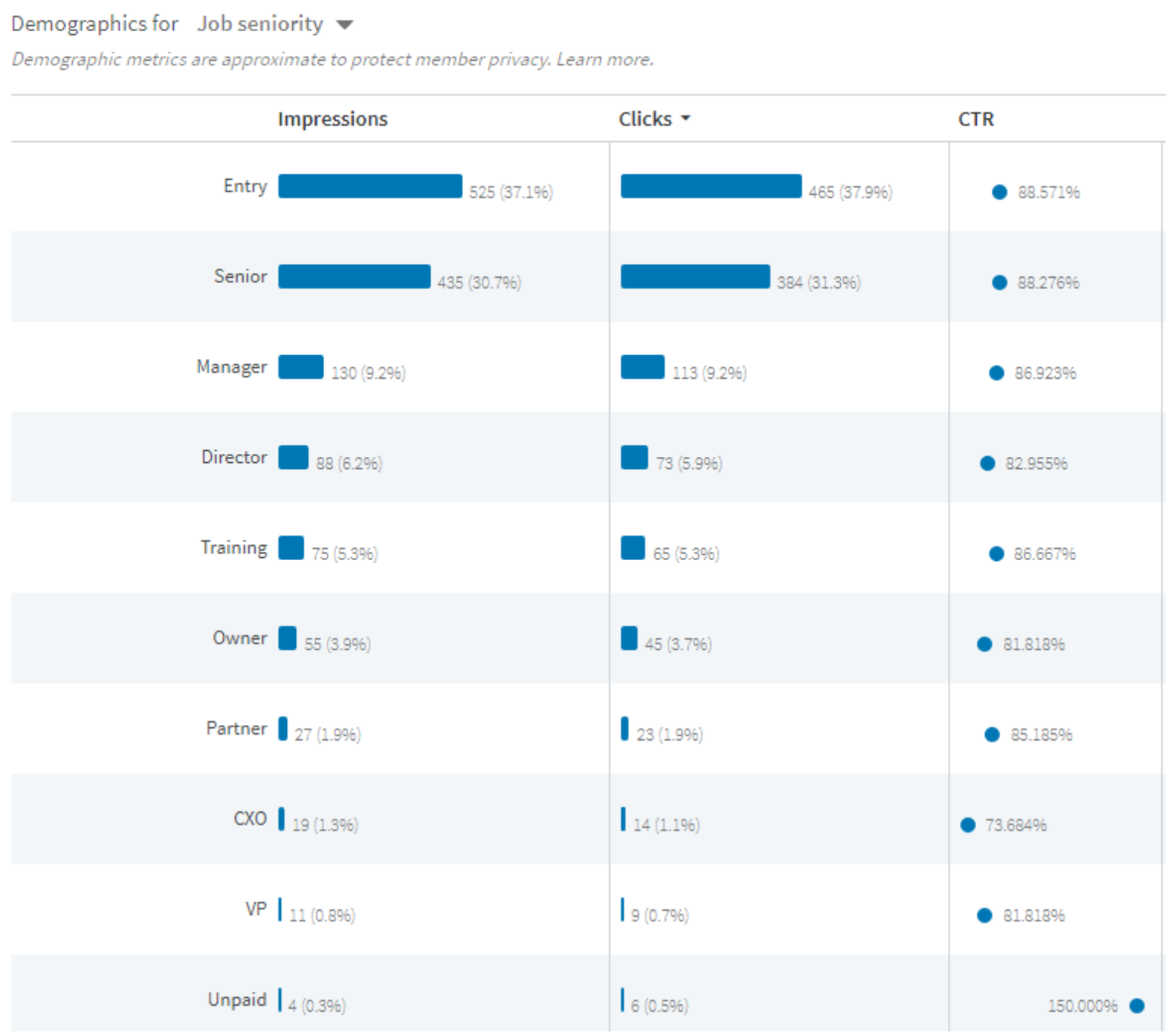


APPENDIX V - ANOVA residual analysis

Residual Plots for Rationality - Score

\section{Residual Plots for Rationality - Score}
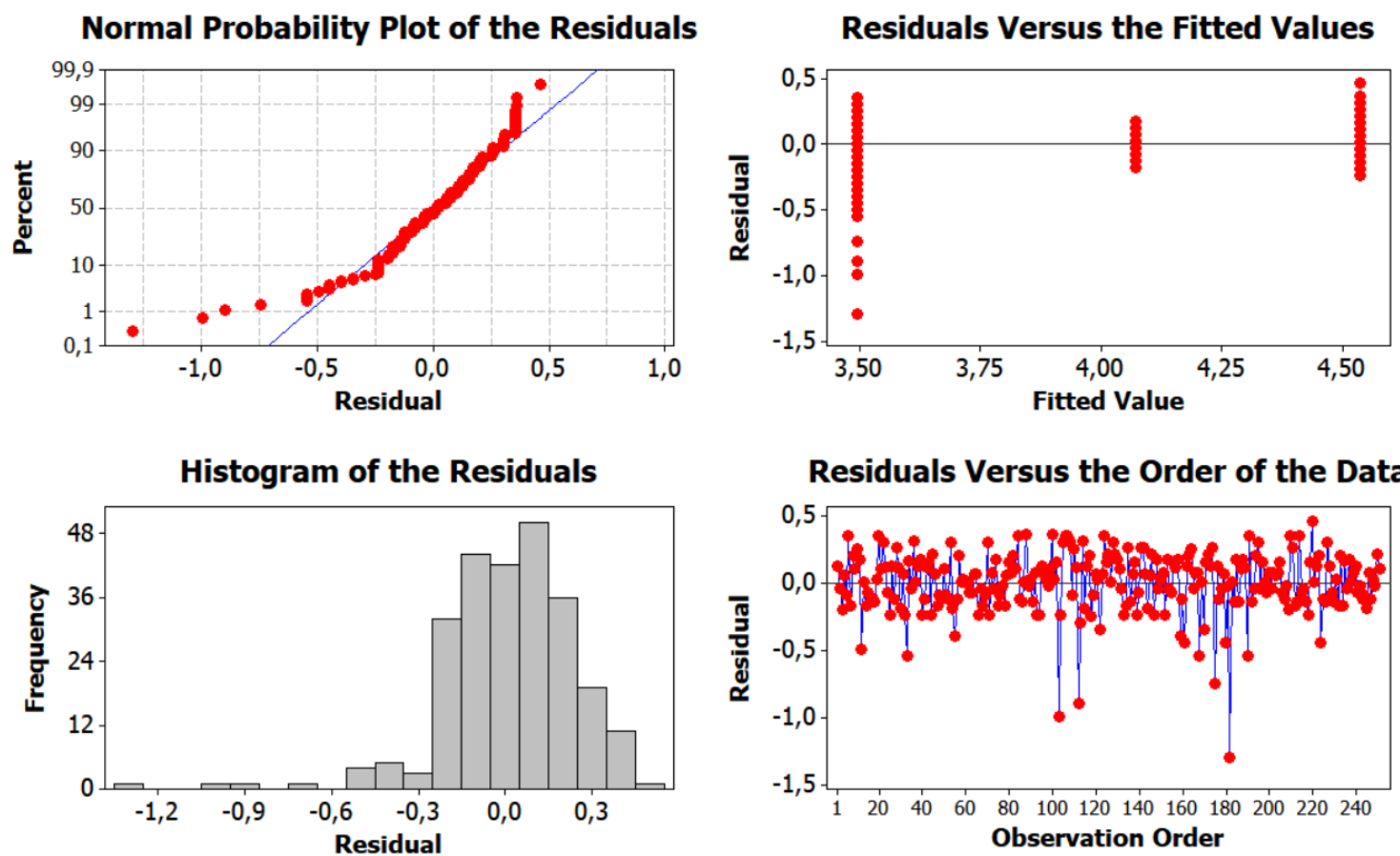

Residual Plots for Rational Ability - Score

\section{Residual Plots for Rational Ability - Score}

Normal Probability Plot of the Residuals

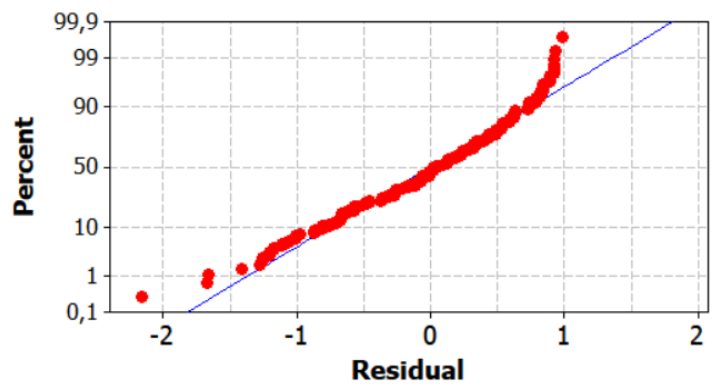

Histogram of the Residuals

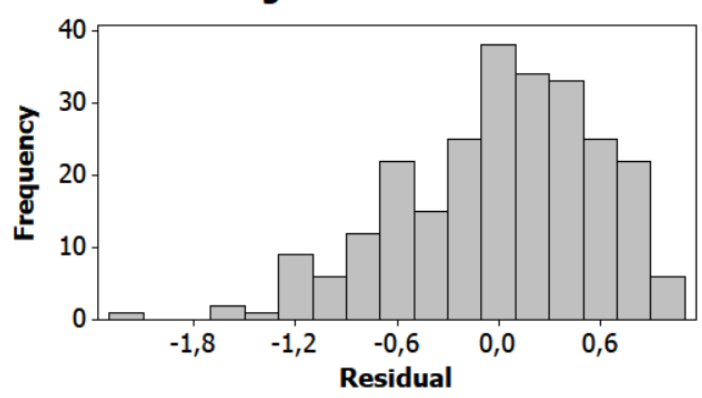

Residuals Versus the Fitted Values

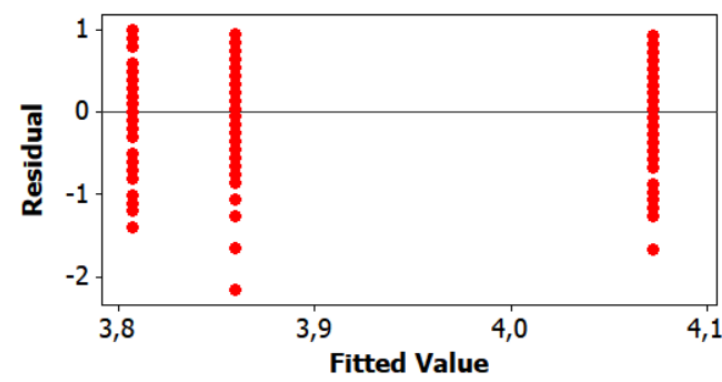

Residuals Versus the Order of the Data

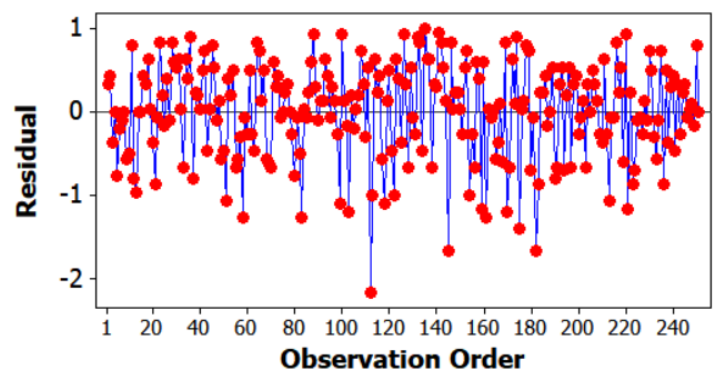


Residual Plots for Rational Engagement - Score

\section{Residual Plots for Rational Engagement - Score}
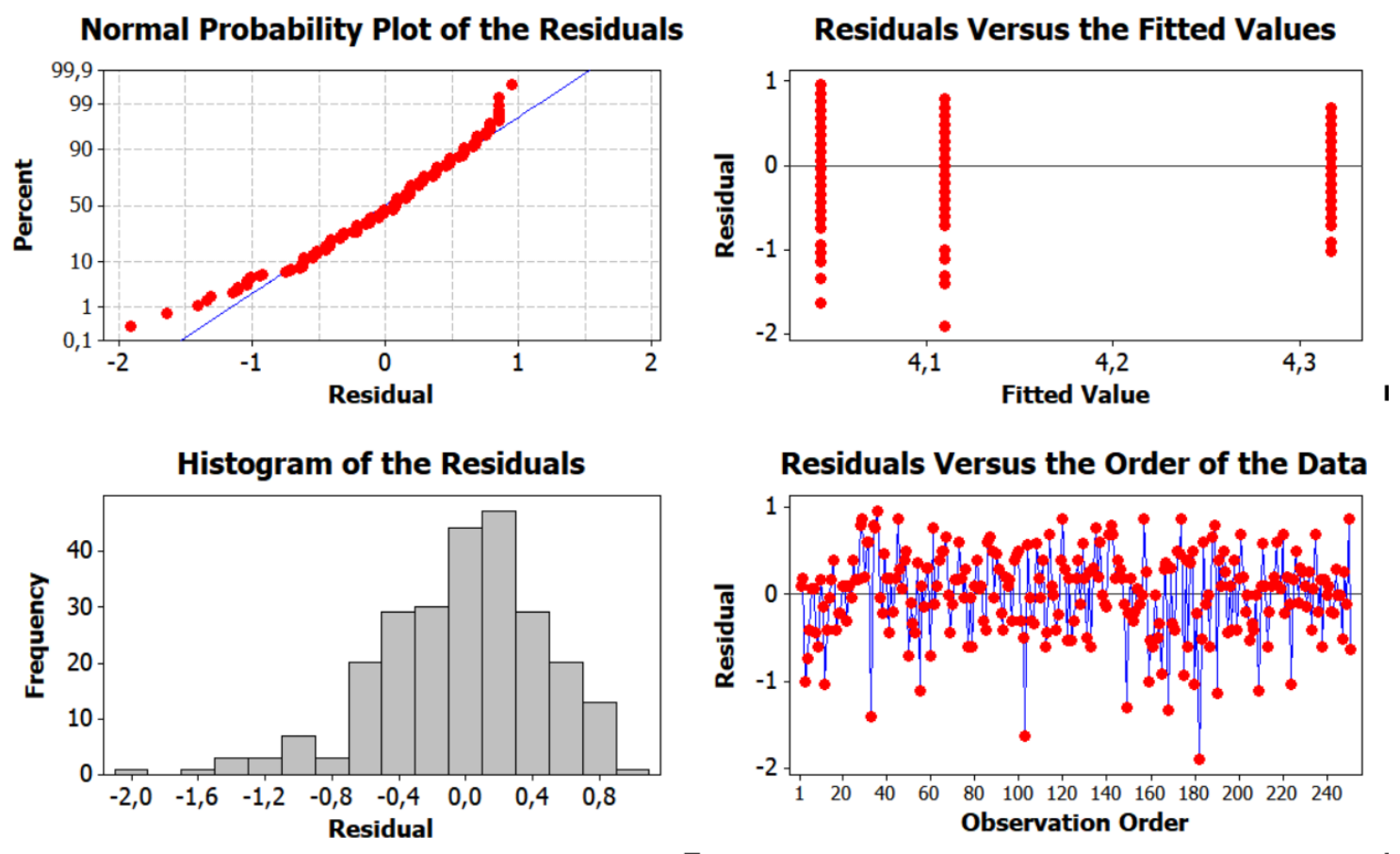

Residuals Versus the Order of the Data

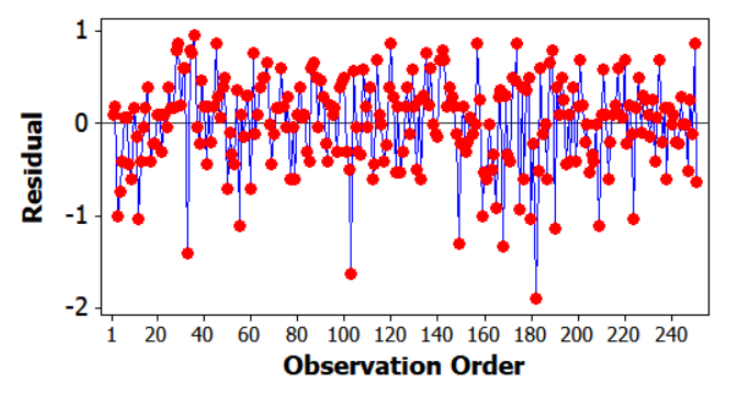

Residual Plots for Experientiality - Score

\section{Residual Plots for Experientiality - Score}

Normal Probability Plot of the Residuals
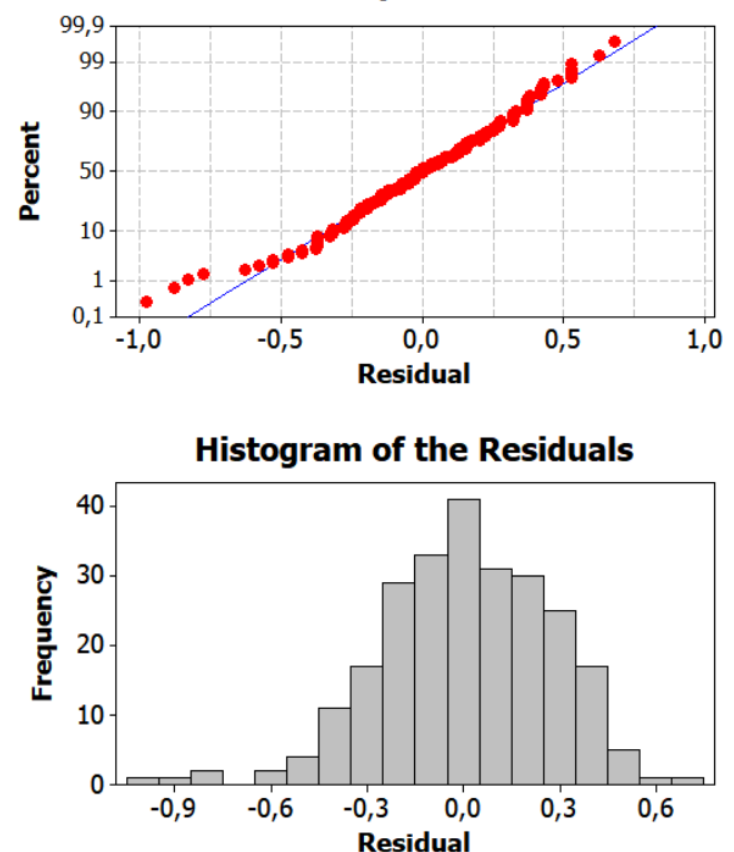

Residuals Versus the Fitted Values

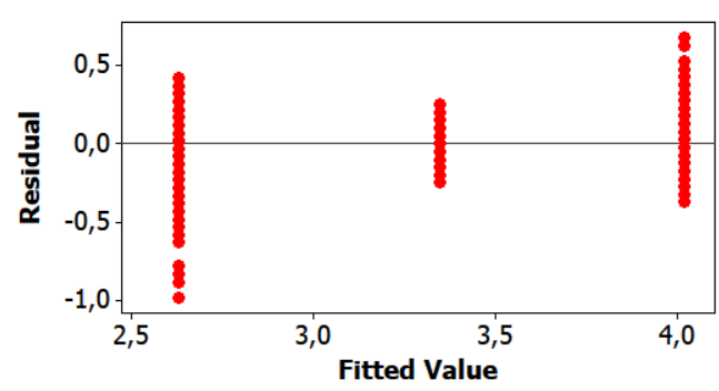

Residuals Versus the Order of the Data

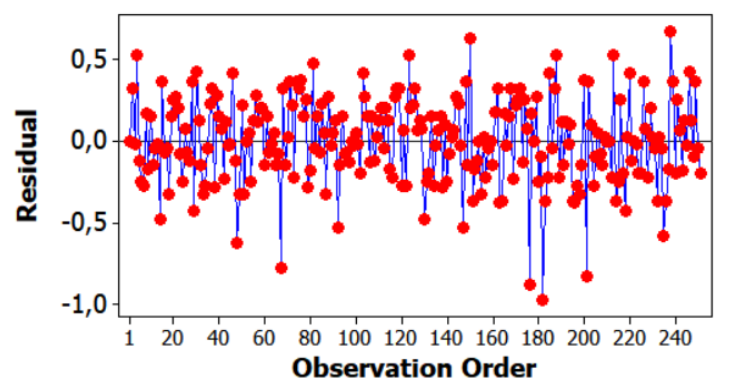


Residual Plots for Experientiality Ability - Score

\section{Residual Plots for Experientiality Ability - Score}
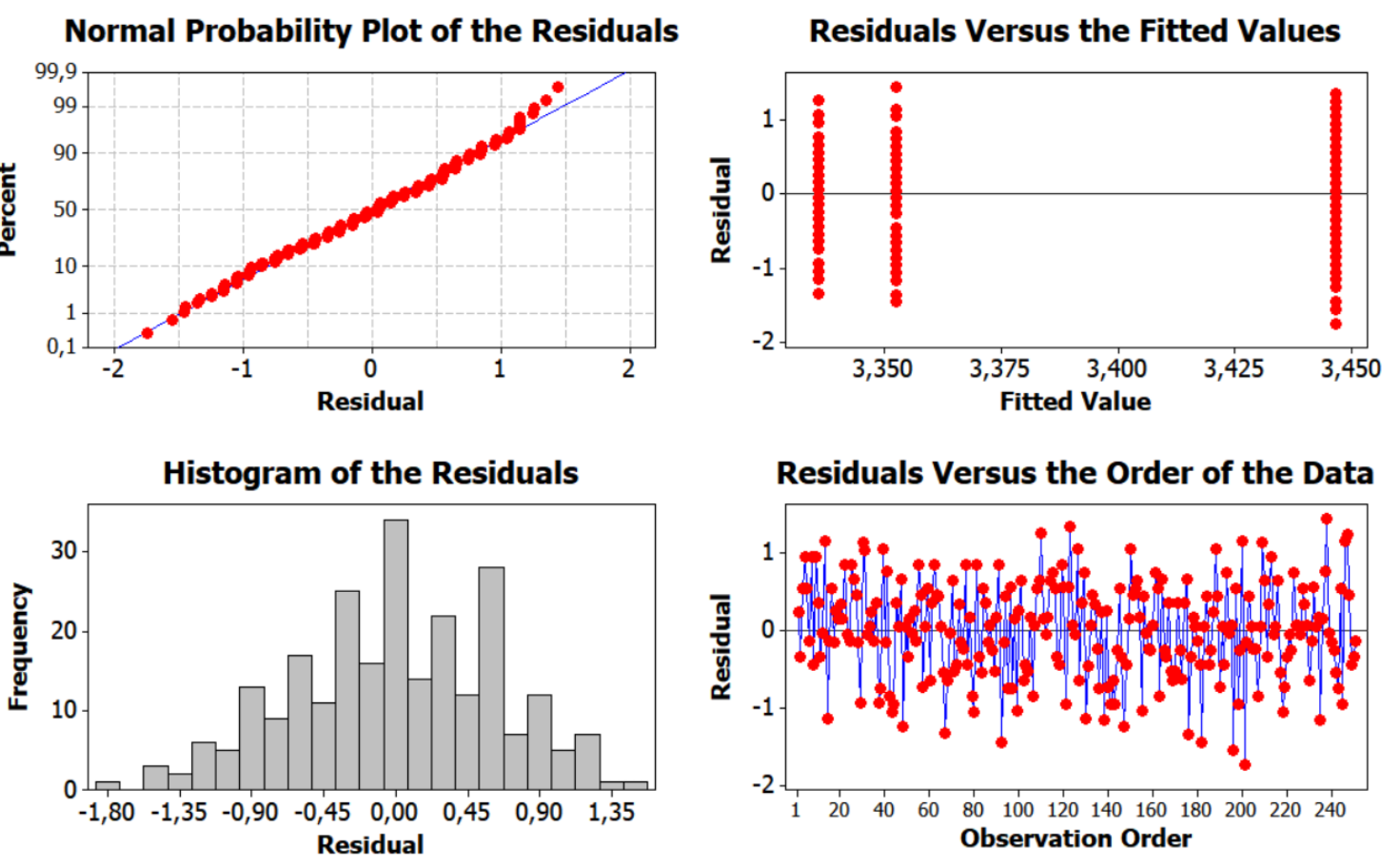

Residuals Versus the Order of the Data

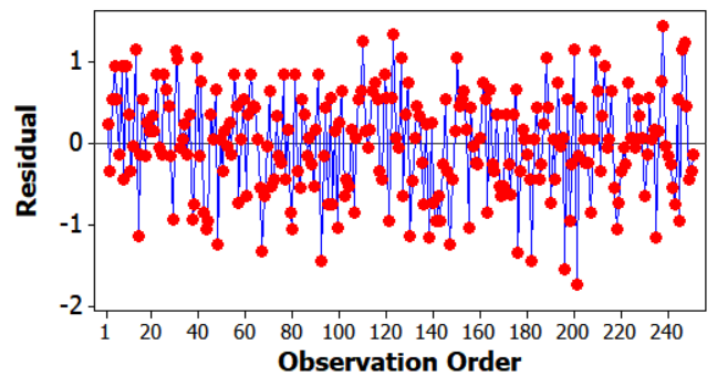

Residual Plots for Experientiality Engagement - Score

Residual Plots for Experientiality Engagement - Sc
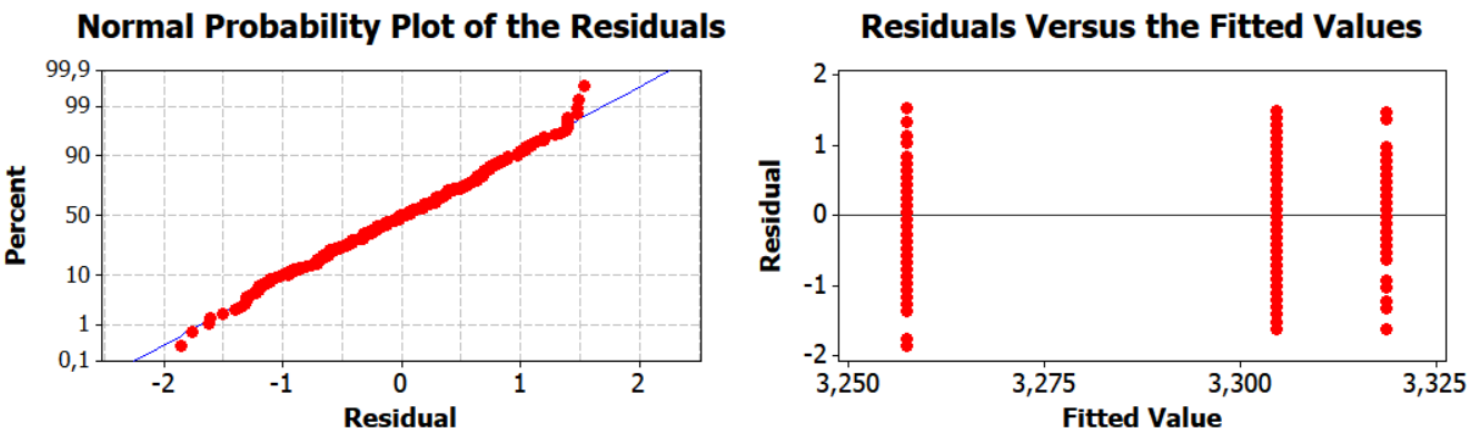

Histogram of the Residuals

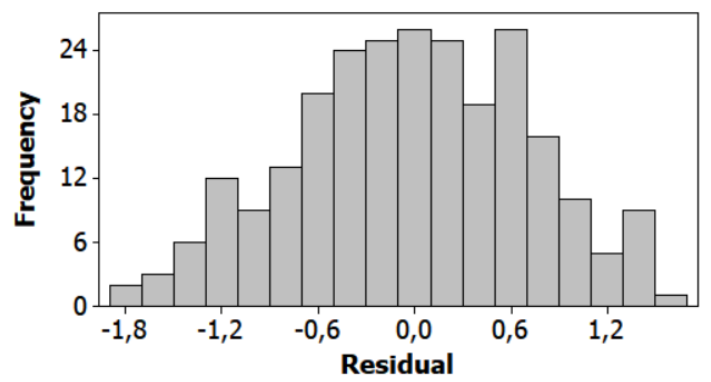

Residuals Versus the Order of the Data

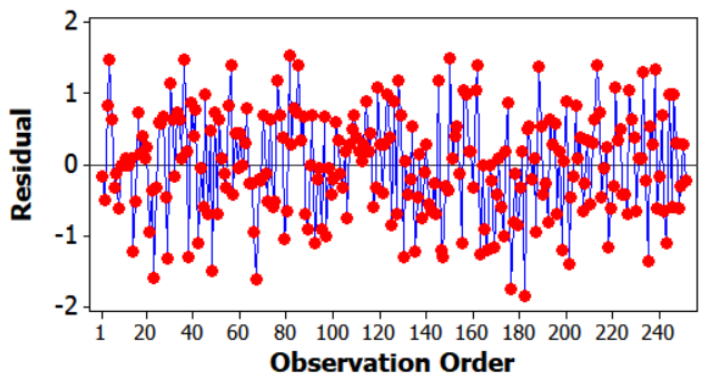


Residual Plots for Readiness - Score

\section{Residual Plots for Readiness - Score}
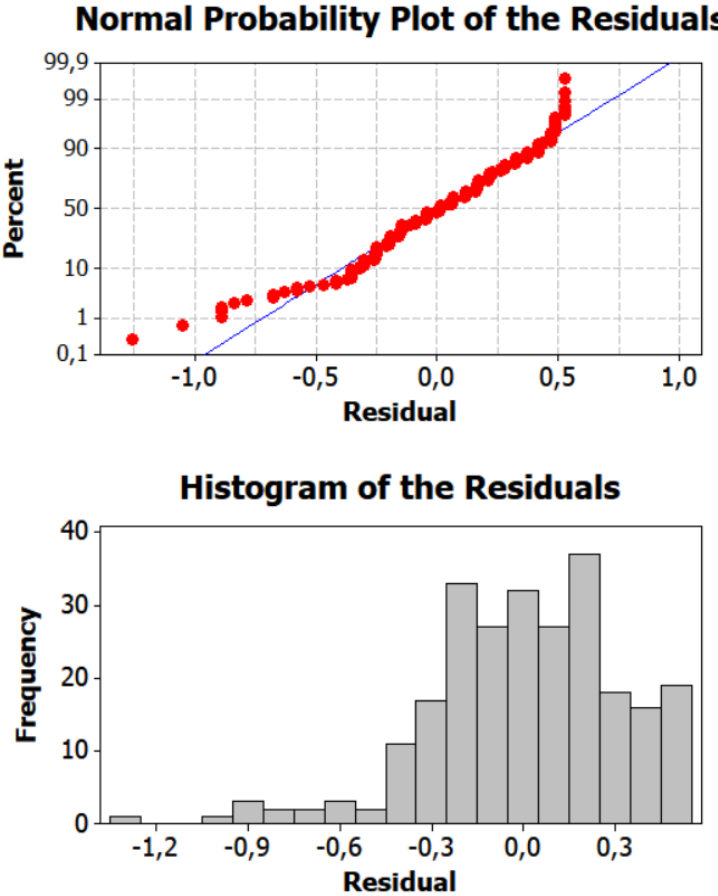

Residuals Versus the Fitted Values

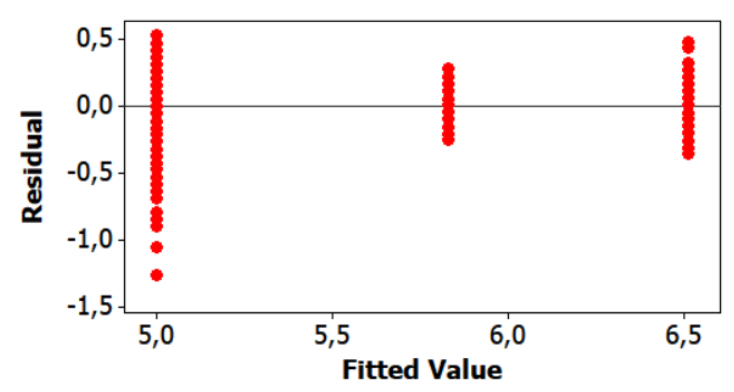

Residuals Versus the Order of the Data

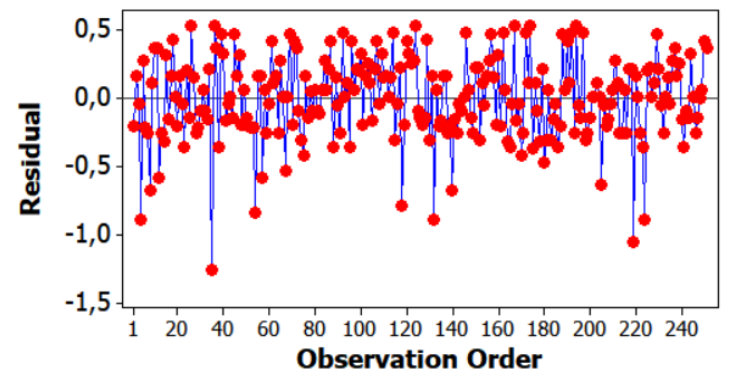

Residual Plots for Appropriateness - Score

\section{Residual Plots for Appropriateness - Score}

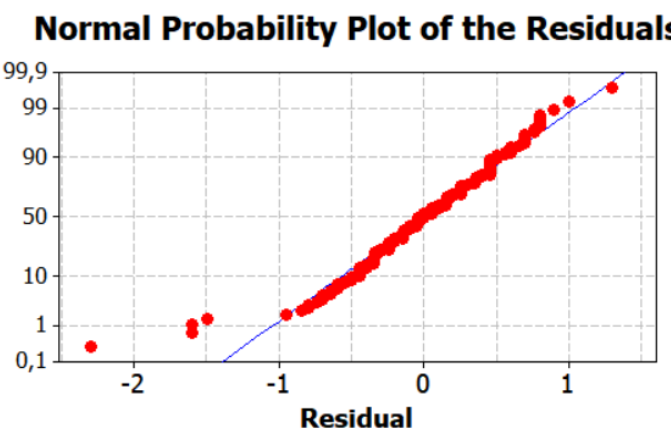

Histogram of the Residuals

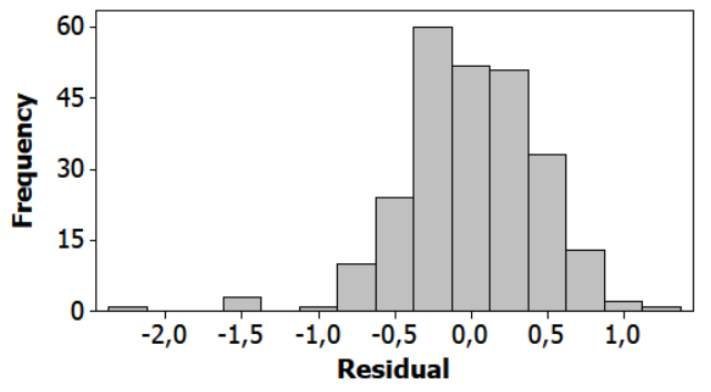

Residuals Versus the Fitted Values

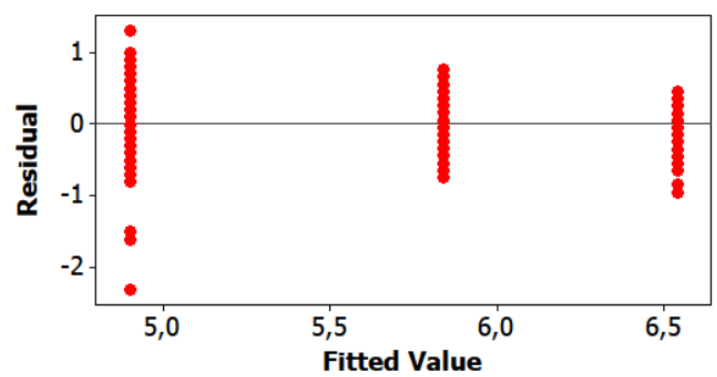

Residuals Versus the Order of the Data

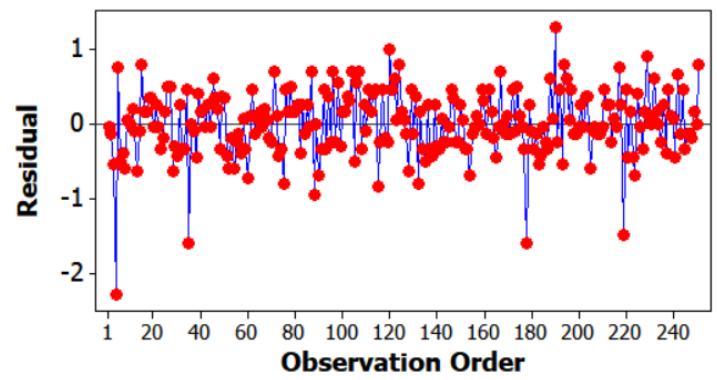


Residual Plots for Change Efficacy - Score

\section{Residual Plots for Change Efficacy - Score}

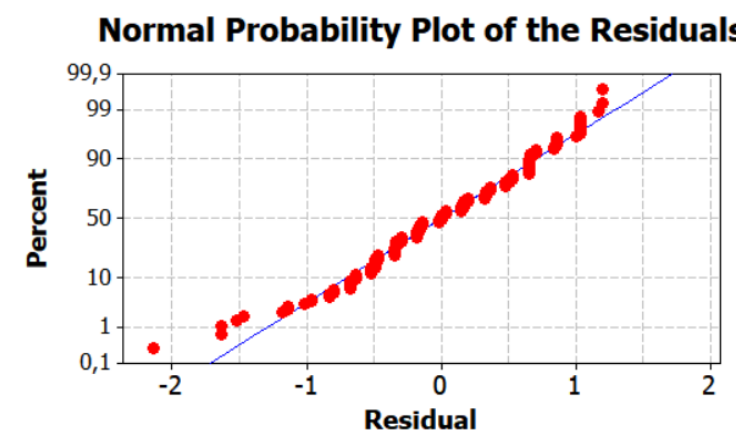

Residuals Versus the Fitted Values
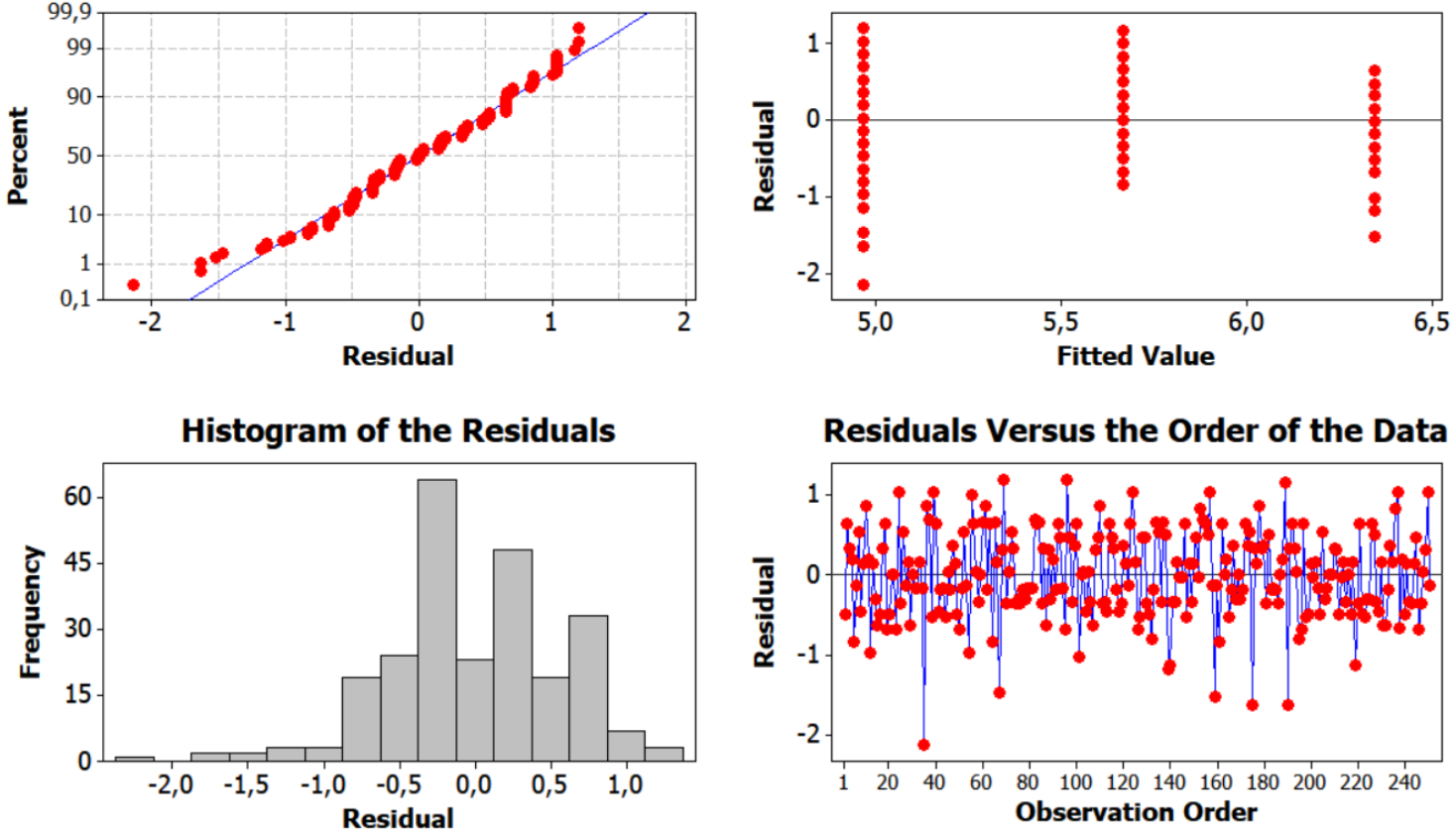

Residuals Versus the Order of the Data

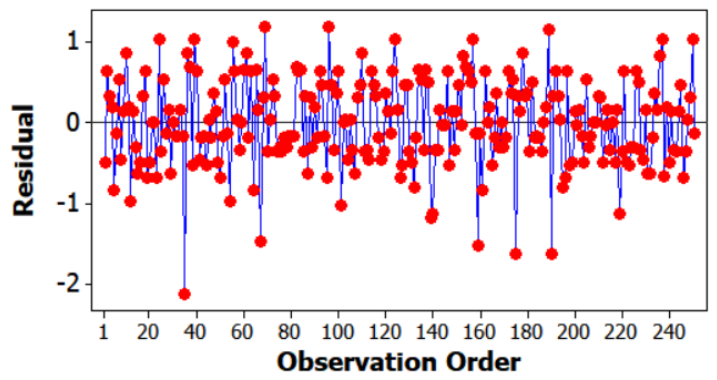

Residual Plots for Personally Beneficial - Score

\section{Residual Plots for Personally Beneficial - Score}

Normal Probability Plot of the Residuals
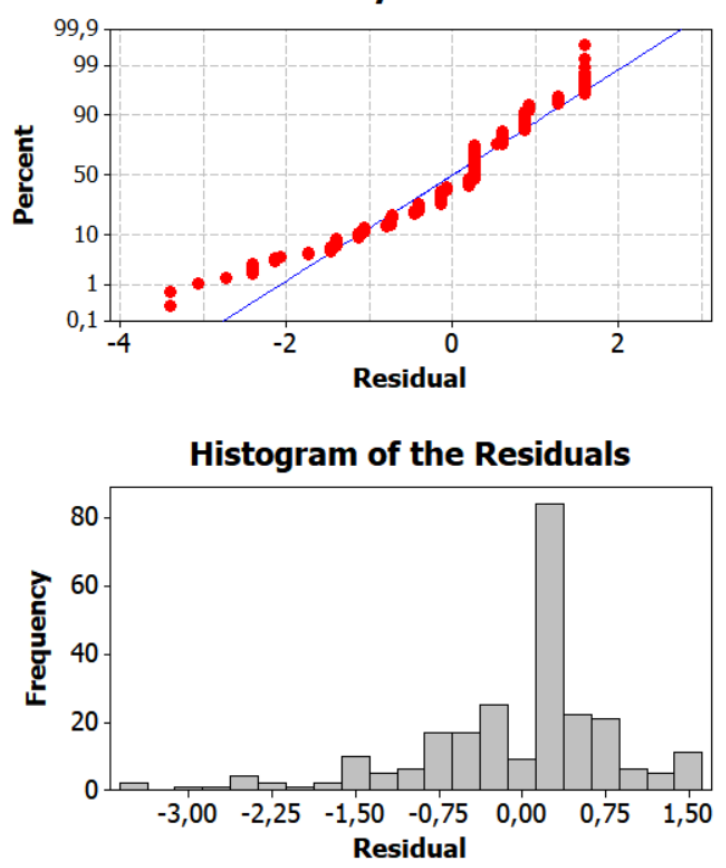

Residuals Versus the Fitted Values

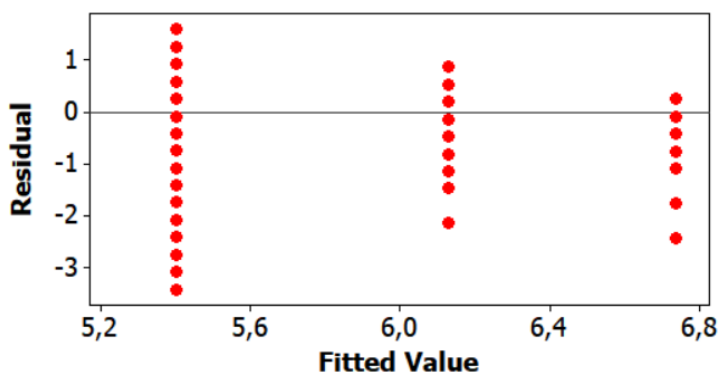

Residuals Versus the Order of the Data

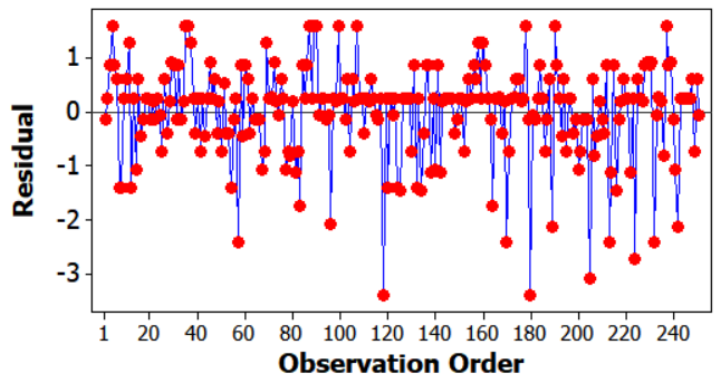




\section{APPENDIX VI - ANOVA statistical data: understanding of Design Thinking}

Below statistical data refers to data presented in Table 37. Source: Minitab 17.

\section{One-way ANOVA: Qualitative / Quantitative versus Readiness score}

\begin{tabular}{|c|c|c|c|c|}
\hline \multicolumn{2}{|l|}{ Source } & $\mathrm{DF}$ & SS & F \\
\hline $5-Q 4$ & -4 & 4 & 10.930 & 6.110 .000 \\
\hline Error & & 246 & 110.084 & 0.447 \\
\hline Total & & 250 & 121.014 & \\
\hline \multirow[t]{2}{*}{$S=0.6$} & 6690 & $\mathrm{R}-\mathrm{Sq}$ & $1=9.03 \%$ & $\mathrm{R}-\mathrm{Sq}(\mathrm{adj})=7.55 \%$ \\
\hline & & & & $\begin{array}{l}\text { Individual 95\% CIs For Mean Based on } \\
\text { Pooled StDev }\end{array}$ \\
\hline Level & $\mathrm{N}$ & Mean & StDev & --------+---------+---------+---------+- \\
\hline 1 & 99 & 5.9436 & 0.6455 & $(---\star---)$ \\
\hline 2 & 68 & 5.4766 & 0.6716 & $(---\star----)$ \\
\hline 3 & 61 & 5.8531 & 0.6830 & $(----\star----)$ \\
\hline 4 & 14 & 5.8771 & 0.7870 & $(---------\star---------)$ \\
\hline 5 & 9 & 6.2111 & 0.6116 & $(-----------*------------)$ \\
\hline & & & & $\begin{array}{rrr}-1-+-1 & \\
5.95 & 6.30 & 6.65\end{array}$ \\
\hline
\end{tabular}

Pooled StDev $=0.6690$

Tukey 95\% Simultaneous Confidence Intervals

All Pairwise Comparisons among Levels of 5 - Q4 - 4

Individual confidence level = $99.32 \%$

$5-24-4=1$ subtracted from:

$\begin{array}{rrr}\text { Lower } & \text { Center } & \text { Upper } \\ -0.7546 & -0.4670 & -0.1794 \\ -0.3877 & -0.0905 & 0.2067 \\ -0.5878 & -0.0665 & 0.4549 \\ -0.3682 & 0.2675 & 0.9032\end{array}$
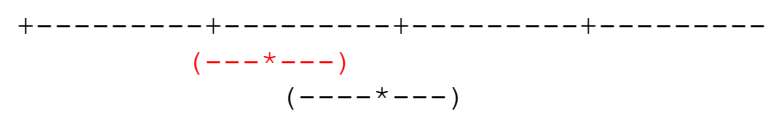

$(------\star------)$

$\begin{array}{lll}-0.3682 & 0.2675 & 0.9032\end{array}$

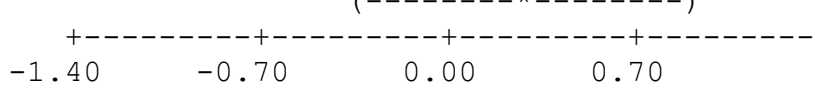

- $24-4=2$ subtracted from:
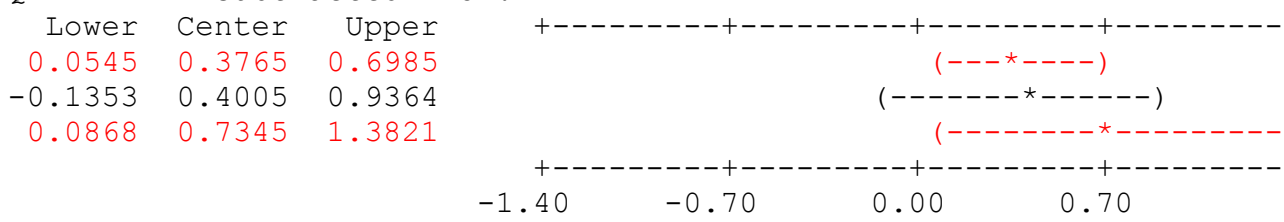

5 - Q4 - 4 = 3 subtracted from:

Lower Center Upper

$\begin{array}{lll}-0.5171 & 0.0240 & 0.5651\end{array}$

$\begin{array}{lll}-0.2940 & 0.3580 & 1.0100\end{array}$

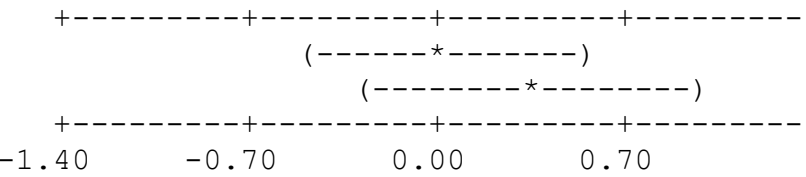

5 - $24-4=4$ subtracted from:

Lower Center Upper

$\begin{array}{llll}5 & -0.4461 & 0.3340 & 1.1141\end{array}$
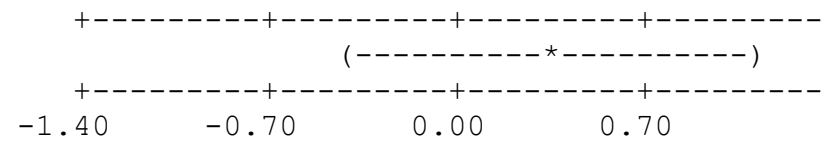


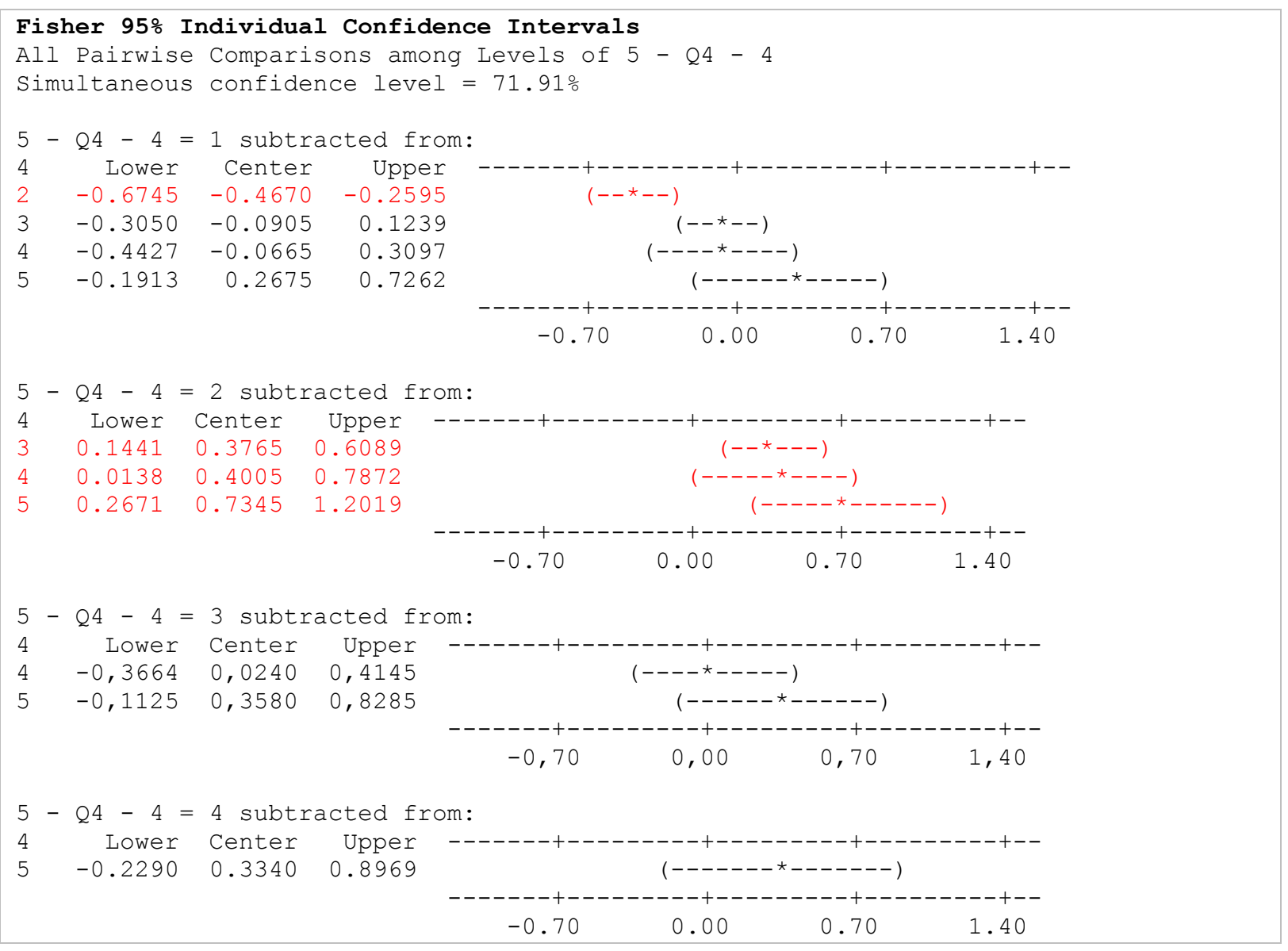

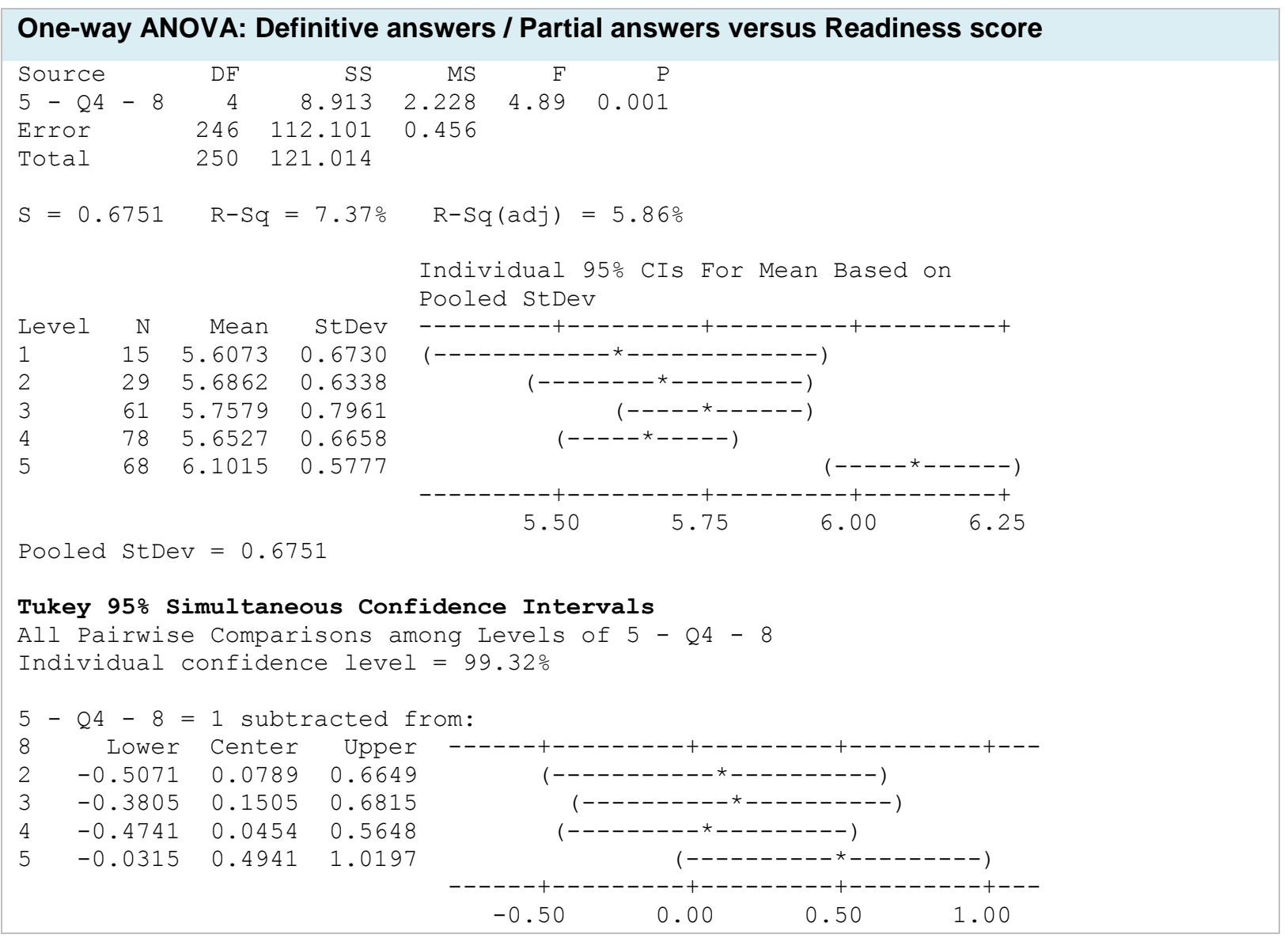




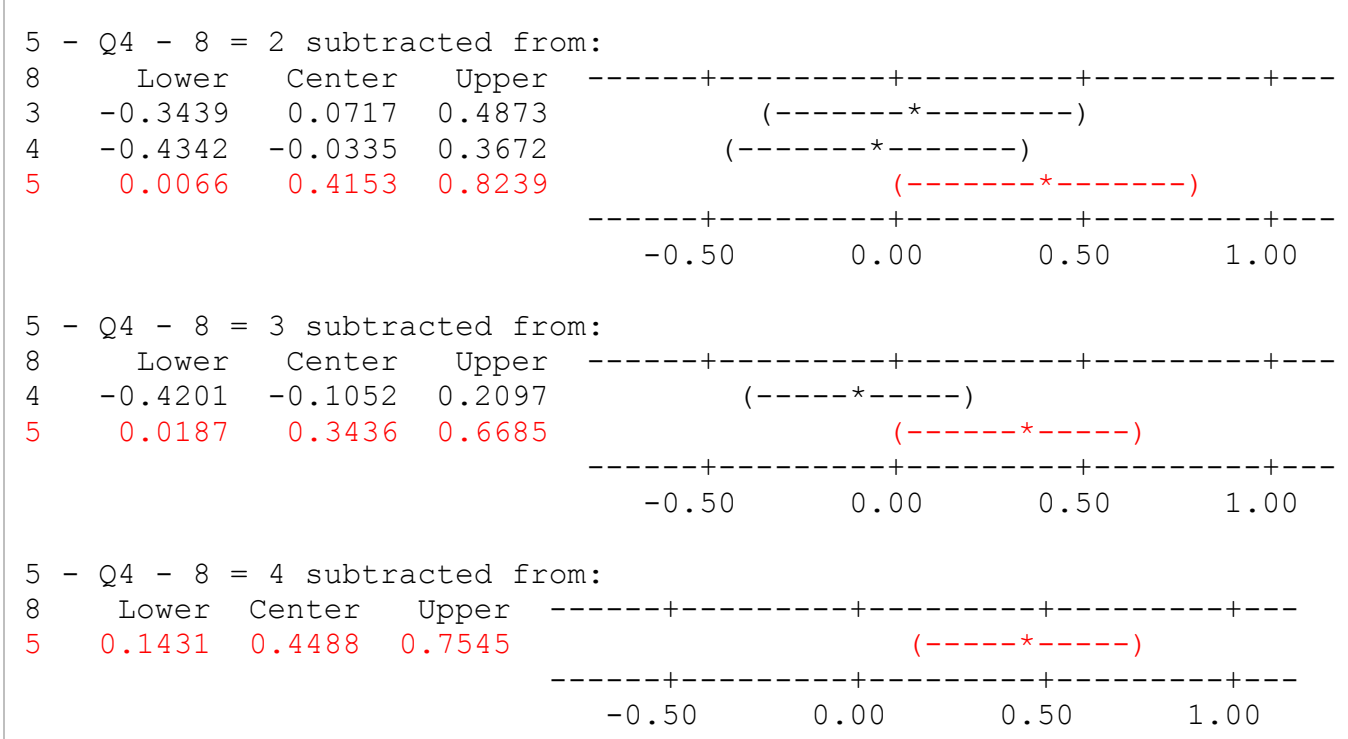

Fisher 95\% Individual Confidence Intervals

All Pairwise Comparisons among Levels of 5 - Q4 - 8

Simultaneous confidence level $=71.91 \%$

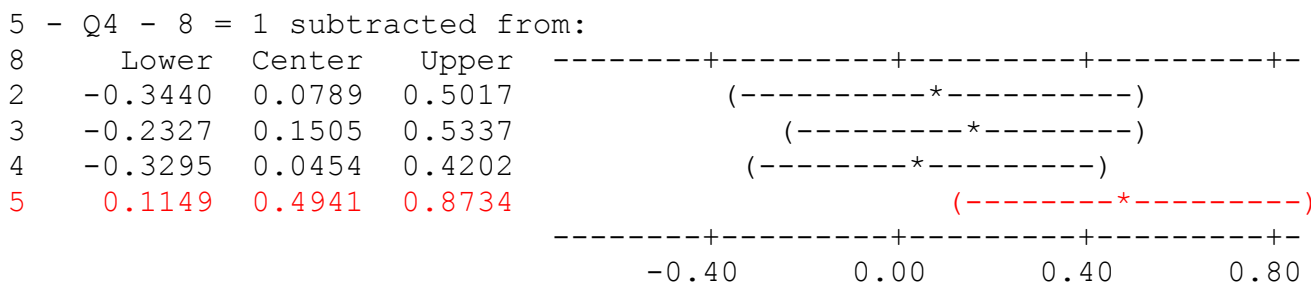

$5-24-8=2$ subtracted from:

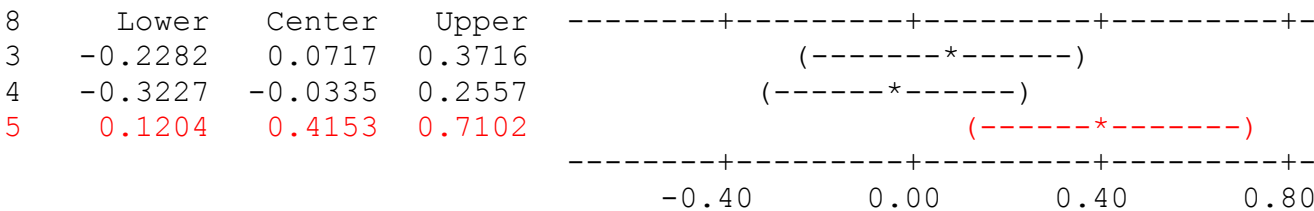

$5-24-8=3$ subtracted from:

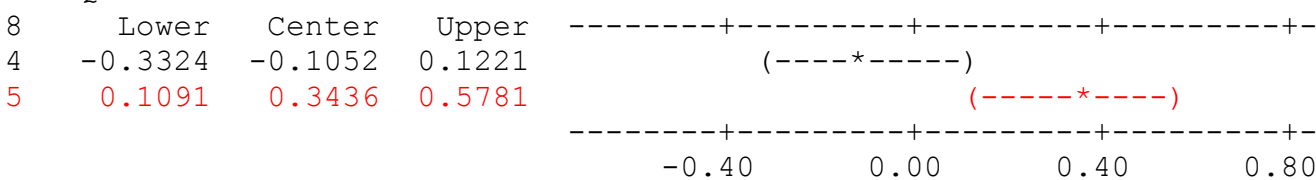

$5-04-8=4$ subtracted from:

8 Lower Center Upper

$\begin{array}{llll}5 & 0.2282 & 0.4488 & 0.6694\end{array}$

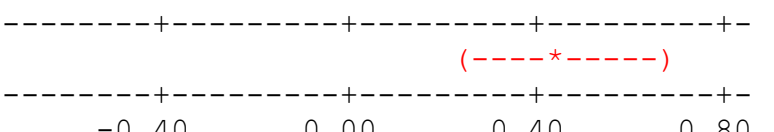




\section{APPENDIX VII - ANOVA statistical data: Thinking Styles sub-components}

Below statistical data refers to data presented in Table 41. Source: Minitab 17.

\section{Rationality Engagement:}

\section{One-way ANOVA: Rational Engagement terciles versus Readiness score}
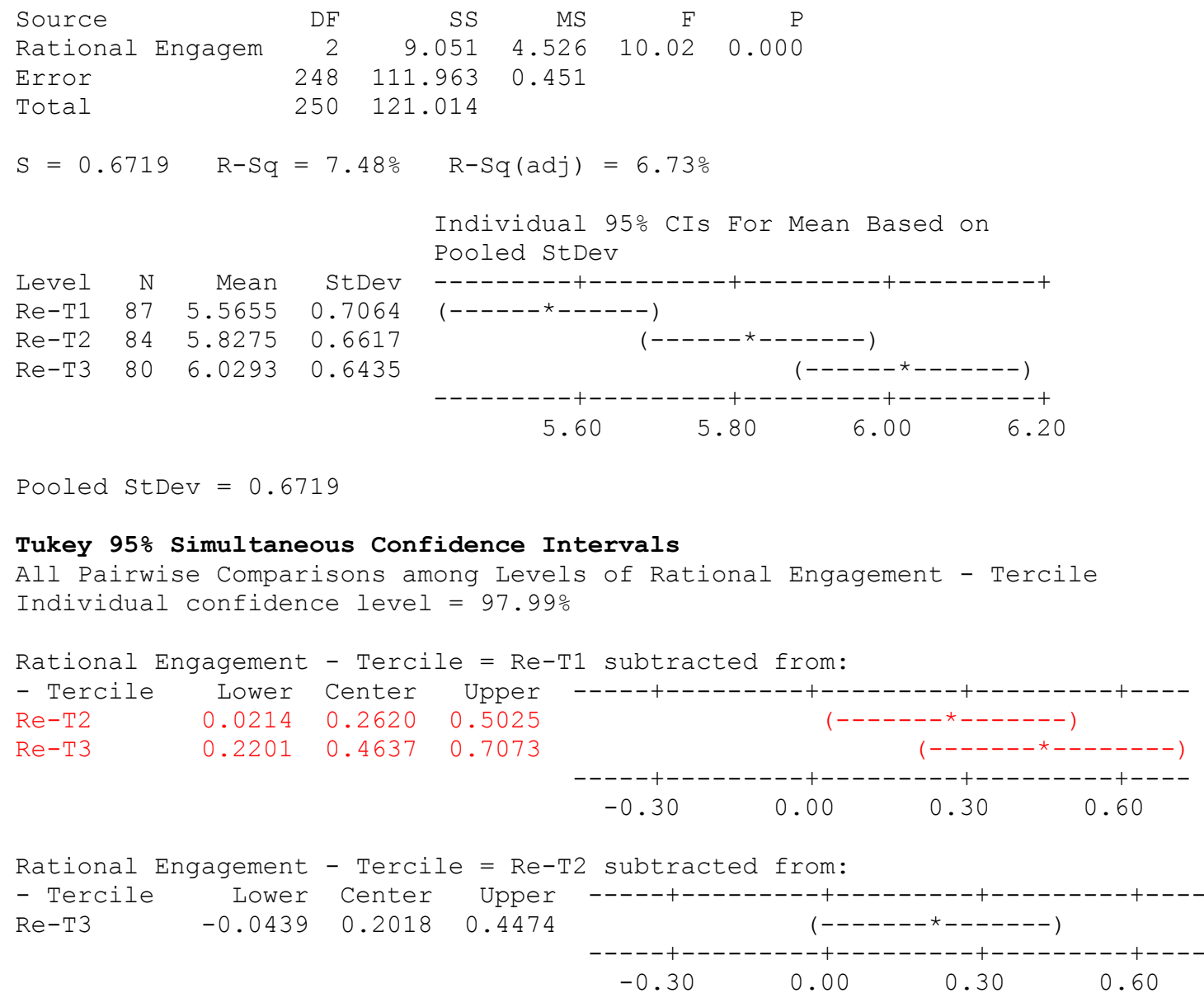

Fisher 95\% Individual Confidence Intervals

All Pairwise Comparisons among Levels of Rational Engagement - Tercile Simultaneous confidence level $=88.02 \%$
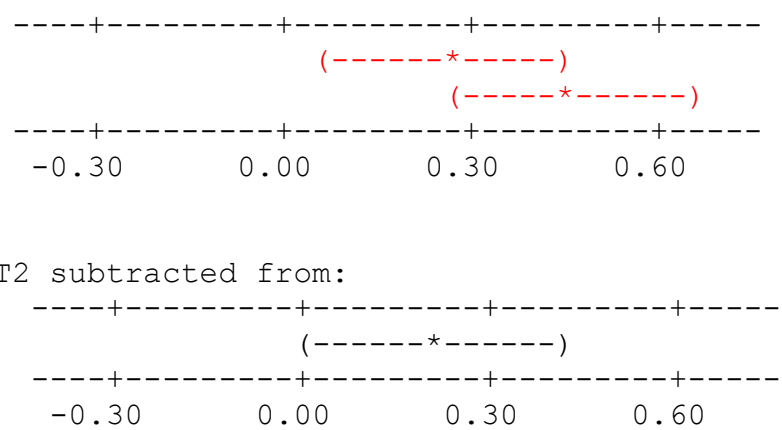


\section{Experientiality Engagement:}

\section{One-way ANOVA: Experientiality Engagement terciles versus Readiness score}

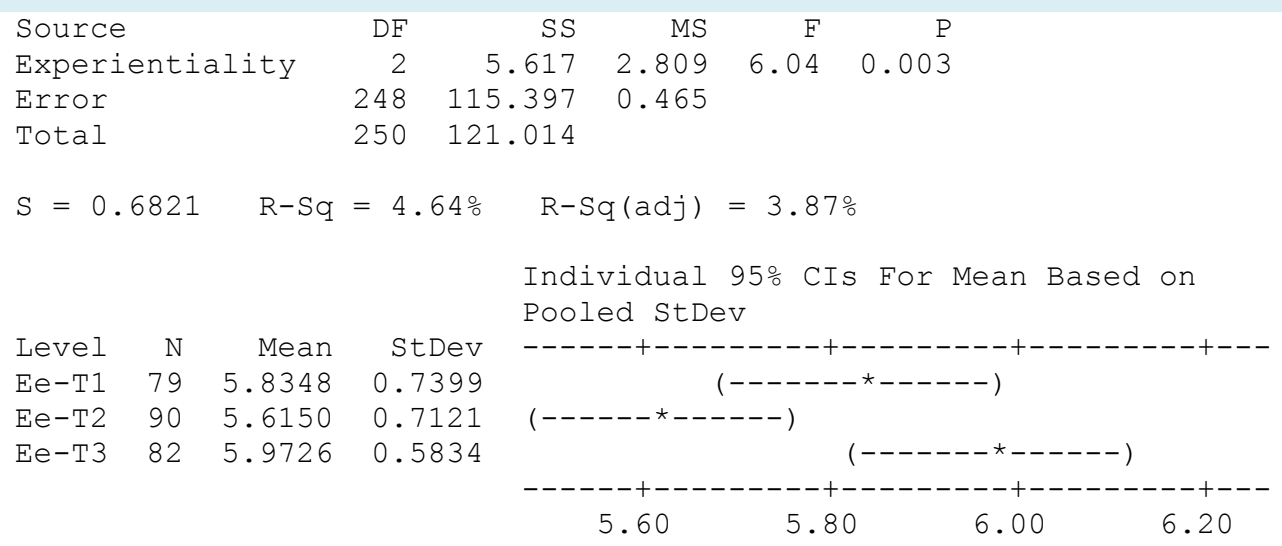

Pooled StDev $=0.6821$

\section{Tukey 95\% Simultaneous Confidence Intervals}

All Pairwise Comparisons among Levels of Experientiality Engagement - Te Individual confidence level $=97.99 \%$

Experientiality Engagement - Te = Ee-T1 subtracted from:

$\begin{array}{rrrr} & \text { Lower } & \text { Center } & \text { Upper } \\ \text { Ee-T2 } & -0.4660 & -0.2198 & 0.0263 \\ \text { Ee-T3 } & -0.1139 & 0.1378 & 0.3894\end{array}$

$\begin{array}{llll}\mathrm{Ee}-\mathrm{T3} & -0.1139 & 0.1378 & 0.3894\end{array}$

$\mathrm{Ee}-\mathrm{T} 2$

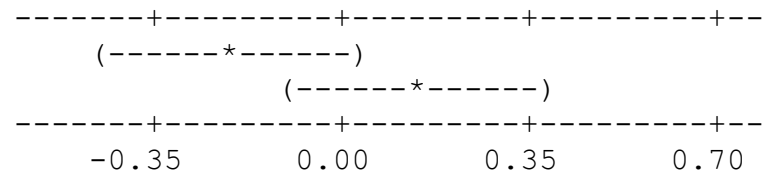

Experientiality Engagement - $\mathrm{Te}=\mathrm{Ee}-\mathrm{T} 2$ subtracted from:

$\begin{array}{lrrr} & \text { Lower } & \text { Center } & \text { Upper } \\ \text { Ee-T3 } & 0.1138 & 0.3576 & 0.6013\end{array}$

$\mathrm{Ee}-\mathrm{T3}$

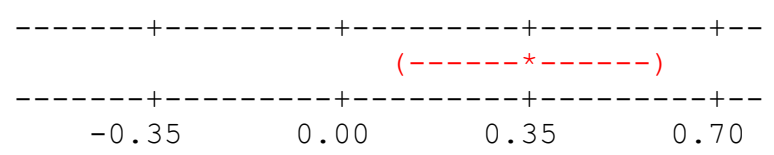

Fisher 95\% Individual Confidence Intervals

All Pairwise Comparisons among Levels of Experientiality Engagement - Te Simultaneous confidence level $=88.02 \%$

Experientiality Engagement - Te = Ee-T1 subtracted from:

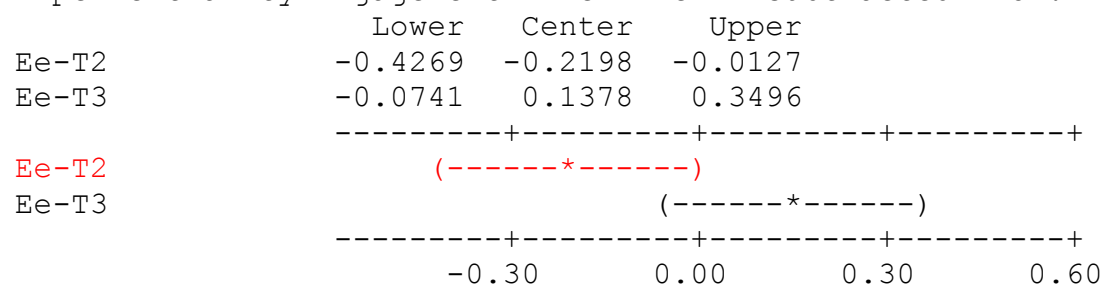

Experientiality Engagement - Te = Ee-T2 subtracted from:

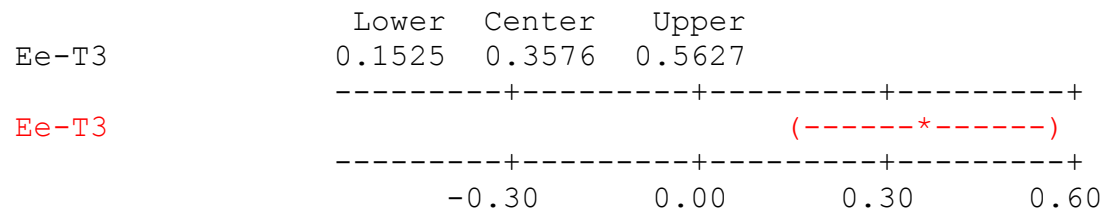




\section{APPENDIX VIII - ANOVA STATISTICAL DATA: READINESS SUB- COMPONENTS}

Below statistical data refers to data presented in Table 42. Source: Minitab 17.

\section{Rationality Engagement:}

\section{One-way ANOVA: Rationality Engagement terciles versus Change Efficacy scores}
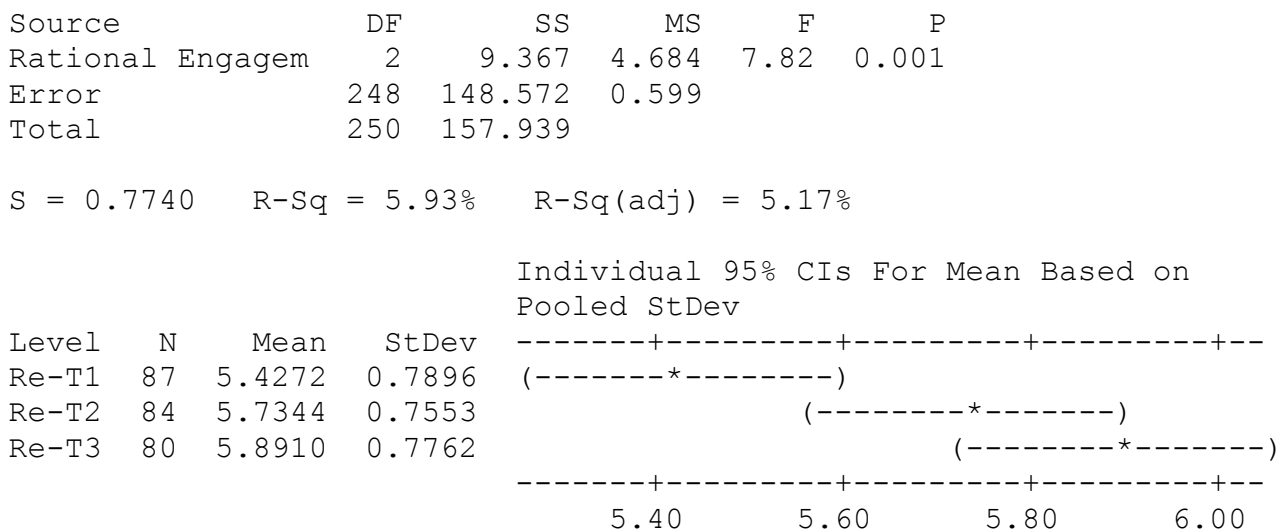

Pooled StDev $=0.7740$

Tukey 95\% Simultaneous Confidence Intervals

All Pairwise Comparisons among Levels of Rational Engagement - Tercile Individual confidence level = $97.99 \%$

Rational Engagement - Tercile = Re-T1 subtracted from:

- Tercile Lower Center Upper

$\begin{array}{llll}\text { Re-T2 } & 0.0301 & 0.3072 & 0.5843\end{array}$

$\begin{array}{llll}\mathrm{Re}-\mathrm{T} 3 & 0.1831 & 0.4638 & 0.7444\end{array}$

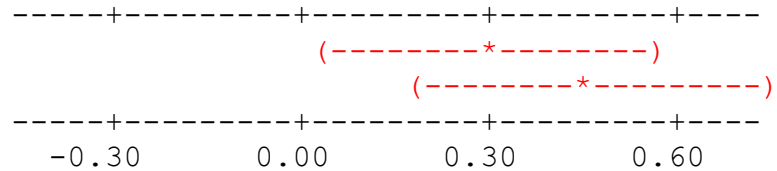

Rational Engagement - Tercile = Re-T2 subtracted from:

- Tercile Lower Center Upper

$\begin{array}{llll}\mathrm{Re}-\mathrm{T} 3 & -0.1264 & 0.1566 & 0.4396\end{array}$

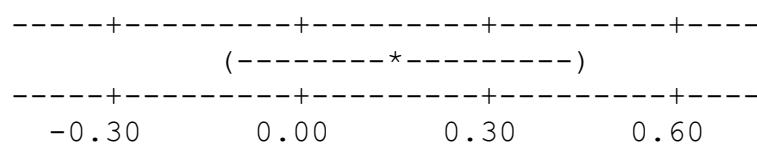

Fisher 95\% Individual Confidence Intervals

All Pairwise Comparisons among Levels of Rational Engagement - Tercile

Simultaneous confidence level $=88.02 \%$

Rational Engagement - Tercile = Re-T1 subtracted from:

- Tercile Lower Center Upper

$\begin{array}{llll}\text { Re-T2 } & 0.0740 & 0.3072 & 0.5404\end{array}$

$\begin{array}{llll}\mathrm{Re}-\mathrm{T} 3 & 0.2276 & 0.4638 & 0.6999\end{array}$

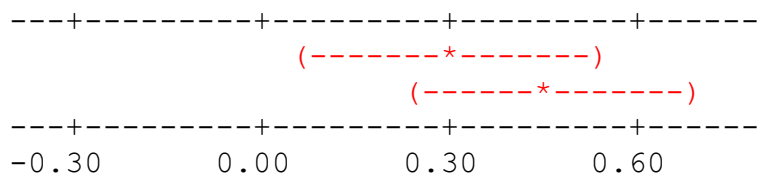

Rational Engagement - Tercile = Re-T2 subtracted from:

- Tercile Lower Center Upper

$\begin{array}{llll}\mathrm{Re}-\mathrm{T} 3 & -0.0816 & 0.1566 & 0.3947\end{array}$

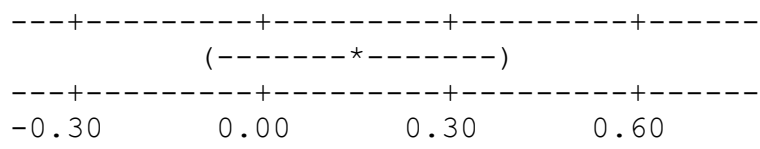




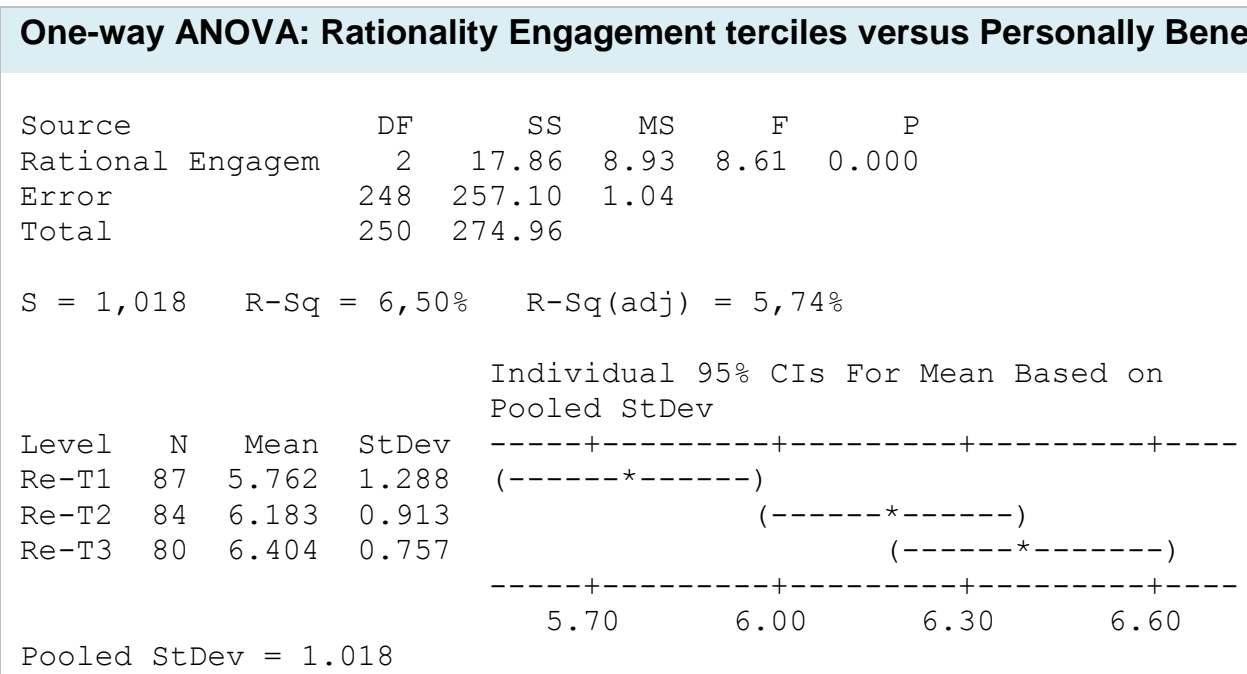

\section{Tukey 95\% Simultaneous Confidence Intervals}

All Pairwise Comparisons among Levels of Rational Engagement - Tercile Individual confidence level = 97.99\%

Rational Engagement - Tercile $=$ Re-T1 subtracted from:

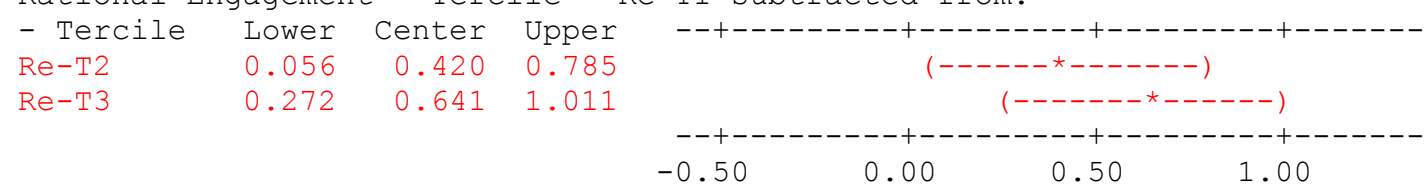

Rational Engagement - Tercile $=$ Re-T2 subtracted from:

- Tercile Lower Center Upper

$\begin{array}{llll}\mathrm{Re}-\mathrm{T} 3 & -0.151 & 0.221 & 0.594\end{array}$

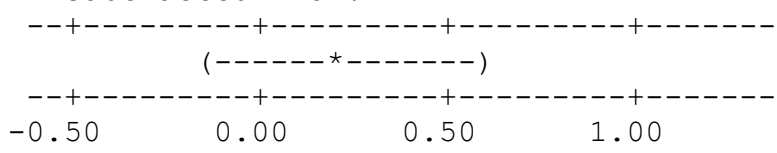

Fisher 95\% Individual Confidence Intervals

All Pairwise Comparisons among Levels of Rational Engagement - Tercile Simultaneous confidence level $=88.02 \%$

Rational Engagement - Tercile = Re-T1 subtracted from:
- Tercile Lower Center Upper
$\begin{array}{llll}R e-T 2 & 0.113 & 0.420 & 0.727\end{array}$
$\begin{array}{llll}\mathrm{Re}-\mathrm{T} 3 & 0.331 & 0.641 & 0.952\end{array}$

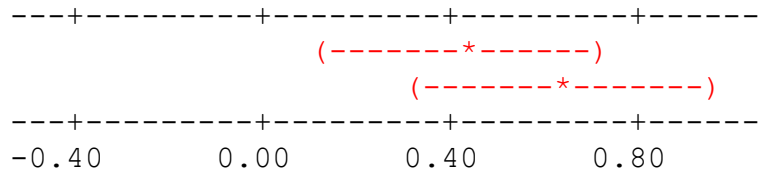

Rational Engagement - Tercile $=$ Re-T2 subtracted from:

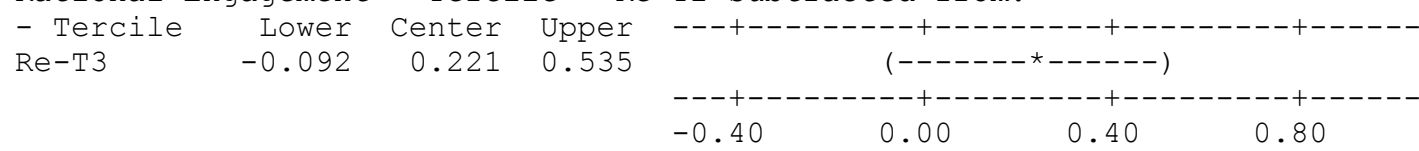

\section{Experientiality Ability:}

One-way ANOVA: Experientiality Ability terciles versus Change Efficacy score

$\begin{array}{lrrrrr}\text { Source } & \text { DF } & \text { SS } & \text { MS } & F & P \\ \text { Experientiality } & 2 & 6.591 & 3.296 & 5.40 & 0.005 \\ \text { Error } & 248 & 151.348 & 0.610 & & \\ \text { Total } & 250 & 157.939 & & & \\ \text { S }=0.7812 \quad \text { R-Sq }=4.17 \% & \text { R-Sq }(\text { adj })=3.40 \%\end{array}$




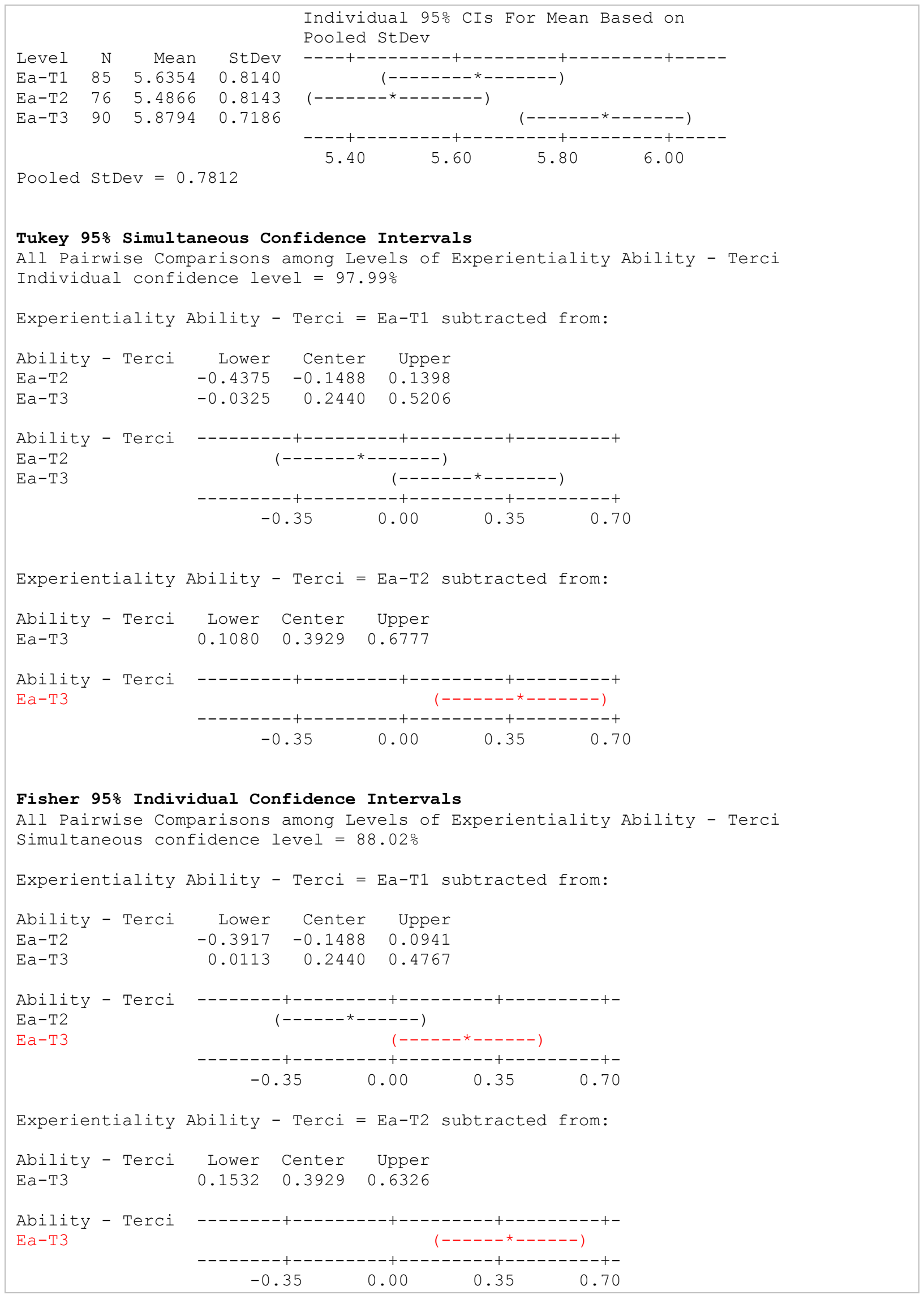

